\title{
PROGRESSO GENÉTICO NA CULTURA DO FEIJÃO NO ESTADO DO PARANÁ PARA O PERÍODO DE 1977 A 1995
}

\author{
NELSON DA SILVA FONSECA JÚNIOR \\ Engenheiro Agrônomo
}

Orientador: Prof. Dr. ISAIAS OLÍVIO GERALDI

Tese apresentada à Escola Superior de Agricultura "Luiz de Queiroz", da Universidade de São Paulo, para a obtenção do título de Doutor em Agronomia, Área de Concentração: Genética e Melhoramento de Plantas.

P I R A C I C A B A

Estado de São Paulo - Brasil

Fevereiro - 1997 
Dados Internacionais de Catalogação na Publicação (CIP) DIVISÃO DE BIBLIOTECA E DOCUMENTAÇÃO - Campus "Luiz de Queiroz"/USP

\section{Fonseca Júnior, Nelson da Silva}

Progresso genético na cultura do feijāo no estado do Paraná para o periodo de 1977 a 1995 / Nelson da Silva Fonseca Júnior - - Piracicaba, 1997.

168 p. : il.

Tese (doutorado) -- Escola Superior de Agricultura Luiz de Queiroz, 1997. Bibliografia.

1. Feijāo 2. Melhoramento genético (avaliaçāo) 3. Paraná (estado) I. Título 


\title{
PROGRESSO GENÉTICO NA CULTURA DO FEIJÃO NO ESTADO DO PARANÁ PARA O PERÍODO DE 1977 A 1995
}

\author{
NELSON DA SILVA FONSECA JÚNIOR
}

Aprovada em: 23.04.1997

Comissão julgadora:

Prof. Dr. Isaías Olívio Geraldi

Prof. Dr. Roland Vencovsky

Prof. Dr. Magno Antônio Patto Ramalho

Pesquisador Dr. Élcio Perpétuo Guimarães

Pesquisador Dr. Carlos Roberto Riede
ESALQ/USP

ESALQ/USP

UFLA

EMBRAPA/CNPAF

IAPAR

Om/

Prof. Dr. ISAÍAsoLívio GERALDI Orientador 
A Deus, por mais este passo, agradeço.

\author{
À minha esposa Marília, \\ às minhas filhas Mariana \\ e Taís Maria, ofereço.
}

Aos meus pais, Nelson e Odette, meus irmãos Nestor José e Ney, dedico. 


\section{AGRADECIMENTOS}

Em especial ao Professor ISAÍAS OLÍVIO GERALDI, pela orientação, confiança, amizade e compreensão.

À querida ESALQ - Escola Superior de Agricultura "Luiz de Queiroz", na pessoa de seus professores e funcionários, pelos ensinamentos e condições de estudo e de infraestrutura computacional oferecidas.

Ao IAPAR - Instituto Agronômico do Paraná, pela Pós-Graduação.

Ao $\mathrm{CNPq}$, pelo apoio financeriro durante parte do curso.

Aos professores ROLAND VENCOVSKY, DÉCIO BARBIN, MARIA IZALINA FERREIRA ALVES, RODOLFO HOFFMANN, ANTÔNIO FRANCISCO IEMMA e DIRCEU PACKER pelas sugestões e ensinamentos.

Aos colegas do curso, ÂNGELA CELIS DE ALMEIDA LOPES, RAINÉRIO MEIRELLES DA SILVA, MARIA INÊS FARALDO, JOSÉ BALDIN PINHEIRO, LUÍS FERNANDO ALLIPRANDINI, SÉRGIO AUGUSTO MORAIS CARBONELL, REGINA LÚCIA GOMES, JOAQUIM AVELINO DE AZEVEDO FILHO, ELAINE APARECIDA SOUZA, GILBERTO KEN-ITI YOKOMIZO, ROGÉRIO DE MELO COSTA PINTO, ISMAEL CAMARGO BUITRAGO, MÁRIO GALLA CAVIEDES CEPEDA, CARMEM LÚCIA DE MELLO SARTORA DA ROCHA, LUCIANA APARECIADA CARLINI, ANTONIO AUGUSTO FRANCO GARCIA, ANTÔNIO ISMAEL INÁCIO CARDOSO, ROBERTO CURY, AMADEU REGITANO NETO. Em especial, pelo auxilio nas análises estatísticas: CLÁUDIO TAKEDA, JÚLIO SÍLVIO DE SOUZA BUENO FILHO, DANIEL FURTADO FERREIRA, EDUARDO BEARZOTI, CARLOS ARRABAL ARIAS e pelos conhecimentos repassados sobre modelos mistos, pelo amigo do curso de Doutorado em Matemática e Estatística, LUIZ MARIA 
SALVARREY e aos colegas PAULO JOSÉ OGLIARI, AFRÂNIO MÁRCIO CORRÊA VIEIRA e ADILSON DOS ANJOS do mesmo departamento.

A secretária do departamento de genética CÂNDIDA VANDERLÉIA DE OLIVEIRA pela gentileza e bom humor no atendimento.

As bibliotecárias do Departamento de Genética da ESALQ, SILVANA MARCHIZELLI GREGÓRIO pela revisão das referências bibliográficas e a APARECIDA ELISABETH DOS SANTOS pela ajuda.

A ELISABETE APARECIDA LEONE RODRIGUES do Setor de Informática Aplicada do Departamento de Genética pela colaboração.

Aos funcionários do CIAGRI - Centro de Informática na Agricultura, MARCELO CORRÊA ALVES e MARCELO ZACARIAS, no processamento das análises.

Ao coordenador da AMG - Área de Melhoramento e Genética do IAPAR, Pesquisador CARLOS ROBERTO RIEDE, pela facilidades e compreensão dispensadas para o término deste trabalho.

Aos pesquisadores do IAPAR, LOURENÇO OLIARI (AMG) e CARLOS ARMÊNIO KHATOUNIAN (AFT) e aos técnicos agrícolas GILSON DE OLIVEIRA CAMPOS e PAULO ROBERTO PONVEQUI pela condução de meus trabalhos no IAPAR, o que permitiu minha liberação para o curso.

Aos professores JOSÉ SEBASTIÃO CUNHA FERNANDES (UFPR) e ANTÔNIO ALVES SOARES (UFV), pelos esclarecimentos sobre os respectivos métodos de estimação de ganho genético.

Ao pesquisadores NELSON SALIM ABBUD (IAPAR), e FLÁVIO BRESEGHELLO (Embrapa/CNPAF) pelos programas sobre ganho genético.

Aos funcionários do NPD - Núcleo de Processamento de Dados da Universidade Estadual de Londrina, HELIÉTE DOMINGUEZ GARCIA, VERA LÚCIA 
OGASSAWARA, EMIKO OTANI KISHINO e HARUMI TAKANO pelo processamento de parte das análises estatisticas no computador IBM 3090.

Ao Dr. MAN MOHAN KHOLI, pesquisador do CIMMYT - Centro Intemacional de Melhoramento de Milho e Trigo, coordenador das pesquisas para o Cone Sul, pelo apoio e incentivo na minha formação de melhorista.

Aos colegas do IAPAR : WELFRID, CÉLIO e PAULO (AIN), SÉPHORA, SÔNIA POSNIK, DIRCE, JACQUELINE e ALESSANDRA (ADC), IRAJÁ (ASP) e DORETO (ASE), RAFAEL, LÉO, CLEONICE e MARLEY (CRH), MÁRIO FUKUSHIMA, PEDRO MÁRIO, SÉRGIO, VÂNIA, ANTÔNIO ALVES e MARCO (AMG), em especial à secretária SAYOKO e ao WALDERI, ambos alocados na Área de Melhoramento e Genética, pela atenção e lealdade demonstradas.

A Dona ALINE FRANCO CÔRTE BRILHO e Dona ARABELA FRANCO BRASIL, pela acolhida e incentivo concretamente demonstrados. 


\section{SUMÁRIO}

RESUMO

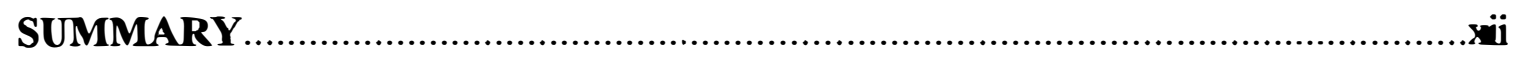

1. INTRODUÇÃO

2. REVISÃO DE ITERATURA

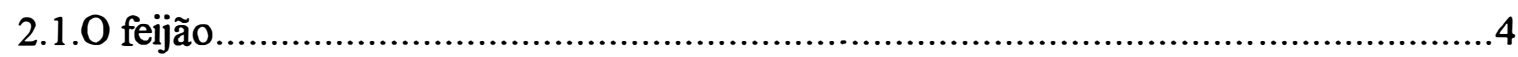

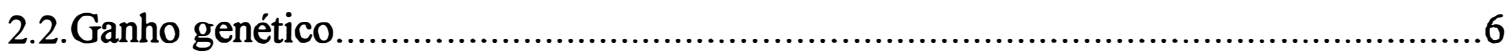

2.2.1 Métodos disponíveis para estimação de ganho genético......................................

2.2.1.1 Método direto

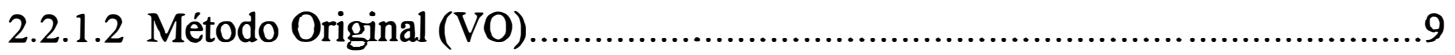

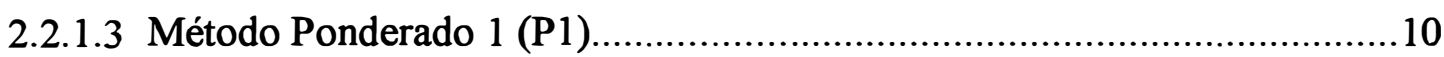

2.2.1.4 Método Ponderado 2 (P2) ...............................................................11

2.2.1.5 Métodos que utilizam um genótipo referência .............................................11

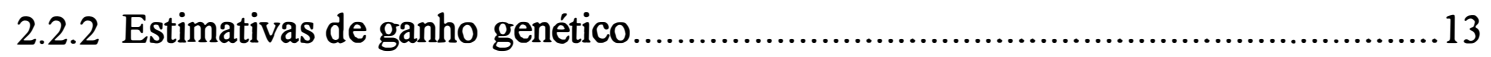

2.2.2.1. Estimativas de ganho genético para o feijão..............................................13

2.2.2.2. Estimativas de ganho genético para outras espécies....................................14

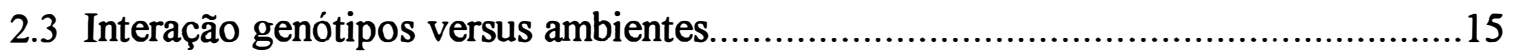

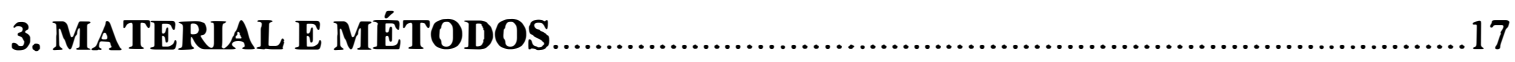

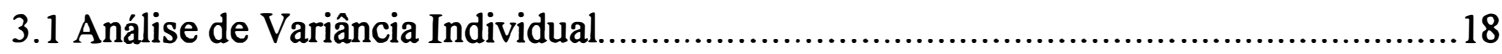

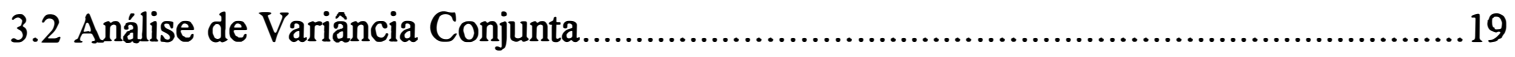

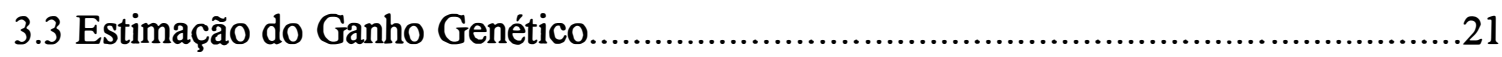

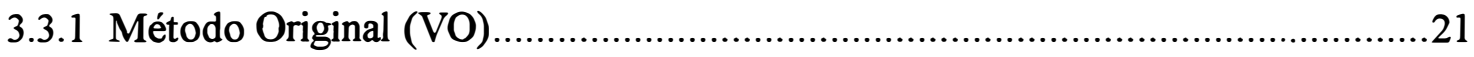

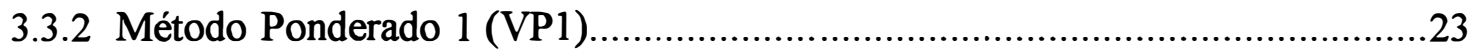




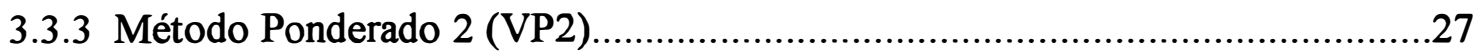

3.3.4 Método da Regressão com Dados Originais (RO)...........................................29

3.3.5 Método da Regressão com Dados Estandardizados (RE).................................32

3.3.6 Método da Regressão com Médias Ajustadas (RA)...........................................34

3.4 Desdobramento das Estimativas de Ganho Genético.............................................42

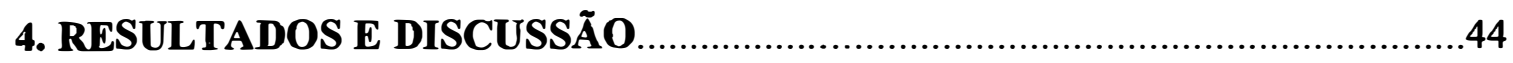

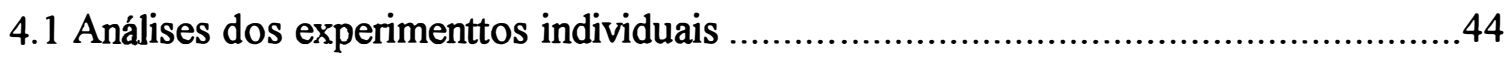

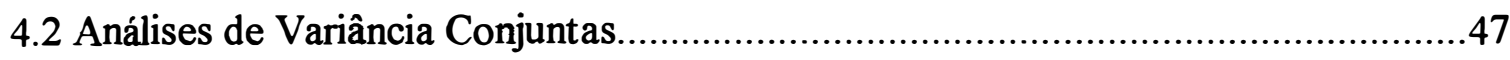

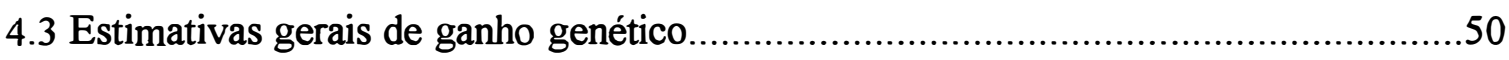

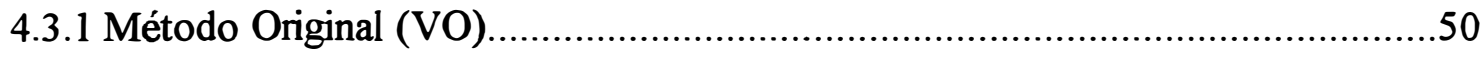

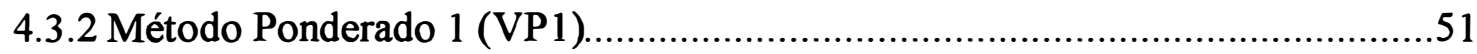

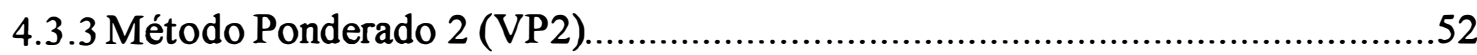

4.3.4 Método da Regressão com dados Originais (RO) .........................................52

4.3.5 Método da Regressão com dados Estandardizados (RE)...................................56

4.3.6 Método da Regressão com Médias Ajustadas (RA)..........................................57

4.3.7 Comparações entre os métodos de estimação de ganho genético.......................59

4.4 Desdobramento das estimativas gerais de ganho genético........................................69

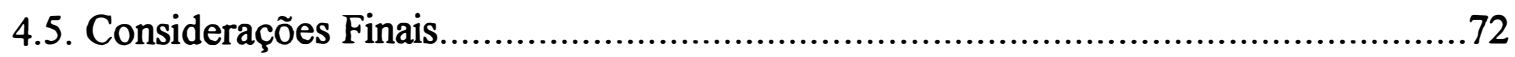

5. CONCLUSÕES

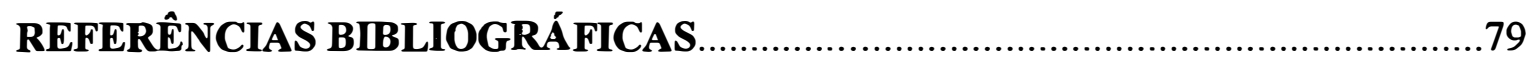

TABELAS

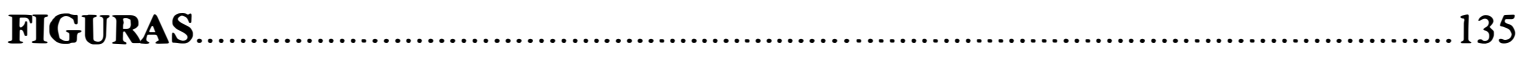

APÊNDICES 


\title{
PROGRESSO GENÉTICO NA CULTURA DO FEIJÃO NO ESTADO DO PARANÁ NO PERÍODO DE 1977 A 1995
}

\author{
Autor: NELSON DA SILVA FONSECA JÚNIOR \\ Orientador: PROF. DR. ISAIAS OLÍVIO GERALDI
}

\section{RESUMO}

O melhoramento genético vegetal visa gerar novas opções aos produtores, possibilitando maiores lucros em função das vantagens oferecidas pelos novos cultivares. Para se verificar se este objetivo está sendo alcançado, é necessário avaliar o desempenho do programa de melhoramento. Visando quantificar o progresso genético do programa de melhoramento de feijão (Phaseolus vulgaris L.) para o estado do Paraná, em relação ao rendimento de grãos, foram analisados 99 ensaios intermediários do grupo preto e 109 do grupo cores, de 1977 a 1995 (18 anos) e 189 ensaios regionais finais de competição de genótipos do grupo preto e 245 do grupo cores no período de 1978 a 1995 (17 anos).

Foram utilizadas seis metodologias, sendo três baseadas no contraste entre genótipos comuns em anos consecutivos, denominadas aqui por método original (VO), ponderado 1 (VP1) e ponderado 2 (VP2), que utilizam a ponderação dos ganhos genéticos anuais, mediante quadrados mínimos ponderados. As outras três metodologias foram baseadas na regressão linear da média anual dos genótipos novos e da testemunha comum em função dos anos de melhoramento; utilizando-se dados originais (método RO), dados estandardizados (método RE) e dados ajustados em função da estimação dos efeitos genotípicos, através do procedimento "BLUE", isto é, melhor estimador linear não viesado (metodologia RA). Nos métodos de regressão, os cultivares testemunhas foram Rio Tibagi no grupo dos feijões pretos e Carioca no grupo cores. 
Todas as metodologias apresentaram estimativas positivas para o progresso genético. O método original (VO) e seus derivados (VP1 e VP2), forneceram estimativas de magnitude semelhante na maioria dos casos, entretanto somente para VP1 e VP2 estas esimativas foram significativas em todos os grupos de ensaios. Os métodos da regressão (RO e RE) forneceram estimativas de menor magnitude. Entre as metodologias testadas, destacou-se o método da regressão com dados ajustados (RA), que forneceu estimativas significativas, e com maiores coeficientes de determinação do modelo. As estimativas de ganho genético obtidas pelo método RA, com base nos ensaios finais, foram de $1,42 \%$ para os genótipos do grupo cores, correspondendo a $18,6 \mathrm{~kg} / \mathrm{ha}$ ano e de $1,64 \%$ para o grupo preto, que equivale a $22,1 \mathrm{~kg} / \mathrm{ha}$.ano. Pode-se concluir que, após 18 anos de trabalho no Paraná, o melhoramento genético de feijão produziu resultado positivo e significativo, tanto para o grupo cores como para o grupo preto, refletido nas estimativas de ganho genético médio, que ficaram acima de $1,4 \%$ ao ano, pelo método RA, equivalentes às obtidas para outras culturas. 


\title{
GENETIC GAIN FOR COMMON BEANS IN THE STATE OF PARANA FROM 1977 TO 1995
}

\author{
Author: NELSON DA SILVA FONSECA JUNIOR \\ Adviser: PROF. DR. ISAIAS OLIVIO GERALDI
}

\section{SUMMARY}

The objective of plant breeding is the development of cultivars, allowing the farmers to increase their higher net income. In order to evaluate the performance of genotypes released from breeding programs from 1977 to 1995, genetic gain with selection were estimated for yield in common beans (Phaseolus vulgaris $\mathrm{L}$.) based on the analysis of 208 experiments from intermediate yield trial (99 of the black group and 109 of the colored group) and 434 experiments from the final regional trials (189 of the black group and 245 of the colored group).

Six methodologies were considered for estimation of the genetic gain. Three methods were based on the contrasts among common genotypes in successive years, denominated as original method (OM), weighted 1 (W1) and weighted 2 (W2), which used the generalized least square (GLS) procedure in order to weight the annual genetic gain. The other three methods were based on the regression of new genotypes over common check as function of years, with original data (OR method), with the standardized data (SR method) and with adjusted means estimated with genotypic effects through the BLUE (best linear unbiased estimator) procedure (AR method). The cultivars Rio Tibagi and Carioca were used as common checks for the black and the colored groups, respectively. 
Estimates of genetic gain were positive for all methods. The original (OM) and the derivatives (W1 and W2) methods provided estimates of the same magnitude; however, only for W1 and W2 the estimates were significative. In many cases, the regression methods (OR and SR) showed the lowest estimates of genetic gain. The regression method with adjusted data (AR) produced estimates for the genetic gain which were more precise and with the highest coefficients of determination for the model. The average genetic gain estimated by the AR method for the final yield trials were $1.42 \%$ for the colored group which corresponds to $18.5 \mathrm{~kg} / \mathrm{ha}$ per year, and $1.64 \%$ or $22.1 \mathrm{~kg} / \mathrm{ha}$ per year for the black group. It can be concluded that after 18 years of common bean breeding, positive results were obtained for both groups with genetic gain reaching values of above $1.4 \%$ per year, which is similar to those obtained for other crops. 


\section{INTRODUÇÃO}

O feijão (Phaseolus vulgaris L.) é um dos principais componentes da alimentação do povo brasileiro. Seu cultivo é distribuído ao longo do ano por todo o Brasil, sendo semeado em diferentes níveis, variando de autoconsumo, até escala comercial, em pequenas e médias propriedades, em sua maioria praticando agricultura tradicional e utilizando mão-de-obra familiar.

YOKOYAMA et alii (1996) relataram que no Brasil, o feijão é cultivado em três épocas (safras) distintas: a) primeira safra (das Águas), semeada principalmente nas regiões Sul, Sudeste (São Paulo e Minas Gerais) e Sul da Bahia, sendo colhida entre os meses de novembro a março. Nesta safra, a região Sul produz $80 \%$ em média do volume total de feijão-preto nacional. Quanto ao feijão-de-cores é suficiente para abastecer o mercado até a entrada da safra da seca; b) segunda safra (da Seca), é cultivada em todo o país e sua colheita ocorre normalmente entre abril e agosto; c) terceira safra (de Inverno), que responde por até $10 \%$ da produção nacional, com predomínio do cultivo do feijão irrigado, principalmente a partir de 1984. Está concentrada nos estados de Minas Gerais, Goiás, São Paulo e Bahia, cuja área cultivada oscila em torno de 260.000 ha. A área ocupada pelas três safras, tem oscilado nos últimos anos, entre 4,5 a 5,8 milhões de hectares. A produtividade média nacional é bastante variada. Na primeira safra tem se situado ao redor de $700 \mathrm{~kg} / \mathrm{ha}$, na segunda tem permanecido em $400 \mathrm{~kg} / \mathrm{ha}$, enquanto em cultivos irrigados tem alcançado $2.800 \mathrm{~kg} / \mathrm{ha}$. 
Segundo os mesmos autores, a produção nacional está equilibrada com o consumo interno, de cerca de 3 milhões de toneladas, não ocorrendo exportação do produto, mas sim eventuais importações, principalmente do feijão preto, oriundo do México ou da Argentina. A produção mundial tem se mantido entre 16 e 17 milhões de toneladas, sendo os principais produtores Índia, Brasil, China, EUA e México.

No estado do Paraná, um dos principais e tradicionais produtores de feijão do Sul do Brasil, na grande maioria de suas regiões produtoras, é baixo o nível de tecnologia adotado pelo agricultor, normalmente pequeno, na condução de sua cultura.

A importância social do feijão, como alimento rico em proteínas e acessível às populações rurais e urbanas, justifica os esforços da pesquisa na geração de tecnologia, bem como em sua difusão, para reverter o quadro de baixa produtividade e oferta perigosamente no limite do consumo, que pode resultar em importações, desabastecimento interno e elevação dos preços para o consumidor em anos adversos.

Em outro sentido, há estudos que indicam aparente mudança no hábito alimentar brasileiro, refletindo em menor consumo anual de feijão por habitante (HOFFMANN, 1995). Contudo esta tendência dificilmente implicará na eliminação completa do feijão da mesa do brasileiro, por se tratar de um saudável costume cultural.

Em projeções de consumo interno para o ano 2000, trabalha-se com uma demanda de 3,7 milhões de toneladas, supondo-se estagnação da área cultivada no país, o que implicará em que a produtividade nacional terá que aumentar na taxa de $1,4 \%$ ao ano (YOKOYAMA et alii, 1996).

Uma das possibilidades de se aumentar a produtividade é através do melhoramento genético, gerando novos cultivares mais produtivos e estáveis, assegurando maiores lucros ao produtor e alimento mais barato para o consumidor final. A simples adoção de uma nova variedade, efetivamente superior, refletirá em maior 
benefício com custo mínimo, em favor do agricultor que dela se utilizar. A geração dessas novas variedades superiores é o objetivo dos programas de mellhoramento.

Portanto, é necessário que de tempos em tempos, cada programa de melhoramento genético faça uma autoavaliação no sentido de verificar se houve progresso efetivo, se determinada condição de cultivo (época de semeadura, ou região, ou sistema de manejo) foi privilegiada pelo melhoramento e corrigir eventuais distorções de metas. Para tanto, neste trabalho, estabeleceram-se os seguintes objetivos:

1) Estimar o progresso genético obtido no programa de melhoramento de feijão nos últimos anos para o estado do Paraná;

2) Adaptar metodologias alternativas para avaliar o progresso genético, através de dados gerados pelos ensaios da rede estadual de competição de linhagens e cultivares;

3) Comparar as metodologias adaptadas com as existentes, definindo a mais indicada para estudos de progresso genético, envolvendo ensaios regionais; 


\section{REVISÃO DE LITERATURA}

\subsection{O feijão}

O feijoeiro comum (Phaseolus vulgaris L.) é uma leguminosa, herbácea de hábito de crescimento determinado (tipo I) ou indeterminado (tipos II, III e IV), com sistema radicular superficial, cujas sementes constituem rica fonte proteíca (entre 20 e 25\%) (VIEIRA, 1978). RAMALHO \& SANTOS (1982) abordando diferentes aspectos do melhoramento do feijoeiro, relataram que é planta autógama, com taxa de fecundação cruzada normalmente abaixo de $1 \%$, havendo relatos de taxas acima de $18 \%$ (WELLS et alii, 1988). É diplóide, com número somático de cromossomos igual a 22. Possui genoma pequeno, com cerca de 637 mega pares de bases (VALLEJOS et alii, 1992).

Os centros de origem são o México, a América Central e os Andes (GEPTS, 1994). Os estudos que abordam a diversidade genética do feijão, sugerem a subdivisão em várias raças, as quais podem ser agrupadas em dois grandes grupos: Mesoamericano e Andino (SINGH et alii, 1991), sendo que a grande maioria dos cultivares brasileiros pertencem ao Grupo Mesoamericano (VOYSEST et alii, 1994).

O Brasil é um dos maiores paises produtores e consumidores de feijão. $O$ feijoeiro está sendo cultivado no Brasil há mais de 300 anos em diferentes regiões do país (CASCUDO, 1983); portanto é explicável o grande número de patógenos que atacam o feijoeiro (PASTOR-CORRALES, 1996), nas condições tropicais e subtropicais. 
O estado do Paraná é um dos maiores produtores na região considerada como tradicional, com área estabilizada ao redor de 600 mil hectares e produtividade oscilando em torno de $700 \mathrm{~kg} / \mathrm{ha}$ (Tabela 1 ).

O Paraná foi o principal produtor de feijão do país desde a década de 50 até o final da década de 80 (LLANILLO, 1993). Durante o período de 1970 a 1982, a área cultivada esteve ao redor de 800 mil hectares, produzindo em média um quarto da produção nacional. A partir do ano agrícola 1982/83 a área semeada reduziu-se a menos de 700 mil hectares, declinando a participação do estado na produção nacional (LLANILLO \& GUERREIRO, 1989). Esta redução não foi causada pela diminuição da área semeada ou produtividade, mas sim pelo aumento da contribuição de outros estados, em função de maior nível de tecnologia empregado, irrigação principalmente. Houve também significativo aumento da produtiviade em regiões do Nordeste brasileiro. A produtividade paranaense, estabilizada ao redor de $700 \mathrm{~kg} / \mathrm{ha}$, é ainda superior à média nacional, em torno de $500 \mathrm{~kg} / \mathrm{ha}$, produções estas muito baixas e distantes do potencial da cultura, acima de $3.500 \mathrm{~kg} / \mathrm{ha}$, segundo WHITE \& ISQUIERDO (1993).

$\mathrm{Na}$ década de 80 o país passou a dar mais atenção aos produtos básicos da alimentação, visando conter suas pressões sobre a inflação. A partir de 1985 , as culturas alimentares apresentaram salto em produtividade, porém para o feijão, esse aumento de produtividade no Paraná, somente pôde ser percebido a partir de 1992, devido a quebra ocorrida em safras anteriores por adversidades climáticas (IPARDES, 1995).

Se por um lado está ocorrendo maior oferta do produto, em nível de país, no Centro-Sul foi detectada queda no consumo, basicamente pela urbanização e mesmo pela alteração dos hábitos alimentares na cidade (HOFFMANN, 1995). Em termos de Brasil, há demanda reprimida originada nas classes menos favorecidas, que se tiverem sua situação melhorada passarão a consumir maior quantidade. Portanto, a atual oferta- 
demanda de feijão em nível de país está equilibrada, ocorrendo eventual importação, em anos com clima adverso à cultura, proveniente de países como o México, Chile e Argentina. Este último está se tornando um fornecedor regular de feijão preto para os grandes centros do país, com ação facilitada pelo MERCOSUL.

Em contrapartida, quando há super produção, frequentemente ocorre baixa generalizada de preços e prejuízos aos produtores, que ficam sem opção de colocação de sua produção, uma vez que a exportação é praticamente inexistente, havendo dificuldade na conservação do produto, principalmente os feijões do grupo cores, sendo a política governamental de estoques reguladores muito incipiente.

Apesar deste quadro de adversidades, o estado do Paraná tem apresentado sustentação de significativa percentagem da produção nacional de feijão. Supõe-se que em grande parte seja devido ao melhoramento genético desenvolvido para a cultura, visto que a alteração na tecnologia de cultivo tem sido pequena em nível estadual, excetuandose algumas regiões, onde é utilizada a técnica do plantio direto.

Existem na literatura diferentes metodologias propostas para se estimar a contribuição do melhoramento genético em um período de tempo amostrado, as quais serão abordadas em seguida, sob o aspecto de estimativas de ganho genético.

\subsection{Ganho genético}

É necessário que inicialmente se proceda a um esclarecimento. A designação de ganho genético adotada neste trabalho, não é a mesma estabeleciada pela Genética Quantitativa que originalmente define o progresso genético ou o ganho por seleção, como sendo estimado pelo contraste, obtido no mesmo ano, entre a média da população melhorada e a média da população original, a qual se pressupõe constituída por 
indivíduos geneticamente distintos. Por sua vez a população melhorada é formada pela descendência dos indivíduos selecionados na geração anterior (FALCONER, 1981). Este conceito é frequentemente aplicado em uma mesma população segregante, para se predizer o ganho esperado por seleção, constituindo-se em critério de escolha de estratégia de melhoramento genético mais eficaz (SOUZA JÚNIOR, 1989).

O sentido de ganho genético adotado neste trabalho, difere do original basicamente por duas razões principais: a) população original - uma vez que este trabalho se pauta nos dados de ensaios regionais de competição de genótipos, a noção de população original fica prejudicada, visto que não existe uma única população original, da qual são selecionados indivíduos de maneira cíclica. Na realidade o que se dispõe é de um fluxo dinâmico de genótipos já fixados, onde os selecionados são mantidos no ensaio, e os piores são descartados e substituídos por novos genótipos originados de outras populações segregantes; e b) avaliação no mesmo ano agrícola do contraste entre população melhorada e original. Caso fosse possível estabelecer uma população tida como original, em se tratando de ensaios regionais, seria necessário testar num mesmo ano agrícola, os genótipos selecionados e os descartados do ano anterior, o que elevaria demasiadamente os custos da experimentação.

Diante do exposto, o termo ganho genético passa a ter, neste trabalho, o sentido de contribuição efetiva do melhoramento genético na elevação da média dos genótipos selecionados e posteriormente testados no ano seguinte. 
2.2.1 Métodos disponíveis para estimação de ganho genético

\subsubsection{Método Direto}

Comparar em um mesmo ano agrícola e em vários ambientes, genótipos lançados em diferentes anos.

Esta metodologia foi utilizada em diferentes espécies, entre elas milho (CARDWELL, 1982 e DUVICK, 1992), soja (WILCOX et alii, 1979 e SALADONAVARRO et alii, 1993), trevo branco (WOODFIELD \& CARADUS, 1994), alfafa (HOLLAND \& BINGHAM, 1994), cevada (BULMAN et alii, 1993), trigo (BERZONSKY \& LAFEVER, 1993; NEDEL, 1994; PELTONEN-SAINIO \& PELTONEN, 1994 e LILL \& PURCHASE, 1995) e arroz de sequeiro (ABBUD, 1991). Esta metodologia apresenta alguns inconvenientes, pois exige ensaios específicos para esta estimação de ganho, requerendo a manutenção cuidadosa dos genótipos primitivos e rigorosa observação quanto à uniformização da origem (local e ano), de suas sementes.

Há no entanto uma outra limitação a este método, que teoricamente seria o mais próximo do ideal: a aceitação da hipótese de que nem o ambiente, nem as exigências do mercado, nem os objetivos do programa de melhoramento se alteraram ao longo do tempo, tornando válida a comparação entre genótipos lançados em diferentes anos. De acordo com MIRANDA FILHO (1994), "Melhoramento genético é o ajustamento genético aos componentes físicos, químicos, biológicos, econômicos e sociais do ambiente", o que implica que o melhoramento é uma atividade dinâmica, pois exige ajustamentos genéticos para se adaptar ao ambiente, visto que este se altera com o tempo, em função das alterações nos diferentes fatores que o compoem. 
Outro fator limitante para o sucesso dessa metodologia é o efeito do ano e a interação genótipos por anos, que podem mascarar a efetiva contribuição dos genótipos novos. Por exemplo, caso os novos materiais apresentem resistência a determinada doença e os genótipos antigos sejam suscetíveis; se no ano em que foram instalados os experimentos para se avaliar o progresso genético não ocorrer esta doença, provavelmente não haverá diferença entre as produções. $\mathrm{O}$ mesmo pode ocorrer em anos desfavoráveis, tomando todos os genótipos semelhantes. Portanto não basta apenas um ano agrícola para se estimar o progresso genético com segurança e representatividade. Este método, que compara genótipos lançados em diferentes anos, mostra-se mais útil na estimação do progresso genético obtido em características com maior herdabilidade e menos sujeitas às influências ambientais, como é o caso das variáveis teor de óleo e proteína em milho, que apresentam um padrão de ganho genético crescente, e menos errático que o apresentado pelo peso de 100 grãos (DUDLEY \& LAMBERT, 1992).

\subsubsection{2) Método Original (VO)}

Outra metodologia é a que utiliza os ensaios da rede oficial de competição de genótipos, cujos resultados embasam a recomendação formal de novas variedades, para estabelecer estimativas de ganho genético. Estes ensaios regionais são compostos por genótipos que podem ser classificados em função de sua origem: a) genótipos novos: são os que participam pela primeira vez nos ensaios; b) genótipos comuns: aqueles que foram selecionados no ano anterior e que permaneceram em teste no ano seguinte para avaliação e c) genótipos padrões ou testemunhas: normalmente enquadram-se no grupo dos genótipos comuns, pois permanecem nos ensaios por mais de dois anos consecutivos. 
VENCOVSKY et alii (1988), utilizando os dados de produção de grãos de milho dos ensaio nacionais, coordenados pela EMBRAPA/CNPMS (Centro Nacional de Pesquisa de Milho e Sorgo), propuseram um método original, (referenciado no presente trabalho como VO), com o intuito de suplantar o efeito de anos que distorce a estimativa do progresso genético, quando se compara as médias dos tratamentos de anos consecutivos e de um mesmo local. De acordo com este método, a estimativa do ganho genético é obtida pelo contraste entre a média de todos os tratamentos de um dado ano e a do ano anterior; deste contraste, subtrai-se o efeito de ano, estimado pela diferença entre a média do grupo de genótipos comuns nesses dois anos consecutivos.

$\mathrm{O}$ método VO vem sendo utilizado em trabalhos que estimam a contribuição do melhoramento genético, aplicado em condições brasileiras, para as culturas de feijão (ABREU et alii, 1994) e algodão (CARVALHO et alii, 1997).

\subsubsection{3) Método Ponderado 1 (VP1)}

FERNANDES (1988), trabalhando com dados do ensaio nacional de milho, propôs uma modificação no método original (VO) para estimar o desvio ambiental médio anual por local, utilizando o método dos quadrados mínimos ponderados (QMP). Esta modificação visava: a) evitar a perda de informações, pois no método original, ao se efetuar a estimativa do desvio genético médio, as médias dos tratamentos dos anos intermediários se cancelavam, restando apenas o primeiro e o último ano para o cálculo da estimativa; e b) eliminar a correlação dos erros experimentais entre anos consecutivos. RODRIGUES (1990) estendeu a metodologia anterior para os estudos de ganho genético em sorgo no Brasil, fornecendo embasamento para as deduções das expressões de ganho genético médio anual e seu desvio por local ou ensaio analisado. 
TOLEDO et alii (1990) aplicaram a metodologia de VENCOVSKY et alii (1988), modificada por FERNANDES (1988), utilizando os resultados dos ensaios intermediários da rede oficial de experimentação de soja do estado do Paraná, para avaliação do progresso genético em soja no período de três anos. Nesse tipo de ensaio "intermediário", os únicos genótipos comuns são as testemunhas, visto que os genótipos novos, ou são descartados, ou então são selecionados para integrarem os ensaios "finais" no próximo ano agrícola. ALLIPRANDINI et alii (1993) estimaram o ganho genético médio anual em soja no estado do Paraná, empregando esta mesma metodologia com a ponderação proposta por FERNANDES (1988).

\subsubsection{Método Ponderado 2(VP2)}

É praticamente idêntico ao VP1, diferindo apenas na maneira de compor a matriz $\mathrm{V}$ de ponderação, cujos coeficientes das variâncias e covariâncias baseiam-se no número de observações de cada média que participa nos cálculos, bem como utiliza os Quadrados Médios do Erro anuais e não apenas o Quadrado Médio do Erro da análise conjunta para efetuar a ponderação. Esta metodologia foi proposta por MORAIS e ABBUD (1993) e implementada por BRESEGHELLO (1995) no estudo do progresso genético do arroz irrigado no Nordeste brasileiro.

\subsubsection{Métodos que utilizam um genótipo referência}

Os experimentos regionais são compostos normalmente por genótipos novos, por genótipos comuns, que integram pelo segundo ano consecutivo estes experimentos, e pelas testemunhas. Os genótipos em teste podem ter dois destinos: ou são descartados ou 
são selecionados. Eventualmente, um determinado genótipo permanece como testemunha ao longo de todos os anos testados e pode ser usado como referencial para estimativa de ganho genético como utilizado por ABREU et alii (1994), EYHERÁBIDE et alii (1994), McCAIG \& CLARKE (1995), BELL et alii (1995), McCAIG \& DePAUW (1995) e CÓRDOVA et alii (1996). Basicamente estes autores utilizaram-se de regressões lineares ou de análise de covariância em seus trabalhos contendo testemunha comum.

a) Método da Regressão com Dados Originais (RO)

Estabeleceram-se duas equações de regressão linear, uma para o cultivar padrão e a segunda para os demais genótipos, onde a variável dependente $(\mathrm{Y})$ representa as médias originais do rendimento de grãos, e a variável independente $(\mathrm{X})$ corresponde aos anos de experimentação. Em seguida compara-se os coeficientes angulares (b) de ambas regressões, mediante subtração ( $b$ de genótipos menos $b$ da testemunha) e obtểm-se $a$ estimativa do ganho genético médio anual em $\mathrm{kg} / \mathrm{ha}$, conforme efetuado por ABREU et alii (1994). Ressalte-se que esta metodologia (RO) é altamente dependente do efeito do ano agrícola, visto que apenas um genótipo, a testemunha comum, é utilizada para indicar as variações ambientais, que ocorrem nos difentes anos.

b) Testemunha como fator de correção

Outro modo de estimação de progresso genético, mediante o auxilio de testemunha comum em todos os experimentos, é utilizando o seu rendimento como covariável do rendimento dos demais genótipos, obtendo-se médias ajustadas, livres do efeito ambiental, à semelhança da correção do rendimento de grãos em função do número 
de plantas na parcela. Com as médias anuais ajustadas efetua-se estudo de regressão em função dos anos e pelo coeficiente angular (b) estima-se o ganho genético médio anual, como utilizado por EYHÉRABIDE \& alii (1994).

CÓRDOVA et alii (1996) alertam para os cuidados na escolha da testemunha referencial, que deve corresponder às expectativas dos agricultores e melhoristas, apresentando desempenho estável e com rendimento em nível satisfatório.

\subsubsection{Estimativas de ganho genético}

\subsubsection{Estimativas de ganho genético para o feijão}

Estimativas de progresso genético do feijoeiro em Minas Gerais, foram obtidas por ABREU et alii (1994), através dos métodos de VENCOVSKY et alii (1988), com as modificações propostas por RODRIGUES (1990) (método VP1) e pela metodologia RO, que envolveu a comparação dos coeficientes angulares da regressão linear da testemunha comum a todos os anos (variedade Carioca), com os demais genótipos. A diferença entre esses coeficientes forneceu a estimativa do ganho genético médio anual. Saliente-se que houve alteração na aplicação da primeira metodologia, visto que a estimativa foi obtida em nível regional e não por local como proposto originalmente.

No trabalho de ABREU et alii (1994), foi constatado que no método da regressão $\mathrm{RO}$, houve interferência da interação anos por genótipos, bem como do próprio efeito do ano, em função do princípio desta metodologia que utiliza regressão com dados originais, o que foi confirmado pelos baixos coeficientes de determinação, menores que 0,35 . Neste trabalho, as estimativas de ganho genético médio anual obtidas para o feijão foram: $1,8 \%$ pela metodologia VP1 e 1,9\% pelo método da regressão $R O$. 
2.2.2.2 Estimativas de ganho genético para outras espécies

TOLEDO et alii (1990) e ALLIPRANDINI et alii (1993) estimaram o ganho genético em soja no estado do Paraná, utilizando o método com ponderação proposta por FERNANDES (1988). SOARES \& RAMALHO (1993) estudaram o progresso genético em arroz de sequeiro em Minas Gerais, com o método original de VENCOVSKY et alii (1988) (método VO) e a regressão linear do ganho genético líquido versus anos (método RO). Ambas metodologias forneceram estimativas próximas. SOARES et alii (1994), também em Minas Gerais, obtiveram as estimativas do ganho genético para arroz irrigado, utilizando as duas metodologias anteriores e mais a da regressão $L_{1}$ (NARULA \& STANGENHAUS, 1988).

Esta regressão é um método robusto, que visa minimizar os resíduos em valores absolutos, tornando a regressão menos influenciada pelos dados discrepantes dos valores do eixo Y (no caso, ganho genético líquido). No entanto, esta regressão é sensível aos erros de medida no eixo $\mathrm{X}$, mas como se trata de anos $(1,2 \ldots \mathrm{A})$, o erro de medida não existe. Este tipo de regressão tem sua maior utilidade em indicar os dados discrepantes, não tanto para explicar o modelo, já que sua reta de regressão é uma espécie de mediana entre os resíduos em módulo e não uma reta de quadrados mínimos dos desvios, que está mais próxima dos valores observados e portanto com maior coeficiente de determinação.

As estimativas de ganho genético médio anual obtidas com outras culturas no Brasil foram 2,0\% para o milho (VENCOVSKY et alii, 1988), 1,8\% para soja precoce (TOLEDO et alii, 1990) e 1,8\% para sorgo granifero (RODRIGUES, 1990). Estas estimativas foram semelhantes às obtidas com a cultura do feijoeiro relatadas por ABREU et alii. (1994), que foram da ordem de 1,9\% para a metodologia da regressão e de $1,8 \%$ pela metodologia de RODRIGUES (1990). 
2.3) Interação genótipos versus ambientes

Em relação à interação genótipos versus ambientes em feijão, há trabalhos que enfocam diferentes aspectos: a)decomposição da interação em parte simples e complexa (CHAVES, 1982 e CRUZ \& CASTOLDI, 1991); b)qualidade nutricional versus ambiente (GHADERI et alii, 1984; HOSFIELD et alii, 1984; PARK, 1987 e SHELLIE \& HOSFIELD, 1991); c)alteração na fisiologia (NIENHUIS \& SINGH, 1985 e ACOSTAGALLEGOS \& WHITE, 1995); d)populações segregantes com ambintes (RAMALHO et alii, 1988; ABREU et alii, 1990; TAKEDA et alii, 1991 e SHONNARD \& GEPTS, 1994); e)análise multivariada (YOURSTONE \& WALLACE, 1990 e SAINDON \& SCHAALJE, 1993); f)análise de estabilidade (DUARTE \& ZIMMERMANN, 1992, 1994 e MIRANDA et alii, 1993); g)sensibilidade a agentes estressantes (MEBRAHTU et alii, 1990); h)escolha de locais contrastantes (DUARTE \& ZIMMERMANN, 1991) e i)estimativas dos componentes de variância (ESCRIBANO et alii, 1994). Em todos os trabalhos que mencionaram a significância da interação, esta foi significativa.

O feijão é tido como uma espécie altamente influenciada pelo ambiente, talvez por ser originário de clima mais ameno, ser planta $\mathrm{C}_{3}$ e, consequentemente, mais adaptada ao sombreamento, pela sua sensibilidade ao calor, que provoca queda de flores e frutos recém-formados, pelo seu sistema radicular pouco agressivo, que torna a planta mais sujeita à seca e a solos compactados, e pela elevada diversidade de patógenos que atacam a cultura em diferentes fases de seu ciclo (WHITE \& ISQUIERDO, 1993). Por estas razões, é encarada, em muitas ocasiões, como uma planta sensível às condições adversas. É importante ressaltar que como planta sensível, esta responde à melhoria de ambiente, como verifica-se em áreas irrigadas. Entretanto, o que prevalece no Brasil e no Paraná como um todo é o cultivo do feijão em áreas marginais, em monocultivo e sem grandes 
investimentos. Em tais situações, toma-se dificil quantificar a contribuição dos cultivares melhorados, pois espera-se maior efeito da interação genótipos $\mathrm{x}$ ambientes nestas condições de cultivo, visto que poderá causar distorções na estimativa do efetivo retorno gerado pelos genótipos melhorados (progresso genético), mediante dados originais obtidos de ensaios regionais de competição de linhagens e cultivares.

Tendo-se por base que as médias originais dos genótipos estão sob influência dos efeitos ambientais, da interação genótipos $\mathrm{x}$ ambientes e do erro experimental, toma-se necessário utilizar metodologias de estimação de ganho genético que gerem estimativas fidedignas e imparciais, menos afetadas pelos fatores não genéticos, proporcionando maior segurança ao melhorista que avalia o progresso do programa de melhoramento genético em uma série histórica. 


\section{MATERIAL E MÉTODOS}

Para alcançar os objetivos estabelecidos, foram utilizados os dados obtidos pela rede oficial de competição de linhagens e cultivares de feijão do estado do Paraná, no período compreendido entre 1977 e 1995, em diferentes locais (Tabela 2) e em duas épocas de semeadura: águas e secas.

Estes ensaios foram de dois tipos, os intermediários e os finais. Os primeiros foram compostos por tratamentos genéticos oriundos dos ensaios preliminares das instituições que desenvolvem programa de melhoramento genético do feijoeiro, os quais são testados por um ano. Os ensaios finais testam as linhagens selecionadas nos ensaios intermediários. Os melhores tratamentos dos ensaios finais permanecem por mais um ano em teste, no mesmo ensaio, para então serem indicados ou não como novos cultivares. Portanto, um novo cultivar é testado por pelo menos três anos nos ensaios em rede, ou seja, um ano em intermediário e dois nos finais, antes que seja recomendado.

Os tratamentos genéticos foram divididos em dois grandes grupos, conforme a cor do tegumento da semente: o grupo cores e o grupo preto. $\mathrm{O}$ grupo cores continha todos aqueles que não eram pretos. Cada experimento foi composto por linhagens e por pelo menos dois cultivares padrões, sendo um o mais cultivado no estado e o segundo o mais produtivo do grupo, preto ou cores. No grupo preto o cultivar testemunha presente 
em todos os anos, foi o Rio Tibagi, enquanto que no grupo cores, o cultivar designado como padrão, em termos de área cultivada, foi o Carioca.

\subsection{Análise de Variância Individual}

O delineamento utilizado foi blocos ao acaso com três ou quatro repetições. Foram conduzidos em épocas de semeadura e locais representativos das regiões produtoras de feijão do Paraná (Tabela 2) e em condição de sequeiro. Efetuou-se a adubação, o controle de ervas daninhas e de insetos, segundo as recomendações para a cultura. $\mathrm{O}$ número de tratamentos variou de ano para ano, conforme o tipo de ensaio. $\mathrm{A}$ variável analisada foi o rendimento de grãos de feijão, expressa em $\mathrm{kg} / \mathrm{ha}$. As parcelas, em sua grande maioria, foram compostas por quatro linhas de 5,0m de comprimento, com 0,50m de espaçamento entre linhas, com cerca de 14 plantas por metro linear.

Inicialmente procedeu-se a análise de variância individual, referente aos 663 experimentos, e a respectiva análise de resíduos, visando detectar dados discrepantes, utilizando-se o procedimento PROC GLM (GLM - General Linear Model) do programa SAS - Statistical Analysis System (1990), cujos procedimentos constam no Apêndice 1. Ensaios com média inferior a $300 \mathrm{~kg} / \mathrm{ha}$ e com coeficiente de variação superior a $25 \%$ não foram considerados nas análises. Parcela com índice de variaçao percentual, (obtido pela razão entre o resíduo e o predito, expresso em porcentagem) abaixo de $-40 \%$ ou acima de $40 \%$ foi considerada suspeita de ser um dado discrepante, exigindo confimação do referido valor. Em todos os experimentos analisados não houve alteração das respectivas médias dos tratamentos, após a análise de resíduos. 


\subsection{Análise de Variância Conjunta}

Para a análise conjunta, utilizou-se o modelo matemático:

$Y_{i j k}=\mu+g_{i}+a_{j}+g a_{i j}+r_{k}(j)+e_{i j k}$, onde

$Y_{\mathrm{ijk}}$ é o valor observado do tratamento genético i no ambiente j na repetição k;

$\mu \quad$ é a média geral;

$\mathrm{g}_{\mathrm{i}} \quad$ é o efeito fixo do tratamento genético i $(\mathrm{i}=1,2 \ldots, \mathrm{G})$;

$a_{j} \quad$ é o efeito aleatório do ambiente $\mathrm{j}(\mathrm{j}=1,2 \ldots, \mathrm{A})$;

$\mathrm{ga}_{\mathrm{ij}}$ é o efeito aleatório da interação do tratamento genético i com o ambiente $\mathrm{j}$;

$\mathrm{r}_{\mathrm{k}(\mathrm{j})}$ é o efeito aleatório da repetição $\mathrm{k}$ dentro do ambiente $\mathrm{j}(\mathrm{k}=1,2 \ldots, \mathrm{R})$;

$\mathrm{e}_{\mathrm{ijk}} \quad$ é o erro experimental associado à parcela ijk.

Atualmente, há disponibilidade de vários programas computacionais relativos à análise de variância, como os mencionados por SCHWARZ (1993), tais como: BMDP, SAS, SPSS entre outros. Entretanto, como no presente trabalho se dispunha de grande quantidade de dados, e principalmente devido ao desbalanceamento causado pelos genótipos, que não estavam presentes em todos os anos analisados, foi necessário subdividir a análise conjunta para poder ser processada em microcomputador, visto que o procedimento PROC GLM do programa SAS, exigia mais de 100 megabites de memória randômica para poder efetuar as análises. Esta quantidade de memória não é normalmente disponível nos microcomputadores.

O parcelamento da análise conjunta se deu em etapas (Apêndice 2):

1)Inicialmente efetuou-se análises em nível de médias para se obter as somas de quadrado, graus de liberdade e quadrados médios das fontes de variação Genótipos, Ambientes e da interação Genótipos X Ambientes;

2)A partir das análises de variância individual, foi obtido o quadrado médio para repetições dentro de ambientes (R/A) pela expressão: 
$\mathrm{QMr}_{(\mathrm{a})}=\frac{\mathrm{SQr}_{(1)}+\mathrm{SQr}_{(2)}+\ldots+\mathrm{SQr}_{(\mathrm{A})}}{\mathrm{GLr}_{(1)}+\mathrm{GLr}_{(2)}+\ldots+\mathrm{GLr}_{(\mathrm{A})}}=\frac{\mathrm{SQr}_{(\mathrm{a})}}{\mathrm{GLr}_{(\mathrm{a})}}$, onde

$\mathrm{SQr}_{(\mathrm{a})}$ é a soma de quadrados de repetições no ambiente a;

$\mathrm{GL}_{(\mathrm{a})}$ é o grau de liberdade de repetições no ambiente a;

3)O quadrado médio do erro conjunto (QMErro) foi obtido também a partir das análises de variância individual, mediante a expressão:

$\mathrm{QMErro}=\frac{\mathrm{SQErro}_{1}+\mathrm{SQErro}_{2}+\ldots+\mathrm{SQErro}_{\mathrm{a}}}{\mathrm{GLErro}_{1}+\mathrm{GLErro}_{2}+\ldots+\mathrm{GLErro}_{\mathrm{a}}}=\frac{\text { SQErro }}{\text { GLErro }}$

$\mathrm{SQErro}_{(a)}$ é a soma de quadrados do erro experimental no ambiente a;

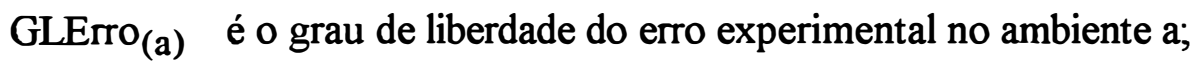

$\mathrm{Na}$ análise de variância conjunta, foram testados apenas os efeitos de genótipos, em função do desbalanceamento dos dados e da orientação seguida em modelos mistos (KEMPHORNE, 1975 e HENDERSON, 1984), que sugere que sejam testados apenas os fatores fixos do modelo, enquanto que para os fatores aleatórios sejam estimados seus componentes de variância, uma vez que se referem a uma amostra. A significância de genótipos foi testada com a interação genótipos por ambientes. Em função do desbalanceamento dos dados, obteve-se valor aproximado para o teste $\mathrm{F}$ dessa fonte de variação. IEMMA (1995) salientou que quando há desbalanceamento de tratamentos, o teste de hipóteses para os efeitos principais (no caso genótipos) fica viesado, no procedimento GLM do programa SAS. LATOUR \& LITTELL (1996) também alertaram para o problema do desbalanceamento nos testes de hipóteses. No presente estudo, a prioridade não foi testar os efeitos de genótipos, mas estimar o progresso genético. 
Foram estimados os componentes de variância, com os respectivos erros padrões, pelo procedimento Proc Mixed do programa SAS (LITTELL et alii, 1996). O detalhamento deste procedimento encontra-se no item 3.3.6 e nos Apêndices 3 e 4 .

\subsection{Estimação do Ganho Genético}

As estimativas do progresso genético foram obtidas por seis diferentes metodologias, sendo duas existentes, duas adaptadas e duas alternativas:

\subsection{1) Método Original (VO): (Metodologia existente)}

A primeira metodologia a ser considerada foi elaborada por VENCOVSKY et alii (1988), que será designada neste trabalho como método original (VO). Por esta metodologia, o ganho genético, estimado pela diferença genética líquida (dg), é obtido pela expressão:

$$
\mathrm{dg}=\mathrm{db}-\mathrm{da}, \text { onde }
$$

$\mathrm{db}$ é a diferença bruta entre a média de todos os tratamentos de um determinado ano e a

de todos os tratamentos do ano anterior;

da é a diferença ambiental obtida pelo contraste entre a média do grupo de

genótipos comuns ao par de anos consecutivos.

Considerando-se dois anos consecutivos (l e 2) tem-se:

$$
\begin{aligned}
d_{21} & =\left(\bar{Y}_{2}-\bar{Y}_{1}\right)-\left(\bar{Y}_{(21)_{2}}-\bar{Y}_{(21)_{1}}\right) \\
d_{21} & =\left(\mathrm{Y}_{2}-\bar{Y}_{1}\right) \\
d_{21} & =\left(\bar{Y}_{(21)_{2}}-\bar{Y}_{(21)_{1} 1}\right),
\end{aligned}
$$


$\bar{Y}_{2}$ é a média dos tratamentos no ano 2 ,

$\overline{\mathrm{Y}}_{1} \quad$ é a média dos tratamentos no ano 1 ,

$\overline{\mathrm{Y}}_{(21)_{2}}$ é a média dos genótipos comuns aos anos $2 \mathrm{e} 1$, obtida no ano $2 \mathrm{e}$

$\overline{\mathrm{Y}}_{(21)_{1}}$ é a média dos genótipos comuns aos anos 2 e 1, obtida no ano 1;

Para cada par de anos consecutivos, é obtido um dg (desvio genético líquido). Para avaliar o progresso total acumulado ao longo dos anos $\left(\mathrm{G}_{\mathrm{T}}\right)$, efetua-se o somatório dos $\mathrm{n}-1 \mathrm{dg}$, sendo $\mathrm{n}$ o total de anos estudados, isto é :

$G T(j)=d g_{21}+d g_{32}+\ldots+d_{g j . j-1} ; j=2,3 \ldots n$

Para se obter o acréscimo médio por ano, divide-se o progresso acumulado pelo número de anos no período. Esta última estimativa dividida pela média geral dos ensaios do primeiro ano, multiplicada por 100, fornece o ganho genético médio anual em porcentagem. $\mathrm{O}$ erro padrão da média desta estimativa pode ser obtida pela raiz quadrada da razão entre a variância dos ganhos genéticos e o número de anos envolvidos, isto é :

$$
\hat{\overline{\mathrm{g}}}=\frac{\sum \hat{\mathrm{g}}_{\mathrm{ij}}}{\mathrm{n}-1},
$$

$\hat{\mathrm{g}}$ é a estimativa do ganho genético médio anual em $\mathrm{kg} / \mathrm{ha}$;

n é o número de anos.

$$
\hat{\mathrm{s}}(\hat{\overline{\mathrm{g}}})=\sqrt{\frac{1}{\mathrm{n}}\left(\frac{\sum(\hat{\mathrm{g}}-\hat{\overline{\mathrm{g}}})^{2}}{\mathrm{n}-1}\right)},
$$

$\hat{\mathbf{s}}(\hat{\overline{\mathrm{g}}})$ é a estimativa do erro padrão da média da esimativa do ganho genético médio.

$\hat{\overline{\mathrm{g}}}(\%)=\frac{\hat{\mathrm{g}}}{\overline{\mathrm{T}}_{1}} 100$,

$\hat{\mathrm{g}}(\%)$ é a estimativa do ganho genético médio anual em (\%).

$\overline{\mathrm{T}}_{1}$ é a média dos tratamentos no ano 1 (média de referência).

A significância da estimativa de ganho genético médio anual foi verificada pelo teste $t$, mediante a expressão: 


$$
t=\frac{\hat{\bar{g}}-0}{\hat{s}(\hat{\bar{g}})},
$$

com n-2 graus de liberdade (sendo n o número total de anos).

3.3.2) Método Ponderado 1 (VP1) : (Metodologia adaptada)

O método original (VO) necessita ser ponderado por duas razões : a)os erros experimentais de determinado ano estão correlacionados com os erros do ano subsequente; b) há o cancelamento das médias dos tratamentos dos anos intermediários no cálculo do ganho genético total, que por sua vez originará o ganho médio, restando apenas para comparação o primeiro e o último ano das médias dos tratamentos, mas sendo mantidos todos os desvios ambientais. Supondo um período de 4 anos, por exemplo, o ganho genético total será:

$$
\begin{aligned}
& \mathrm{G}_{\mathrm{T}(4)}=\mathrm{dg}_{21}+\mathrm{dg}_{32}+\mathrm{dg}_{43} \\
& \mathrm{G}_{\mathrm{T}(4)}=\left\{\left[\left(\overline{\mathrm{Y}}_{2}-\overline{\mathrm{Y}}_{1}\right)-\left(\overline{\mathrm{Y}}_{(21)_{2}}-\overline{\mathrm{Y}}_{(21) 1}\right)\right]+\left[\left(\overline{\mathrm{Y}}_{3}-\overline{\mathrm{Y}}_{2}\right)-\left(\overline{\mathrm{Y}}_{(32)_{3}}-\overline{\mathrm{Y}}_{(32)_{2}}\right)\right]+\right. \\
& \left.+\left[\left(\bar{Y}_{4}-\bar{Y}_{3}\right)-\left(\bar{Y}_{(43)_{4}}-\bar{Y}_{(43)_{3}}\right)\right]\right\} \\
& \mathrm{G}_{\mathrm{T}(4)}=\left\{\left[\overline{\mathrm{Y}}_{4}-\overline{\mathrm{Y}}_{1}\right]-\left[\left(\overline{\mathrm{Y}}_{(21)_{2}}-\overline{\mathrm{Y}}_{(21)_{1}}\right)+\left(\overline{\mathrm{Y}}_{(32)_{3}}-\overline{\mathrm{Y}}_{(32)_{2}}\right)+\left(\overline{\mathrm{Y}}_{(43)_{4}}-\overline{\mathrm{Y}}_{(43)_{3}}\right)\right]\right\}
\end{aligned}
$$

FERNANDES (1988), estudando a interação genótipos $\mathrm{x}$ ambientes, sob o ponto de vista da estabiliade ambiental, propôs uma correção na metologia original de VENCOVSKY et alii (1988), na estimação dos desvios ambientais, mediante a utilização de Quadrados Mínimos Ponderados (QMP). RODRIGUES (1990) estendeu esta ponderação dos desvios ambientais, para a expressão do ganho genético líquido. Ambos autores se restringiram à estimação por local. Como no presente trabalho considerou-se o 
estado do Paraná como um todo e não apenas um local individualmente, fez-se necessário uma pequena adaptação, ponderando-se pelo número de observações utilizadas no cálculo da média de cada ano e não apenas pelo número de repetições de cada média. Este número de observações é função da média harmônica anual do número de locais e de repetições utilizados.

Originalmente, a estimativa de ganho genético pode ser obtida por quadrados mínimos ordinários. Este procedimento foi mencionado por SEARLE (1982) como OLS (Ordinary Least Square), sendo o modelo geral:

$$
\mathrm{Y}=\mathrm{X} \beta+\varepsilon \text {, onde }
$$

Y é o vetor das observações;

$\mathrm{X}$ é a matriz do delineamento;

$\beta$ é o vetor dos parâmetros;

$\varepsilon$ é o vetor dos erros.

As estimativas dos parâmetros são obtidas pela expressão:

$\hat{\beta}=\left(X^{\prime} X\right)^{-1} X^{\prime} Y$

e sua variância por:

$$
\mathrm{V}(\hat{\beta})=\left(\mathrm{X}^{\prime} \mathrm{X}\right)^{-1} \sigma^{2}
$$

$\mathrm{O}$ método envolvendo ponderação utiliza a matriz $\mathrm{V}$, que é a matriz de variâncias e covariâncias entre as observações, no caso, os ganhos genéticos. Para se proceder ao método dos quadrados mínimos ponderados, denominado GLS (Generalised Least Square), segundo SEARLE (1982), multiplica-se todos os termos da expressão (13) pela matriz V de ponderação, como exemplificado em HOFFMANN \& VIERA (1977), isto é: 


$$
\mathrm{VY}=\mathrm{VX} \beta+\mathrm{V} \varepsilon
$$

resultando em:

$\hat{\beta}=\left(X^{\prime} V^{-1} X\right)^{-1} X^{\prime} V^{-1} Y$, sendo :

$\hat{\beta}$ : estimativa do ganho genético médio anual e

$\hat{\mathrm{V}}(\hat{\boldsymbol{\beta}})=\left(\mathrm{XV}^{-1} \mathrm{X}\right)^{-1}$, onde

$\hat{V}(\hat{\beta})$ é a estimativa da variância da estimativa de $b$, referindo-se por local ou ensaio analisado. $\mathrm{O}$ componente $\sigma^{2}$ integra a matriz V.

Neste caso o vetor $\mathrm{Y}$ é constituído pelos A-1 ganhos genéticos anuais observados, $\mathrm{X}$ é também um vetor coluna unitário (com as dimensões A-1 linhas e uma coluna, sendo A o número total de anos) e a matriz $\mathrm{V}$ de ponderação que é composta apenas pelas estimativas das variâncias e covariâncias entre os ganhos genéticos em anos sucessivos. Estas estimativas dependem da estimativa da variância ambiental $\left(\sigma^{2}\right)$ e de coeficientes que a ponderam. Estes coeficientes são função do número de tratamentos e do número de genótipos comuns a cada par de anos consecutivos.

A matriz $\mathrm{V}$ tem a seguinte estrutura : é quadrada, com dimensões de A-1 linhas e colunas, onde A é o número total de anos, é simétrica, com as variâncias na diagonal principal, as covariâncias adjacentes a estas e os demais termos iguais a zero:

$$
\mathrm{V}=\left[\begin{array}{ccccc}
\hat{\mathrm{V}}\left(\hat{\mathrm{g}}_{2,1}\right) & \operatorname{CÔV}\left(\hat{\mathrm{g}}_{2,1}, \hat{\mathrm{g}}_{3,2}\right) & 0 & \ldots & 0 \\
\operatorname{CÔV}\left(\hat{\mathrm{g}}_{2,1}, \hat{\mathrm{g}}_{3,2}\right) & \hat{\mathrm{V}}\left(\hat{\mathrm{g}}_{3,2}\right) & \operatorname{CÔV}\left(\hat{\mathrm{g}}_{3,2}, \hat{\mathrm{g}}_{4,3}\right) & \ldots & 0 \\
0 & \operatorname{COOV}\left(\hat{\mathrm{g}}_{3,2}, \hat{\mathrm{g}}_{4,3}\right) & \hat{\mathrm{V}}\left(\hat{\mathrm{g}}_{4,3}\right) & \ldots & 0 \\
\cdot & \cdot & \cdot & \ldots & \cdot \\
\cdot & \cdot & \cdot & \ldots & \cdot \\
. & \cdot & . & \ldots & \cdot \\
0 & 0 & 0 & \ldots & \hat{\mathrm{V}}\left(\hat{\mathrm{g}}_{\mathrm{A}, \mathrm{A}-1}\right)
\end{array}\right]
$$

Conforme demonstrou RODRIGUES (1990), as variâncias foram estimadas por: 
$\mathrm{V}\left(\hat{\mathrm{g}}_{\mathrm{i}, \mathrm{i}-1}\right)=\hat{\sigma}^{2}\left(\frac{2}{\mathrm{C}_{\mathrm{i}, \mathrm{i}-1}}-\frac{1}{\mathrm{~T}_{\mathrm{i}}}-\frac{1}{\mathrm{~T}_{\mathrm{i}-1}}\right)$, sendo

$\hat{\sigma}^{2}$ : estimativa da variância do erro médio, obtido por:

$\hat{\sigma}^{2}=\frac{\text { QMErro Conjunto }}{\overline{\mathbf{r}}}$, sendo :

$\overline{\mathrm{r}} \quad$ : número de repetiões associado às médias;

$\mathrm{C}_{\mathrm{i}, \mathrm{i}-1}$ : número de genótipos comuns aos anos i e i-1;

$\mathrm{T}_{\mathrm{i}} \quad$ : número de tratamentos no ano $\mathrm{i}$;

$\mathrm{T}_{\mathrm{i}-1} \quad$ : número de tratamentos no ano $\mathrm{i}-1$;

e as covariâncias por:

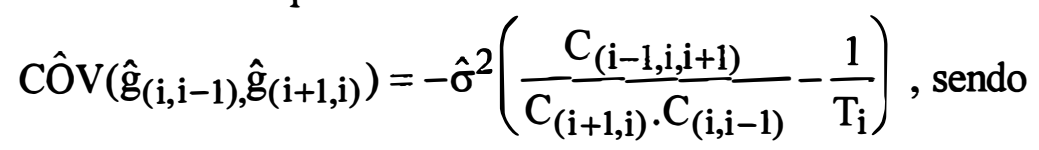

$\hat{\sigma}^{2} \quad$ : estimativa da variância do erro médio;

$\mathrm{C}_{(\mathrm{i}-1, \mathrm{i}, \mathrm{i}+1)}$ : número de genótipos comuns a 3 anos consecutivos;

$\mathrm{C}_{(\mathrm{i}+1, \mathrm{i})} \quad$ : número de genótipos comuns ao par de anos $\mathrm{i}+1 \mathrm{e}$;

$\mathrm{C}_{(\mathrm{i}, \mathrm{i}-1)} \quad$ : número de genótipos comuns ao par de anos i e i-1.

$\mathrm{T}_{\mathrm{i}} \quad$ : número de tratamentos no ano $\mathrm{i}$;

Neste método VP1, como $\hat{\sigma}^{2}$ compõe tanto as estimativas das variâncias, como das covariâncias, esta estimativa $\left(\sigma^{2}\right)$ pode multiplicar extemamente a matriz $\mathrm{V}$, a qual passa a ser composta apenas pelos coeficientes das variâncias e covariâncias e zeros.

A adaptação efetuada nesta metodologia, visou a estimativa da variância do erro médio, que passou a se referir à região como um todo, no caso o estado, possibilitando assim, obter estimativas de ganho genético médio relativas ao Paraná e não apenas a um local como consta no trabalho de RODRIGUES (1990). Para tanto, o denominador da expressão (21) passou a ser composto pela média harmônica de observações por ano, estimado pelo produto das média harmônicas de repetições $(\overline{\mathrm{r}})$ e de locais por ano $(\overline{1})$ : 


$$
\hat{\sigma}^{2}=\frac{\text { QMErro Conjunto }}{\overline{\mathbf{r}} \bar{l}}
$$

Pela resolução das equações normais, obtem-se a estimativa do ganho genético anual no método 1 de quadrados mínimos ponderados (VP1):

$$
\hat{\overline{\mathrm{g}}}=\left(\mathrm{X}^{\prime} \mathrm{V}^{-1} \mathrm{X}\right)^{-1}\left(\mathrm{X}^{\prime} \mathrm{V}^{-1} \mathrm{Y}\right)
$$

e o desvio padrão desta estimativa é obtido pela raiz quadrada da variância da média do ganho genético anual $(\hat{\mathrm{V}}(\hat{\mathrm{g}}))$ :

$$
\hat{\mathrm{V}}(\hat{\overline{\mathrm{g}}})=\left(\mathrm{X}^{\prime} \mathrm{V}^{-1} \mathrm{X}\right)^{-1}
$$

A estimativa do ganho genético anual médio, expressa em percentagem $(\hat{\overline{\mathrm{g}}}(\%))$, foi baseada na média geral dos ensaios $(\bar{T})$, como utilizado por RODRIGUES (1990): $\hat{\overline{\mathrm{g}}}(\%)=\frac{\hat{\mathrm{g}}}{\overline{\mathrm{T}}} 100$, onde

$\overline{\mathrm{T}}$ é a média geral dos ensaios (média de referência).

\subsection{3) Método Ponderado 2 (VP2): (Metodologia existente)}

É basicamente idêntico ao VP1, diferindo na maneira de compor a matriz V, cujos coeficientes dos termos das variâncias e covariâncias baseiam-se no número de observações de cada média que participa dos cálculos e na utilização dos Quadrados Médios do Erro anuais, ao invés do Quadrado Médio do Erro da análise conjunta para efetuar a ponderação. Esta metodologia foi proposta por MORAIS e ABBUD (1993) e utilizada por BRESEGHELLO (1995).

O método VP2 necessita da mesma matriz V do método VP1, explicitada em (19), sendo que as estimativas de variâncias e covariâncias foram obtidas através das seguintes expressões : 
$\hat{\mathrm{V}}\left(\hat{\mathrm{g}}_{\mathrm{i}, \mathrm{i}-1}\right)=\left[\frac{1}{\mathrm{n}_{\mathrm{i}, \mathrm{i}-1}}-\frac{1}{\mathrm{n}_{\mathrm{i}}}\right] \hat{\sigma}_{\mathrm{ei}}^{2}+\left[\frac{1}{\mathrm{n}_{\mathrm{i}-1, \mathrm{i}}}-\frac{1}{\mathrm{n}_{\mathrm{i}-1}}\right] \hat{\sigma}_{\mathrm{ei}-1}^{2}$, onde

$n_{i, i-1}$ é o número de observações no ano $i$, envolvendo os genótipos comuns aos anos $i$

e i-1 (Observações = número de ambientes $\mathrm{X}$ repetições $\mathrm{X}$ genótipos comuns);

$\mathrm{n}_{\mathrm{i}} \quad$ é o número de observações para o ano $\mathrm{i}$;

$\mathrm{n}_{\mathrm{i}-1, \mathrm{i}}$ é o número de observações no ano $\mathrm{i}-1$, das linhagens comuns aos anos $\mathrm{i}-1$ e $\mathrm{i}$;

$\mathrm{n}_{\mathrm{i}-1}$ é o número de observações para o ano i-1;

$\hat{\sigma}_{\text {ei }}^{2}$ é a estimativa da variância devida ao erro da análise conjunta dentro do ano i; $\hat{\sigma}_{\mathrm{ei}-1}^{2}$ é a estimativa da variância devida ao erro da análise conjunta dentro do ano i-1.

As estimativas de variância do erro médio de determinado ano podem ser obtidas por:

$$
\hat{\sigma}_{\mathrm{e}_{\mathrm{i}}}^{2}=\frac{\text { SQErro }_{1 \mathrm{i}}+\mathrm{SQErro}_{2 \mathrm{i}}+\ldots+\mathrm{SQErro}_{\mathrm{Ai}}}{\text { GLErro }_{\mathrm{li}}+\text { GLErro }_{2 \mathrm{i}}+\ldots \text { GLErro }_{\mathrm{Ai}}} \text {, onde }
$$

$\mathrm{SQErro}_{\text {ai }}$ é a soma dos quadrados do erro médio do ambiente a no ano i;

GLErro $_{\text {ai }}$ é o número de graus de liberdade do erro médio do ambiente a no ano i; A é o número total de ambientes no ano i.

De manđeira semelhante as covariâncias são estimadas por:

$\operatorname{Côv}\left(\hat{\mathrm{g}}_{\mathrm{i}+1, \mathrm{i}}, \hat{\mathrm{g}}_{\mathrm{i}, \mathrm{i}-1}\right)=\left[\frac{1}{\mathrm{n}_{\mathrm{i}}}-\frac{\mathrm{n}_{\mathrm{i}+1, \mathrm{i}, \mathrm{i}-1}}{\mathrm{n}_{\mathrm{i}+1, \mathrm{i}} \cdot \mathrm{n}_{\mathrm{i}, \mathrm{i}-1}}\right] \hat{\sigma}_{\mathrm{ei}}^{2}$, onde

$\mathrm{n}_{\mathrm{i}+1, \mathrm{i}, \mathrm{i}-1}$ é o número de observações, no ano intermediário $\mathrm{i}$, dos genótipos comuns aos três anos consecutivos : i+1, i e i-1;

$\mathrm{n}_{\mathrm{i}} \quad$ é o número de observações para $\mathrm{o}$ ano $\mathrm{i}$;

$n_{i+1, i}$ é o número de observações no ano $i+1$, das linhagens comuns aos anos $i+1$ e $i$;

$\mathrm{n}_{\mathrm{i}, \mathrm{i}-1}$ é o número de observações no ano i dos genótipos comuns ao par de anos i e i-1;

$\hat{\sigma}_{\text {ei }}^{2}$ é a estimativa da variância devida ao erro da análise conjunta dentro do ano i.

Uma vez montada a matriz $\mathrm{V}$, procede-se à estimação do ganho genético médio anual, em $\mathrm{kg} / \mathrm{ha}$ e em porcentagem, bem como sua precisão, utilizando-se os mesmos 
estimadores do método VP1, visto que a diferença básica com VP2 é a composição da matriz V de ponderação, pois ambos são métodos de quadrados míninos ponderados.

\subsection{4) Método da Regressão com Dados Originais (RO): (Metodologia Adaptada)}

Este método de estimação de ganho genético foi baseado no trabalho de ABREU et alli (1994), que utiliza os dados originais, sem nenhum tipo de transformação ou padronização e que estabelece duas equações de regressão linear, uma para as médias anuais da testemunha comum e outra para as médias anuais dos demais genótipos em teste, ambas em função dos anos. Para os ensaios do grupo cores, utilizou-se o cultivar Carioca, descrito por ALMEIDA et alii (1971) como testemunha e para o grupo preto o cultivar Rio Tibagi, originado de linhagem fixa, proveniente da Costa Rica, introduzido no Paraná nos anos 60, segundo MODA-CIRINO ${ }^{1}$.

Efetuaram-se algumas alterações nessa metodologia:

a) Considerou-se apenas os tratamentos genéticos que participaram pela primeira vez dos ensaios para comporem a média anual dos genótipos agora considerados como "novos" e não os "demais" tratamentos, como no original, visto que no conjunto dos "demais" tratamentos, podem ser encontrados, além dos genótipos novos, os genótipos comuns ao ano anterior e até eventuais testemunhas transitórias. Portanto o conjunto dos "demais" tende a possuir média de rendimento de grãos superior ao grupo dos novos, pois estes podem ser compostos por genótipos que serão selecionados, como também por aqueles que serão descartados. Diante desta pressuposição, seria esperada superestimação dos ganhos genéticos, se fosse adotado o contraste "demais" versus testemunha comum.

${ }^{1}$ Comunicação pessoal. 
b) A segunda alteração buscou uma terceira equação de regressão linear, considerando-se como variável dependente $(\mathrm{Y})$ o contraste da média anual dos genótipos novos versus a média anual da testemuha, que passou a estimar o ganho genético diretamente pela estimativa do coeficiente de regressão $\hat{b}$ desta terceira equação e não mais pelo contraste dos coeficientes de regressão linear de ambas equações, como propunha o método original. A vantagem desta alteração é que permite obter diretamente o desvio e a significância da estimativa do ganho genético anual.

c) A terceira adaptação foi no referencial para o cálculo da estimativa do ganho genético médio anual, expressa em percentagem. No trabalho de ABREU et alii (1994), o valor de referência foi a média aritmética original de todos os tratamentos no primeiro ano do período considerado. Certamente este valor é influenciado pelas condições ambientais que ocorreram naquele ano, podendo sub ou superestimar o valor da estimativa de ganho genético médio. Para diminuir estas possívies distorções, optou-se por adotar como valor de referência, a estimativa do coeficiente linear (a) da reta da equação de regressão linear relativa aos genótipos novos em função dos anos, que corresponde à média esperada dos genótipos novos no ano anterior ao primeiro ano considerado, (ano zero), teoricamente mais próximo à média da população considerada original. A relação entre o coeficiente angular (b) e ocoeficiente linear (a) da regressão foi adotado por BYRNE et alii (1995).

Esta metodologia (RO) se fundamenta na hipótese de que a estimativa do coeficiente da regressão linear dos genótipos novos $\hat{b}_{n}$ estima as alterações fenotípicas ocorridas ao longo dos anos de melhoramento, enquanto que a estimativa do coeficiente de regressão linear da média anual das testemunhas $\hat{b}_{t}$ estima a variação ambiental. A diferença entre os dois coeficientes, estima a alteração genotípica no período, que corresponde ao ganho genético, isto é: 


$$
\hat{\bar{g}}=\hat{b}_{g}=\left(\hat{b}_{n}-\hat{b}_{t}\right)
$$

Para isso foram estabelecidas três equações de regressão linear:

$Y_{n}=a_{n}+b_{n} X+e_{n}$ (para os genótipos novos)

$Y_{t}=a_{t}+b_{t} X+e_{t}$ (para a testemunha)

$\mathrm{Yg}=\mathrm{ag}+\mathrm{bgX}+\mathrm{eg}$ (para o ganho genético), sendo:

$\mathrm{Y}_{\mathrm{n}}$ : média anual observada dos genótipos novos em $\mathrm{kg} / \mathrm{ha}$,

$Y_{t}$ : média anual observada da testemunha em $\mathrm{kg} / \mathrm{ha}$,

$\mathrm{Yg}=\left(\mathrm{Y}_{\mathrm{n}}-\mathrm{Y}_{\mathrm{t}}\right)$

$X=\operatorname{anos}($ de 1 a $A)$;

A estimativa do erro padrão correspondente foi obtida por:

$$
\hat{\mathrm{s}}(\hat{\overline{\mathrm{g}}})=\sqrt{\frac{\mathrm{QMDesvio}_{\mathrm{g}}}{\mathrm{SQX}_{\mathrm{g}}}}, \text { sendo: }
$$

QMDesvio $_{\mathrm{g}}$ : Quadrado Médio do Desvio da Regressão do ganho genético.

SQX $_{\mathrm{g}} \quad$ : Soma de Quadrado de X (de anos) referente ao contraste (ganho genético), conforme SOKAL \& ROHLF (1981).

A estimativa do ganho genético médio anual em porcentagem foi obtida por: $\hat{\bar{g}}(\%)=\frac{\hat{b}_{g}}{\hat{a}_{n}} 100$, sendo:

$\hat{b}_{\mathrm{g}}$ a estimativa do coeficiente angular da equação de regressão linear, relativa ao ganho genético em função dos anos;

$\hat{a}_{n}$ a estimativa do intercepto ou coeficiente linear da equação de regressão linear, relativa à média anual dos genótipos novos em função dos anos.

A significância da estimativa de ganho genético médio anual pode ser testada de duas maneiras, a primeira mediante $\mathrm{o}$ teste $\mathrm{t}$ e a segunda pelo teste $\mathrm{F}$ da análise de variância da análise de regressão, testando-se o Quadrado Médio da Regressão Linear 
com o Quadrado Médio dos Desvios da Regressão, repectivamente com 1 e A-2 graus de liberdade, sendo A o número total de anos.

Em estudos envolvendo ganho genético, mediante a utilização de regressão, a prioridade é testar a significância do efeito linear da regressão. Com menor prioridade, foi testado o desvio da regressão. Em sendo ambos significativos, a regressão linear e seu desvio, indicarão que existem outras causas, além do efeito linear, para explicar o comportamento dos dados, mas o que importa é a tendência linear dos ganhos, cuja explicação biológica é mais consistente. $\mathrm{O}$ desvio da regressão linear foi testado com o quadrado médio do erro da análise de variância conjunta, dividido pela média harmônica do número de locais e repetições, pois as análises foram realizadas em nível de médias.

\subsection{5) Método da Regressão com Dados Estandardizados (RE):}

(Metodologia Alternativa)

De acordo com esta metodologia, inicialmente as médias originais dos tratamentos genéticos novos e da testemunha em cada ano foram estandardizadas, mediante a expressão:

$$
\mathrm{z}_{\mathrm{ij}}=\frac{\mathrm{m}_{\mathrm{ij}}-\overline{\mathrm{m}}_{\mathrm{j}}}{\mathrm{s}_{\mathrm{j}}} \text {, onde }
$$

$\mathrm{z}_{\mathrm{ij}}$ é a média estandardizada do tratamento i no ano $\mathrm{j}$, expressa em UDP (unidades de desvio padrão);

$\mathrm{m}_{\mathrm{ij}}$ é a média original, em $\mathrm{kg} / \mathrm{ha}$, do tratamento $\mathrm{i}$ no ano $\mathrm{j}$;

$\overline{\mathrm{m}}_{\mathrm{j}}$ é a média geral, em $\mathrm{kg} / \mathrm{ha}$, de tratamentos no ano $\mathrm{j}$;

$\mathrm{s}_{\mathrm{j}}$ é o desvio padrão do erro experimental no ano $\mathrm{j}$, expresso em $\mathrm{kg} / \mathrm{ha}$;

A finalidade desta estandardização foi eliminar o efeito de ano e aumentar a precisão da estimativa de ganho genético médio, visto que todos os anos passariam a ter 
média zero. Esta estandardização foi adaptada a partir do trabalho de FOX \& ROSIELLE (1982) sobre interação genótipos X ambientes, onde a média de cada ambiente foi zerada. Esta metodologia de estudo da interação é conhecida na literatura internacional como "Pattern Analysis" e vem sendo adotada por diferentes autores como DELACY \& COOPER (1990), COOPER et alii. (1993), CROSSA et alii. (1995), JACKSON et alii (1995) e ABDALLA et alii (1996), entre outros.

Uma vez obtidos os dados transformados, pode-se utilizar qualquer método já descrito para estimar o ganho genético. Pode-se usar a metodologia da regressão linear, comparando-se o desempenho da média dos tratamentos genéticos novos com a média da testemunha, objetivando aumentar a precisão das estimativas. Para tanto estimaram-se três equações de regressão linear da mesma maneira da metodologia anterior (RO), obtendo-se as estimativas e verificando-se a significância com os mesmos procedimentos. Todas as estimativas foram expressas em $\mathrm{kg} / \mathrm{ha}$, convertidas de unidades de desvio padrão (u.d.p.), mediante as expressões:

$$
\hat{\bar{g}}_{(\mathrm{kg} / \mathrm{ha})}=\hat{\mathrm{b}}_{\mathrm{g}} \hat{\mathrm{s}} \text {, sendo: }
$$

$\hat{\mathrm{g}}_{(\mathrm{kg} / \mathrm{ha})}$ : estimativa do ganho genético médio anual em $\mathrm{kg} / \mathrm{ha}$;

$\hat{\mathrm{b}}_{\mathrm{g}}$ : estimativa do coeficiente de regressão linear do ganho genético em unidades de desvio padrão (u.d.p.);

s : estimativa do desvio padrão do erro experimental da análise conjunta, em $\mathrm{kg} / \mathrm{ha}$.

$$
\hat{\overline{\mathrm{g}}}_{(\%)}=\frac{\hat{\mathrm{g}}_{(\mathrm{kg} / \mathrm{ha})}}{\left[\left(\hat{\mathrm{a}}_{\mathrm{n}}\right) \hat{\mathrm{s}}+\hat{\mathrm{m}}\right]} 100, \text { onde }
$$

$\hat{a}_{n}$ é a estimativa do intercepto (em u.d.p) dos genótipos novos;

$\hat{\mathrm{m}}$ é a estimativa da média geral em $\mathrm{kg} / \mathrm{ha}$. 


\subsection{6)Método da Regressão com Médias Ajustadas (RA): (Metodologia Alternativa)}

Em estudos envolvendo tratamentos genéticos, considerados como fator fixo, testados em diferentes ambientes, designados como aleatórios, é conveniente estimar os efeitos dos genótipos, e não apenas testar a significância dos termos do modelo matemático. Assim, de posse dos efeitos dos genótipos, pode-se estimar as médias ajustadas e efetuar a seleção dos melhores. Este procedimento é mais seguro que a seleção realizada com base nas médias originais, visto que as médias ajustadas tem menor influência do erro experimental e dos ambientes. De posse das médias ajustadas gerais dos genótipos pode-se utilizar o método da regressão linear, para a testemunha e para as médias dos tratamentos novos, para se estimar o ganho genético médio anual ajustado.

Atualmente, considera-se a maneira mais adequada de estimar os efeitos fixos, através da resolução das equações de modelos mistos (MME) propostas por HENDERSON et alii (1959), mediante o método de quadrados mínimos generalizados (GLS), que fornece o melhor estimador linear não viesado ("BLUE" - Best Linear Unbiased Estimator) que gera a estimativa dos efeitos dos fatores fixos do modelo. Podese obter também o melhor preditor linear não viesado ("BLUP" - Best Linear Unbiased Predictor) que proporciona a estimativa dos "efeitos" dos fatores aleatórios. A resolução dessas equações pressupõe duas condições, que até há pouco tempo dificultavam a sua execução em experimento com desbalanceamento: a) conhecimento dos componentes de variância e b) possibilidade de efetuar cálculos com matrizes de grande dimensão.

Quando se objetiva obter as estimativas dos componentes de variância, provenientes de um conjunto de dados com desbalanceamento, verifica-se que o tema estimação de componentes de variância é assunto de controvertida literatura (CRUZ \& 
REGAZZI, 1994). Segundo LOPES et alii (1993), estão disponiveis diferentes procedimentos de estimação de componentes de variância para modelos mistos:

- ANAVA : Análise de variância (método dos momentos);

- Método de Henderson I;

- Método de Henderson II

- Método de Henderson III;

- MINQUE : Método de estimação quadrática não viesada de norma mínima;

- MIVQUE : Método de estimação quadrática não viesada de variância mínima;

- ML : Máxima verossimilhança;

- REML : Máxima verossimilhança restrita;

Em se tratando de dados desbalanceados, os métodos de uso mais intenso no momento são o ML e o REML, basicamente em função do progresso na área de informática e na existência de algoritmos mais eficientes (LOPES et alii, 1993). Certa preferência tem sido dada aos procedimentos que tem o método REML como base (VERNEQUE, 1994; GOGEL et alii, 1995). No entanto continuam surgindo novas opções na literatura para estimação de componentes de variância na presença de desbalanceamento, como apontado por ÖFVERSTEN (1993) e BERNARDO (1995). No presente trabalho, os componentes de variância foram estimados pelo método REML no procedimento PROC MIXED do programa SAS, que segundo WOLFINGER \& CHANG (1995) é mais apropriado aos dados desbalanceados que o procedimento PROC GLM do mesmo programa.

O método de estimação de componentes de variância pelo procedimento "REML" (Restricted Maximum Likelihood), que foi esendido para todos os modelos lineares de análise de variância por PATTERSON \& THOMPSON (1971), resume-se em: 
1) Definir o modelo matemático misto de análise de variância dos dados.

2) Estabelecer a função de densidade de probabilidade conjunta dos vetores $Y$ (vetor das observações) e U (vetor dos parâmetros aleatórios), que é a função de verossimilhança, a qual permite estimar a possibilidade do vetor de parâmetros explicar os dados observados. Esta função é proveniente do produtório das densidades associadas a cada observação da amostra aleatória.

Os termos da função de máxima verossimilhança, são semelhantes aos termos da função de distribuição normal, onde a média da amostra é substituída pelo valor esperado (Y-Xß) e a variância, pela matriz V (matriz de variâncias e covariâncias dos dados). No termo constante desta função é incluído o determinante da matriz V.

3) Aplica-se uma restrição na função de verossimilhança, que passa a ser subdividida em duas funções de densidade de probabilidade independentes, sendo uma relacionada aos efeitos fixos do modelo e outra aos efeitos aleatórios. Tornando esta função com termos distintos da função de máxima verossimilhança.

4) Como a função de verossirnilhança envolve produto de termos, é conveniente transformá-la, mediante logaritmo.

5) Para se obter a estimativa do valor máximo dessa função, deriva-se parcialmente em relação aos termos fixos, aleatórios e erro experimental, iguala-se a zero e resolve-se o sistema de equações.

6) O sistema de equações formado pelas derivadas não tem solução explícita, ou seja, o estimador de cada componente está em função dos estimadores dos outros componentes. Neste ponto, é necessária a utilização de processo iterativo, como por exemplo NewtonRaphson, para se obter as estimativas de componentes de variância.

No processo iterativo, adotam-se valores iniciais aleatórios ou previamente selecionados, obtendo-se as primeiras estimativas dos parâmetros desejados. Com estes 
novos valores, repete-se a estimação. O processo de iteração cessa quando os valores da penúltima estimação é praticamente igual à última (o programa SAS tem como critério de semelhança o valor de $1 / 10^{8}$ ). O primeiro valor a ser iteragido pode ser baseado nas estimativas de componentes de variância, considerando-se o modelo matemático fixo, obtidos pelo processo ANAVA ou MIVQUE0 (método de estimação quadrática não viesada de variância mínima, sendo que as estimativas negativas das variâncias são revertidas a zero). Este último método é utilizado pelo programa SAS. Este cuidado com os primeiros valores se faz necessário, visto que a eficiência do processo de iteração depende dos valores iniciais.

7) Para constatar se as estimativas obtidas conferem ponto de máximo à função de verossimilhança, é necessário efetuar a derivada segunda em relação aos parâmetros e verificar se esta derivada é negativa. Se o for, a condição de máximo está satisfeita. A derivada segunda forma a matriz $\mathrm{H}$ (matriz Hessiana).

8) As estimativas dos componentes de variância foram obtidas simultaneamente por processo de otimização, baseado em função de máxima verossimilhança restrita, envolvendo iteração. Por este método todas as estimativas não são negativas.

9) Para obter os erros padrões das respectivas estimativas dos componentes de variância, inverte-se a matriz $\mathrm{H}$, que implica em efetuar a raiz quadrada dos elementos da diagonal principal da matriz Hessiana.

10) Para testar a significância das estimativas dos componentes de variância (ecv), podese realizar o teste de Wald, que utiliza os erros padrões (ep) para obter a estatística z: $z=\frac{\text { ecp }}{\text { ep }}$,

usando-se a tabela bilateral de z para determinar a significância.

Todas estas etapas são efetuadas automaticamente pelo procedimento Proc Mixed do programa SAS, bastando declarar o modelo matemático e quais são os efeitos fixos e 
aleatórios. Maiores detalhamentos do procedimento REML de estimação de componentes de variância, podem ser encontrados em CIÓL (1982), SAS (1992), LOPES et alii (1993), SALVARREY \& IEMMA (1995) e VIEIRA (1996).

LATOUR \& LITTELL (1996), afirnaram que em modelos mistos, com desbalanceamento de dados, é necessário redobrar os cuidados, principalmente nos seguintes pontos: estabelecer criteriosamente quem são os fatores fixos e os aleatórios do modelo matemático; especificar qual é a estrutura de covariância entre as observações da variável resposta. Nos testes de hipóteses, apenas os efeitos fixos são testados, verificando a composição do numerador e do denominador do teste $\mathrm{F}$, para confirmar a independência entre ambos. Quanto aos intervalos de confiança, estes são aproximados.

Conforme mencionado, o método REML é utilizado para obter estimativas de componentes de variância, que serão utilizadas no processo de estimação dos efeitos fixos do procedimento BLUE. As estimativas BLUE, em conjunto de dados desbalanceados, podem ser obtidas pelo PROC MIXED LATOUR \& LITTELL (1996).

O que torna os BLUEs e os BLUPs tão amplamente aceitos é basicamente o fato de serem consideradas as estimativas mais precisas e menos contaminadas pelos efeitos ambientais e interação, uma vez que em sua estimação é considerada a relação dos componentes de variância dos fatores aleatórios com o componente de variância relativo ao erro experimental. Em trabalhos de melhoramento, para os fatores fixos do modelo, a seleção pode ser efetuada sobre os BLUEs ou suas respectivas médias ajustadas (VERDOOREN, 1992), enquanto que para os fatores aleatórios, a seleção se faz diretamente sobre os BLUPs.

Este procedimento começou a ser utilizado nos programas de melhoramento animal (HENDERSON, 1984 e VAN VLECK, 1993), em seguida no melhoramento florestal (WHITE \& HODGE, 1989, FINS et alii. 1992 e SOH, 1994), e mais 
recentemente em espécies anuais, como milho (BERNARDO, 1996a, 1996b, 1996c e 1996d), soja (PANTER \& ALLEN, 1995) e também como auxiliar nos estudos com marcadores moleculares, como indicado por FAMULA (1986), BERNARDO (1994) e YANG \& WANG (1995).

Uma revisão sobre modelos mistos, com as devidas derivações, pode ser encontrada em HOCKING (1985), MLLIKEN \& JOHNSON (1992) e MARTINS et alii. (1993). Pela filosofia de trabalho dos modelos mistos, considera-se que os fatores fixos devem ser testados quanto a sua significância, bem como estimados seus efeitos, enquanto que para os termos aleatórios estimam-se seus respectivos componentes de variância, uma vez que se referem a uma população base (HENDERSON, 1984).

O método RA de estimação do ganho genético, baseou-se na regressão das médias ajustadas dos genótipos novos e da testemunha em função dos anos. As médias ajustadas foram obtidas pela estimação dos efeitos dos genótipos segundo o modelo: $\mathrm{Y}_{\mathrm{ijk}}=\mu+\mathrm{g}_{\mathrm{i}}+\mathrm{a}_{\mathrm{j}}+\mathrm{ga}_{\mathrm{ij}}+\mathrm{r}_{\mathrm{k}(\mathrm{j})}+\mathrm{e}_{\mathrm{ijk}}$, onde

$\mathrm{Y}_{\mathrm{ijk}}$ é o valor observado do tratamento genético $\mathrm{i}$, no ambiente $\mathrm{j}$ na repetição $\mathrm{k}$;

$\mu \quad$ é a média geral;

$\mathrm{g}_{\mathrm{i}} \quad$ é o efeito fixo do tratamento genético $\mathrm{i}(\mathrm{i}=1,2 \ldots, \mathrm{G})$;

$a_{j} \quad$ é o efeito aleatório do ambiente $j(j=1,2 \ldots, A)$;

$\mathrm{ga}_{\mathrm{ij}}$ é o efeito aleatório da interação do tratamento genético $\mathrm{i}$ com $\mathrm{o}$ ambiente $\mathrm{j}$;

$r_{k}(j)$ é o efeito aleatório da repetição $k$ dentro do ambiente $j(k=1,2 \ldots, R)$;

$\mathrm{e}_{\mathrm{ijk}} \quad$ é o erro experimental associado à parcela $\mathrm{ijk}$.

Este modelo pode ser expresso em termos matriciais, separando-se os efeitos fixos dos aleatórios como indicado por SEARLE (1987) e mais claramente por MARTINS et alii (1993): 


$$
\mathrm{Y}=\mathrm{X} \beta+\mathrm{ZU}+\mathrm{E} \text {, onde }
$$

Y é o vetor dos dados observados;

$\mathrm{X}$ é a matriz de incidência dos efeitos fixos conhecida;

$\beta$ é o vetor dos parâmetros de efeitos fixos desconhecido;

$\mathrm{Z}$ é a matriz de incidência dos efeitos aleatórios conhecida;

U é o vetor dos parâmetros de efeitos aleatórios desconhecido;

E é o vetor dos erros aleatórios.

Considera-se que U e E não são correlacionados com esperança matemática zero:

$$
\mathrm{E}\left[\begin{array}{l}
\mathrm{U} \\
\mathrm{E}
\end{array}\right]=\left[\begin{array}{l}
0 \\
0
\end{array}\right]
$$

e variâncias $G$ e $R$ respectivamente, a saber:

$$
\operatorname{Var}\left[\begin{array}{l}
\mathrm{U} \\
\mathrm{E}
\end{array}\right]=\left[\begin{array}{cc}
\mathrm{G} & 0 \\
0 & \mathrm{R}
\end{array}\right] \text {, sendo: }
$$

G : matriz de variâncias e covariâncias dos efeitos aleatórios presentes no vetor $\mathrm{U}$ e $\mathrm{R}$ : matriz de variâncias e covariâncias residuais.

A matriz G é uma matriz quadrada, que neste trabalho foi composta pelos componentes de variância dos fatores aleatórios do modelo, dispostos na diagonal, com os demais termos iguais a zero. Cada componente de variância estava presente em n células da matriz $\mathrm{G}$, sendo n o número de níveis do respectivo fator. Por sua vez, a matriz $\mathrm{R}$, também quadrada, com o número de linhas e colunas igual ao número de observações, foi composta pelo componente de variância do erro experimental na diagonal, sendo os outros termos iguais a zero.

A variância de Y (vetor das observações) representada pela matriz $\mathrm{V}$, foi obtida mediante a expressão matricial: 
$\operatorname{Var}(\mathrm{Y})=\mathrm{V}=\mathrm{ZGZ}+\mathrm{R}$, onde

$Z$ é a matriz conhecida de incidência dos efeitos aleatórios;

G é a matriz desconhecida de variâncias e covariâncias dos efeitos aleatórios presentes no vetor $\mathrm{U}$;

$Z^{\prime}$ é a matriz $Z$ transposta e

$\mathrm{R}$ é a matriz desconhecida de variâncias e covariâncias residuais.

Para se obter as estimativas dos parâmetros do modelo, é necessário conhecer todas as matrizes, inclusive $\mathrm{G}$ e $\mathrm{R}$, que são compostas pelos componentes de variâncias. Para tanto, utilizou-se o método REML de estimação de componentes de variância. Este procedimento permitiu tornar conhecidas as matrizes $\mathrm{G}$ e $\mathrm{R}$ e por sua vez $\mathrm{V}$, podendo-se estabelecer as equações MM de HENDERSON et alii (1959):

$$
\left[\begin{array}{cc}
X^{\prime} R^{-1} X & X^{\prime} R^{-1} Z \\
Z^{\prime} R^{-1} X & X^{\prime} R^{-1} Z+G^{-1}
\end{array}\right]\left[\begin{array}{l}
\beta \\
U
\end{array}\right]=\left[\begin{array}{l}
X^{\prime} R^{-1} Y \\
Z^{\prime} R^{-1} Y
\end{array}\right],
$$

cuja resolução fornece as estimativas dos efeitos fixos $(\beta)$ e aleatórios $(U)$ do modelo:

$$
\begin{aligned}
& \hat{\beta}=\left(X^{\prime} V^{-1} X\right)^{-1} X^{\prime} V^{-1} Y \\
& \hat{U}=G Z^{\prime} V^{-1} r, \text { onde } \\
& r=Y-X \beta
\end{aligned}
$$

Nestas circunstâncias $\hat{\beta}$ é o melhor estimador linear não viesado ("BLUE" - Best Linear Unbiased Estimator) que é a estimativa dos efeitos fixos do modelo misto e $\hat{U}$ é o melhor preditor linear não viesado ("BLUP" - Best Linear Unbiased Predictor), para os fatores aleatórios do modelo. No presente trabalho, como os tratamentos genéticos foram considerados fixos, concentrou-se maior atenção na estimação dos "BLUEs" desses tratamentos. Uma vez obtidos os BLUEs, foram estimadas as médias ajustadas, adicionando-se os BLUEs à constante $(\mu)$ do modelo misto. 
A estimativa da variância de $\hat{\beta}$, neste caso BLUE, é obtida por:

$\hat{\mathrm{V}}(\hat{\boldsymbol{\beta}})=\left(\mathrm{X}^{\prime} \mathrm{V}^{-1} \mathrm{X}\right)^{-1}$

Observa-se que a expressão referente à estimativa dos efeitos fixos (BLUE) de modelo misto indexada em (47) é a mesma referida em (17), relativa à estimativa de ganho genético obtida por quadrados mínimos ponderados. A razão é o fato de que estas expressões se originam do método de quadrados mínimos genelarizados (GLS) que envolve ponderação pela matriz V. O mesmo ocorre com as expressões de suas variâncias, indicadas em (50) e (18) respectivamente.

Para se obter as estimativas das médias ajustadas utilizou-se o programa SAS, através da rotina PROC MIXED (SAS, 1992; LATOUR et alii, 1994 e LATOUR \& LITTELL et alii, 1996), cujos procedimentos estão no Apêndices 3 e 4.

Com as médias ajustadas de todos os genótipos, obteve-se as médias aritméticas anuais dos genótipos novos e da testemunha, para em seguida aplicar o método da regressão e estimar o ganho genético médio anual, utilizando-se os mesmos estimadores e testes do método de regressão com dados originais (RO).

\subsection{Desdobramento das Estimativas de Ganho Genético}

Após a obtenção das estimativas de ganho genético pelas seis metodologias estudadas, procedeu-se à seleção da mais indicada, observando-se sua magnitude, precisão e significância. Uma vez selecionada uma metodologia, esta foi utilizada para a estimação do progresso genético no estado do Paraná, subdividido nos níveis:

a)Estadual: refere-se a estimativa geral do estado do Paraná; b)por região: I (locais com elevadas temperaturas e baixa incidência de patógenos) e II (temperaturas amenas, porém com maior risco de doenças); c)por época: águas (semeadura de julho a setembro) e seca 
(semeadura de dezembro a fevereiro) e d)por condição ambiental: favorável e desfavorável, como sugeriram EYHÉRABIDE et alii (1994) e BYRNE et alii (1995). Estabeleceu-se como referencial a média geral em cada ano, sendo considerado favorável o ambiente cuja média fosse maior ou igual à média geral do ano.

Para se comparar as estimativas de ganho genético, obtidas por regressão linear, envolvendo ensaios (intermediários vs finais), grupos (cores vs preto) e regiões (I vs II), épocas (águas vs secas) e condição ambiental (favorável vs desfavorável), utilizou-se a expressão que testa a heterogeneidade da declividade das retas de regressão linear, obtidas independentemente, como propuseram STEEL \& TORRIE, (1980):

$$
\mathrm{t}=\frac{\hat{\mathrm{b}}_{1}-\hat{\mathrm{b}}_{2}}{\sqrt{\mathrm{s}_{\mathrm{p}}^{2}\left(\frac{1}{\mathrm{SQ}} \overline{\mathrm{X}_{1}}+\frac{1}{\mathrm{SQX}_{2}}\right)}}=; \text { sendo: }
$$

$$
\mathrm{s}_{\mathrm{p}}^{2}=\frac{\mathrm{SQDR}_{1}+\mathrm{SQDR}_{2}}{\mathrm{GLDR}_{1}+\mathrm{GLDR}_{2}}
$$

$\hat{b}_{1}$ : estimativa do coeficiente angular da regressão linear da condição 1 ;

$\hat{b}_{2}$ : estimativa do coeficiente angular da regressão linear da condição 2;

$\mathrm{SQX}_{1}$ : Soma de Quadrados de X (anos) da condição 1;

$\mathrm{SQX}_{2}$ : Soma de Quadrados de X (anos) da condição 2;

SQDR 1 : Soma de Quadrados dos Desvios da Regressão 1;

$\mathrm{SQDR}_{2}$ : Soma de Quadrados dos Desvios da Regressão 2;

$\mathrm{GLDR}_{1}=$ Graus de liberdade dos Desvios da Regressão 1.

GLDR $2=$ Graus de liberdade dos Desvios da Regressão 2.

Teste $t$ com $(G L D R 1+$ GLDR2) graus de liberdade. 


\section{RESULTADOS E DISCUSSĀO}

\subsection{Análises dos experimentos individuais}

Os experimentos foram divididos em quatro tipos, segundo a sua natureza: intermediários e finais dos grupos cores e preto, identificados por IC, FC, IP e FP respectivamente. Na Tabela 3, constam os valores médios, mínimos e máximos, referentes às médias, coeficientes de variação, número de tratamentos testados anualmente e número de experimentos por ano; além dos totais de ensaios e de parcelas. Estes resultados médios foram baseados em 642 experimentos, selecionados do total de 663 conduzidos no período compreendido entre 1977 a 1995. Por esta tabela, observa-se que a média geral do rendimento de grãos ficou ao redor de $1.500 \mathrm{~kg} / \mathrm{ha}$, o coeficiente de variação experimental apresentou média próxima a $13,5 \%$ e em mais de $80 \%$ dos experimentos houve significância para os efeitos de genótipos a $5 \%$ de probabilidade. Foram descartados os experimentos que apresentaram média geral de rendimento de grãos inferior a $300 \mathrm{~kg} / \mathrm{ha}$ e coeficiente de variação experimental superior a $25 \%$.

Examinando-se a mesma Tabela 3, verifica-se que o número médio de tratamentos testados anualmente variou conforme o ensaio, sendo ao redor de 18 para os ensaios intermediários do grupo cores e cerca de 12 para os demais ensaios. A maior amplitude

no número de tratamentos foi detectada dentro dos ensaios intermediários do grupo cores, que variaram de 8 a 48. Esta oscilação foi em função de que este grupo, no início 
do programa de melhoramento, era composto não apenas por genótipos do tipo de grão carioca, mas sim por todos aqueles que não tivessem tegumento da semente de cor preta. Em termos de número médio de experimentos conduzidos anualmente, constata-se que os ensaios finais foram testados em, aproximadamente, o dobro de vêzes o número de experimentos dos ensaios intermediários respectivos, destacando-se os ensaios finais do grupo cores com mais de 14 pontos de teste por ano em média. Destes fatos, resultou que aos ensaios finais coube maior volume total de ensaios e consequentemente de parcelas que aos ensaios intermediários.

Em se tratando de rendimento de grãos, deve-se ressaltar que a média obtida nos ensaios foi superior ao dobro do alcançado pelo produtor paranaense (Tabela 1). Este fato pode ter ocorrido devido aos cuidados na experimentação, tais como: a)no estabelecimento da cultura, assegurando o estande pré-estabelecido, devido à seleção manual das sementes, semeadura de número maior de sementes, seguido de desbaste de plântulas; b)na adubação de base e cobertura com Nitrogênio e c)no controle de ervas daninhas no tempo oportuno. Estes cuidados são tomados na maioria dos ensaios bem conduzidos, o que nem sempre acontece nas lavouras, muitas vêzes por dificuldade de financiamento. É necessário salientar também, que as estatísticas disponíveis frequentemente referem-se à area total semeada e à produção obtida, enquanto que neste trabalho considera-se apenas os ensaios selecionados, com base no rendimento médio e coeficiente de variação, que é provavelmente outra forte razão para tamanha discrepância da média paranaense com as médias dos ensaios de competição de genótipos da rede estadual de feijão. Outra observação que pode ser levantada, é a preferência na instalação dos ensaios em propriedades pertencentes a agricultores líderes e principalmente com melhor nível tecnológico, o que não constitui o padrão geral do estado. 
Observando-se a elevada amplitude do rendimento médio dos ensaios (de 311 a $3.410 \mathrm{~kg} / \mathrm{ha}$ ), comprova-se a ocorrência de diversidade ambiental. Embora abrangendo diferentes condições de cultivo, os experimentos tem a limitação de não espelhar fielmente a realidade de todos os agricultores. Mesmo com esta limitação, pode-se afirmar que os ensaios regionais, previamente delineados, constituem-se no modo mais imparcial de comparação de genótipos, com o intuito de indicar aos produtores as opções mais lucrativas e mais seguras de cultivo.

Quanto ao valor médio do coeficiente de variação experimental, da ordem de $13,5 \%$, pode ser considerado como bom, por ser inferior à média detectada para o feijão. ESTEFANEL et alii (1987), em trabalho de revisão, verificaram para o rendimento de grãos, coeficiente de variação experimental médio de $21,1 \%$, com desvio padrão de $8,7 \%$, com base na análise de 137 experimentos em blocos ao acaso.

Convém frisar que quanto mais preciso for o experimento, menor será o coeficiente de variação, tornando mais evidente a distinção entre os tratamentos, por exemplo, mediante o teste Tukey de comparação de médias, cuja diferença mínima significativa (D.M.S.), guarda relação direta como o coeficiente de variação, como explicado por GOMES (1987), sendo muito raro obter D.M.S (em porcentagem em relação à média geral do ensaio), menor que o coeficiente de variação.

A questão da classificação do coeficiente de variação, em níveis alto, médio e baixo, depende de vários fatores, entre eles, a espécie considerada, a variável analisada, o delineamento experimental utilizado, o número de repetições, o tamanho e forma da parcela, bem como das condições tecnológicas de condução do experimento. Diante de tais fatores, torna-se dificil estabelecer um valor único para todas as situações. No entanto, para uma mesma espécie e variável, ao se acumular um grande volume de análises, pode-se estabelecer critério mais claro de eliminação de ensaios menos precisos. 
SCAPIM et alii (1995) propuseram para diferentes variáveis do milho, os limites de um desvio padrão para os coeficientes de variação (C.V.) médios obtidos de 66 teses na área de Genética e Melhoramento de Plantas. Outro critério já proposto por BOWMAN \& RAWLINGS (1995), que sugerem eliminar os ensaios com coeficiente de variação superior a $\sqrt{2}$ vêzes o C.V. médio, isto é, $1,41 \overline{\mathrm{CV}}$. Segundo estes autores, este procedimento é válido, quando a relação entre os logaritmos das médias e variâncias (b da regressão) é superior a 2; caso contrário este critério passa a ser excessivamente rigoroso, descartando ensaios desnecessariamente.

No presente trabalho, foi considerado inicialmente, que os ensaios possuíam coeficiente de variação médio ao redor de 20\%, conforme SCAPIM et alii (1995), e que foram descartados todos os experimentos com C.V. superior a $25 \%$. Verifica-se portanto, que o critério de eliminação correspondeu a descartar todos os ensaios com C.V. superiores a $25 \%$ do coeficiente de variação médio $(1,25 \overline{\mathrm{CV}})$, ou seja, mais drástico que o proposto por BOWMAN \& RAWLINGS (1995).

\subsection{Análises de Variância Conjuntas}

Na Tabela 4, encontram-se os resumos das análises de variância conjuntas para os quatro tipos de ensaios. Verifica-se que em todos, houve efeito significativo de genótipos. As estimativas dos quadrados médios do erro médio foram utilizadas nos testes de significância das estimativas de ganho genético discutidas adiante.

Com a finalidade de se verificar a variabilidade disponivel nos dados analisados, foram estimados os componentes de variância dos termos do modelo da análise conjunta, obtidos pelo método de máxima verossimilhança restrita (REML), bem como a relação de cada estimativa com a estimativa do erro experimental médio, com o objetivo de se ter 
uma medida da magnitude relativa de cada componente, como sugerido por PARK (1987) (Tabela 5). Por se tratar de dados desbalanceados, os valores obtidos para as respectivas estimativas de variância, devem ser observados com cautela, como sugeriram LATOUR \& LITTELL, 1996). Com as devidas ressalvas, verifica-se que o fator mais preponderante foi o ambiental, isto é, os experimentos, visto que cada experimento foi considerado como um ambiente específico na análise conjunta. Este componente superou em mais de seis vêzes a estimativa do erro experimental em todos tipos de ensaios, em especial nos experimentos do grupo cores.

A estimativa do componente de variância relativo à interação Genótipos $\mathrm{X}$ Ambientes (GxA) apresentou baixa magnitude da relação com a estimativa do erro experimental (próxima ou inferior a 1,0), o que aparentemente implicaria em aceitar que praticamente em média os genótipos de feijão interagem pouco com os ambientes. Este fato é diferente do previsto, uma vez que dada a diversidade de genótipos e ambientes testados, o esperado seria uma elevada magnitude da estimativa do componente de variância referente à interação GxA, como observado no trabalho de MIRANDA et alii (1993); visto que o feijoeiro não é considerado uma planta rústica e estável. Diante deste resultado, uma possível explicação pode ser o desbalanceamento dos dados, que não permitiu efetiva precisão dos efeitos dos fatores e que pode ter gerado distorção nas estimativas dos componentes de variância, mesmo quando é utilizado o método REML (SEARLE, 1987).

Pequenas magnitudes da estimativa de variância do componente devido à interação GxA também foram detectadas em outros trabalhos com a cultura do feijão (HOSFIELD et alii, 1984; PARK, 1987; ABREU et alii, 1990; DUARTE \& ZIMMERMANN, 1991 e RAMALHO et alii, 1993). É conveniente mencionar, que uma estimativa de componente de variância depende de vários fatores, entre êles, a amostra de 
dados considerada, o modelo matemático adotado, com seus termos fixos ou aleatórios, a precisão experimental, o tamanho da parcela e a unidade de medida. Nos trabalhos referidos acima, todos tinham área útil de parcela semelhante aos do presente estudo, porém não continham dados desbalanceados.

Outra possibilidade para explicar o baixo valor dessa estimativa em feijão, foi resultado obtido por CHAVES (1982), que verificou que parte da interação foi causada pelo efeito multiplicativo (e não aditivo) do ambiente, podendo distorcer a real magnitude da interação GxA. Atualmente, têm sido propostos modelos multiplicativos para melhor interpretar a ação da interação GxA, como relataram DELACY et alii (1996).

Em todos os experimentos foi utilizado o delineamento de blocos ao acaso e ao ser comparada a estimativa do componente de variância de repetições dentro de ambientes, frente à estimativa do componente de variância do erro experimental, verificou-se a menor estimativa desta relação, em comparação com as demais fontes de variação. Este resultado pode ter sido causado pela uniformidade das áreas onde foram instalados os experimentos, uniformidade esta, que seguramente vem aumentando ao longo dos anos. Outra possibilidade, em sentido contrário à primeira, é a provável heterogeneidade ambiental existente dentro de cada repetição, que pode ter contribuído para a baixa estimativa do componente de variância relativo à repetições dentro de ambientes. Para confirmar a ocorrência desta heterogeneidade, seria necessário analisar as parcelas segundo sua posição ocupada no experimento, efetuando-se a análise espacial, como indicado por CRESSIE (1993), detectando-se dependência entre parcelas vizinhas.

Quanto à estimativa do componente relativo a genótipos, não se fará nenhum comentário, visto que por se tratar de fator fixo, neste trabalho, este componente não é, a rigor, uma estimativa de variância típica e sim uma medida de diversidade entre os tratamentos (VENCOVSKY \& BARRIGA, 1992). É possível afirmar que o efeito de 
genótipos foi significativo, como demonstram os dados da Tabela 4, indicando que os genótipos diferiram entre si pelo teste $\mathrm{F}$.

As informações contidas na Tabela 5, referentes aos termos aleatórios do modelo, por serem provenientes de 642 experimentos, abrangendo o período de 1977 a 1995, podem subsidiar a pesquisa com estimativas de componentes de variância em feijão, para a variável rendimento de grãos, expressa em $(\mathrm{kg} / \mathrm{ha})^{2}$, proporcionando valores comparativos para trabalhos com desbalanceamento de dados.

\subsection{Estimativas gerais de ganho genético}

\subsubsection{Método Original (VO)}

Os ganhos genéticos líquidos anuais observados (GGL), obtidos pelo método original (VO) desenvolvido por VENCOVSKY et alii (1988), estão apresentados nas Tabelas 6 a 9, referentes aos ensaios finais e intermediários dos grupos cores e preto. Pode-se observar que a maioria dos valores são positivos, o que é evidenciado pelas Figuras 1 e 2 . Por estas figuras não se visualiza nenhuma tendência para aumentar ou diminuir os ganhos em função do tempo. Pode-se notar alguns pontos discrepantes, como nos ciclos 6 e 13 dos ensaios intermediários cores e no ciclo 4 dos finais preto. Quando se menciona ciclo 4, refere-se ao ganho genético estimado em função dos anos 5 e 4.

Os dados apresentados nas tabelas 6 a 9 e nas Figuras 1 e 2, são os ganhos anuais observados. As estimativas do ganho genético médio no período estudado, encontram-se nas Tabelas 15 a 18. Nestas tabelas constam as estimativas de ganho genético médio, obtidas pelas seis diferentes metodologias de estimação. Inicialmente, serão discutidas as estimativas obtidas pelo método original (VO). 
Pela metodologia VO, todas as estimativas de ganho genético médio anual apresentaram valores superiores a $1,5 \%$ ao ano, porém apenas as estimativas para os ensaios do grupo preto foram significativas pelo teste $t$ (Tabelas 15 a 18).

Estes resultados não são definitivos, visto que as estimativas e seus erros padrões podem estar viesados, como salientado por RODRIGUES (1990), TOLEDO et alii (1990) e BRESEGHELLO (1995), pois neste método original (VO) há dependência dos erros, necessitando-se de ponderação, que foi realizada pelos métodos VP1 eVP2.

\subsubsection{Método Ponderado 1 (VP1)}

Tendo-se por base os mesmos valores de ganhos genéticos líquidos anuais observados (GGL), obtidos pelo método original (VO), (Tabelas 6 a 9 e Figuras 1 e 2), procedeu-se à ponderação pelo método dos quadrados mínimos ponderados, para composição do método VP1.

As estimativas do ganho genético médio anual, estão apresentadas nas Tabelas 15 a 18. Verifica-se que as estimativas obtidas pelo método VP1, variaram de cerca de 10 a $43 \mathrm{~kg} / \mathrm{ha} / \mathrm{ano}$, conforme o ensaio, sendo que as estimativas referentes ao grupo cores não diferiram em magnitude daquelas obtidas pelo método original (VO), enquanto que as do grupo preto foram menores. Os resultados de ABREU et alii (1994) também indicaram maiores valores para a estimativa de ganho genético para o feijão em Minas Gerais, obtida pelo método VO, em relação ao VP1, respectivamente 39,90 e 13,63 kg/ha por ano. Nota-se pelas Tabelas 15 a 18, que as estimativas do método VP1 evidenciaram maior precisão, sendo significativas, pelo teste $t$, para todos os tipos de ensaios.

Os dados necessários à estruturação da matriz $\mathrm{V}$ de ponderação, pelo método VP1, encontram-se nos Apêndices 5 a 8. 


\subsubsection{Método Ponderado 2 (VP2)}

$\mathrm{O}$ método VP2, também foi baseado nos dados originais de ganhos genéticos líquidos anuais observados (GGL), obtidos pelo método original (VO), (Tabelas 6 a 9 e Figuras 1 e 2). As estimativas de ganho genético médio anual ponderado, obtidas pelo método VP2, constam nas Tabelas 15 a 18 . Verifica-se que tais estimativas oscilaram entre 19 e $43 \mathrm{~kg} / \mathrm{ha} / \mathrm{ano}$, sendo todas significativas.

Analisando-se conjuntamente as três metodologias correlatas: VO, VP1 e VP2, constata-se que a magnitude das estimativas, dentro de cada tipo de ensaio do grupo cores, é semelhante, enquanto no grupo preto as estimativas ponderadas foram menores.

Ficou evidente que os métodos que utilizaram ponderação produziram estimativas mais precisas, tomando-as significativas pelo teste $t$.

$\mathrm{O}$ detalhamento da composição da matriz $\mathrm{V}$ de ponderação, pelo método VP2, também encontra-se nos Apêndices 5 a 8.

\subsubsection{Método da Regressão com Dados Originais (RO)}

As estimativas de ganho genético médio anual, obtidas pelo método da regressão com dados originais (RO), adaptado de ABREU et alii (1994), foram baseadas nos valores observados das médias anuais dos genótipos novos (MGN), médias anuais da testemunha (MTE) e ganhos genéticos anuais (GG), cujos valores estão relacionados nas Tabelas 10 a 13. Nestas tabelas, constam as bases de cálculo de todos os métodos que utilizaram regressão linear ( $\mathrm{RO}, \mathrm{RE}$ e $\mathrm{RA})$.

Com base nestes dados, foram estimadas três equações de regressão linear relativas a: a)genótipos novos, b)testemunha e c)ganho genético. Estas equações, sua 
significância pelo teste $\mathrm{F}$ e as as estimativas de ganho genético médio anual estão apresentadas na Tabela 14.

Analisando-se as estimativas das equações de regressão linear da Tabela 14, observa-se, que em todos os tipos de ensaios, houve significância do efeito linear referente aos genótipos novos. Suas retas de regressão estão apresentadas nas Figuras 3 e 4. Nestas figuras, verifica-se que nos ensaios do grupo cores, nos primeiros anos, a testemunha, cultivar Carioca, apresentou melhor desempenho, mas paulatinamente a tendência se inverteu, tornando o contraste, rendimento médio de genótipos novos versus testemunha, positivo (Figura 3). No grupo preto, praticamente desde o início do período amostrado, a testemunha, Rio Tibagi, foi superada pelos genótipos novos (Figura 4).

Ao serem testadas as equações de regressão linear estimadas para o ganho genético (Tabela 14), verificou-se que foram significativas apenas para os ensaios intermediários, isto é, os ganhos genéticos foram efetivamente aumentando com os anos de melhoramento, apenas para os ensaios intermediários dos grupos cores e preto, embora as Figuras 3 e 4 tenham indicado tendência crescente do desempenho dos genótipos novos em todos os tipos de ensaios, o que não ocorreu com os ganhos genéticos. Observando-se os coeficientes de determinação $\left(\mathrm{R}^{2}\right)$, nota-se que os coeficientes relativos às testemunhas estão sempre com magnitude inferior aos genótipos novos correspondentes, o que possivelmente prejudicou a precisão da estimativa da regressão para o ganho genético, baseada no contraste entre o rendimento médio dos genótipos novos e da testemunha.

Nas Tabelas 15 a 18 estão relacionadas as estimativas de ganho genético médio anual, seus erros padrões, o valor de referência para se estimar os ganhos expressos em porcentagem, os coeficientes de determinação, os quadrados médios da regressão e do desvio da regressão linear e sua significância pelo teste F. As estimativas de ganho 
genético médio ficaram acima de $1,0 \%$ para todos os ensaios, embora tenham sido detectadas estimativas significativas apenas para os ensaios intermediários. Estas estimativas expressas em $\mathrm{kg} / \mathrm{ha}$ por ano obtidas para os ensaios intermediários foram: 17,25 para o grupo cores e 22,04 para o grupo preto, no período de 18 anos de experimentação. Estes valores são próximos dos obtidos por ABREU et alii (1994) para a cultura do feijão no estado de Minas Gerais, durante 19 anos de dados de ensaios regionais, que resultaram na estimativa de $14,52 \mathrm{~kg} / \mathrm{ha} / \mathrm{ano}$. Estes resultados foram obtidos com a mesma metodologia da regressão linear da média da testemunha, cultivar Carioca, em comparação com a média dos demais tratamentos, não apenas os genótipos considerados novos, como utilizados no presente estudo.

Em magnitude, as estimativas relativas ao grupo preto foram superiores às do grupo cores, assim como os ensaios intermediários superaram os finais. Estas diferenças não foram significativas pelo teste t conjunto, conforme propuseram STEEL \& TORRIE (1980) para regressões independentes. Em todos os ensaios foram detectados efeitos significativos para o desvio da regressão, indicando que o modelo linear não explicou completamente os dados.

Uma possível causa da aparente superioridade dos genótipos do grupo preto, seria a testemunha utilizada, visto que em experimentos de competição de cultivares e em plantios comerciais, o desempenho do cultivar Carioca (do grupo cores) é frequentemente superior ao do Rio Tibagi, principalmente nos locais de clima mais quente e com riscos de estiagem. Esta superioridade do Carioca pode ser detectada em ensaios que testaram conjuntamente ambas testemunhas, como o realizado por YAN et alii (1995a, 1995b e 1996). Portanto sugere-se que Carioca seja testemunha mais competitiva que Rio Tibagi e consequentemente torne mais estreitos os ganhos genéticos. 
Outro fato que deve ser considerado é a arquitetura de planta mais agressiva (tipo III, isto é, semi-prostrada) do Carioca, em relação ao Rio Tibagi (tipo II) possibilitando rápido fechamento do dossel nas parcelas experimentais. Normalmente, as plantas do Carioca suplantam a área a elas destinada na parcela, avançando pelos corredores do experimento. Como nos ensaios regionais são colhidas as duas linhas centrais inteiras, sem eliminação das plantas das extremidades, os rendimentos de grãos relativos ao cultivar Carioca devem ficar superestimados.

Esta agressividade não é observada no Rio Tibagi, nem na maioria dos genótipos novos testados, originados do melhoramento mais recente, que visa obter plantas mais eretas. Portanto, a não utilização de bordaduras nas extremidades das linhas centrais das parcelas pode mascarar os resultados, fato verificado por COSTA \& ZIMMERMANN (1996) e ESTEFANEL et alii (1993) e que pode ter sido responsável pelos ganhos genéticos médios subestimados nos ensaios do grupo cores pelo método RO.

Em se tratando de testemunha, é necessário salientar que na inexistência da alteração ambiental, o esperado seria uma reta de regressão paralela ao eixo X (anos), visto que a testemunha é representada por um genótipo fixo, e assim não haveria razão para esta ir melhorando seu desempenho ao longo do tempo. Se isso ocorreu, é porque a testemunha respondeu à melhoria do ambiente (Figuras 3 e 4). Embora as retas das testemunhas sejam ascendentes, apenas para os ensaios finais do grupo cores a regressão linear foi significativa, apesar de ter apresentado coeficiente de determinação $\left(R^{2}\right)$ relativamente baixo (Tabela 14). Esta baixa precisão da regressão referente à testemunha, especificamente ao cultivar Carioca, também foi detectada por ABREU et alii (1994), que encontrou valor 0,13 para o coeficiente de determinação.

A aparente melhoria ambiental ocorrida ao longo dos anos, pode ser creditada ao acúmulo de experiência da equipe que conduzia os experimentos e também ao aumento 
da frequência de ensaios conduzidos em locais onde predominava a alta tecnologia, entre elas o plantio direto.

Outro fator que pode ter influído no desempenho das testemunhas é a origem de suas sementes. As sementes das linhagens em teste provém dos experimentos do ano anterior, enquanto que as sementes das testemunhas, que são cultivares recomendados para o estado, são sementes básicas, que foram produzidas em campos específicos de responsabilidade do IAPAR - Instituto Agronômico do Paraná. No processo de produção de sementes básicas, plantas atípicas e os lotes com padrão, inferior de pureza e qualidade fisiológica e sanitária de sementes, são eliminados. Esses cuidados certamente possibilitaram melhor estabelecimento inicial das testemunhas, em função de melhor emergência, vigor e sanidade de plântulas, que certamente favoreceu seu desempenho.

O reflexo deste aparente favorecimento das testemunhas, certamente implicou em estimativas subestimadas de ganho genético, obtidas pelo método da regressão com dados originais (RO), em ambos grupos de genótipos, cores e preto.

\subsubsection{Método da Regressão com dados Estandardizados (RE)}

As médias anuais dos genótipos novos (MGN), médias anuais da testemunha (MTE) e ganhos genéticos anuais (GG), cujos valores originais foram estandardizados, passando a ser expressos em unidades de desvio padrão (UDP), estão apresentados nas Tabelas 10 a 13. Com base nesses dados estandardizados estimou-se equações de regressão linear para os genótipos novos, testemunha e ganho genético, com a finalidade de se estimar o ganho genético médio anual pelo método da regressão estandardizada (RE). Na Tabela 14 encontram-se as três equações de regressão. 
Nas Tabelas 15 a 18 podem ser observadas as estimativas de ganho genético médio. Por estas tabelas, verifica-se que as estimativas de ganho genético médio anual obtidas pelo método RE foram próximas as do método da regressão com dados originais (RO), mantendo o mesmo nível de significância. Observando-se os erros padrões dessas estimativas e os coeficientes de determinação $\left(R^{2}\right)$ das equações de ganho genético, constata-se que o método RE foi menos preciso que o RO. Isto se confirma nas Figuras 5 e 6, nas quais verifica-se que os valores estandardizados observados não estão, de maneira geral, mais próximos da reta de regressão predita (expressa em UDP) conforme o esperado, uma vez que o efeito de ano foi eliminado pela estandardização e portanto, a precisão deveria ser maior que a regressão com dados originais. A razão da menor precisão, pode ser atribuída à interação dos genótipos com os anos, visto que a estandardização eliminou o efeito do ano, mas não a interação.

\subsubsection{Método da Regressão com Médias Ajustadas (RA)}

$\mathrm{O}$ método RA foi baseado nas médias ajustadas dos genótipos novos (MGN), médias ajustadas da testemunha (MTE) e ganhos genéticos ajustados (GG), cujos valores estão relacionados nas Tabelas 10 a 13. É conveniente observar nessas tabelas que as médias ajustadas de genótipos novos (MGN) diferem de suas médias gerais originais, visto que estas foram influenciadas pelo efeito dos anos. A média geral ajustada da testemunha (MTE) possui um único valor para todos os anos, enquanto que MGN não, porque em cada ano foram considerados novos os tratamentos genéticos que pela primeira vez integraram os experimentos e como em cada ano havia um grupo diferente de genótipos novos, MGN assumiu um valor ajustado distinto para cada ano. 
Em função das médias ajustadas relacionadas nas Tabelas 10 a 13, equações de regressão linear foram estimadas com o objetivo de obter as estimativas de ganho genético médio anual pelo método RA. As equações de regressão são apresentadas na Tabela $14 \mathrm{e}$ as estimativas de ganho genético, nas tabelas 15 a 18 . Nestas tabelas verificase que todas as estimativas de ganho genético médio ficaram acima de $1,40 \%$ ao ano e em todos os tipos de ensaios foram significativas. Comparando-se os erros dessas estimativas e os coeficientes de determinação $\left(\mathrm{R}^{2}\right)$ das equações de ganho genético, das três metodogias que envolveram regressão linear, isto é, RO, RE e RA, verifica-se que o método RA forneceu resultados mais precisos, apresentando $\mathrm{R}^{2}$ superiores a 0,49 e com significância da regressão linear em todos os tipos de ensaios.

Observando-se os coeficientes angulares (b) das três equações de regressão linear, dos métodos RO, RE e RA, (TAbela 14), constata-se que o coeficiente angular da regressão linear referente ao ganho genético é igual à diferença entre os coeficientes relativos aos genótipos novos e testemunha (bganho=bnovos-btestemunha), como assinalado no item Material e Métodos, na expressão (30).

Nas Figuras 7 e 8 estão representados os ganhos genéticos observados e as retas preditas das regressões lineares relativas aos genótipos novos e à testemunha. Verifica-se a tendência crescente dos ganhos genéticos em todos os ensaios, sendo que os ensaios do grupo preto apresentaram melhor ajuste da reta de regressão, embora as escalas do eixo Y não sejam as mesmas entre os grupos.

Pelo método RA, a média ajustada da testemunha, nos diferentes anos, foi reduzida a uma constante (Tabelas 10 a 13), tornando-se referencial com reta paralela ao eixo X (Figuras 7 e 8). Esta constância e paralelismo indicam que este método pode dispensar a obrigatoriedade de testemunha comum em todos os ensaios e em todo o período estudado, uma vez que basta a equação de regressão das médias ajustadas dos 
genótipos novos para se obter a estimativa de ganho genético médio anual, dada pelo coeficiente angular de regressão (b), visto que o ajustamento dado pelo modelo misto e a estimação dos efeitos genotípicos pelo procedimento "BLUE", implica em estimativas com menor influência do ambiente, da interação genótipos por ambientes e do erro experimental (SEARLE, 1987).

Um exemplo de ajustamento de médias pelo procedimento "BLUE", é apresentado nos Apêndices 9 a 12, com dados reais referentes aos ensaios finais do grupo cores, onde são apresentadas as médias originais e ajustadas para cada genótipo novo e testemunha nos diferentes anos.

Evidentemente quanto mais o genótipo for testado, ou seja, quanto maior sua frequência ao longo dos anos, mais confiável será a estimativa de seu efeito. É o que pode ser observado na Tabela 19, que apresenta as médias originais e ajustadas das testemunhas nos quatro tipos de ensaios. Quando a testemunha participou em todos os ensaios, sua média ajustada foi idêntica à original, como ocorreu com o cultivar Carioca nos ensaios do grupo cores. Este fato indica que o ajustamento efetuado visa corrigir o desbalanceamento dos dados, simulando a presença de todos os genótipos em todos os experimentos conduzidos nos diferentes anos.

\subsubsection{Comparações entre os métodos de estimação de ganho genético.}

Nas Tabelas 15 a 18 estão dispostas as estimativas de ganho genético, seus erros padrões, suas significâncias e detalhamentos de sua obtenção, referentes às seis metodologias e aos quatro tipos de ensaios. Para maior facilidade de abordagem, todas as estimativas de ganho genético expressas em $\mathrm{kg} / \mathrm{ha}$ e em percentagem, estão agrupadas na Tabela 20. Nesta tabela, verifica-se que, de modo geral, os métodos VO, VP1 e VP2 
apresentaram maior magnitude de ganho em $\mathrm{kg} / \mathrm{ha}$, enquanto que os métodos de regressão $\mathrm{RO}$ e RE foram não significativos e com menores estimativas. A metodologia de regressão com médias ajustadas (RA) apresentou valores significativos e de magnitude intermediária em relação aos demais métodos.

Em relação às estimativas de ganho genético expressas em percentagem, cabem algumas observações sobre a média de referência utilizada para o cálculo das referidas estimativas, pois existem três tipos de médias para os seis métodos estudados: VO utilizou a média dos tratamentos do primeiro ano de testes; VP1 e VP2 empregaram a média geral dos tratamentos, enquanto os métodos de regressão, RO, RE e RA usaram o valor do intercepto, isto é, o coeficiente linear (a) da equação de regressão linear dos genótipos novos. Portanto a comparação simultânea das seis metodologias, expressas em percentagem, fica prejudicada, uma vez que a média de referência não é a mesma.

Pode-se afimar que a média de referência do método VO foi muito dependente do efeito do primeiro ano de teste. Por outro lado, a média geral dos tratamentos (métodos VP1 e VP2) esteve influenciada pelas testemunhas utilizadas, bem como incorporou um certo ganho genético acumulado ao longo da metade do período de anos amostrados. A média de referências dos métodos de regressão, pareceu ser aquela que mais se assemelhou à média da população original hipotética, onde nenhum melhoramento foi realizado, uma vez que o coeficiente linear (a) refere-se ao valor predito pela equação de regressão linear de genótipos novos no ano zero.

$\mathrm{O}$ método original $\mathrm{VO}$, pelo seu pioneirismo em utilizar dados dos ensaios regionais nos estudos de ganho genético, merece maior atenção e análise de suas propriedades intrínsecas. É um método que tem por característica basear-se em genótipos comuns entre anos consecutivos, com a finalidade de cancelar o efeito do ano. Pressupõe 
que a interação desses tratamentos comuns com os anos, representa as interações dos demais genótipos não comuns.

Nos ensaios intermediários, cujo dinamismo dos genótipos novos refere-se a apenas um ano de teste, os genótipos comuns são então representados apenas pelas testemunhas e por um ou outro genótipo que apresentou desempenho duvidoso e que foi mantido no ensaio, não por mérito, mas sim por incerteza, uma vez que os melhores foram selecionados para integrarem os ensaios finais. Quanto menor for o número de genótipos comuns, mais frágil se torna a correção do efeito do ano por esta metodologia. Por outro lado, se não houver renovação de genótipos e os mesmos tratamentos forem testados por anos seguidos, no período não haverá ganho genético. Esta condição não é exclusiva do método VO, pois se aplica a todos os seis métodos estudados.

Em se tratando de dinamismo, ou seja, substituição anual de genótipos testados nos ensaios, as Tabelas 21 e 22 indicam que a renovação nos ensaios intermediários foi ao redor de $80 \%$, enquanto nos finais de $40 \%$. Portanto nos ensaios intermediários, praticamente apenas os cultivares testemunhas representaram o conjunto de tratamentos comuns entre anos consecutivos. Consequentemente, as estimativas dos efeitos anuais nestes ensaios foram mais frágeis, em função do tipo e do número de tratamentos genéticos considerados comuns. Esta observação foi confirmada pelos resultados obtidos pelos métodos VP1 e VP2, onde os erros padrões das estimativas de ganho genético foram maiores nos ensaios intermediários que nos finais, pois a ponderação dos ganhos anuais depende, não apenas do número total de tratamentos no ano, como também do número de tratamentos comuns envolvidos, que é menor nos ensaios intermediários.

Outra característica do método VO, que deve ser analisada, é a natureza do contraste que envolve as médias dos tratamentos e dos genótipos comuns em anos consecutivos, como apresentado no item 3.3.1 do Material e Métodos, expressão (15). 
Considerando-se os ensaios finais, onde os genótipos selecionados permaneceram por pelo menos dois anos em testes, antes que fossem recomendados aos agricultores, os tratamentos podem então ser classificados em três grupos: testemunhas, novos e comuns. As testemunhas são normalmente representadas pelos cultivares comerciais amplamente cultivadas, os genótipos novos são aqueles que participam pela primeira vez neste tipo de ensaio, e os comuns são os que já participaram neste ensaio no ano anterior. Com o auxilio da Tabela 23, que exemplifica a sucessão de genótipos ao longo de quatro anos consecutivos nos ensaios finais, verifica-se que pelo método VO, a estimativa de ganho genético relativa aos anos 2 e 1 envolve os genótipos:

$\operatorname{gg}=\left\{\left[(1,2,3,4,5,11,12,13,14,15)_{2}\right]-\left[(1,2,3,4,5,6,7,8,9,10)_{1}\right]\right\}-\left\{\left[(1,2,3,4,5)_{2}\right]-[(1,2,3,4,5) 1]\right\}$.

Supondo-se que em determinado par de anos, o número total de tratamentos seja o mesmo e que não ocorra efeito de ano. Neste exemplo (ano 2 versus anol) o número de tratamentos é igual a 10 e suponha-se que não tenha ocorrido efeito de ano. Esta coincidência simplificará a expressão acima de ganho genético (gg), tornando-a resultante da comparação entre a médias dos genótipos novos do ano 2 (tratamentos 11, 12, 13, 14 e 15) e a média dos tratamentos descartados no ano $1(6,7,8,9$ e 10$)$, pois os comuns se cancelam, como indicado na Tabela 23 (ano 2 versus ano 1). Esta constatação já foi explicitada por RODRIGUES (1990, pag. 79 e 80), que designou os tratamentos novos do ano 2 com índice $\mathrm{n}$ e os descartados do ano 1 por índice $\mathrm{v}$.

Neste exemplo da Tabela 23, a tendência deste contraste foi ser positivo, visto que a média dos genótipos novos do ano 2 , incluiu não só tratamentos que seriam descartados (14 e 15), mas também os que seriam selecionados e mantidos nos ensaios (tratamentos 11, 12 e 13). Eventualmente, todos os genótipos novos do ano 2 poderiam ser descartados e então o ganho genético poderia não ser superestimado, porque compararia descartados do ano 2 com descartados do ano 1; mais raramente ainda, todos 
os genótipos novos do ano 2 poderiam ser selecionados e o ganho genético seria altamente positivo, desde que fossem mantidos os mesmos critérios de seleção nos dois anos considerados.

Analisando-se os demais pares de anos consecutivos, 3 e 2 por exemplo, nota-se que a essência do contraste é a mesma: média dos genótipos novos do ano $3(16,17,18$, 19 e 20) menos a média dos genótipos descartados do ano $2(3,4,5,14$ e 15). Porém a natureza dos tratamentos descartados foi diferente do primeiro exemplo (ano 2 versus ano 1), uma vez que os genótipos descartados do ano $2(3,4,5,14$ e 15$)$ não foram representados unicamente pelos tratamentos que participaram apenas um ano nos ensaios (14 e 15), mas também pelos que já participaram por mais de um ano (tratamentos 3,4 e 5). Portanto se a tendência do contraste do ano 3 versus ano 2 ainda é ser positivo, deveria, no entanto, decrescer em magnitude. Outra razão para que este contraste seja menor, em relação aos anos 2 e 1, é a possibilidade dos genótipos descartados (no ano 2) e que já participaram por mais de um ano nos ensaios, como é o caso dos genótipos 3,4 e 5, serem eliminados dos ensaios, não por péssimo desempenho, mas sim por terem se tornados cultivares recomendados e portanto não mais testados nestes ensaios finais. A média desses três genótipos $(3,4$ e 5$)$ contribuiu para elevar a média dos tratamentos descartados do ano 2, diminuindo a magnitude do contraste do par de anos 3 e 2 .

$\mathrm{Na}$ Tabela 24, observa-se que foram lançados 10 cultivares do grupo cores e seis do grupo preto, no período de 1977 a 1995, para o estado do Paraná. Como foram testados 83 genótipos novos nos ensaios finais do grupo cores (Tabela 21) e 93 nos finais preto (Tabela 22), verifica-se que apenas $12,1 \%$ e $6,5 \%$ dos genótipos testados nos grupos cores e preto, respectivamente, tornaram-se cultivares. Portanto o alto índice de tratamentos descartados deveu-se ao desempenho insatisfatório, o que deve ter 
contribuído para que as estimativas de ganho genético anuais, obtidas pelos métodos VO, VP1 e VP2, fossem artificialmente positivas em sua maioria (Tabelas 6 a 9).

Outra metodologia alternativa ao método VO foi proposta por FERNANDES \& VENCOVSKY (1994), que visou expressar o ganho genético em função dos genótipos substituídos. Para tanto foi estabelecido que o desvio genético bruto passasse a ser estimado pelo contraste entre a média dos cultivares de um dado ano e a dos cultivares não comuns do ano anterior. Deste contraste foi também subtraído o efeito do ano (desvio ambiental), estimado pela diferença entre as médias dos genótipos comuns ao par de anos considerado. No exemplo da Tabela 23, considerando-se os anos 2 e 1, por esta metodologia alternativa o ganho genético (gg) seria estimado por:

$\mathrm{gg}=\{[(11+12+13+14+15) / 5]-[(6+7+8+9+10) / 5]\}-\left\{[(1+2+3+4+5) / 5]_{2}-[(1+2+3+4+5) / 5]_{1}\right\}$.

O contraste que estima o ganho genético é, portanto, a comparação direta entre os genótipos novos do ano $2(11,12,13,14,15)$ versus os descartados do $1(6,7,8,9,10)$. Por ser a comparação direta, sem a presença dos comuns no desvio bruto como o é no método original, a estimativa do ganho genético líquido deve torna-se superestimada, mais ainda que no original, visto que a média dos genótipos novos tende a ser superior à média dos descartados. Os resultados de FERNANDES \& VENCOVSKY (1994), obtidos com dados dos ensaios regionais de milho conduzidos em Minas Gerais por nove anos, confirmam estas suspeitas: método original estimou o ganho genético médio em $65,1 \mathrm{~kg} / \mathrm{ha} / \mathrm{ano}$, enquanto o método alternativo em $95,5 \mathrm{~kg} / \mathrm{ha} / \mathrm{ano}$.

Aparentemente o contraste mais equilibrado para se estimar o ganho genético referente aos anos 2 e 1, seria o formado entre os genótipos novos do ano 2 versus os genótipos novos do ano 1. Mesmo neste tipo de contraste, poderiam surgir problemas nos anos em que não houvesse renovação de tratamentos nos ensaios, sendo necessário desconsiderar este ano, ou supor ganho zero. 
Nestas metodologias, que envolvem contrastes entre tratamentos em anos consecutivos, considera-se que a interação dos tratamentos comuns com os anos represente a interação de todos os demais tratamentos, permitindo a plena eliminação do efeito do ano, mediante o contraste entre os tratamentos comuns em anos consecutivos. $\mathrm{Na}$ realidade, espera-se que ocorra interação genótipos com anos e esta pode ser a razão principal da ocorrência das estimativas anuais negativas de ganho genético, que foram obtidas em todas os seis métodos.

As possíveis explicações agronômicas para as estimativas negativas de ganho genético incluem: a)alteração do critério de seleção em anos consecutivos. Por exemplo, em um ano a prioridade foi reação às enfermidades, mas no ano subsequente, esta maior resistência aos patógenos, não refletiu em maior rendimento de grãos, que foi a variável usada nos estudos de ganho genético; b)alteração das testemunhas. Por exemplo, uma variedade comercial com rendimentos cada vez mais decrescentes, foi substituída por um novo cultivar, recém lançado, com alto potencial produtivo, tornando o critério de seleção mais rigoroso, e c)intensa interação de genótipos com ano, sendo que os genótipos tidos como superiores não confirmaram seu desempenho no ano subsequente.

As estimativas negativas de ganho genético ocorrem mesmo em ensaios conduzidos com a finalidade específica de se estimar o ganho genético, como o realizado por POMMER \& GERALDI (1983), que estudaram três populações de milho, submetidas a quatro ciclos de seleção, que foram concomitantemente testadas em cinco repetições, em dois anos e quatro locais. $\mathrm{O}$ ciclo 2 , embora tenha apresentado ganho positivo para o caráter peso de espiga por hectare em relação à população original (ciclo 0), apresentou média inferior em comparação como o ciclo anterior (ciclo 1), gerando ganho genético negativo, quando se analisou os ciclos consecutivos (ciclo 2 versus ciclo 1). Estas estimativas negativas também podem ocorrer com outras variáveis, como óleo e 
proteína em milho (DUDLEY \& LAMBERT, 1992). É possível inferir que, váriáveis mais sujeitas aos efeitos ambientais e portanto com menor herdabilidade, apresentem com maior frequência estimativas negativas de ganhos em anos consecutivos.

Comparando-se diretamente as seis metodologias de estimação de ganho genético, pode-se afirmar que todas produziram estimativas positivas de ganho genético médio, porém nem todas as estimativas foram significativas. As metodologias que utilizaram o contraste entre médias de tratamentos entre anos consecutivos (métodos VO, VP1 e VP2), apresentaram, na maioria dos ensaios, as maiores estimativas de ganho genético médio anual, variando de 10,2 a $58,7 \mathrm{~kg} / \mathrm{ha} / \mathrm{ano}$.

Estas superestimativas possivelmente foram resultantes do tipo de contraste estabelecido por estas metodologias (VO, VP1 e VP2), cuja natureza se resume na comparação entre a média dos genótipos novos de um determinado ano e a média dos genótipos descartados do ano anterior, sendo artificialmente positiva a tendência deste contraste, visto que o grupo de genótipos novos pode incluir não apenas genótipos que serão descartados, mas os selecionados também, cuja média normalmente é superior à dos descartados (Tabela 23).

Em termos de precisão, as metodologias com ponderação (VP1 e VP2) produziram estimativas mais precisas em relação às do método original (VO), sendo significativas em todos os casos (Tabela 20). Em termos de ponderação, pode-se afirmar que esta se faz necessária para se evitar a correlação entre os erros experimentais em anos consecutivos, tornando as estimativas mais precisas e significativas. Para tanto, surege-se efetuar o método VP1, que demanda menor número de informações para realizar a devida ponderação dos ganhos genéticos, produzindo estimativas com magnitude e precisão semelhante ao rigoroso método VP2. 
Em relação às metodologias de regressão, $R O, R E$ e $R A$, constatou-se a sua grande vantagem de evidenciar a tendência geral dos ganhos genéticos no decorrer do tempo, o que pôde ser comprovado mediante a reta de regressão linear (Figuras 3 a 8).

Os métodos RO e RE mostraram-se muito dependentes do desempenho da testemunha, que foi o único referencial de medida do efeito ambiental, o que seguramente provocou, na maioria dos casos, as menores estimativas de ganho genético médio, que variaram de 9,7 a 23,0 kg/ha/ano para o método $\mathrm{RO}$, sendo que apenas as estimativas referentes aos ensaios intermediários foram significativas.

A metodologia RE apresentou estimativas de mesma magnitude que o método $\mathrm{RO}$, porém com menor precisão, contrariando a expectativa, pois, teoricamente, o efeito de ano foi neutralizado pela estandardização dos dados. Esta transformação dos dados aparentemente não eliminou a interação genótipos $\mathrm{x}$ anos.

A metodologia RA produziu estimativas intermediárias de ganho genético médio, que variaram de 18,6 a $29,7 \mathrm{~kg} / \mathrm{ha} / \mathrm{ano}$, e com grande vantagem: em todos os tipos de ensaios, todas estimativas foram significativas e precisas, visto que suas regressões apresentaram os maiores coeficientes de determinação em relação aos métodos RO e RE. Esta maior precisão certamente foi devida à diminuição dos efeitos ambientas, da interação genótipos por ambientes e do erro experimental nas estimativas de progresso genético, visto que o método RA incluiu em seu modelo matemático estes fatores, o que propiciou a obtenção de estimativas imparciais (não viesadas) e precisas (com variância minima) dos efeitos genotípicos, estimados pelo procedimento BLUE.

Nas metologias com regressão, verificou-se que o efeito linear não explicou totalmente os dados, porque foi significativo o desvio da regressão linear (Tabelas 15 a 18), indicando que outros modelos podem explicar melhor a relação dos ganhos 
genéticos com os anos de melhoramento. Certamente este novo modelo apresentará explicação mais complexa e menos evidente em termos biológicos e agronômicos.

Em todas as seis metodologias, a tendência geral das estimativas de ganho genético médio anual, em termos de magnitude, foi: grupo preto superar o grupo cores, e ensaios intermediários superarem os finais. Possíveis explicações para estas tendências globais, podem ser: a) os genótipos do grupo preto possuiam maior potencial produtivo, que foi sendo alcançado com maior rapidez ou facilidade; b) os ensaios intermediários, por serem conduzidos na maioria dos locais onde são normalmente testados os ensaios preliminares conduzidos pelo programa de melhoramento genético de feijão do Instituto Agronômico do Paraná, tornaram-se sua repetição em ano subsequente. Assim, foi assegurado aos ensaios intermediários, estimativas mais elevadas e precisas que as obtidas pelos ensaios finais, que foram testados em maior número de locais, muitos deles distintos daqueles onde foram conduzidos o programa de melhoramento (ensaios preliminares).

Entre as seis metodologias estudadas, destacou-se o método RA, visto que mostrou ser de maior aplicabilidade, não dependendo da existência de testemunhas comuns para a sua realização e porque produziu estimativas precisas e significativas de ganho genético, com menor influência do ambiente, da interação genótipos $\mathrm{x}$ ambientes $\mathrm{e}$ do erro experimental. Por esta metodologia, as estimativas obtidas para os ensaios finais do grupo cores foram: $1,42 \% \pm 0,38 \%$, correspondendo a $18,6 \mathrm{~kg} / \mathrm{ha} / \mathrm{ano}$ e para os mesmos ensaios do grupo preto $1,64 \% \pm 0,33 \%$, ou seja, $22,1 \mathrm{~kg} / \mathrm{ha} / \mathrm{ano}$. O método RA necessita porém de programa e equipamento de computação capazes de realizar processos iterativos de estimação de componentes de variância e covariância (REML) e cálculos com matrizes de grande dimensão, que demandam grande capaciade de memória randômica e tempo de processamento, nem sempre disponíveis. 
De modo geral, espera-se que os ganhos genéticos sejam maiores no início do programa de melhoramento e que vão decrescendo com o tempo até atingir um patamar relativamente estável. Os dados do programa de melhoramento de feijão aqui examinados, não sugerem esta tendência. Analisando-se as Figuras 7 e 8, relativas ao método RA, nota-se tendência crescente e que aparentemente não foi atingido o patamar. Este fato é auspicioso, embora demande muitos recursos, humanos e financeiros, para a pesquisa, particularmente para o melhoramento genético, para que este continue cumprindo bem seu papel. Pois, como mencionado na introdução deste trabalho, é necessário que a produtividade das lavouras de feijão do Brasil, aumentem na taxa de $1,4 \%$ ao ano para atender a demanda estimada para o ano 2000 (YOKOYAMA et alii, 1996). Pode-se afirmar que o Paraná está cumprindo este objetivo, visto que pelo método $\mathrm{RA}$, as estimativas de ganho genético médio, para todos os tipos de ensaios, ficaram acima de $1,4 \%$ ao ano (Tabelas 15 a 18). Saliente-se que este valor é compatível com as estimativas de ganho genético obtidas para outras culturas, mediante diferentes métodos: 2,0\% para o milho (VENCOVSKY et alii, 1988), 1,8\% para soja precoce (TOLEDO et alii, 1990), 1,8\% para sorgo granífero (RODRIGUES, 1990), 1,35\% para arroz de sequeiro (ABBUD, 1991) e 1,03\% para algodão herbáceo (CARVALHO et alii, 1997).

\subsection{Desdobramento das estimativas gerais de ganho genético}

Adotou-se a metodologia de regressão com médias ajustadas (RA), para se efetuar o desdobramento das estimativas de ganho genético, obtidas globalmente para o estado do Paraná, uma vez que esta metodologia forneceu estimativas mais precisas e significativas para todos os ensaios. Tal desdobramento foi feito em função das seguintes subdivisões: a) Épocas de semeadura (safra das águas e seca), b) Regiões (I e II, esta 
última sendo representada pelos locais de clima mais ameno, relacionados na Tabela 2) e c) Ambientes (favoráveis e desfavoráveis, segundo a média de cada ano e não a média geral, para que em cada ano houvesse os dois tipos de ambientes). $\mathrm{O}$ objetivo deste desdobramento foi verificar se determinada condição foi privilegiada pelo melhoramento.

Os ganhos genéticos anuais obtidos em função das épocas de semeadura, águas e seca, utilizados como base do desdobramento pelo método RA, encontram-se nas Tabelas 25 a 28, os referentes às regiões nas Tabelas 29 a 32 e os referentes aos ambientes, nas Tabelas 33 a 36 .

As estimativas de ganho genético médio, seus erros padrões, sua significância e as comparações entre as condições, dentro da mesma subdivisão, constam nas Tabelas 37 a 40. Por estas tabelas, verifica-se que apenas os ensaios intermediários do grupo cores na região I, não apresentaram estimativa de ganho genético significativa pelo teste $t$.

Ao se analisar o desdobramento, foi observada significância em duas situações específicas nos ensaios intermediários: para regiões no grupo cores e para ambientes no grupo preto. Para o caso dos ensaios intermediários do grupo cores (Tabela 37), a magnitude das estimativas de ganho, expressas tanto em $\mathrm{kg} / \mathrm{ha}$ como em percentagem, foram aproximadamente o triplo em favor da região II, caracterizada como de clima mais ameno, onde o risco de estiagem e altas temperaturas é menor, mas há incidência de patógenos, entre os quais, os agentes causadores da antracnose e de bacteriose.

Para os ensaios finais do grupo cores, (Tabela 38) a magnitude das estimativas de ganho para a região II foi cerca do dobro da região I, embora não tenha sido detectada significância entre as regiões pelo teste estatístico adotado. Pode-se supor que o melhoramento, em se tratando de regiões para o grupo cores, proporcionou maior resistência às enfermidades. Porém, como neste estudo não foram relatadas a reação às enfermidades, a afirmação acima constitui uma conjectura baseada na experiência na 
condução dos ensaios, mas não uma conclusão respaldada nos dados apresentados. Entretanto, para o grupo cores, o desdobramento evidenciou o efeito marcante das regiões em relação às demais subdivisões (Figuras 9 a 11).

Para o grupo preto (Tabelas 39 e 40), os desdobramentos salientaram as discrepâncias apenas nos ensaios intermediários. Nestes ensaios, na safra das águas, a magnitude das estimativas de ganho foi superior, porém não diferindo estatisticamente da safra das secas. Já a separação dos ambientes, em favoráveis e desfavoráveis, foi efetiva, indicando que a estimativa de ganho genético, em $\mathrm{kg} / \mathrm{ha}$, nos ambientes favoráveis foi superior ao dobro da obtida em ambientes desfavoráveis (Tabela 39).

Basicamente no grupo preto, as magnitudes das estimativas de ganho genético dos ensaios intermediários foram superiores em relação aos finais e o efeito do desdobramento foi semelhante em ambos tipos de ensaios (Figuras 12 a 14), sendo significativo apenas para ambientes nos ensaios intermediários (Tabela 39). Esta significância pode indicar que o melhoramento genético agiu no sentido de dotar os novos genótipos do grupo preto de maior capacidade responsiva à melhoria ambiental. Porém esta tendência não foi significativa nos ensaios finais.

O desdobramento das estimativas de ganho, em função de diferentes condições, permitiu supor que o melhoramento genético proporcionou maior tolerância às enfermidades para os genótipos do grupo cores, especialmente nos locais de clima mais ameno, enquanto que os genótipos do grupo preto tornaram-se mais responsivos, com maior potencial produtivo, principalmente em condições favoráveis de cultivo. 


\subsection{Considerações Finais}

Em trabalhos de estimação de ganho genético, baseados em dados de ensaios regionais, contendo vários genótipos testados em diferentes locais e anos, mas com desbalanceamento inevitável, que tem como causa a renovação dos genótipos ao longo do tempo, sugere-se que antes de se proceder às estimativas de ganho, procure-se verificar a qualidade dos dados obtidos em cada experimento e em cada parcela.

Para isso, é importante verificar se o tamanho e forma de parcela é adequado para se avaliar a variável de interesse, se a área útil está devidamente livre dos efeitos de bordadura, tanto nas linhas laterais, quanto nas extremidades e se o número de repetições

é compatível com a variabilidade do terreno utilizado. É importante também realizar a análise de resíduos, visando detectar eventuais parcelas discrepantes, que podem comprometer os resultados e as análises estatísticas, e verificar se há variabilidade de solo dentro de cada repetição, em ensaios com delineamento de blocos ao acaso. Caso estas ocorram, deve-se analisar se seguem alguma tendência de dependência com parcelas vizinhas, e se houver, efetuar as correções e obter as médias ajustadas por experimento, como sugeriu CRESSIE (1993), nos ensaios submetidos às análises da variação espacial. Uma vez obtidas as médias ajustadas por experimento, para o estudo de ganho genético, sugere-se o método da regressão das médias ajustadas (RA), baseado em modelos mistos, onde os efeitos fixos dos genótipos foram estimados pelo procedimento BLUE. Caso se deseje avaliar também a interação genótipos $\mathrm{x}$ ambientes, esta pode ser estudada por algum dos métodos indicados por LIN \& BINNS (1994) e DELACY et alii (1996).

É necessário extrair o máximo de informação dos dados disponíveis, desde que analisados criteriosamente. De posse de uma série histórica desses dados referentes a ensaios regionais de competição de genótipos, é conveniente estimar o ganho genético 
médio obtido no período considerado, sugerindo-se que seja preferencialmente superior a 15 anos, caso seja utilizada alguma metodologia de regressão linear para estimação dos ganhos, para melhor embasamento dos resultados e conclusões. Para obter esta estimativa de ganho genético, pode-se optar pela metodologia da regressão com médias ajustadas (RA), que aparentemente permite melhor estimação dos efeitos genotípicos e ganho genético, com menor influência ambiental.

Para a devida seleção entre as metodologias disponiveis de estimação de ganho genético, mediante ensaios regionais, seria conveniente explicitar cada método em vários aspectos. Entre eles a natureza de seus constrastes estabelecidos, quer entre tratamentos em anos consecutivos (métodos VO, VP1 e VP2), quer entre genótipos novos e testemunha dentro do mesmo ano (metodologias RO, RE e RA). Definir qual é a distribuição das estimativas de ganho genético produzidas em cada método, pois sabendo-se a distribuição probabilística, pode-se, com mais segurança, aplicar os testes de significância entre as estimativas obtidas em diferentes tipos de ensaios ou situações. Deverá ser analisada a esperança matemática das estimativas de ganho genético, decompondo-a em seus componentes, para ser possivel a seleção segura entre os métodos. Aspectos da esperança matemática dessa estimativa foram abordados na metodologia original (VO) estabelecida por VENCOVSKY et alii (1988), entretanto estes aprofundamentos estão além do escopo do presente trabalho.

Este estudo sobre ganho genético em feijoeiro se restringiu à variável rendimento de grãos e consequentemente é limitado, pois se tivesse abrangido os componentes de rendimento, poder-se-ia verificar se o melhoramento genético alterou o balanço entre os componentes no sentido de favorecer um componente em relação aos demais, como alertou RAMALHO et alii (1993) ao abordar estudos envolvendo interação genótipos por ambientes. $\mathrm{O}$ que foi mencionado para os componentes do rendimento em feijão, a 
saber, número de vagens por planta, número de sementes por vagem e peso de sementes, pode ser extendido para demais variáveis, como reação às doenças, arquitetura de planta, tipo de grão, entre outras. Normalmente, a variável coletada sistematicamente em ensaios regionais é o rendimento de grãos, mas se fosse considerado outro caráter nesse estudo de ganho genético, por exemplo os componentes de rendimento, o desbalanceamento seria ainda maior, limitando a abrangência dos dados, pois dificilmente em todos os locais testados haveria condições de se obter todos os componentes de rendimento, mediante equipe local, visto que esta é uma operação meticulosa e o transporte das plantas colhidas poderia causar deiscência de vagens, ou mesmo perda de vagens, influindo na interpretação dos dados de componentes de rendimento de grãos.

Se o objetivo for verificar as possíveis alterações na morfologia da planta e na distribuição de assimilados, pode-se efetuar experimento específico, composto por cultivares novos e antigos, analisando-se além do rendimento de grãos, os seus componentes e outras variáveis que o fisiologista e o melhorista julgarem necessárias, como efetuado em trigo no Brasil (NEDEL, 1994), no México (BELL, 1995) e no Canadá (McCAIG \& CLARKE, 1995 e McCAIG \& DePAUW, 1995) e em soja nos Estados Unidos (SALADO-NAVARRO et alii, 1993).

Pode-se optar por analisar todos os dados da rede de competição de cultivares conjuntamente, isto é, ensaios intermediários e finais numa única análise sobre ganho genético. $\mathrm{O}$ que pode definir esta análise são os objetivos do melhorista e principalmente se obrigatoriamente todos os genótipos integram os ensaios intermediários para posteriormente integrarem os finais. Caso isto não ocorra, a análise deverá ser realizada em separado, visto que o conjunto de genótipos não é o mesmo. Foi o caso deste estudo, onde genótipos promissores ou já recomendados em estados vizinhos ao Paraná foram 
testados diretamente nos ensaios finais, dispensando os intermediários, reduzindo em um ano o período de teste no Paraná, antes de ter sua recomendação estendida.

Em termos de condução de ensaios regionais, que possuam a metodologia de testar por pelo menos três anos os genótipos, sendo um nos ensaios intermediários e dois nos finais, é conveniente manter nos ensaios finais os genótipos testados por um e dois anos concomitantemente, evitando-se estabelecer um ensaio final para genótipos de primeiro ano e outro final para genótipos de segundo ano. A razão de se manter unidos estes dois tipos de genótipos nos ensaios finais é de proporcionar o maior número possível de genótipos comuns em anos consecutivos, para melhor estimar, e consequentemente eliminar, o efeito ambiental, causado pelo fator ano agrícola. Isto é válido especialmente quando o objetivo for estimar o ganho genético por metodologia diferente da regressão linear com médias ajustadas (RA), a qual prescinde deste cuidado na estimação dos efeitos genotípicos, que posteriormente estimarão os ganhos genéticos.

Quanto ao melhoramento em si, após 18 anos de trabalho no Paraná, pode-se afirmar que o resultado foi positivo, tanto no grupo cores como no preto, cujas estimativas de ganho genético médio ficaram acima de $1,4 \%$ ao ano, pelo método da regressão das médias ajustadas.

Para continuar com progresso genético crescente, é necessário que o melhoramento aumente sua eficiência. Uma das possibilidades, como assinalado por FEHR (1987), é que a pesquisa científica expanda o conhecimento da base genética do desempenho das plantas e que este conhecimento seja aplicado nos diferentes programas de melhoramento. Quer este conhecimento venha da Genética Quantitativa, quer seja proveniente da biotecnologia, o melhorista tem que saber aplicá-lo.

Para manter este progresso genético e até melhorá-lo é necessário analisar as perspectivas do melhoramento do feijoeiro. O primeiro ponto é a equipe de trabalho, que 
tem que contar com melhoristas experientes, e que esta tenha condições de executar seus trabalhos, pois como afirmou ADAMS (1996), nem sempre os ganhos genéticos são obtidos rapidamente e o melhoramento não deve sofrer interrupções. Outro ponto é a definição dos objetivos da equipe de melhoramento, a qual deve continuar buscando rusticidade, como sugeriu AZEVEDO FILHO \& SANTOS (1993), que pode ser alcançada mediante processos clássicos de melhoramento de feijão, mencionados em ZIMMERMANN et alii (1996). Não apenas a rusticidade, mas também a resposta à melhoria tecnológica deve ser objetivada. Contando com os elementos do melhoramento genético clássico, aliados ao melhor embasamento em Genética Quantitativa, que permitirá utilização de processos mais complexos de melhoramento genético, como a seleção recorrente para o melhoramento do feijão, conforme propôs RAMALHO (1996), será possível alcançar ambos objetivos.

Além do melhoramento clássico e do melhor uso de Genética Quantitativa, é conveniente utilizar processos biotecnológicos para aumentar o ganho genético nos programas de melhoramento de feijão. As técnicas moleculares vem, aos poucos, apresentando resultados favoráveis ao melhoramento do feijoeiro, como o mapeamento genético (VALLEJOS et alii, 1992), regeneração de plantas in vitro, visando transformação genética de genótipos já adaptados (MODA-CIRINO et alii, 1995), seleção assistida por marcadores na identificação de QTLs (SCHNEIDER et alii, 1996) e escolha de genitores com auxílio de marcadores moleculares (VASCONCELOS et alii, 1996), porém o caminho é longo até a consolidação dos ganhos genéticos expressos em novos cultivares comerciais, efetivamente superiores e que assegurem melhor relação custo/benefico ao produtor.

Com o melhor emprego das técnicas clássicas, aliado ao uso criterioso de métodos não convencionais de melhoramento genético, é possível obter o ideótipo de 
feijoeiro. Entretanto, antes de se precisar as características deste ideótipo, há necessidade de se optar por uma das duas grandes rotas principais: a primeira visa obter genótipos de feijão mais semelhantes às espécies relativamente rústicas, como a soja, com maior tolerância às enfermidades, ao calor (BAIGES et alii, 1996), a solos ácidos (AZEVEDO FILHO \& SANTOS, 1993) e mais eretos (VANDERBERG et alii, 1996). A segunda é aquela que considera o feijoeiro como planta responsiva em condições de irrigação e fertilização, que pode ser protegida por defensivos e não necessita ser ereta, pois basta a colheita semi-mecanizada. Nos dois tipos de planta considerados, é necessário a atenção com o tipo de grão, cor do tegumento e do halo (região próxima ao hilo), forma e tamanho do grão, e características culinárias, uma vez que o mercado é muito exigente, como advertiu MYERS \& McLEAN (1996).

Sugere-se que no estado do Paraná, deve-se continuar na primeira opção (rusticidade). Em termos de Brasil, há lugar para os dois ideótipos, pois há diferentes classes de produtores e todos devem ser atendidos pelo melhoramento genético. 


\section{CONCLUSÕES}

1) As seis metodologias indicaram estimativas positivas de ganho genético para a produtividade do feijoeiro; porém, apenas os métodos VP1, VP2 e RA forneceram estimativas significativas para todos os grupos de genótipos;

2) O método da regressão com médias ajustadas (RA), destacou-se por fornecer estimativas de ganho genético significativas para todos os grupos e com maiores coeficientes de determinação do modelo, sendo por isso considerado o mais eficiente para este tipo de análise;

3) As estimativas do progresso genético obtidas com o melhoramento genético do feijoeiro, realizado no estado do Paraná, no período de 17 anos, foram: $1,42 \%$ ao ano para o grupo cores e $1,64 \%$ ao ano para o grupo preto, que corresponde a um aumento em produtividade de $18,6 \mathrm{~kg} / \mathrm{ha}$.ano e $22,1 \mathrm{~kg} / \mathrm{ha}$.ano, respectivamente.

4) Quando computado separadamente por regiões e ambientes, as estimativas do progresso genético para os ensaios intermediários foram significativamente maiores na região de clima mais ameno para os genótipos do grupo cores e na condição ambiental mais favorável para o grupo preto. 


\section{REFERÊNCIAS BIBLIOGRÁFICAS}

ABBUD, N.S. Melhoramento genético do arroz de sequerio (Oriza sativa L.) no Estado do Paraná de 1975 a 1989. Piracicaba, 1991. 141p. (Doutorado - Escola Superior de Agricultura "Luiz de Queiroz"/USP).

ABDALLA, O.S.; CROSSA, J.; AUTRIQUE, E.; DELACY, I.H. Relationships among international testing sites of spring Durum wheat. Crop Science, Madison, 36(1): 33-40, 1996.

ABREU, A.F.B.; RAMALHO, M.A.P.; SANTOS, J.B.; PEREIRA-FILHO, L.A.; SANTOS, J.B. Effect of genotype $x$ environment on estimation of genetic and phenotypic parameters of common beans. Revista Brasileira de Genética, Ribeirão Preto, 13(1): 75-82, 1990.

ABREU, A.F.B.; RAMALHO, M.A.P.; SANTOS, J.B.; MARTINS, L.A. Progresso do melhoramento genético do feijoeiro nas décadas de setenta e oitenta nas regiões Sul e alto Paranaiba em Minas Gerais. Pesquisa Agropecuária Brasileira, Brasília, 29(1): 105-12, 1994.

ACOSTA-GALLEGOS \& WHITE, J.W. Phenological plasticity as an adaptation by common bean to rainfed environments. Crop Science, Madison, 35 (1): 63-69, 1995.

ADAMS, M.W. An historical perspective on significant accomplishments in dry bean research - The first 100 years. Annual Report of the Bean Improvement Cooperative -1995, Fort Collins, 39: 32-45, 1996. 
ALLIPRANDINI, L.F.; TOLEDO, J.F.F.; FONSECA JÚNIOR, N.S.; KIIHL, R.A.; ALMEIDA, L.A. Ganho genético em soja no estado do Paraná, via melhoramento, no peródo de 1985/86 a 1989/90. Pesquisa Agropecuária Brasileira, Brasilia, 28(4): 48997, 1993.

ALMEIDA, L.D.; LEITÃO FILHO, H.F.; MIYASAKA, S. Características do feijão Carioca, um novo cultivar. Bragantia, Campinas, 30(1) nota n 7: 33-8, 1971.

AZEVEDO FILHO, J.A. \& SANTOS, J.B. Potencialidade de cultivares de feijão (Phaseolus vulvaris $\mathrm{L}$.) para o melhoramento visando a tolerância às condições químicas de solos ácidos de baixa fertilidade. Ciência e Prática, Lavras, 17(1): 49-57, 1993.

BAIGES, S.; BEAVER, J.S.; MIKLAS, P.N.; ROSAS, J.C. Evaluation and selection of dry beans for heat tolerance. Annual Report of the Bean Improvement Cooperative 1995, Fort Collins, 39: 46-7, 1996.

BELL, M.A.; FISHER, R.A.; BYERLEE, D.; SAYRE, K. Genetic and agronomic contributions to yield gains: a case of study for wheat. Field Crops Research, Amsterdam, 44(1): 55-65, 1995.

BERNARDO, R. Prediction of maize single-cross performance using RFLPs and information from related hybrids. Crop Science, Madison, 34(1): 20-5, 1994.

BERNARDO, R. Genetic models for predicting maize single-cross performance in unbalanced yield trial data. Crop Science, Madison, 35(1): 141-7, 1995.

BERNARDO, R. Best linear unbiased prediction of maize single-cross performance. Crop Science, Madison, 36(1): 50-6, 1996 .

BERNARDO, R. Best linear unbiased prediction of maize single-cross performance given erroneous inbred relationships. Crop Science, Madison, 36(4): 862-6, $1996 \mathrm{~b}$.

BERNARDO, R. Testcross selection prior to further inbreeding in maize: mean performance and realized genetic variance. Crop Science, Madison, 36(4): 867-71, $1996 \mathrm{c}$. 
BERNARDO, R. Best linear unbiased prediction of the performance of crosses between untested maize inbreds. Crop Science, Madison, 36(4): 872-6, 1996d.

BERZONSKY, W.A. \& LAFEVER, H.N. Progress in Ohio soft red winter wheat breeding: grain yield and agronomic traits of cultivars released from 1871 to 1987 . Crop Science, Madison, 33(6): 1382-6, 1993.

BOWMAN. D.T. \& RAWLINGS, J.O. Establishing a rejection procedure for crop performance data. Agronomy Journal, Madison, 87(2): 147-51, 1995.

BRESEGHELLO, F. Ganhos para produtividade pelo melhoramento genético do arroz irrigado no Nordeste do Brasil. Goiânia, 1995. 93p. (Mestrado - Escola de Agronomia da Universidade Federal de Goiás)

BULMAN, P.; MATHER, D.E.; SMITH, D.L. Genetic improvement of spring barley cultivars grown in eastern Canada from 1910 to 1988. Euphytica, Wageningen, 71(1): 35-48, 1993.

BYRNE, P.F.; BOLAÑOS, J.; EDMEADES, G.O.; EATON, D.L. Gains from selection under drought versus multilocation testing in related tropical maize populations. Crop Science, Madison, 35(1): 63-9, 1995.

CARDWELL, V.B. Fifty years of Minnesota corn production: sources of yield increase. Agronomy Journal, Madison, 74(6): 984-90, 1982 .

CARVALHO, L.P.; BARBOSA, M.H.P.; COSTA, J.N.; FARIAS, F.J.C.; SANTANA, J.C.F.; ANDRADE, F.P. Progresso genético do algodoeiro herbáceo no Nordeste. Pesquisa Agropecuária Brasileira, Brasília, 32(3): 283-91, 1997.

CASCUDO, L.C. História da alimentação no Brasil. São Paulo, Itatiaia. 1983, p. 489-510.

CHAVES, L.J. Um modelo não linear aplicado ao estudo das interações de genótipos com ambientes. Piracicaba, 1982. 117p. (Mestrado - Escola Superior de Agricultura "Luiz de Queiroz"/USP). 
CIÓL, M.A. Métodos de estimação de componentes de variância em modelos mistos. Campinas, 1982. 126p. (Mestrado - Universidade Estadual de Campinas).

COOPER, M.; DELACY, I.H.; BYTH, D.E. e WOODRUFF, D.R. Predicting grain yield in Australian environments using data from CIMMYT international wheat perfornance trials. 2. The application of classification to identity environmental relationships which exploit correlated response to selection. Field Crops Research, Amsterdam, 32(3-4): $322-42,1993$.

CÓRDOVA, H.S.; BARRETO, H.J.; CROSSA, J. Hybrid development in central America: reliability of yield gains against a regional check. Maydica, Bergamo, 41(4): 349-53, 1996.

COSTA, J.G.C. \& ZIMMERMANN, F.J.P. Efeito das bordaduras laterais e da cabeceira em parcelas experimentais de feijoeiro comum. In: REUNIÃO NACIONAL DE PESQUISA DE FEIJÃO, 5., Goiânia, 1996. Anais. Goiânia, Embrapa-CNPAF-APA, 1996. v. 1, p. 456-8.

CRESSIE, N.A.C. Statistics for spatial data. New York, John Wiley \& Sons, 1993, 900p.

CROSSA, J.; CORNELIUS, P.L.; SAYRE, K. e ORTIZ-MONASTERIO, J.I. A shifted multiplicative model fusion method for grouping environments without cultivar rank change. Crop Science, Madison, 35(1): 54-62, 1995.

CRUZ, C.D. \& CASTOLDI, F.L. Decomposição da interação genótipos $x$ ambientes em partes simples e complexa. Revista Ceres, Viçosa, 38(219): 422-30, 1991.

CRUZ, C.D. \& REGAZZI, A.J. Modelos biométricos aplicados ao melhoramento genético. Viçosa, UFV, 1994, 390p.

DELACY, I.H. \& COOPER, M. Pattern analysis for the analysis of regional variety trials. In: KANG, M.S., ed. Genotype-by-environment interaction and plant breeding. Baton Rouge, Louisiana State University, 1990 p. 301-34. 
DELACY, I.H.; BASFORD, K.E.; COOPER, M.; BULL, J.K. e McLAREN, C.G. Analysis of multi-environment trials - an historical perspective. In: COOPER, M. \& HAMMER, G.L., ed. Plant adaptation and crop improvement. Wallingford, CAB International, 1996. cap. 4, p.38-122.

DUARTE, J.B. \& ZIMMERMANN, M.J.O. Selection of locations for common bean (Phaseolus vulgaris L.) germplasm evaluation. Revista Brasileira de Genética, Ribeirão Preto, 14(3): 765-70, 1991.

DUARTE, J.B. \& ZIMMERMANN, M.J.O. Comparison of three methods used for the study of adaptation and phenotypic stability in the common bean (Phaseolus vulgaris L.). Revista Brasileira de Genética, Ribeirão Preto, 15(1): 125-36, 1992.

DUARTE, J.B. \& ZIMMERMANN, M.J.O. Adaptabilidade e estabilidade de rendimento de genótipos de feijoeiro comum. Pesquisa Agropecuária Brasileira, Brasília, 29(1): 25 32, 1994.

DUDLEY, J.W. \& LAMBERT, R.J. Ninety generations of selection for oil and protein in maize. Maydica, Bergamo, 37(1): 81-7, 1992.

DUVICK, D.N. Genetic contributions to advances in yield of U.S. maize. Maydica, Bergamo, 37(1): 69-79, 1992.

ESCRIBANO, M.R.; RON, A.M.; AMURRIO, J.M.; DE-RON, A.M. Diversity in agronomical traits in common bean populations from northwestern Spain. Euphytica, Wageningen, 76(1/2): 1-6, 1994.

ESTEFANEL, V.; PIGNATARO, I.A.B. e STORCK, L. Availação dos coeficientes de variação com algumas culturas agrícolas. In: SIMPÓSIO DE ESTATÍSTICA APLICADA À EXPERIMENTAÇÃO AGRONÔMICA, 2, Londrina, 1987. Anais. Londrina, Sociedade Internacional de Biometria, 1987. p. 115-20. 
ESTEFANEL, V.; PIGNATARO, I.A.B.; STORCK, L. e GARCIA, D.C. Determinação do tamanho ideal da parcela para estimar o rendimento de grãos da cultura do feijoeiro. Ciência Rural, Santa Maria, 23(1): 97-8, 1993.

EYHÉRABIDE, G.H.; DAMILANO, A.L.; COLAZO, J.C. Genetic gain for grain yield of maize in Argentina. Maydica, Bergamo, 39(3): 207-11, 1994.

FALCONER, R. Introdução à genética quantitativa. Viçosa, UFV, 1981.279p.

FAMULA, T.R. Identifying single genes of large effect in quantitative traits using best linear unbiased prediction. Journal of Animal Science, Albany, 63: 68-76, 1986.

FEHR, W.R. Role of plant breeding in agriculture. In: FEHR, W.R., ed. Principles of cultivar development - theory and technique. New York, McGraw-Hill, 1987. vol. 1, cap. 1, p.1-10.

FERNANDES, J.S.C. Estabilidade ambiental de cultivares de milho (Zea mays L.) na região Centro Sul do Brasil. Piracicaba, 1988. 94p. (Mestrado - Escola Superior de Agricultura "Luiz de Queiroz"/USP).

FERNANDES, J.S.C. \& VENCOVSKY, R. Método alternativo para se estimar progressos anuais devido ao melhoramento genético. In: CONGRESSO NACIONAL DE MILHO E SORGO, 20, Goiânia, 1994. Resumos, Goiânia, Associação Brasileira de Milho e Sorgo, 1994. p.44.

FIBGE - FUNDAÇÃO INSTITUTO BRASILEIRO DE GEOGRAFIA E ESTATÍSTICA. Anuário estatístico do Brasil. Rio de Janeiro, 1980, 1984, 1985, 1989, 1992, 1993 e 1994.

FINS, L.; FRIEDMAN, S.T. e BROTSCHOL, J.V. Handbook of quantitative forest genetics. Dordrecht, Kluwer Academic Publishers, 1992. 403p. 
FOX, P.N. \& ROSIELLE, A.A. Reducing the influence of environmental main effects on pattern analysis of plant breeding environments. Euphytica, Wageningen, 31: 645-56, 1982.

GEPTS, P. Analisis moleculares del proceso de domestificacion en plantas: el ejemplo del frijol comun (Phaseolus vulgaris). In: CONGRESSO LATINO AMERICANO DE GENETICA (Area Vegetal), 11 ; CONGRESSO DE FITOGENETICA, 15, Monterrey, 1994. Memórias. Chapingo, eds. P.R. VALLEJO, F.Z. GARCIA, N.E.T. HERNANDEZ, E.C. CERDA e M.M. RODRIGUEZ, 1994. p.4-27.

GHADERI, A.; HOSFIELD, G.L.; ADAMS, M.W.; UEBERSAX, M.A. Variability in culinary quality, component interrelationships, and breeding implications in navy and pinto beans. Journal of the American Society for Horticultural Sciense, Saint Joseph, 109(1): 85-90, 1984.

GOGEL, B.J.; CULLIS, B.R.; VERBYLA, A.P. REML estimation of multiplicative effects in multi-environment variety trials. Biometrics, Blacksburg, 51: 744-9, 1995.

GOMES, F.P. Os testes ou provas de significância. In: GOMES, F.P. Curso de estatística experimental. 12. ed. Piracicaba, Nobel, 1987. p.39-40.

HENDERSON, C.R.; KEMPTHORNE, O.; SEARLE, S.R. e KROSIGK, C.M. The estimation of environmental and genetic trends from records subject to culling. Biometrics, Blacksburg, 15(2): 192-218, 1959.

HENDERSON, C.R. Applications of linear models in animal breeding. Guelph, University of Guelph, 1984. p.462.

HOCKING, R.R. The analysis of linear models. Monterey, Brooks/Cole Publishing Company, 1985. 381p.

HOFFMANN, R. A diminuição do consumo de feijão no Brasil. Estudos Econômicos, São Paulo, 25(2): 189-201, 1995. 
HOFFMANN, R. \& VIEIRA, S. Heterocedastecia. In: HOFFMANN, R. \& VIEIRA, S. Análise de regressão: uma introdução à econometria. São Paulo, HUCITEC-USP, 1977, cap. 6, p.204-210.

HOLLAND, J.B. \& BINGHAM, E.T. Genetic improvement for yield and fertility of alfafa cultivars representing different eras of breeding. Crop Science, Madison, 34(4): 953-7, 1994.

HOSFIELD, G.L.; UEBERSAX, M.A.; ISLEIB, T.G. Seasonal and genotypic effects on yield and physico-chemical seed characteristics to food quality in dry, edible beans. Journal of the American Society for Horticultural Sciense, Saint Joseph, 109(2): 1829, 1984.

IEMMA, A.F. Que hipóteses estatísticas testamos através do SAS em presença de caselas vazias? Scientia Agricola, Piracicaba, 52(2): 210-20, 1995.

IPARDES - INSTITUTO PARANAENSE DE DESENVOLVIMENTO ECONÔMICO E SOCIAL. Estudo da competitividade do feijão do sul do Brasil. Curitiba, IPARDES, 1995. 73p.

JACKSON, P.; McRAE, T.; HOGARTH, M. Selection of sugarcane families across variable environments II. Patterns of response and association with environmental factors. Field Crops Research, Amesterdam, 43: 119-30, 1995.

KEMPTHORNE, O. Fixed and mixed models in the analysis of variance. Biometrics, Blacksburg, 31(2): 473-80, 1975.

LATOUR, D.; LATOUR, K.; WOLFINGER, R. Getting started with PROC MIXED. Cary, SAS Institute, 1994. 121p.

LATOUR, D.; \& LITTELL, R.C. Advanced general linear models with an emphasis on mixed models. Cary, SAS Institute, 1996. 614p. 
LILL, D. \& PURCHASE, J.L. Directions in breeding for winter wheat yield and quality in South Africa from 1930 do 1990. Euphytica, Wageningen, 82(1): 79-87, 1995.

LIN, C.S. \& BINNS, M.R. Concepts and methods for analysing regional trial data for cultivar and location selection. Plant Breeding Reviews. New York, 12: 271-97, 1994.

LITTELL, R.C.; MILLIKEN, G.A.; STROUP,W.W.; WOLFINGER, R.D. SAS $^{\circledR}$ System for mixed models. Cary, SAS Institute, 1996. 633p.

LLANILLO, R.F. \& GUERREIRO, E. Panorama da produção paranaense de feijão. In: IAPAR - FUNDAÇÃO INSTITUTO AGRONÔMICO DO PARANÁ. O feijão no Paraná. Londrina, IAPAR, 1989. p.9-23. (Circular 63).

LLANILLO, R.F. Evolução da concentração municipal da área cultivada com feijão no Estado do Paraná, 1967 - 1991. In: REUNIÃO NACIONAL DE PESQUISA DE FEIJÃO, 4., Londrina, 1993. Resumos, Londrina, IAPAR, 1993. p. 151.

LOPES, P.S.; MARTINS, E.N.; SILVA, M.A.; REGAZZI, A.J. Estimação de componentes de variância. Viçosa, UFV, 1993. 61p. (Boletim 326).

MARTINS, E.N.; LOPES, P.S.; SILVA, M.A.; REGAZZI, A.J. Modelo linear misto. Viçosa, UFV, 1993. 46p. (Boletim 323).

McCAIG, T.N. \& CLARKE, J.M. Breeding durum wheat in western Canada: historical trends in yield and related variables. Canadian Journal of Plant Science, Ottawa, 75(1): 55-60, 1995.

McCAIG, T.N. \& DePAUW, R.M. Breeding hard red spring wheat in western Canada: historical trends in yield and related variables. Canadian Journal of Plant Science, Ottawa, 75: 387-93, 1995.

MEBRAHTU, T.; MERSIE, W.; RANGAPPA, M. Inheritance of ambient ozone insensitivity in common bean (Phaseolus vulgaris L.). Environmental Pollution, Barking, 67(1): 79-89, 1990. 
MILLIKEN, G.A. \& JOHNSON, D.E. Analysis of messy data. New York, Chapman \& Hall, 1992. v.1, 473p.

MIRANDA, G.V.; VIEIRA, C.; CRUZ, C.D.; ARAÚJO, G.A.A. Adaptabilidade e estabilidade de comportamento de cultivares de feijão em quatro municípios da zona da Mata de Minas Gerais. Revista Ceres, Viçosa, 41(232): 591-609, 1993.

MIRANDA FILHO, J.B. Melhoramento genético vegetal : princípios e métodos; Melhoramento genético e melhoramento ambiental. Piracicaba, ESALQ/Departamento de Genética, 1994. cap. 1, p.1-6. (Publicação Didática).

MODA-CIRINO, V.; NICOLODI, C.; CHICHIRICCÒ, G.; MARIOTTI, D. In vitro meristematic organogenesis and plant regeneration in bean (Phaseolus vulgaris L.) cultivars. Journal of Genetics \& Breeding. Roma, 49:133-38, 1995.

MORAIS, O.P. \& ABBUD, N.S. Subsídios para avaliação do progresso genético dos programas estaduais de melhoramento de arroz no Brasil. , Goiânia, EMBRAPA/CNPAF, 1993. 26p. (Apostila).

MYERS, J.R. \& McLEAN, P.E. Study of the "light" corona colors of common bean. Annual Report of the Bean Improvement Cooperative -1995, Fort Collins, 39: 158-9, 1996.

NARULA, S.C. \& STANGENhaUS, G. Análise de regressão $\mathbf{L}_{\mathbf{1}}$. In: SIMPÓSIO NACIONAL DE PROBABILIDADE E ESTATÍSTICA, 8., São Paulo, 1988. São Paulo, USP, 1988. 67p.

NEDEL, J.L. Progresso genético no rendimento de grãos de cultivares de trigo lançadas para cultivo entre 1940 e 1992. Pesquisa Agropecuária Brasileira, Brasília, 29(10): 1565 $70,1994$.

NIENHUIS, J. \& SINGH, P. Effects of location and plant density on yield and architectural traits in dry beans. Crop Sciense, Madison, 25(4): 579-84, 1985. 
ÖFVERSTEN, J. Exact tests for variance components in unbalanced mixed linear models. Biometrics, Blacksburg, 49(1): 45-57, 1993.

PANTER, D.M. \& ALLEN, F.L. Using best linear unbiased predictions to enhance breeding for Yield in soybean: I. Choosing parents. Crop Science, Madison, 35(2): 397-405, 1995.

PARANÁ. Secretaria da Agricultura e do Abastecimento. Departamento de Economia Rural Acompanhamento da situação agropecuária do Paraná. Curitiba, DERAL/CEPA/PR, 22(6): 57-58, 1996.

PARK, S.J. Cultivar by environment interactions, yield stability and grouping of test locations for field bean cultivar trials in Ontario. Canadian Journal of Plant Science, Ottawa, 67(3): 653-9, 1987.

PASTOR-CORRALES, M.A. Traditional and molecular confirmation of the coevolution of beans and pathogens in Latin America. Annual Report of the Bean Improvement Cooperative -1995, Fort Collins, 39: 46-7. 1996.

PATTERSON, H.D. \& THOMPSON, R. Recovery of inter-block information when block sizes are unequal. Biometrika, London, 58(3): 545-54, 1971.

PELTONEN-SAINIO, P. \& PELTONEN, J. Progress since the 1930s in breeding for yield, its components, and quality traits of spring wheat in Finland. Plant Breeding, Berlin, 113(3): 177-86, 1994.

POMMER, C.V. \& GERALDI, I.O. Selection among and within half-sib families in opaque-2 maize populations. Revista Brasileira de Genética, Ribeirão Preto, 6(3): 461-72, 1983.

RAMALHO, M.A.P.; \& SANTOS, J.B. Melhoramento do feijão. Informe Agropecuário, Belo Horizonte, 8(90): 16-9, 1982. 
RAMALHO, M.A.P.; SANTOS, J.B.; PEREIRA FILHO,I. Choice of parents of dry bean (Phaseolus vulgaris L.) breeding. I. Interaction of mean components by generation and by location. Revista Brasileira de Genética, Ribeirão Preto, 11(2): 391-400, 1988.

RAMALHO, M.A.P.; SANTOS, J.B.; ZIMMERMANN, M.J. Genética quantitativa em plantas autógamas - aplicações ao melhoramento do feijoeiro. Goiânia, UFG, 1993. $271 \mathrm{p}$.

RAMALHO, M.A.P. Seleção recorrente. In: REUNIÃO NACIONAL DE PESQUISA DE FEIJÃO, 5., 1996, Goiânia. Anais. Goiânia: EMBRAPA-CNPAF/APA, 1996. v.2, p.112.

RODRIGUES, J.A.S. Progresso genético e potencial de risco da cultura do sorgo granifero (Sorghum bicolor (L.) Moench) no Brasil. Piracicaba, 1990. 171p. (Doutorado Escola Superior de Agricultura "Luiz de Queiroz"/USP).

SAINDON, G. \& SCHAALJE, G.B. Evaluation of locations for testing dry bean cultivars in western Canada using statistical procedures, biological interpretation and multiple traits. Canadian Journal of Plant Science, Ottawa, 73(4): 985-94, 1993.

SALADO-NAVARRO, L.R.; SINCLAIR, T.R.; HINSON, K. Changes in yield and seed growth traits in soybean cultivars released in the Southern USA from 1945 to 1983. Crop Science, Madison, 33(6): 1204-9, 1993.

SALVARREY, L.M. \& IEMMA, A.F. Aplicação da teoria de modelos mistos à análise de blocos incompletos. In: SIMPÓSIO DE ESTATÍSTICA APLICADA À EXPERIMENTAÇÃO AGRONÔMICA, 6, Ribeirão Preto, 1995. Programa e Resumos. Ribeirão Preto, USP, 1995. p.34.

SAS INSTITUTE - STATISTICAL ANALYSIS SYSTEM. SAS/STAT® users' guide. The GLM procedure. Cary: SAS Institute Inc. Version 6, 4.ed v.2. cap.24, p.891-996, 1990. 
SAS INSTITUTE - STATISTICAL ANALYSIS SYSTEM. SAS Technical Report P-229, SAS/STAT (B) Software: Changes and Enhancements, release 6.07. Cary, SAS Institute, cap. 16, p.287-366, 1992.

SCAPIM, C.A.; CARVALHO, C.G.P. e CRUZ, C.D. Uma proposta de classificação dos coeficientes de variação para a cultura do milho. Pesquisa Agropecuária Brasileira, Brasilia, 30(5): 683-6, 1995.

SCHWARZ, C.J. The mixed-model ANOVA: the truth, the computer packages, the books. Part I: Balanced Data. The American Statistician, Washington, 47(1): 48-59, 1993.

SCHNEIDER, K.; ACOSTA-GALEGOS, J.; IBARRA-PEREZ, F. e KELLY, J.D. Application of marker assited selection to improving a quantitative trait in common bean. Annual Report of the Bean Improvement Cooperative - 1995, Fort Collins, 39: 61-2. 1996.

SEARLE, S.R. Applications in Statistics. In: Matrix algebra useful for Statistics. New York, John Wiley \& Sons, 1982, cap.13, 357-358.

SEARLE, S.R. Mixed models: a thumbnail survey. In: SEARLE, S.R. Linear models for unbalanced data. New York, John Wiley \& Sons, 1987, cap. 13, p.484-519.

SHELLIE, K.C. \& HOSFIELD, G.L. Genotype $\mathrm{x}$ environmental effects on food quality of common bean: resource efficient testing procedures. Journal of the American Society for Horticultural Science, Saint Joseph, 116(4): 732-6, 1991.

SHONNARD, G.C. \& GEPTS, P. Genetics of heat tolerance during reproductive development in common bean. Crop Science, Madison, 34(5): 1168-75, 1994.

SINGH, S.P.; GEPTS, P. e DEBOUCK, D.G. Races of common bean (Phaseolus vulgaris, Fabaceae). Economic Botany, New York, 45(3): 379-96, 1991. 
SOARES, A.A. \& RAMALHO, M.A.P. Estimates of the genetic progress obtained by the upland rice breeding program of the State of Minas Gerais. Revista Brasileira de Genética, Ribeirão Preto, 16(4): 1019-27, 1993.

SOARES, A.A.; RAMALHO, M.A.P.; SOUSA, A.F. Estimativa do progresso genético obtido pelo programa de melhoramento de arroz irrigado da EPAMIG, na época de oitenta. Pesquisa Agropecuária Brasileira, Brasília, 29(1): 97-104, 1994.

SOH, A.C. Ranking parents by best linear unbiased prediction (BLUP) breeding values in oil palm. Euphytica, Wageningen, 76(1): 13-21, 1994.

SOKAL, R.R. \& ROHLF, F.J. The linear regression equation. In: SOKAL, R.R. \& ROHLF, F.J., ed. Biometry - the principles and practic in biological research. San Francisco, W.H. Freeman \& Cia. ed. 2., 1981, cap. 14, p.454-560.

SOUZA JÚNIOR, C.L. Componentes da variância genética e suas implicações no melhoramento vegetal. Piracicaba, FEALQ, 1989. 134p.

STEEL, R.G.D. \& TORRIE, J.H. Principles and procedures of statistics. New York, McGraw-Hill, 1980. 633p.

TAKEDA, C.; SANTOS, J.B.; RAMALHO, M.A.P. Choice of parental lines for common bean (Phaseolus vulgaris L.) breeding. II. Reaction of cultivars and their segregant populations to variations in different environments. Revista Brasileira de Genética, Ribeirão Preto, 14(2): 455-65, 1991.

TOLEDO, J.F.F.; ALMEIDA, L.A.; KIIHL, R.A.S; MENOSSO, O.G. Ganho genético em soja no Estado do Paraná, via melhoramento. Pesquisa Agropecuária Brasileira, Brasilia, 25(1): 89-94, 1990.

VALLEJOS, C.E.; SAKIYAMA, N.S.; CHASE, C.D. A molecular marker-based linkage map of Phaseolus vulgaris L.. Genetics, Austin, 131: 733-40, 1992. 
VAN VLECK, L.D. Selection index and introduction to mixed models methods. Boca Raton, CRC Press, 1993. 482p.

VANDENBERG, A.; ZYLA, L.; HUCL, P.J.; RECKSIEDLER, B.; WALLACE, T.; SLINKARD, A.E.; SING, S.P. New approaches to direct harvesting of dry beans. Annual Report of the Bean Improvement Cooperative -1995, Fort Collins, 39: 108-9. 1996.

VASCONCELOS, M.J.V.; BARROS, E.G.; MOREIRA, M.A.; VIEIRA, C. Genetic diversity of the common bean Phaseolus vulgaris L. determined by DNA-based molecular markers. Revista Brasileira de Genética, Ribeirão Preto, 19(3): 447-51,1996.

VENCOVSKY, R. \& BARRIGA, P. Genética biométrica no fitomelhoramento. Ribeirão Preto, Revista Brasileira de Genética, 1992. 496p.

VENCOVSKY, R.; MORAES, A.R.; GARCIA, J.C.; TEIXEIRA, N.M. Progresso genético em vinte anos de melhoramento do milho no Brasil. In: CONGRESSO NACIONAL DE MILHO E SORGO, 16., Belo Horizonte, 1986. Anais. Sete Lagoas, EMBRAPA/CNPMS, 1988. p.300-307.

VERDOOREN, L.R. Practical aspects of the estimation of varietal contrasts from variety trials. Biuletyn Oceny Odmian (Cultivar Testing Bulletin), Polônia, 17: 105-37, 1992.

VERNEQUE, R.S. Procedimentos numéricos e estimação de componentes de covariância em análise multivariada pelo método da máxima verossimilhança restrita - Modelos mistos aplicados ao melhoramento animal. Piracicaba, 1994. 157p. (Doutorado - Escola Superior de Agricultura "Luiz de Queiroz"/USP).

VIEIRA, A. M. C. Estimação por máxima verossimilhança através de algoritmos iterativos. Piracicaba, 1996. 21p. (Seminário apresentado na disciplina LME 804 - Estatística Matemática I - Departamento de Matemática e Estatística - ESALQ).

VIEIRA, C. Cultura do feijão. Viçosa, UFV, 1978. 146p. 
VOYSEST, O.; VALENCIA, M.C.; AMEZQUITA, M.C. Genetic diversity among Latin American Andean and Mesoamerican common bean cultivars. Crop Science, Madison, 34(4): 1100-10, 1994.

WELLS, W.C.; ISOM, W.H. e WAINES, J.G. Outcrossing rates of six common bean lines. Crop Science, Madison, 28: 177-8, 1988.

WHITE, T.H. \& HODGE, G.R. Predicting Breeding Values - with applications in forest tree improvement. Dordrecht, Kluwer Academic Publishers, 1989. 367p.

WHITE, J.W. \& ISQUIERDO, J. Physiology of yield potential and stress tolerance. In: SCHOONHOVEN, A.; VOYSEST, O. ed. Common Beans - research for crop improvement. Melksham, C.A.B. International - CIAT, 1993, cap. 6, p.287-382.

WILCOX, J.R.; SCHAPAUGH JÚNIOR, W.T.; BERNARD, R.L.; COOPER, R.L.; FEHR, W.R.; NEIHAUS, M.H. Genetic improvement of soybeans in the Midwest. Crop Science, Madison, 19(6):803-5, 1979.

WOLFINGER, R. \& CHANG, M. Comparing the SAS $®$ GLM and MIXED procedures for repeated measures. In: ANNUAL SAS® USERS GROUP INTERNATIONAL CONFERENCE, 20., Cary, 1995. Proceedings. Cary, SAS Institute, 1995, p.1172-82.

WOODFIELD, D.R. \& CARADUS, J.R. Genetic improvement in white clover representing six decades of plant breeding. Crop Science, Madison, 34(5): 1205-13, 1994.

YAN, X.; LYNCH, J.P.; BEEBE, S.E. Genetic variation for Phosphorus efficiency of common bean in contrasting soil types: I. Vegetative response. Crop Science, Madison, 35(4): 1086-93, 1995a.

YAN, X.; BEEBE, S.E.; LYNCH, J.P. Genetic variation for Phosphorus efficiency of common bean in contrasting soil types: II. Yield response. Crop Science, Madison, 35(4): 1094-9, 1995 b. 
YAN, X.; LYNCH, J.P.; BEEBE, S.E. Utilization of Phosphorus by contrasting common bean genotypes. Crop Science, Madison, 36(4): 936-41, 1996.

YANG, Z. \& WANG, T. Mixed model analysis of DNA sequence evolution. Biometrics, Blacksburg, 51: 552-61, 1995.

YOKOYAMA, L.P.; BANNO, K.; KLUTHCOUSKI, J. Aspectos socioeconômicos da cultura. In: ARAUJO, R.S.; RAVA, C.A.; STONE, L.F.; ZIMMERMANN, M.J.O., coords. Cultura do feijoeiro comum no Brasil. Piracicaba, POTAFOS, 1996. p. 121.

YOURSTONE, K.S. \& WALLACE, D.H. Effects of photoperiod and temperature on rate node development in indeterminate bean. Journal of the American Society for Horticultural Science, Saint Joseph, 115(5): 824-8, 1990.

ZIMMERMANN, M.J.O.; CARNEIRO, J.E.S.; PELOSO, M.J.D.; COSTA, J.G.C.; RAVA, C.A.; SARTORATO, A.; PEREIRA, P.A.A. Melhoramento genético e cultivares. In: ARAUJO, R.S.; RAVA, C.A.; STONE, L.F. e ZIMMERMANN, M.J.O., ed. Cultura do feijoeiro comum no Brasil. Piraciacaba, Potafos, 1996. p. 223-73. 
TABELAS 
Tabela 1. Dados de área cultivada (ha), produção (toneladas) e rendimento de grãos de feijão (kg/ha), no Paraná e no Brasil, no período de 1977 a 1995.

\begin{tabular}{|c|c|c|c|c|c|c|c|}
\hline \multirow[b]{2}{*}{ Anos } & \multicolumn{3}{|c|}{ PARANA } & \multicolumn{3}{|c|}{ BRASIL } & \multirow{2}{*}{$\begin{array}{c}\text { PRODUÇĀO } \\
\text { Paraná / Brasil } \\
\text { (\%) }\end{array}$} \\
\hline & $\begin{array}{c}\text { AREA } \\
(1000 \mathrm{ha})\end{array}$ & $\begin{array}{l}\text { PROD. } \\
(1000 \mathrm{t})\end{array}$ & $\begin{array}{r}\text { REND. } \\
\mathrm{kg} / \mathrm{ha}\end{array}$ & $\begin{array}{l}\text { ÁREA } \\
(1000 \text { ha) }\end{array}$ & $\begin{array}{l}\text { PROD. } \\
(1000 \mathrm{t})\end{array}$ & $\begin{array}{l}\text { REND. } \\
\mathrm{kg} / \mathrm{ha}\end{array}$ & \\
\hline 1977 & 809,6 & 576,9 & 713 & 4551,0 & 2290,0 & 503 & 25,2 \\
\hline 1978 & 747,0 & 507,0 & 679 & 4617,3 & 2194,0 & 475 & 23,1 \\
\hline 1979 & 746,5 & 503,5 & 674 & 4212,4 & 2186,3 & 519 & 23,0 \\
\hline 1980 & 815,1 & 462,3 & 567 & 4643,4 & 1968,2 & 424 & 23,5 \\
\hline 1981 & 852,8 & 570,9 & 669 & 5026,9 & 2340,9 & 466 & 24,4 \\
\hline 1982 & 880,0 & 666,8 & 758 & 5926,1 & 2902,7 & 490 & 23,0 \\
\hline 1983 & 699,7 & 347,0 & 496 & 4064,0 & 1580,5 & 389 & 22,0 \\
\hline 1984 & 741,0 & 479,1 & 647 & 5320,2 & 2625,7 & 494 & 18,2 \\
\hline 1985 & 723,8 & 499,6 & 690 & 5315,9 & 2548,7 & 479 & 19,6 \\
\hline 1986 & 628,1 & 213,9 & 341 & 5477,7 & 2209,2 & 403 & 9,7 \\
\hline 1987 & 754,2 & 391,4 & 519 & 5201,8 & 2007,2 & 386 & 19,5 \\
\hline 1988 & 741,9 & 457,7 & 617 & 5781,2 & 2808,6 & 486 & 16,3 \\
\hline 1989 & 528,7 & 223,0 & 422 & 5181,0 & 2310,5 & 446 & 9,7 \\
\hline 1990 & 550,6 & 279,0 & 507 & 4680,1 & 2334,5 & 499 & 12,0 \\
\hline 1991 & 624,0 & 348,3 & 558 & 5433,6 & 2744,7 & 505 & 12,7 \\
\hline 1992 & 582,4 & 450,6 & 774 & 5150,3 & 2799,2 & 543 & 16,1 \\
\hline 1993 & 577,6 & 473,9 & 820 & 4722,4 & 2479,2 & 525 & 19,1 \\
\hline 1994 & 589,5 & 526,2 & 893 & 5469,0 & 3368,4 & 616 & 15,6 \\
\hline 1995 & 665,3 & 422,5 & 635 & 5048,2 & 3060,5 & 606 & 13,8 \\
\hline
\end{tabular}

Fonte: FIBGE - Anuario Estatistico do Brasil: 1977 a 1993;

PARANA - SEAB/DERAL : 1994 e 1995. 
Tabela 2. Locais e números de experimentos da rede paranaense de competição de genótipos de feijão, no período de 1977 a 1995.

\begin{tabular}{|c|c|c|c|c|c|c|c|c|}
\hline \multirow[b]{4}{*}{ LOCAIS } & \multicolumn{8}{|c|}{ REGIÂO I } \\
\hline & \multicolumn{4}{|c|}{ Águas } & \multicolumn{4}{|c|}{ Secas } \\
\hline & \multicolumn{2}{|c|}{ Final } & \multicolumn{2}{|c|}{ Intermediário } & \multicolumn{2}{|c|}{ Final } & \multicolumn{2}{|c|}{ Intermediário } \\
\hline & Cor & Preto & Cor & Preto & Cor & Preto & Cor & Preto \\
\hline ARAPOTI & 3 & 4 & I. & 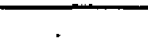 & 4 & $\overline{3}$ & $\Gamma$ & 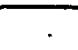 \\
\hline BARBOSA FERRAZ & 1 & 1 & . & . & . & . & . & . \\
\hline CAMPINA DA LAGOA & 1 & 1 & . & . & 1 & 1 & . & . \\
\hline CAMPO MOURÃO & 6 & 3 & . & . & 1 & 1 & . & . \\
\hline CURIÚVA & 2 & . & . & . & 1 & . & . & . \\
\hline FORMOSA DO OESTE & 4 & 1 & . & . & . & . & . & . \\
\hline GODOY MOREIRA & 2 & . & . & . & . & . & . & . \\
\hline IVAIPORÃ & 12 & 6 & 2 & & 14 & 7 & 1 & . \\
\hline LEONDAS MARQUES & 2 & 2 & 2 & 2 & . & . & . & \\
\hline LONDRINA & 17 & 12 & 17 & 17 & 1 & 1 & 1 & 1 \\
\hline MANGUEIRINHA & 1 & . & . & . & 1 & & . & \\
\hline MANOEL RIBAS & 1 & . & . & . & . & . & 1 & 1 \\
\hline MARINGÁ & 12 & 6 & . & . & . & . & . & . \\
\hline MORRETES & & . & . & . & 2 & & . & . \\
\hline ORTIGUEIRA & 4 & 2 & & . & 2 & 1 & . & . \\
\hline PALOTINA & 2 & 1 & 2 & 1 & . & & & . \\
\hline PALOTINA OCEPAR & . & . & . & . & 1 & . & . & . \\
\hline PARANAVAÍ & 1 & . & 1 & . & 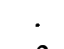 & $\dot{2}$ & . & . \\
\hline PITANGA & & . & . & . & 3 & 2 & & . \\
\hline REALEZA & 4 & 6 & 3 & 3 & 1 & 2 & . & . \\
\hline ROSÁRIO & 1 & 1 & . & . & 2 & 1 & . & . \\
\hline SÃO JOÃO DO IVAÍ & 7 & 3 & 2 & . & 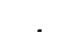 & . & . & - \\
\hline SÃO JOSÉ DA BOA VISTA & 2 & . & . & . & 2 & & . & . \\
\hline SAPOPEMA & 1 & . & & 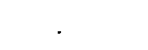 & & 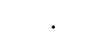 & & \\
\hline SIQUEIRA CAMPOS & 14 & 7 & 14 & 10 & 10 & 8 & 12 & 10 \\
\hline TAMARANA & & & & . & 1 & 1 & . & . \\
\hline TIBAGI & 1 & 1 & . & . & 2 & 2 & . & . \\
\hline TOLEDO & 1 & & . & . & . & & . & . \\
\hline UMUARAMA & 2 & 2 & . &. & . & . & . & . \\
\hline \multirow[t]{2}{*}{ WENCESLAU BRAZ } & & . & . & & 4 & . & 3 & . \\
\hline & \multicolumn{8}{|c|}{ REGIÃO II } \\
\hline ADRIANÓPOLIS & 1 & . & . & . & . & . & . & . \\
\hline CARAMBEÍ & 1 & 1 & . & . & 1 & . & . & . \\
\hline CASCAVEL & & . & . & . & 1 & 1 & . & . \\
\hline CURTIBA & & & . & . & 5 & 5 & . & . \\
\hline FRANCISCO BELTRÃO & & & . & . & 1 & . & 1 & 1 \\
\hline RATI & 8 & 10 & 5 & 6 & 8 & 13 & 6 & 7 \\
\hline LAPA & 2 & 4 & 4 & 4 & 7 & 8 & 6 & 7 \\
\hline PALMTAL & & & & & 1 & & & \\
\hline PATO BRANCO & 13 & 14 & 5 & 6 & 13 & 14 & 8 & 8 \\
\hline PONTA GROSSA & 12 & 12 & 7 & 7 & 11 & 14 & 4 & 5 \\
\hline PONTA GROSSA FT & 1 & 1 & . & 1 & 2 & 2 & 2 & 2 \\
\hline REBOUÇAS & 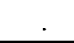 & . & . & & 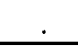 & 1 & 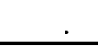 & \\
\hline
\end{tabular}


Tabela 3. Valores médios (m), mínimos (min) e máximos (max) do rendimento médio dos ensaios, do coeficiente de variação (C.V.\%), do número de tratamentos e de experimentos por ano. Frequência de ensaios com teste $\mathrm{F}$ significativo para efeitos de genótipos, número de experimentos e número total de parcelas dos ensaios intermediários e finais de feijão dos grupos cores e preto no estado do Paraná, no período de 1977 a 1995.

\begin{tabular}{|c|c|c|c|c|c|c|c|}
\hline & \multicolumn{2}{|c|}{ INTERMEDIÁRIOS } & \multicolumn{2}{|c|}{ FINAIS } & \multirow[b]{2}{*}{ Médias } & \multirow[b]{2}{*}{ Totais } \\
\hline & & CORES & PRETO & CORES & PRETO & & \\
\hline Rendimento & $\mathbf{m}$ & 1472,8 & 1482,4 & 1482,0 & 1552,1 & 1497,3 & \\
\hline$(\mathrm{kg} / \mathrm{ha})$ & $\min -\max$ & $413,2-3410,8$ & $311,3-2893,3$ & $374,3-3321,9$ & $359,5-2805,2$ & & \\
\hline C.V. & $\mathbf{m}$ & 13,54 & 13,38 & 13,66 & 13,78 & 13,59 & \\
\hline (\%) & $\min -\max$ & $7,1-22,8$ & $4,3-23,9$ & $6,2-24,5$ & $4,9-24,2$ & & \\
\hline $\mathrm{N}^{\circ}$ de trats. & $\mathbf{m}$ & 18,5 & 13,5 & 11,8 & 11,6 & 13,9 & \\
\hline por ano & $\min -\max$ & $8-48$ & $4-20$ & $5-16$ & $4-18$ & & \\
\hline $\mathrm{N}^{\circ}$ de expers. & m & 6,1 & 5,5 & 14,4 & 11,1 & 9,3 & \\
\hline por ano & $\min -\max$ & $2-10$ & $2-9$ & $9-21$ & $3-20$ & & \\
\hline $\begin{array}{l}F(\text { trat) } \\
\text { sig. (\%) }\end{array}$ & & 89,0 & 82,5 & 91,7 & 84,8 & 87,0 & \\
\hline $\mathrm{N}^{\circ}$ de expers. & & 109 & 99 & 245 & 189 & 160,5 & 642 \\
\hline $\mathrm{N}^{\circ}$ de parcelas & & 7370 & 5029 & 11676 & 8776 & 8213 & 32851 \\
\hline
\end{tabular}


Tabela 4. Resumo das análises de variâncias conjuntas, referentes aos ensaios intermediários do grupo cores (IC), finais cores (FC), intermediários preto (IP) e finais preto (FP), relativas ao rendimento de grãos de feijão, cujos quadrados médios (QM) estão expressos em (kg/ha)2 dividos por 1000.

\begin{tabular}{|c|c|c|c|c|c|}
\hline \multirow{3}{*}{ Fontes de Variação } & \multicolumn{5}{|c|}{ GRUPO CORES } \\
\hline & \multicolumn{2}{|c|}{ INTERMEDIÁRIOS } & \multicolumn{2}{|c|}{ FINAIS } & \\
\hline & GL & QM & GL & $\mathbf{Q M}$ & \\
\hline Genótipos (G) & 273 & $684,2 * *$ & 93 & $2.531,5$ & ** \\
\hline Ambientes (A) & 108 & $25.473,7$ & 244 & $17.497,4$ & \\
\hline GxA & 1636 & 222,6 & 2581 & 230,8 & \\
\hline Rep/A & 292 & 450,8 & 735 & 352,1 & \\
\hline Erro Médio & 5060 & 48,4 & 8022 & 42,9 & \\
\hline \multirow[t]{4}{*}{ Total } & 7369 & & 11675 & & \\
\hline & \multicolumn{5}{|c|}{ GRUPO PRETO } \\
\hline & \multicolumn{2}{|c|}{ INTERMEDIÁRIOS } & \multicolumn{2}{|c|}{ FINAIS } & \\
\hline & GL & $\overline{Q M}$ & GL & QM & \\
\hline Genótipos (G) & 186 & $554,1^{* *}$ & 97 & $1.471,3$ & ** \\
\hline Ambientes (A) & 98 & $14.194,5$ & 188 & $14.769,0$ & \\
\hline GxA & 1052 & 181,9 & 1908 & 190,9 & \\
\hline Rep/A & 263 & 325,9 & 567 & 290,1 & \\
\hline Erro Médio & 3429 & 46,5 & 6015 & 43,5 & \\
\hline Total & 5028 & & 8775 & & \\
\hline
\end{tabular}

'TApenas o efeito fixo de genótipos foi testado sua significância em função da interação $\mathrm{GxA}$. ** Significativo a $1 \%$ de probabilidade pelo teste $\mathrm{F}$. 


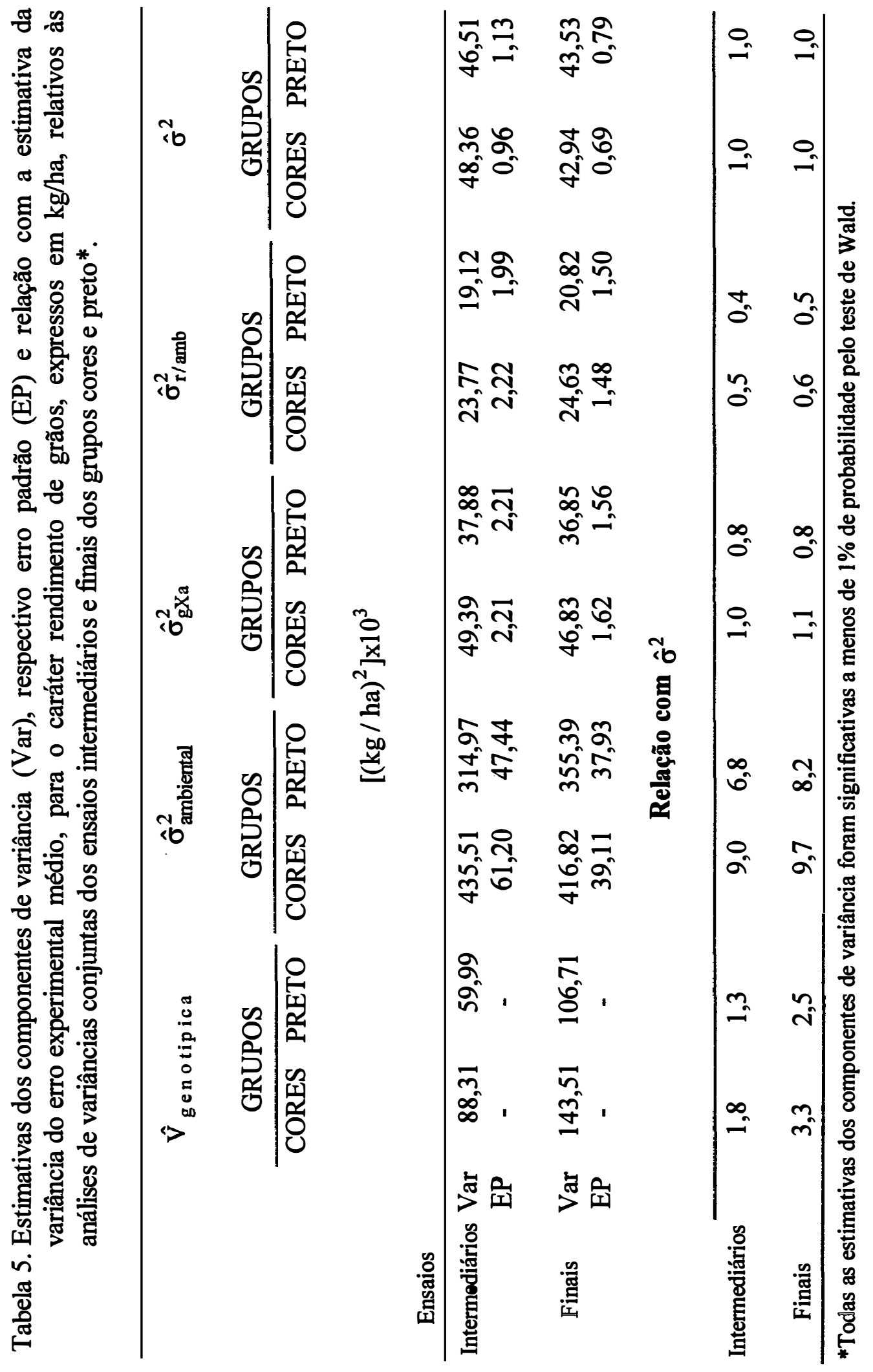




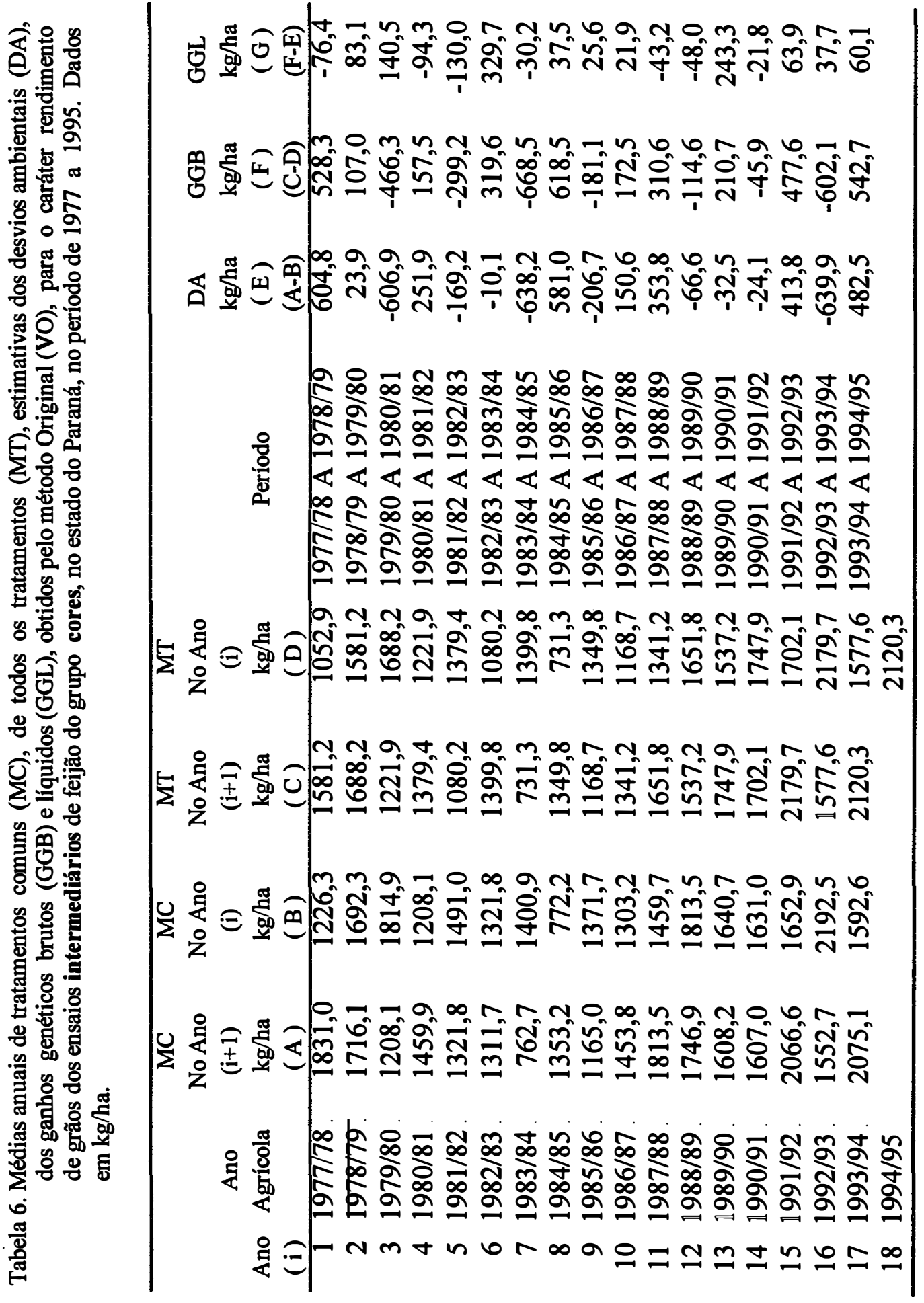




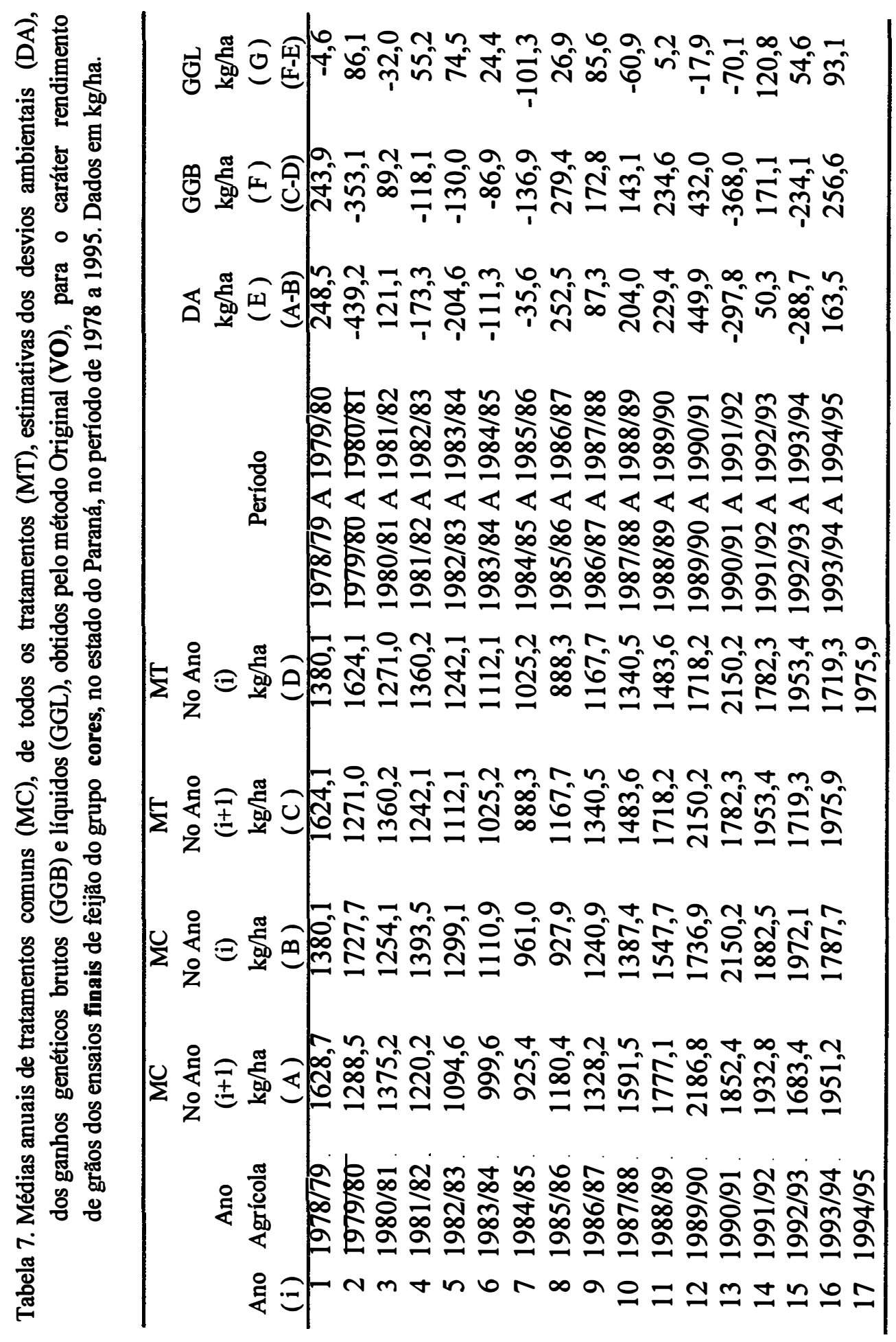




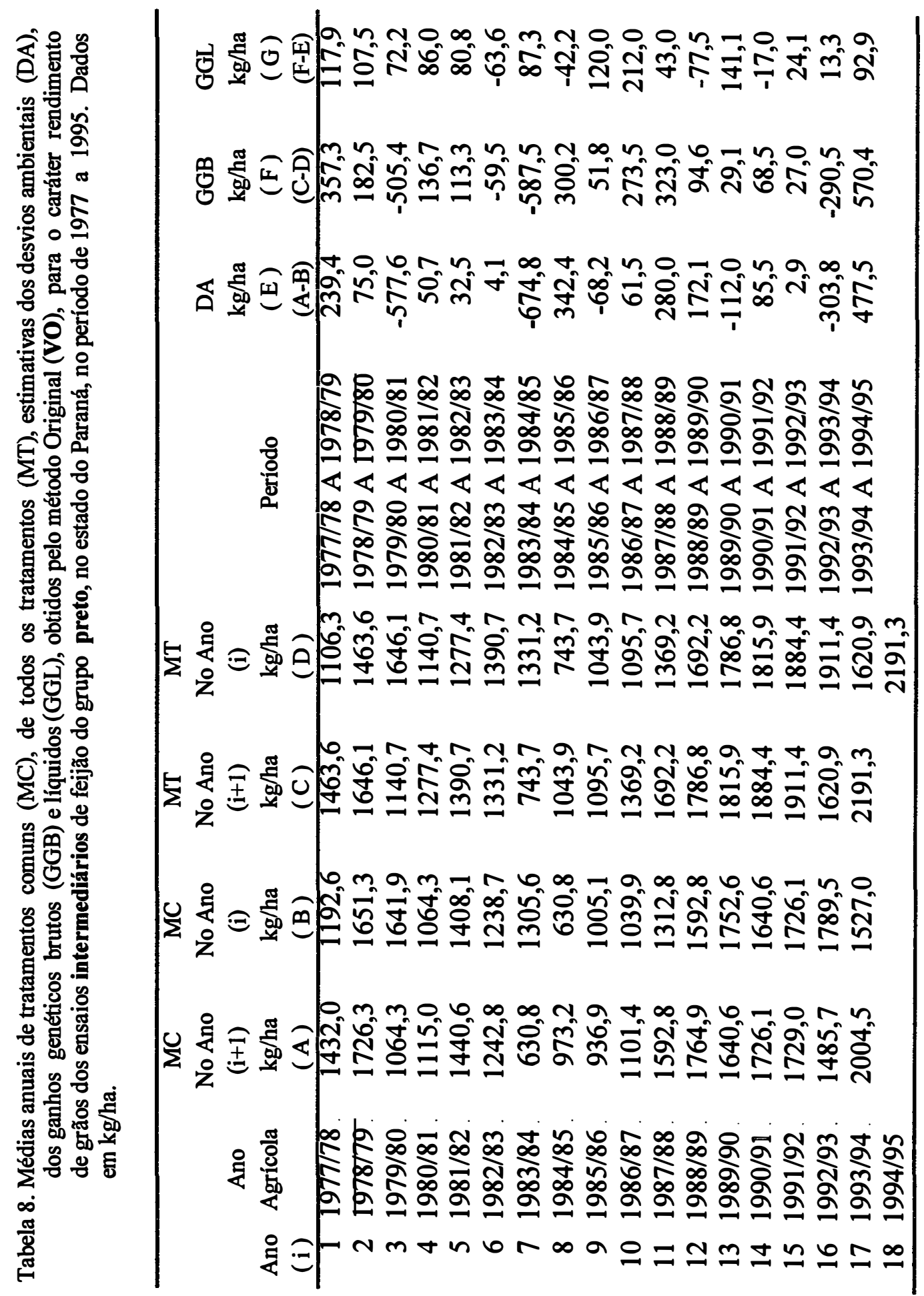




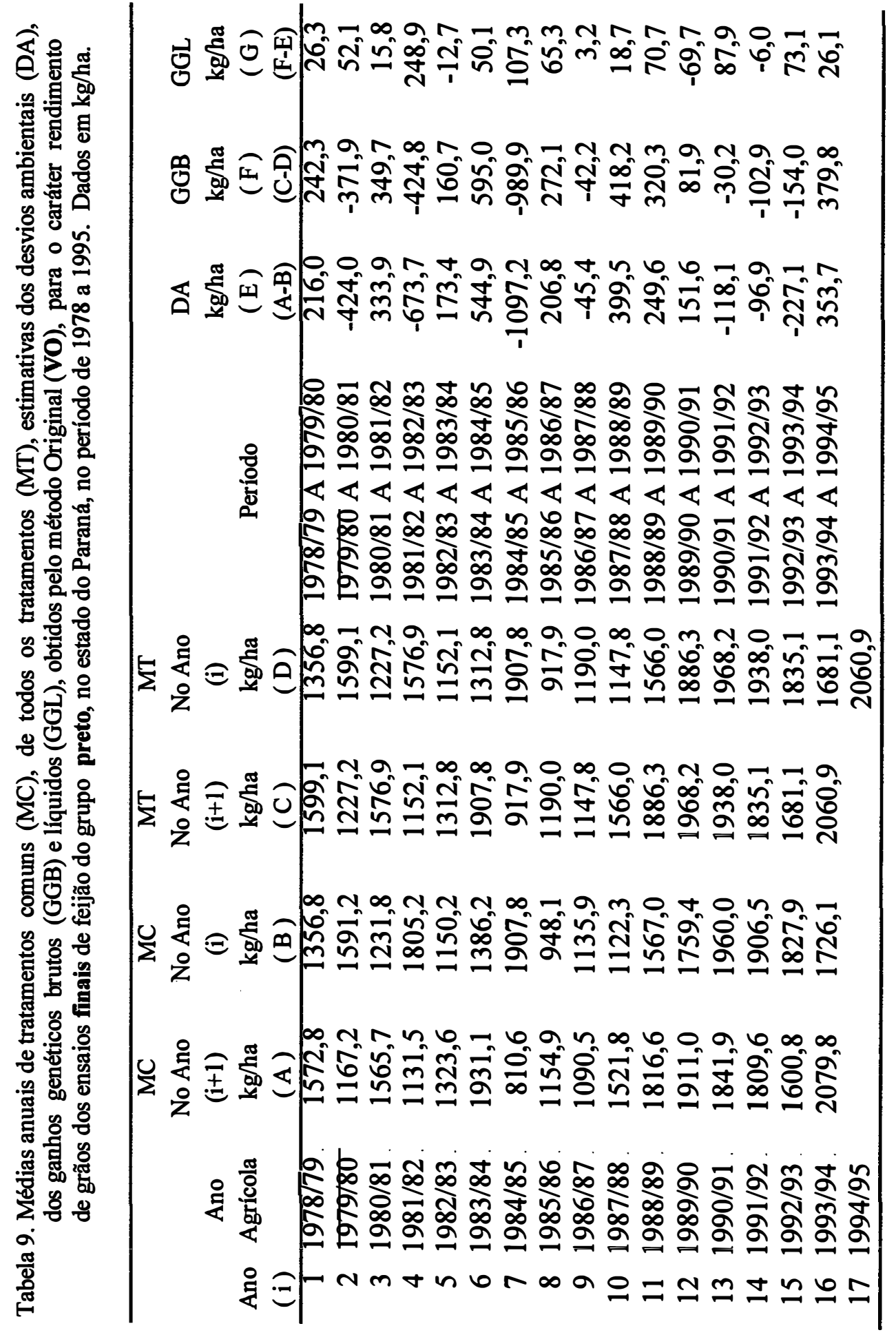




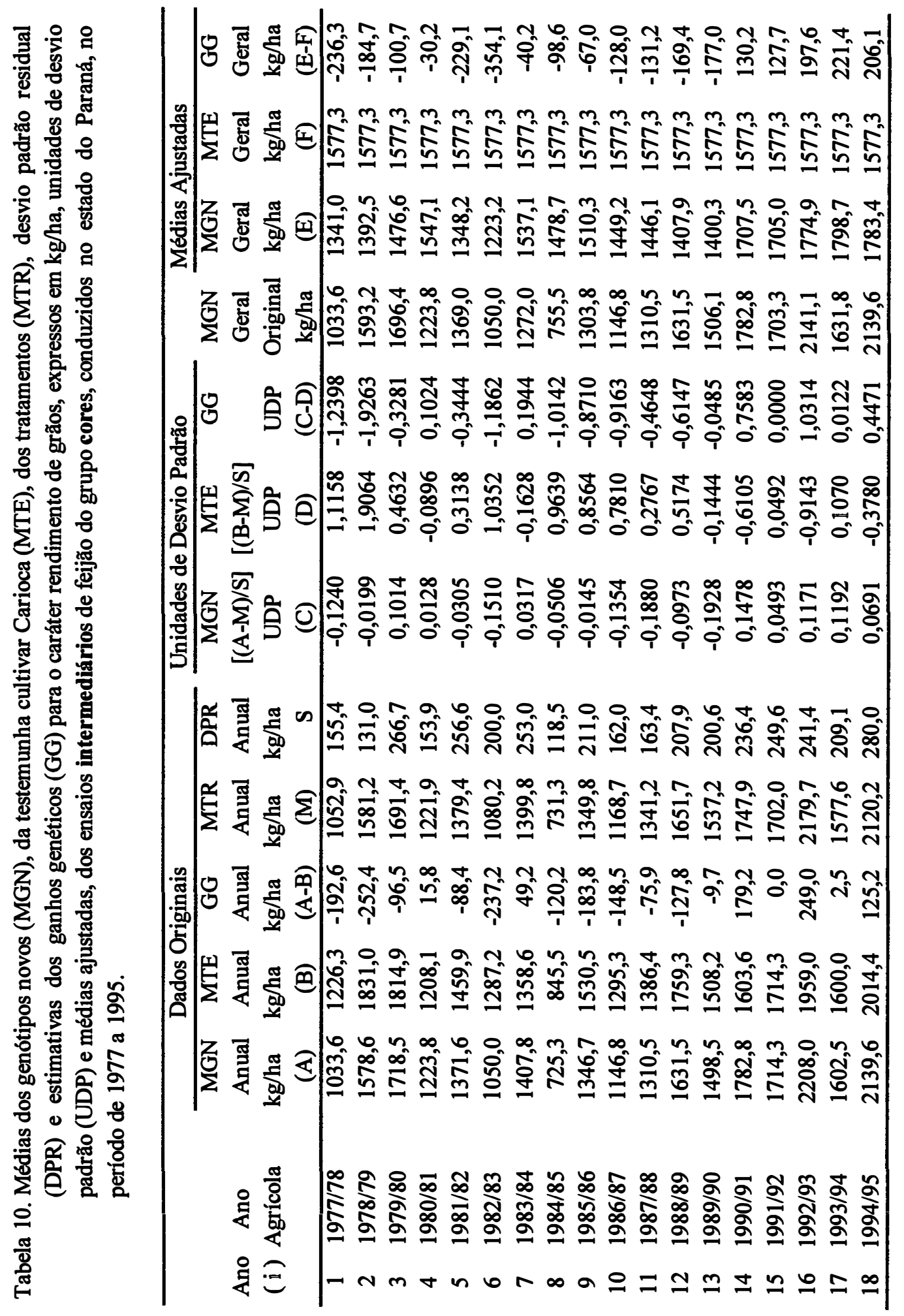




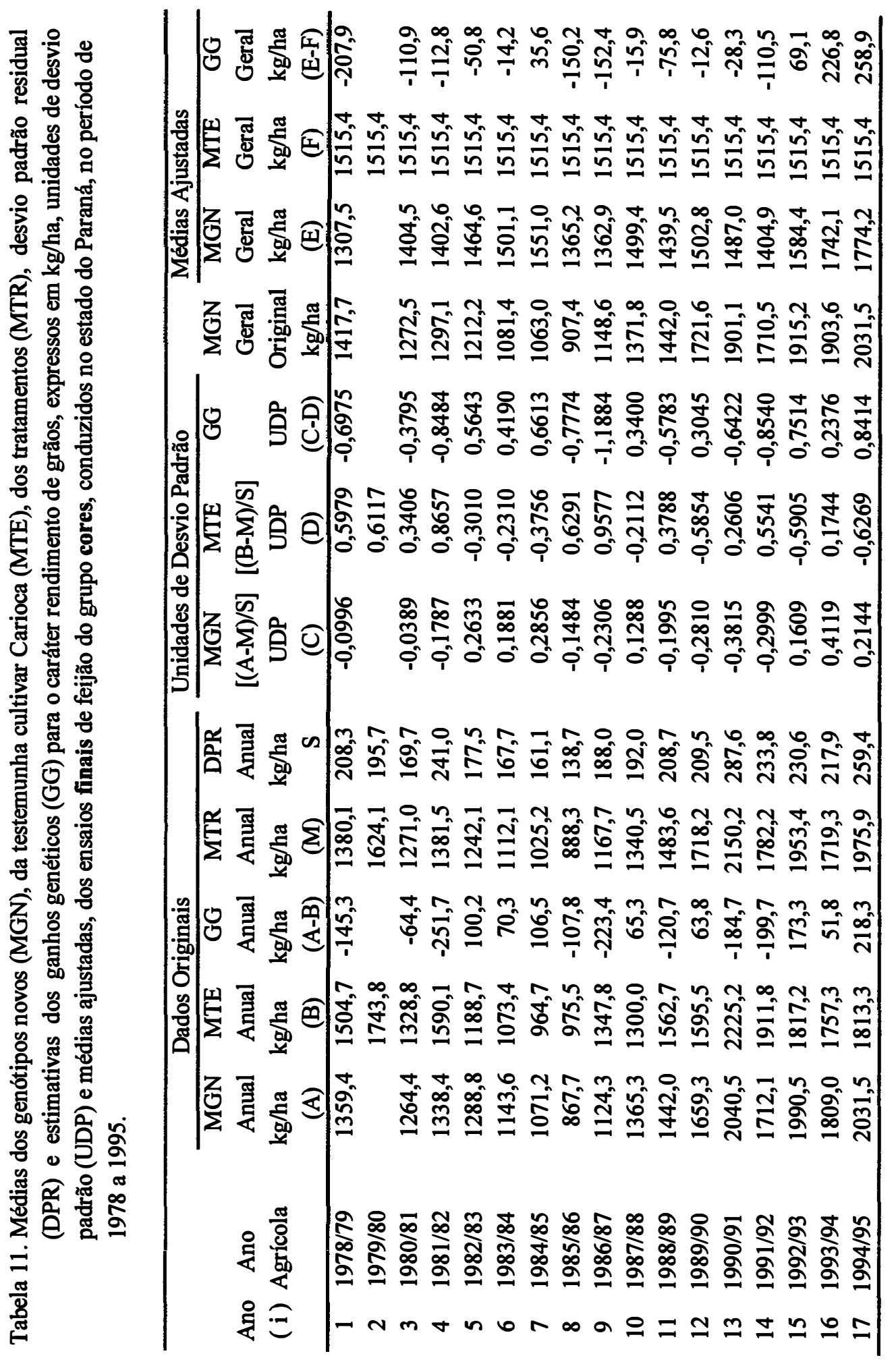




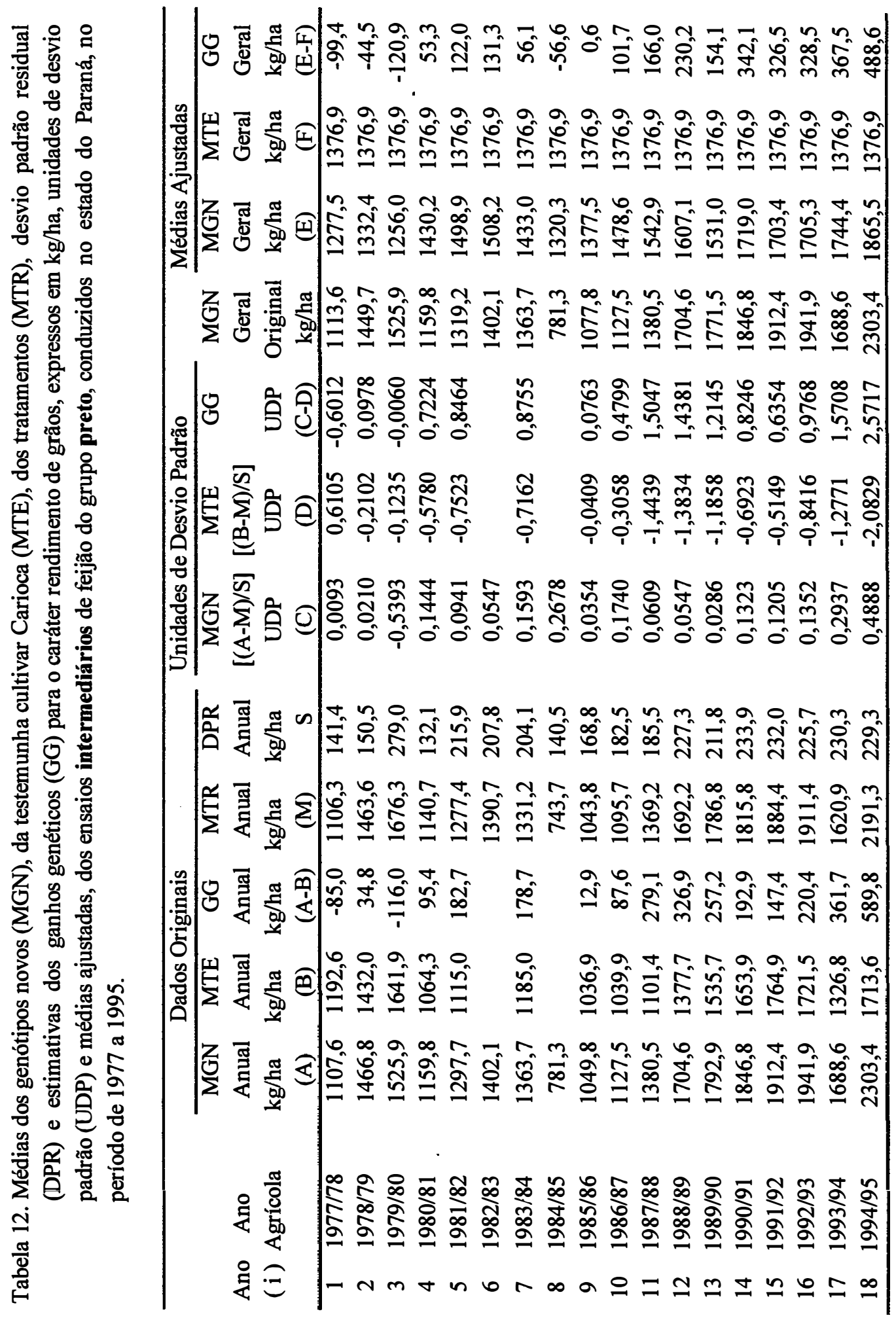




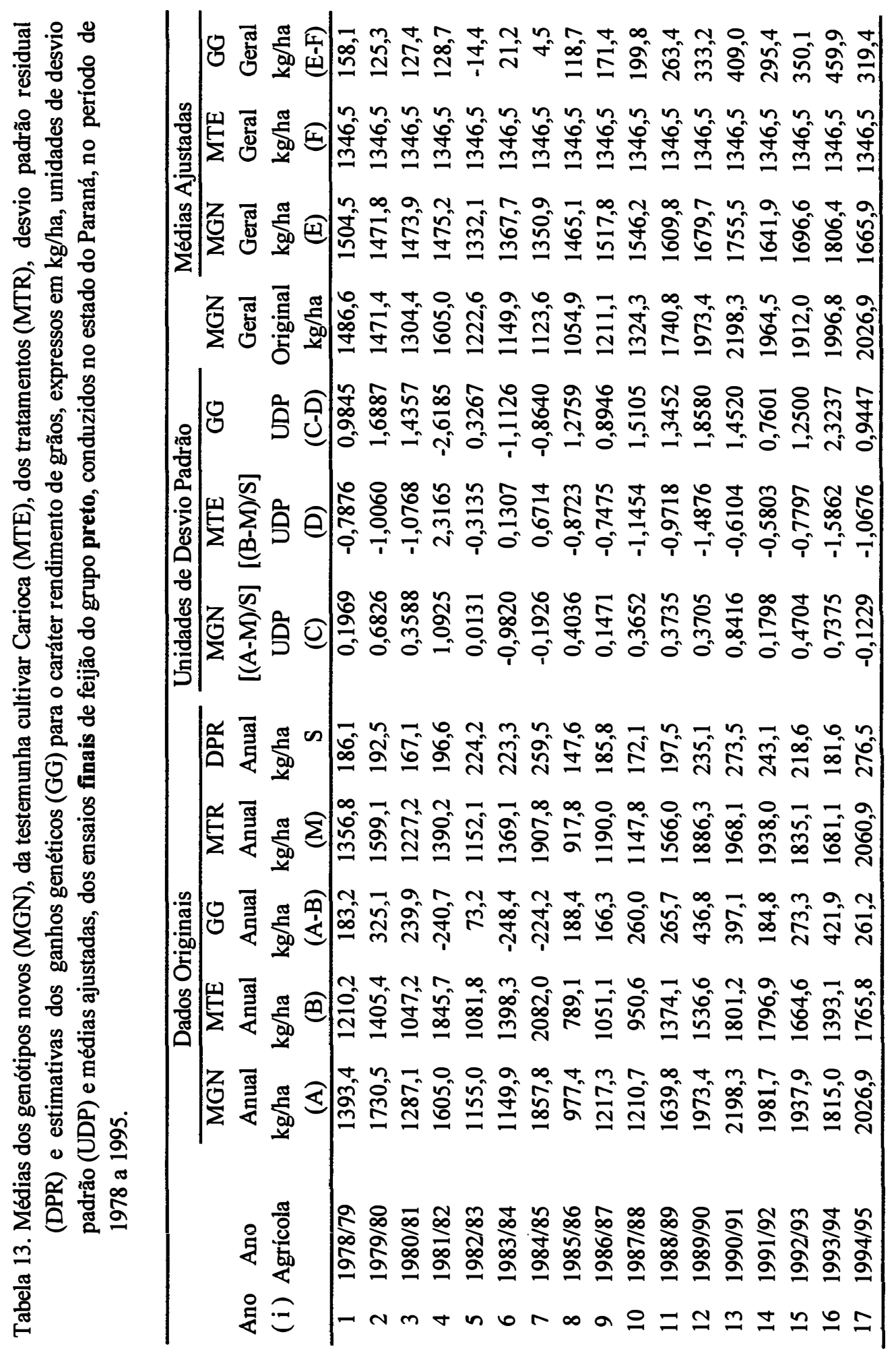




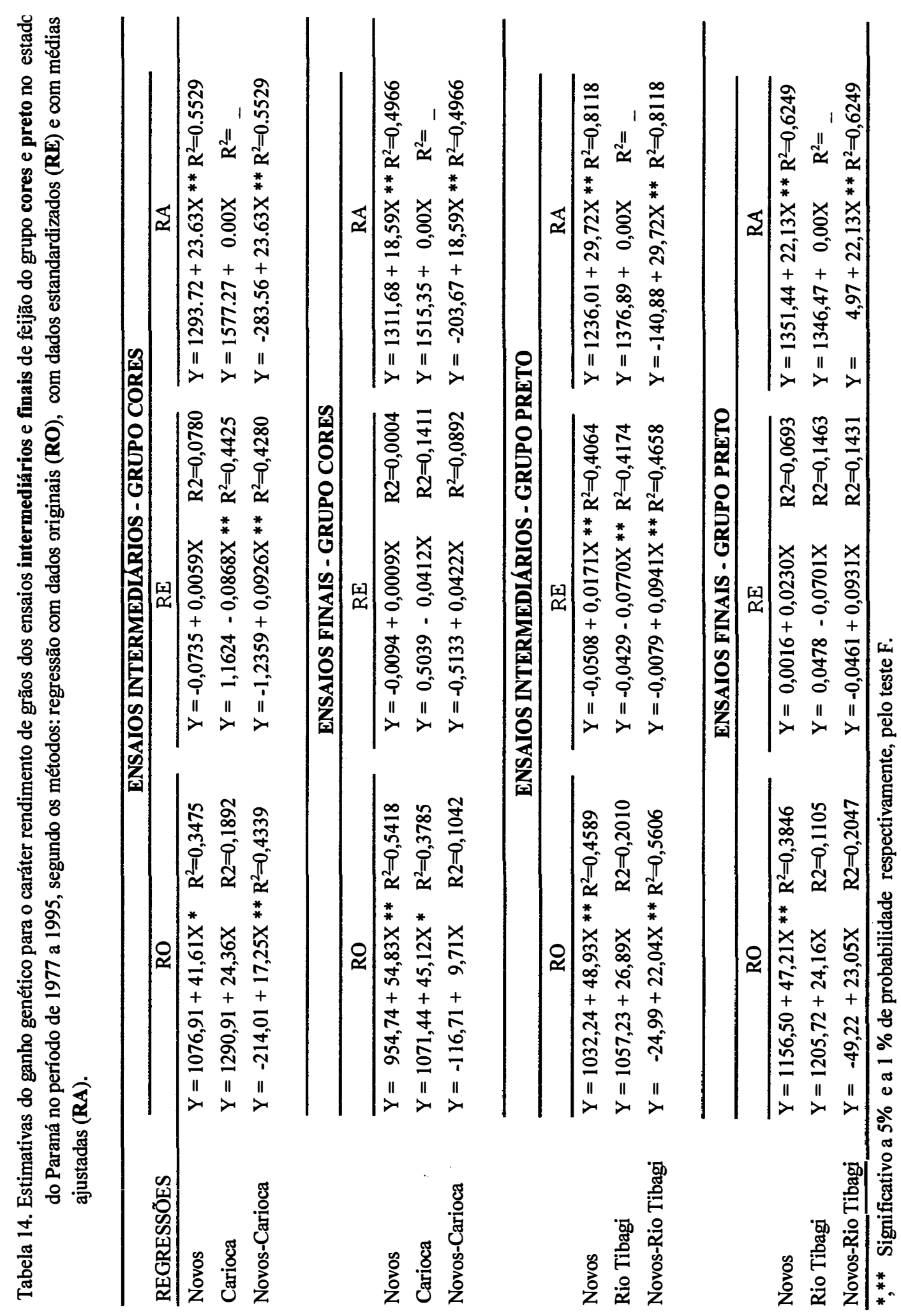


Tabela 15. Estimativas e erros padrões dos ganhos genéticos anuais médios, em $\mathrm{kg} / \mathrm{ha}$ e porcentagem, e respectivos detalhamentos obtidos pelos métodos Original (VO), Ponderado 1 (VP1) e 2 (VP2), regressão original (RO), regressão com dados estandardizados (RE) e com médias ajustadas (RA), referentes aos ensaios intermediários de feijão do grupo cores, no período de 1977 a 1995, no estado do Paraná.

\begin{tabular}{|c|c|c|c|c|c|c|c|c|}
\hline \multirow[b]{2}{*}{ Itens } & \multicolumn{8}{|c|}{ MÉTODOS } \\
\hline & VO & VP1 & VP2 & $\mathrm{RO}$ & & $\mathrm{RE}$ & & $\mathrm{RA}$ \\
\hline$\overline{\text { Ganho (kg/ha) }}$ & 35,2526 & $41,1582 \quad * *$ & $43,2874^{* *}$ & $17,2464 *$ & ** & 20,4368 & ${ }^{* *}$ & $23,6290^{* *}$ \\
\hline Ganho (\%) & 3,3481 & 2,7945 & 2,9391 & 1,6015 & & 1,3166 & & 1,8264 \\
\hline Erro Padrão (kg/ha) & 27,7793 & 4,8425 & 4,1154 & 4,9250 & & 5,9061 & & 5,3127 \\
\hline Erro Padrão (\%) & 2,6384 & 0,3288 & 0,2794 & 0,4571 & & 0,3805 & & 0,4107 \\
\hline Média de Referência (kg/ha) & 1052,9 & 1472,8 & 1472,8 & 1076,9 & & 1552,3 & & 1293,7 \\
\hline Número de Genótipos & 274 & 274 & 274 & 274 & & 274 & & 274 \\
\hline Número de Experimentos & 109 & 109 & 109 & 109 & & 109 & & 109 \\
\hline Número de Anos & 18 & 18 & 18 & 18 & & 18 & & 18 \\
\hline $\mathrm{R}^{2}$ & & & & 0,4339 & & 0,4280 & & 0,5529 \\
\hline QM Erro Conjunto & 48689 & 48689 & 48689 & 48689 & & 1 & & 48689 \\
\hline Média Harmônica de reps. (R) & & 3,5466 & & 3,5466 & & 3,5466 & & 3,5466 \\
\hline Média Harmônica de exps. (E) & & 4,7722 & & 4,7722 & & 4,7722 & & 4,7722 \\
\hline [(QM Erro Conjunto)/(R.E)] & & 2877 & & 2877 & & 0,0591 & & 2877 \\
\hline GL Erro Cojunto & & & & 5060 & & 5060 & & 5060 \\
\hline QM Regressão & & & & 144109 & ++ & 4,1561 & ++ & $270511++$ \\
\hline SQ $X(X=$ Anos $)$ & & & & 484,5 & & 0,01 & & 484,5 \\
\hline QM Desvio da Regressão & & & & 11752,0 & ++ & 0,3471 & ++ & $13674,7++$ \\
\hline GL Desvio da Regressão & & & & 16 & & 16 & & 16 \\
\hline Teste F do Desvio da Regressão & & & & 4,0850 & ++ & 5,8747 & ++ & $4,7540++$ \\
\hline
\end{tabular}


Tabela 16. Estimativas e erros padrões dos ganhos genéticos anuais médios, em $\mathrm{kg} / \mathrm{ha}$ e porcentagem, e respectivos detalhamentos obtidos pelos métodos Original (VO), Ponderado 1 (VP1) e 2 (VP2), regressão original (RO), regressão com dados estandardizados (RE) e com médias ajustadas (RA), referentes aos ensaios finais de feijão do grupo cores, no periodo de 1978 a 1995, no estado do Paraná.

\begin{tabular}{|c|c|c|c|c|c|c|c|}
\hline \multirow[b]{2}{*}{ Itens } & \multicolumn{7}{|c|}{ MÉTODOS } \\
\hline & $\mathrm{VO}$ & VP1 & VP2 & $\mathrm{RO}$ & $\mathrm{RE}$ & RA & \\
\hline Ganho (kg/ha) & 21,232 & $22,849 * *$ & $23,432 * *$ & $\overline{9,7102}$ & 8,7503 & 18,588 & ** \\
\hline Ganho (\%) & 1,5384 & 1,5417 & 1,5811 & 1,017 & 0,5941 & 1,4171 & \\
\hline Erro Padrão (kg/ha) & 15,8403 & 1,8426 & 1,7602 & 7,6093 & 7,4752 & 5,0022 & \\
\hline Erro Padrão (\%) & 1,1477 & 0,1243 & 0,1188 & 0,797 & 0,5076 & 0,3814 & \\
\hline Média de Referência (kg/ha) & 1380,1 & 1482,0 & 1482,0 & 954,7 & 1472,8 & 1311,7 & \\
\hline Número de Genótipos & 94 & 94 & 94 & 94 & 94 & 94 & \\
\hline Número de Experimentos & 245 & 245 & 245 & 245 & 245 & 245 & \\
\hline Número de Anos & 17 & 17 & 17 & 16 & 16 & 16 & \\
\hline $\mathrm{R}^{2}$ & & & & 0,1042 & 0,0892 & 0,4966 & \\
\hline QM Erro Conjunto & 42942 & 42942 & & 43067 & 1 & 43067 & \\
\hline Média Harmônica de reps. (R) & & 4 & & 4 & 4 & 4 & \\
\hline Média Harmônica de exps. (E) & & 13,71 & & 13,69 & 13,69 & 13,69 & \\
\hline [(QM Erro Conjunto)/(R.E)] & & 783,2 & & 786,5 & 0,0183 & 786,5 & \\
\hline GL Erro Cojunto & & & & 7812 & 7812 & 7812 & \\
\hline QM Regressão & & & & 33561 & 0,4618 & 122980 & ++ \\
\hline SQ $X(X=$ Anos $)$ & & & & 355,94 & 0,0083 & 355,94 & \\
\hline QM Desvio da Regressão & & & & $20609,6++$ & $0,4618++$ & 8906,2 & ++ \\
\hline GL Desvio da Regressão & & & & 14 & 14 & 14 & \\
\hline Teste F do Desvio da Regressão & & & & $26,205++$ & $25,289++$ & 11,324 & ++ \\
\hline
\end{tabular}


Tabela 17. Estimativas e erros padrões dos ganhos genéticos anuais médios, em $\mathrm{kg} / \mathrm{ha}$ e porcentagem, e respectivos detalhamentos obtidos pelos métodos Original (VO), Ponderado 1 (VP1) e 2 (VP2), regressão original (RO), regressão com dados estandardizados (RE) e com médias ajustadas (RA), referentes aos ensaios intermediários de feijão do grupo preto, no periodo de 1977 a 1995, no estado do Paraná.

\begin{tabular}{|c|c|c|c|c|c|c|c|c|}
\hline \multirow[b]{2}{*}{ Itens } & \multicolumn{8}{|c|}{ MÉTODOS } \\
\hline & VO & VP1 & VP2 & RO & & $\mathrm{RE}$ & & $\mathrm{RA}$ \\
\hline Ganho (kg/ha) & $58,6866^{* *}$ & $43,5618^{* *}$ & $40,314^{* *}$ & 22,044 & *** & 20,295 & ** & $29,724^{* *}$ \\
\hline Ganho (\%) & 5,3047 & 2,9385 & 2,7194 & 2,1355 & & 1,3262 & & 2,4048 \\
\hline Erro Padrão (kg/ha) & 18,2818 & 5,0144 & 4,1321 & 4,8788 & & 5,4339 & & 3,5783 \\
\hline Erro Padrão (\%) & 1,6525 & 0,3383 & 0,2787 & 0,4726 & & 0,3551 & & 0,2895 \\
\hline Média de Referência (kg/ha) & 1106,3 & 1482,4 & 1482,4 & 1032,2 & & 1530,3 & & 1236,0 \\
\hline Número de Genótipos & 187 & 187 & 187 & 187 & & 187 & & 187 \\
\hline Número de Experimentos & 99 & 99 & 99 & 99 & & 99 & & 99 \\
\hline Número de Anos & 18 & 18 & 18 & 18 & & 18 & & 18 \\
\hline $\mathrm{R}^{2}$ & & & & 0,5606 & & 0,4658 & & 0,8118 \\
\hline QM Erro Conjunto & 46514 & 46514 & 46514 & 46514 & & 1 & & 46514 \\
\hline Média Harmônica de reps. (R) & & 3,65 & & 3,65 & & 3,65 & & 3,65 \\
\hline Média Harmônica de exps. (E) & & 4,73 & & 4,73 & & 4,73 & & 4,73 \\
\hline [(QM Erro Conjunto)/(R.E)] & & 2697,5 & & 2697,5 & & 0,06 & & 2697,5 \\
\hline GL Erro Cojunto & & & & 3429 & & 3429 & & 3429 \\
\hline QM Regressão & & & & 235434 & + & 4,2904 & h+ & $428060++$ \\
\hline SQ $X(X=A n o s)$ & & & & 484,5 & & 0,0104 & & 484,5 \\
\hline QM Desvio da Regressão & & & & 11532,2 & ++ & 0,3076 & ++ & $6203,6++$ \\
\hline GL Desvio da Regressão & & & & 16 & & 16 & & 16 \\
\hline Teste F do Desvio da Regressão & & & & 4,2750 & + & 5,3040 & ++ & $2,3000++$ \\
\hline
\end{tabular}

*;* Significativo a $5 \%$ e $1 \%$ de probabilidade respectivamente, pelo teste t.

,++ Signifactivo a $5 \%$ e $1 \%$ de probabilidade respectivamente, pelo teste $\mathrm{F}$. 
Tabela 18. Estimativas e erros padrões dos ganhos genéticos anuais médios. em $\mathrm{kg} / \mathrm{ha}$ e porcentagem, e respectivos detalhamentos obtidos pelos métodos Original (VO), Ponderado 1 (VP1) e 2 (VP2), regressão original (RO), regressão com dados estandardizados (RE) e com médias ajustadas (RA), referentes aos ensaios finais de feijão do grupo preto, no período de 1978 a 1995, no estado do Paraná.

\begin{tabular}{|c|c|c|c|c|c|c|}
\hline \multirow[b]{2}{*}{ Itens } & \multicolumn{6}{|c|}{ MÉTODOS } \\
\hline & VO & VP1 & VP2 & RO & $\mathrm{RE}$ & RA \\
\hline$\overline{\text { Ganho (kg/ha) }}$ & $47,3233^{*}$ & $10,1731^{* *}$ & $19,1173 * *$ & 23,046 & 19,418 & $22,135 * *$ \\
\hline Ganho (\%) & 3,4879 & 0,6554 & 1,2317 & 1,9928 & 1,2921 & 1,6379 \\
\hline Erro Padrão (kg/ha) & 16,8301 & 2,0993 & 1,9989 & 11,729 & 12,268 & 4,4276 \\
\hline Erro Padrão (\%) & 1,6525 & 0,3383 & 0,2787 & 1,0142 & 0,8163 & 0,3276 \\
\hline Média de Referência (kg/ha) & 1356,8 & 1552,1 & 1552,1 & 1156,5 & 1502,8 & 1351,4 \\
\hline Número de Genótipos & 98 & 98 & 98 & 98 & 98 & 98 \\
\hline Número de Experimentos & 189 & 189 & 189 & 189 & 189 & 189 \\
\hline Número de Anos & 17 & 17 & 17 & 17 & 17 & 17 \\
\hline $\mathrm{R}^{2}$ & & & & 0,2047 & 0,1431 & 0,6249 \\
\hline QM Erro Conjunto & 43531 & 43531 & & 43531 & 1 & 43531 \\
\hline Média Harmônica de reps. (R) & & 4 & & 4 & 4 & 4 \\
\hline Média Harmônica de exps. (E) & & 8,8616 & & 8,8616 & 8,8616 & 8,8616 \\
\hline [(QM Erro Conjunto)/(R.E)] & & 1228,1 & & 1228,1 & 0,0282 & 1228,1 \\
\hline GL Erro Cojunto & & & & 6015 & 6015 & 6015 \\
\hline QM Regressão & & & & 216703 & 3,5341 & $199900++$ \\
\hline SQ $X(X=$ Anos $)$ & & & & 408 & 0,0094 & 408 \\
\hline QM Desvio da Regressão & & & & $56129,3++$ & $1,4106+$ & $7998,2++$ \\
\hline GL Desvio da Regressão & & & & 15 & 15 & 15 \\
\hline Teste F do Desvio da Regressão & & & & $45,705++$ & $49,999++$ & $6,513++$ \\
\hline
\end{tabular}


Tabela 19. Médias gerais originais e ajustadas das testemunhas nos respectivos ensaios regionais de feijão da rede paranaense no período de 1977 a 1995.

\begin{tabular}{|c|c|c|c|c|c|}
\hline \multirow[b]{2}{*}{ Ensaios } & \multirow[b]{2}{*}{ Testemunhas } & \multicolumn{2}{|c|}{ Dados Originais } & \multicolumn{2}{|c|}{ Dados Ajustados } \\
\hline & & $\begin{array}{l}\text { Média } \\
(\mathrm{kg} / \mathrm{ha})\end{array}$ & $\begin{array}{c}\text { Número de } \\
\text { Experimentos }\end{array}$ & $\begin{array}{l}\text { Média } \\
(\mathrm{kg} / \mathrm{ha})\end{array}$ & $\begin{array}{c}\text { Total de } \\
\text { Experimentos }\end{array}$ \\
\hline Intermediário Cores & Carioca & 1577,27 & 109 & 1577,27 & 109 \\
\hline Final Cores & Carioca & 1515,35 & 245 & 1515,35 & 245 \\
\hline Intermediário Preto & Rio Tibagi & 1403,79 & 92 & 1376,89 & 99 \\
\hline Final Preto & Rio Tibagi & 1369,03 & 176 & 1346,47 & 189 \\
\hline
\end{tabular}

Tabela 20. Estimativas do ganho genético médio anual, em função dos métodos de estimação e dos grupos de ensaios de feijão, em kg/ha e percentagem.

\begin{tabular}{lll}
\hline Métodos & GRUPO CORES & GRUPO PRETO \\
${$\cline { 2 - 3 }$} }$ & Intermediários Finais \\
\hline
\end{tabular}

Estimativas expressas em $\mathrm{kg} / \mathrm{ha}$

\begin{tabular}{lllll} 
VO & 35,3 & 21,2 & $58,7 * *$ & $47,3 *$ \\
VP1 & $41,2 * *$ & $22,9 * *$ & $43,6 * *$ & $10,2 * *$ \\
VP2 & $43,3 * *$ & $23,4 * *$ & $40,3 * *$ & $19,1 * *$ \\
RO & $17,3 * *$ & 9,7 & $22,0 * *$ & 23,1 \\
RE & $20,4 * *$ & 8,8 & $20,3 * *$ & 19,4 \\
RA & $23,6 * *$ & $18,6 * *$ & $29,7 * *$ & $22,1 * *$ \\
& \multicolumn{5}{c}{} \\
& \multicolumn{5}{c}{ Estimativas expressas em $\mathbf{( \% )}$} \\
VO & 3,35 & 1,54 & $5,31 * *$ & $3,49 *$ \\
VP1 & $2,80 * *$ & $1,54 * *$ & $2,94 * *$ & $0,66 * *$ \\
VP2 & $2,94 * *$ & $1,58 * *$ & $2,72 * *$ & $1,23 * *$ \\
RO & $1,60 * *$ & 1,02 & $2,14 * *$ & 1,99 \\
RE & $1,32 * *$ & 0,59 & $1,33 * *$ & 1,29 \\
RA & $1,83 * *$ & $1,42 * *$ & $2,41 * *$ & $1,64 * *$ \\
\hline
\end{tabular}

${ }^{* * * *}$ Significativo a $5 \%$ e a $1 \%$ de probabilidade pelo teste $t$ respectivamente. 
Tabela 21. Taxa de renovação de genótipos testados nos ensaios intermediánios e finais de feijão do grupo cores no período de 1977 a 1995 no estado do Paraná.

\begin{tabular}{|c|c|c|c|c|c|c|c|}
\hline \multirow[b]{2}{*}{ Ano } & \multirow[b]{2}{*}{$\begin{array}{c}\text { Ano } \\
\text { Agrícola }\end{array}$} & \multicolumn{3}{|c|}{ Ensaios Intermediários } & \multicolumn{3}{|c|}{ Ensaios Finais } \\
\hline & & $\begin{array}{c}\text { Número de } \\
\text { Genótipos } \\
\text { Novos }\end{array}$ & $\begin{array}{l}\text { Número de } \\
\text { Tratamentos }\end{array}$ & $\begin{array}{c}\text { Taxa } \\
\text { de } \\
\text { Renovação }\end{array}$ & $\begin{array}{l}\text { Número de } \\
\text { Genótipos } \\
\text { Novos }\end{array}$ & $\begin{array}{l}\text { Número de } \\
\text { Tratamentos }\end{array}$ & $\begin{array}{c}\text { Taxa } \\
\text { de } \\
\text { Renovação }\end{array}$ \\
\hline 1 & $1977 / 78$ & 9 & 10 & 90,0 & - & - & - \\
\hline 2 & 1978/79 & 14 & 16 & 87,5 & 2 & 5 & 40,0 \\
\hline 3 & 1979/80 & 2 & 11 & 18,2 & 0 & 6 & 0,0 \\
\hline 4 & $1980 / 81$ & 7 & 8 & 87,5 & 4 & 8 & 50,0 \\
\hline 5 & $1981 / 82$ & 44 & 48 & 91,7 & 5 & 11 & 45,5 \\
\hline 6 & $1982 / 83$ & 24 & 27 & 88,9 & 7 & 16 & 43,8 \\
\hline 7 & $1983 / 84$ & 33 & 36 & 91,7 & 5 & 14 & 35,7 \\
\hline 8 & $1984 / 85$ & 15 & 32 & 46,9 & 5 & 14 & 35,7 \\
\hline 9 & $1985 / 86$ & 5 & 12 & 41,7 & 10 & 15 & 66,7 \\
\hline 10 & $1986 / 87$ & 10 & 14 & 71,4 & 7 & 14 & 50,0 \\
\hline 11 & $1987 / 88$ & 11 & 14 & 78,6 & 4 & 12 & 33,3 \\
\hline 12 & $1988 / 89$ & 16 & 18 & 88,9 & 6 & 12 & 50,0 \\
\hline 13 & $1989 / 90$ & 17 & 20 & 85,0 & 5 & 10 & 50,0 \\
\hline 14 & 1990/91 & 16 & 20 & 80,0 & 2 & 8 & 25,0 \\
\hline 15 & 1991/92 & 16 & 20 & 80,0 & 8 & 16 & 50,0 \\
\hline 16 & $1992 / 93$ & 16 & 20 & 80,0 & 5 & 14 & 35,7 \\
\hline 17 & 1993/94 & 6 & 12 & 50,0 & 4 & 14 & 28,6 \\
\hline \multirow[t]{3}{*}{18} & $1994 / 95$ & 7 & 10 & 70,0 & 4 & 13 & 30,8 \\
\hline & Total & 268 & 348 & & 83 & 202 & \\
\hline & Média & 14,9 & 19,3 & 77,0 & 4,9 & 11,9 & 41,1 \\
\hline
\end{tabular}

Tabela 22. Taxa de renovação de genótipos testados nos ensaios intermediánios e finais de feijão do grupo preto no período de 1977 a 1995 no estado do Paraná.

\begin{tabular}{|c|c|c|c|c|c|c|c|}
\hline \multirow[b]{2}{*}{ Ano } & \multirow[b]{2}{*}{$\begin{array}{c}\text { Ano } \\
\text { Agrícola }\end{array}$} & \multicolumn{3}{|c|}{ Ensaios Intermediários } & \multicolumn{3}{|c|}{ Ensaios Finais } \\
\hline & & $\begin{array}{c}\text { Número de } \\
\text { Genótipos } \\
\text { Novos }\end{array}$ & $\begin{array}{l}\text { Número de } \\
\text { Tratamentos }\end{array}$ & $\begin{array}{c}\text { Taxa } \\
\text { de } \\
\text { Renovação }\end{array}$ & $\begin{array}{l}\text { Número de } \\
\text { Genótipos } \\
\text { Novos }\end{array}$ & $\begin{array}{l}\text { Número de } \\
\text { Tratamentos }\end{array}$ & $\begin{array}{c}\text { Taxa } \\
\text { de } \\
\text { Renovação }\end{array}$ \\
\hline 1 & $1977 / 78$ & 10 & 12 & 83,3 & - & $=$ & - \\
\hline 2 & 1978/79 & 10 & 11 & 90,9 & 4 & 5 & 80,0 \\
\hline 3 & $1979 / 80$ & 2 & 5 & 40,0 & 1 & 6 & 16,7 \\
\hline 4 & $1980 / 81$ & 4 & 5 & 80,0 & 3 & 6 & 50,0 \\
\hline 5 & $1981 / 82$ & 8 & 9 & 88,9 & 2 & 7 & 28,6 \\
\hline 6 & $1982 / 83$ & 9 & 11 & 81,8 & 14 & 16 & 87,5 \\
\hline 7 & $1983 / 84$ & 8 & 11 & 72,7 & 1 & 16 & 6,3 \\
\hline 8 & $1984 / 85$ & 3 & 4 & 75,0 & 1 & 5 & 20,0 \\
\hline 9 & $1985 / 86$ & 13 & 15 & 86,7 & 9 & 14 & 64,3 \\
\hline 10 & $1986 / 87$ & 10 & 12 & 83,3 & 9 & 16 & 56,3 \\
\hline 11 & $1987 / 88$ & 10 & 12 & 83,3 & 7 & 16 & 43,8 \\
\hline 12 & $1988 / 89$ & 16 & 18 & 88,9 & 6 & 16 & 37,5 \\
\hline 13 & $1989 / 90$ & 17 & 20 & 85,0 & 8 & 18 & 44,4 \\
\hline 14 & 1990/91 & 17 & 20 & 85,0 & 1 & 8 & 12,5 \\
\hline 15 & $1991 / 92$ & 17 & 20 & 85,0 & 11 & 16 & 68,8 \\
\hline 16 & $1992 / 93$ & 16 & 20 & 80,0 & 5 & 14 & 35,7 \\
\hline 17 & 1993/94 & 8 & 12 & 66,7 & 6 & 16 & 37,5 \\
\hline \multirow[t]{3}{*}{18} & $1994 / 95$ & 5 & 8 & 62,5 & 5 & 14 & 35,7 \\
\hline & Total & 183 & 225 & & 93 & 209 & \\
\hline & Média & 10,2 & 12,5 & 81,3 & 5,5 & 12,3 & 44,5 \\
\hline
\end{tabular}


Tabela 23. Exemplo de substituição de genótipos de feijão em 4 anos de testes nos ensaios regionais.

\begin{tabular}{|c|c|c|c|}
\hline \multicolumn{4}{|c|}{$\operatorname{ANOS}(=\mathrm{i})$} \\
\hline$T$ & 2 & 3 & 4 \\
\hline$(i+1,1)$ & $(i+2, i+1)$ & $(i+3, i+2)$ & \\
\hline $01^{\mathrm{t}}<---------->*$ & $01<-------->>$ & $01<--------->$ & 01 \\
\hline $02^{t}<---------->$ & $02<----------->$ & $02<---------->>$ & 02 \\
\hline $03<---------->>$ & 03 & & \\
\hline $04<---------->$ & 04 & & \\
\hline $05<-\infty$ & 05 & & \\
\hline 06 & & & \\
\hline 07 & & & \\
\hline 08 & & & \\
\hline 09 & & & \\
\hline 10 & & & \\
\hline & $11<-------->>$ & 11 & \\
\hline & $12<----------->$ & 12 & \\
\hline & $13<--------->$ & 13 & \\
\hline & 14 & & \\
\hline & 15 & & \\
\hline & & $16<-------->>$ & 16 \\
\hline & & $17<----------->$ & 17 \\
\hline & & $18<---------->$ & 18 \\
\hline & & 19 & \\
\hline & & 20 & \\
\hline & & & 21 \\
\hline & & & 22 \\
\hline & & & 23 \\
\hline & & & 24 \\
\hline & & & 25 \\
\hline
\end{tabular}

${ }^{\natural}:$ Genótipos testemunhas

*<----> : Indicam genótipos comuns em anos consecutivos 
Tabela 24. Cultivares recomendados e testados nos ensaios de competição de genótipos de feijão, no período de 1977 a 1996, no estado do Paraná.

\begin{tabular}{|c|c|c|c|c|c|}
\hline Cultivar & Linhagem & $\begin{array}{l}\text { Número } \\
\text { de } \\
\text { Ambientes }\end{array}$ & $\begin{array}{c}\text { Média } \\
\text { Geral } \\
(\mathrm{kg} / \mathrm{ha}) \\
\end{array}$ & $\begin{array}{c}\text { Comparativo } \\
\text { com a } \\
\text { Testemunha } \\
(\%) \\
\end{array}$ & $\begin{array}{c}\text { Ano } \\
\text { de } \\
\text { Recomendação }\end{array}$ \\
\hline & GRUPO COR & \multicolumn{4}{|c|}{ (Testemunha $=$ Carioca $)$} \\
\hline IAPAR 2-RIO IVAI & AETE $1 / 38$ & 32 & 1574,4 & $-0,2$ & 1980 \\
\hline IAPAR 5-RIO PIQUIRI & RAI 46 + RAI 53 & 21 & 1516,8 & 1,6 & 1981 \\
\hline IAPAR 7-RIO VERMELHO & RAI 12 & 42 & 1290,4 & $-16,3$ & 1982 \\
\hline IAPAR 16 & IAPARBAC 14 & 33 & 1256,1 & 21,9 & 1985 \\
\hline IAPAR 14 & IAPARBAC 38 & 31 & 1203,7 & 19,7 & 1986 \\
\hline FT PAULISTINHA & FT $84-292$ & 29 & 1139,2 & $-13,9$ & 1988 \\
\hline IAPAR 31 & IAPARBAC 204 & 32 & 1412,9 & 5,2 & 1988 \\
\hline IAPAR 57 & MD 806 & 37 & 1663,9 & $-12,3$ & 1992 \\
\hline IAPAR 72 & IAPARMD 820 & 19 & 1686,8 & $-7,2$ & 1995 \\
\hline \multirow[t]{2}{*}{ RUDÁ } & A 285 & 35 & 2069,2 & 12,9 & 1995 \\
\hline & GRUPO PRETO & \multicolumn{4}{|c|}{ (Testemunha = Rio Tibagi) } \\
\hline IAPAR 8-RIO NEGRO & RAI 78 + RAI 79 & 13 & 1416,9 & 11,0 & 1984 \\
\hline IAPAR 20 & RAI 76 & 25 & 1218,1 & 1,7 & 1985 \\
\hline FT 120 & FT 83-120 & 23 & 1363,1 & 43,7 & 1987 \\
\hline FT TARUMÃ & FT 83-86 & 23 & 1012,6 & 6,7 & 1987 \\
\hline IAPAR 44 & RAI 305 & 36 & 1149,0 & 14,4 & 1988 \\
\hline FT NOBRE & FT 90-1849 & 22 & 2155,2 & 32,1 & 1996 \\
\hline
\end{tabular}


Tabela 25. Médias dos genótipos novos (MGN), médias da testemunha cultivar Carioca (MTE) e estimativas dos ganhos genéticos (GG), para o caráter rendimento de grãos, obtidos pelo método de médias ajustadas (RA) em função dos ensaios intermediários de feijão do grupo cores conduzidos no estado do Paraná, no período de 1977 a 1995, desdobrados em safras (águas e secas). Dados em kg/ha.

\begin{tabular}{|c|c|c|c|c|c|c|c|}
\hline \multirow[b]{3}{*}{$\begin{array}{l}\text { Ano } \\
\text { (i) } \\
\end{array}$} & \multirow{3}{*}{$\begin{array}{c}\text { Ano } \\
\text { Agrícola }\end{array}$} & \multicolumn{6}{|c|}{ SAFRAS } \\
\hline & & \multicolumn{3}{|c|}{ Águas } & \multicolumn{3}{|c|}{ Secas } \\
\hline & & $\begin{array}{l}\text { MGN } \\
\text { (A) } \\
\end{array}$ & $\begin{array}{l}\text { MTE } \\
\text { (B) } \\
\end{array}$ & $\begin{array}{c}\text { GG } \\
(\mathrm{A}-\mathrm{B}) \\
\end{array}$ & $\begin{array}{c}\text { MGN } \\
\text { (C) } \\
\end{array}$ & $\begin{array}{l}\text { MTE } \\
\text { (D) } \\
\end{array}$ & $\begin{array}{c}\text { GG } \\
(C-D) \\
\end{array}$ \\
\hline 1 & $1977 / 78$ & 1407,3 & 1680,6 & $-273,4$ & 1280,5 & 1416,5 & $-136,0$ \\
\hline 2 & $1978 / 79$ & 1755,8 & 1680,6 & 75,1 & 951,1 & 1416,5 & $-465,5$ \\
\hline 3 & $1979 / 80$ & 1760,6 & 1680,6 & 79,9 & 1201,5 & 1416,5 & $-215,1$ \\
\hline 4 & $1980 / 81$ & 1703,4 & 1680,6 & 22,8 & 1314,3 & 1416,5 & $-102,2$ \\
\hline 5 & $1981 / 82$ & 1514,5 & 1680,6 & $-166,2$ & 1146,6 & 1416,5 & $-270,0$ \\
\hline 6 & $1982 / 83$ & 1181,8 & 1680,6 & $-498,9$ & 1362,8 & 1416,5 & $-53,7$ \\
\hline 8 & $1984 / 85$ & 1541,4 & 1680,6 & $-139,3$ & 1243,5 & 1416,5 & $-173,0$ \\
\hline 9 & $1985 / 86$ & 1570,7 & 1680,6 & $-109,9$ & 1416,1 & 1416,5 & $-0,4$ \\
\hline 10 & $1986 / 87$ & 1577,6 & 1680,6 & $-103,1$ & 1274,9 & 1416,5 & $-141,6$ \\
\hline 11 & $1987 / 88$ & 1620,4 & 1680,6 & $-60,2$ & 1160,6 & 1416,5 & $-256,0$ \\
\hline 12 & $1988 / 89$ & 1426,4 & 1680,6 & $-254,3$ & 1497,6 & 1416,5 & 81,1 \\
\hline 13 & $1989 / 90$ & 1550,2 & 1680,6 & $-130,5$ & 1150,6 & 1416,5 & $-265,9$ \\
\hline 14 & 1990/91 & 1808,9 & 1680,6 & 128,2 & 1531,1 & 1416,5 & 114,5 \\
\hline 15 & 1991/92 & 1770,8 & 1680,6 & 90,2 & 1534,4 & 1416,5 & 117,9 \\
\hline 16 & $1992 / 93$ & 1940,3 & 1680,6 & 259,7 & 1499,5 & 1416,5 & 82,9 \\
\hline 17 & $1993 / 94$ & 1923,4 & 1680,6 & 242,8 & 1596,5 & 1416,5 & 180,0 \\
\hline 18 & $1994 / 95$ & 2058,2 & 1680,6 & 377,5 & 1376,4 & 1416,5 & $-40,2$ \\
\hline
\end{tabular}


Tabela 26. Médias dos genótipos novos (MGN), médias da testemunha cultivar Carioca (MTE) e estimativas dos ganhos genéticos (GG), para o caráter rendimento de grãos, obtidos pelo método de médias ajustadas (RA) em função dos ensaios finais de feijão do grupo cores conduzidos no estado do Paraná, no período de 1978 a 1995, desdobrados em safras (águas e secas). Dados em kg/ha.

\begin{tabular}{|c|c|c|c|c|c|c|c|}
\hline \multirow[b]{3}{*}{$\begin{array}{l}\text { Ano } \\
\text { (i) }\end{array}$} & \multirow{3}{*}{$\begin{array}{c}\text { Ano } \\
\text { Agrícola }\end{array}$} & \multicolumn{6}{|c|}{ SAFRAS } \\
\hline & & \multicolumn{3}{|c|}{ Águas } & \multicolumn{3}{|c|}{ Secas } \\
\hline & & $\begin{array}{c}\text { MGN } \\
\text { (A) } \\
\end{array}$ & $\begin{array}{l}\text { MTE } \\
\text { (B) } \\
\end{array}$ & $\begin{array}{c}\text { GG } \\
(\mathrm{A}-\mathrm{B}) \\
\end{array}$ & $\begin{array}{c}\text { MGN } \\
\text { (C) } \\
\end{array}$ & $\begin{array}{l}\text { MTE } \\
\text { (D) }\end{array}$ & $\begin{array}{c}G G \\
(C-D)\end{array}$ \\
\hline 1 & $1978 / 79$ & 1382,1 & 1588,7 & $-206,6$ & 1176,0 & 1391,2 & $-215,2$ \\
\hline 3 & $1980 / 81$ & 1618,2 & 1588,7 & 29,5 & 1119,2 & 1391,2 & $-272,0$ \\
\hline 4 & $1981 / 82$ & 1533,1 & 1588,7 & $-55,6$ & 1198,7 & 1391,2 & $-192,5$ \\
\hline 5 & $1982 / 83$ & 1569,8 & 1588,7 & $-18,9$ & 1294,6 & 1391,2 & $-96,6$ \\
\hline 6 & $1983 / 84$ & 1619,7 & 1588,7 & 31,0 & 1320,0 & 1391,2 & $-71,2$ \\
\hline 7 & $1984 / 85$ & 1665,8 & 1588,7 & 77,1 & 1354,3 & 1391,2 & $-36,9$ \\
\hline 8 & $1985 / 86$ & 1436,1 & 1588,7 & $-152,6$ & 1235,9 & 1391,2 & $-155,3$ \\
\hline 9 & $1986 / 87$ & 1423,6 & 1588,7 & $-165,1$ & 1271,2 & 1391,2 & $-120,0$ \\
\hline 10 & $1987 / 88$ & 1616,3 & 1588,7 & 27,6 & 1282,8 & 1391,2 & $-108,4$ \\
\hline 11 & $1988 / 89$ & 1567,6 & 1588,7 & $-21,1$ & 1213,9 & 1391,2 & $-177,3$ \\
\hline 12 & $1989 / 90$ & 1571,0 & 1588,7 & $-17,8$ & 1405,9 & 1391,2 & 14,7 \\
\hline 13 & $1990 / 91$ & 1512,9 & 1588,7 & $-75,8$ & 1423,8 & 1391,2 & 32,6 \\
\hline 14 & $1991 / 92$ & 1450,7 & 1588,7 & $-138,1$ & 1282,7 & 1391,2 & $-108,5$ \\
\hline 15 & $1992 / 93$ & 1730,2 & 1588,7 & 141,5 & 1315,2 & 1391,2 & $-76,0$ \\
\hline 16 & $1993 / 94$ & 1837,2 & 1588,7 & 248,5 & 1571,8 & 1391,2 & 180,7 \\
\hline 17 & $1994 / 95$ & 1926,2 & 1588,7 & 337,5 & 1502,7 & 1391,2 & 111,5 \\
\hline
\end{tabular}


Tabela 27. Médias dos genótipos novos (MGN), médias da testemunha cultivar Carioca (MTE) e estimativas dos ganhos genéticos (GG), para o caráter rendimento de grãos, obtidos pelo método de médias ajustadas (RA) em função dos ensaios intermediários de feijão do grupo preto conduzidos no estado do Paraná, no período de 1977 a 1995, desdobrados em safras (águas e secas). Dados em kg/ha.

\begin{tabular}{|c|c|c|c|c|c|c|c|}
\hline \multirow[b]{3}{*}{$\begin{array}{l}\text { Ano } \\
\text { (i) }\end{array}$} & \multirow{3}{*}{$\begin{array}{c}\text { Ano } \\
\text { Agrícola }\end{array}$} & \multicolumn{6}{|c|}{ SAFRAS } \\
\hline & & \multicolumn{3}{|c|}{ Águas } & \multicolumn{3}{|c|}{ Secas } \\
\hline & & $\begin{array}{c}\text { MGN } \\
\text { (A) } \\
\end{array}$ & $\begin{array}{c}\text { MTE } \\
\text { (B) }\end{array}$ & $\begin{array}{c}\text { GG } \\
\text { (A-B) } \\
\end{array}$ & $\begin{array}{r}\text { MGN } \\
\text { (C) } \\
\end{array}$ & $\begin{array}{c}\text { MTE } \\
\text { (D) }\end{array}$ & $\begin{array}{c}\text { GG } \\
(C-D) \\
\end{array}$ \\
\hline 1 & $1977 / 78$ & 1400,7 & 1499,6 & $-98,8$ & 1077,9 & 1200,8 & $-122,9$ \\
\hline 2 & $1978 / 79$ & 1494,2 & 1499,6 & $-5,3$ & 1102,8 & 1200,8 & $-98,1$ \\
\hline 3 & $1979 / 80$ & 1346,3 & 1499,6 & $-153,3$ & 1596,3 & 1200,8 & 395,4 \\
\hline 4 & $1980 / 81$ & 1477,8 & 1499,6 & $-21,8$ & 1355,7 & 1200,8 & 154,9 \\
\hline 5 & $1981 / 82$ & 1697,5 & 1499,6 & 197,9 & 1213,1 & 1200,8 & 12,3 \\
\hline 6 & $1982 / 83$ & 1689,3 & 1499,6 & 189,8 & 1211,5 & 1200,8 & 10,6 \\
\hline 8 & $1984 / 85$ & 1324,9 & 1499,6 & $-174,7$ & 1057,3 & 1200,8 & $-143,6$ \\
\hline 9 & $1985 / 86$ & 1375,4 & 1499,6 & $-124,2$ & 1290,5 & 1200,8 & 89,6 \\
\hline 10 & $1986 / 87$ & 1543,2 & 1499,6 & 43,6 & 1245,5 & 1200,8 & 44,6 \\
\hline 11 & $1987 / 88$ & 1752,4 & 1499,6 & 252,8 & 1217,9 & 1200,8 & 17,1 \\
\hline 12 & $1988 / 89$ & 1733,7 & 1499,6 & 234,1 & 1428,7 & 1200,8 & 227,9 \\
\hline 13 & $1989 / 90$ & 1645,6 & 1499,6 & 146,0 & 1371,8 & 1200,8 & 171,0 \\
\hline 14 & $1990 / 91$ & 1762,0 & 1499,6 & 262,5 & 1640,7 & 1200,8 & 439,9 \\
\hline 15 & $1991 / 92$ & 1917,7 & 1499,6 & 418,1 & 1454,1 & 1200,8 & 253,2 \\
\hline 16 & $1992 / 93$ & 1906,0 & 1499,6 & 406,4 & 1323,5 & 1200,8 & 122,6 \\
\hline 17 & $1993 / 94$ & 1912,7 & 1499,6 & 413,1 & 1497,7 & 1200,8 & 296,9 \\
\hline 18 & $1994 / 95$ & 2116,4 & 1499,6 & 616,8 & 1443,0 & 1200,8 & 242,1 \\
\hline
\end{tabular}


Tabela 28. Médias dos genótipos novos (MGN), médias da testemunha cultivar Carioca (MTE) e estimativas dos ganhos genéticos (GG), para o caráter rendimento de grãos, obtidos pelo método de médias ajustadas (RA) em função dos ensaios finais de feijão do grupo preto conduzidos no estado do Paraná, no período de 1978 a 1995, desdobrados em safras (águas e secas). Dados em kg/ha.

\begin{tabular}{|c|c|c|c|c|c|c|c|}
\hline \multirow[b]{3}{*}{$\begin{array}{l}\text { Ano } \\
\text { (i) } \\
\end{array}$} & \multirow{3}{*}{$\begin{array}{c}\text { Ano } \\
\text { Agrícola }\end{array}$} & \multicolumn{6}{|c|}{ SAFRAS } \\
\hline & & \multicolumn{3}{|c|}{ Águas } & \multicolumn{3}{|c|}{ Secas } \\
\hline & & $\begin{array}{c}\text { MGN } \\
\text { (A) }\end{array}$ & $\begin{array}{c}\text { MTE } \\
\text { (B) } \\
\end{array}$ & $\begin{array}{c}\text { GG } \\
\text { (A-B) } \\
\end{array}$ & $\begin{array}{c}\text { MGN } \\
\text { (C) } \\
\end{array}$ & $\begin{array}{l}\text { MTE } \\
\text { (D) }\end{array}$ & $\begin{array}{c}\text { GG } \\
\text { (C-D) } \\
\end{array}$ \\
\hline 1 & $1978 / 79$ & 1578,2 & 1502,3 & 75,9 & 1340,6 & 1070,5 & 270,1 \\
\hline 2 & $1979 / 80$ & 1585,9 & 1502,3 & 83,6 & 1260,2 & 1070,5 & 189,8 \\
\hline 3 & $1980 / 81$ & 1589,7 & 1502,3 & 87,4 & 1255,8 & 1070,5 & 185,4 \\
\hline 4 & $1981 / 82$ & 1617,7 & 1502,3 & 115,5 & 1220,6 & 1070,5 & 150,2 \\
\hline 5 & $1982 / 83$ & 1489,2 & 1502,3 & $-13,1$ & 1079,4 & 1070,5 & 8,9 \\
\hline 6 & $1983 / 84$ & 1603,2 & 1502,3 & 100,9 & 997,0 & 1070,5 & $-73,4$ \\
\hline 8 & $1985 / 86$ & 1607,5 & 1502,3 & 105,2 & 1228,6 & 1070,5 & 158,1 \\
\hline 9 & $1986 / 87$ & 1672,9 & 1502,3 & 170,6 & 1240,0 & 1070,5 & 169,5 \\
\hline 10 & $1987 / 88$ & 1707,8 & 1502,3 & 205,5 & 1255,9 & 1070,5 & 185,5 \\
\hline 11 & $1988 / 89$ & 1755,7 & 1502,3 & 253,4 & 1346,1 & 1070,5 & 275,6 \\
\hline 12 & $1989 / 90$ & 1831,0 & 1502,3 & 328,7 & 1406,3 & 1070,5 & 335,9 \\
\hline 13 & $1990 / 91$ & 1853,0 & 1502,3 & 350,7 & 1612,5 & 1070,5 & 542,0 \\
\hline 14 & $1991 / 92$ & 1792,6 & 1502,3 & 290,3 & 1363,5 & 1070,5 & 293,1 \\
\hline 15 & $1992 / 93$ & 1846,7 & 1502,3 & 344,4 & 1440,9 & 1070,5 & 370,4 \\
\hline 16 & $1993 / 94$ & 1996,1 & 1502,3 & 493,8 & 1478,2 & 1070,5 & 407,7 \\
\hline 17 & $1994 / 95$ & 1830,3 & 1502,3 & 328,0 & 1394,2 & 1070,5 & 323,7 \\
\hline
\end{tabular}


Tabela 29. Médias dos genótipos novos (MGN), médias da testemunha cultivar Carioca (MTE) e estimativas dos ganhos genéticos (GG), para o caráter rendimento de grãos, obtidos pelo método de médias ajustadas (RA) em função dos ensaios intermediários de feijão do grupo cores conduzidos no estado do Paraná, no período de 1977 a 1995, desdobrados em regiōes (I e II). Dados em kg/ha.

\begin{tabular}{|c|c|c|c|c|c|c|c|}
\hline \multirow[b]{3}{*}{$\begin{array}{l}\text { Ano } \\
\text { (i) }\end{array}$} & \multirow{3}{*}{$\begin{array}{c}\text { Ano } \\
\text { Agrícola }\end{array}$} & \multicolumn{6}{|c|}{ Regiões } \\
\hline & & \multicolumn{3}{|c|}{ I } & \multicolumn{3}{|c|}{ II } \\
\hline & & $\begin{array}{c}\text { MGN } \\
\text { (A) }\end{array}$ & $\begin{array}{c}\text { MTE } \\
\text { (B) } \\
\end{array}$ & $\begin{array}{c}\text { GG } \\
(\mathrm{A}-\mathrm{B}) \\
\end{array}$ & $\begin{array}{c}\text { MGN } \\
\text { (C) } \\
\end{array}$ & $\begin{array}{c}\text { MTE } \\
\text { (D) } \\
\end{array}$ & $\begin{array}{c}\text { GG } \\
\text { (C-D) }\end{array}$ \\
\hline 1 & $1977 / 78$ & 1218,6 & 1396,0 & $-177,3$ & 1511,3 & 1862,7 & $-351,4$ \\
\hline 2 & $1978 / 79$ & 1352,7 & 1396,0 & $-43,2$ & 1539,5 & 1862,7 & $-323,3$ \\
\hline 3 & $1979 / 80$ & 1379,1 & 1396,0 & $-16,9$ & 1650,3 & 1862,7 & $-212,4$ \\
\hline 4 & $1980 / 81$ & 1330,4 & 1396,0 & $-65,6$ & 1887,9 & 1862,7 & 25,2 \\
\hline 5 & $1981 / 82$ & 1244,5 & 1396,0 & $-151,5$ & 1741,6 & 1862,7 & $-121,1$ \\
\hline 11 & $1987 / 88$ & 1276,8 & 1396,0 & $-119,1$ & 1719,2 & 1862,7 & $-143,5$ \\
\hline 12 & $1988 / 89$ & 1368,9 & 1396,0 & $-27,1$ & 1542,3 & 1862,7 & $-320,4$ \\
\hline 13 & $1989 / 90$ & 1279,7 & 1396,0 & $-116,3$ & 1624,7 & 1862,7 & $-238,0$ \\
\hline 14 & $1990 / 91$ & 1454,5 & 1396,0 & 58,5 & 2064,4 & 1862,7 & 201,7 \\
\hline 15 & $1991 / 92$ & 1547,2 & 1396,0 & 151,2 & 1950,4 & 1862,7 & 87,7 \\
\hline 16 & $1992 / 93$ & 1334,3 & 1396,0 & $-61,6$ & 2200,3 & 1862,7 & 337,6 \\
\hline 17 & $1993 / 94$ & 1443,0 & 1396,0 & 47,0 & 2162,3 & 1862,7 & 299,6 \\
\hline 18 & $1994 / 95$ & 1398,2 & 1396,0 & 2,2 & 2132,5 & 1862,7 & 269,8 \\
\hline
\end{tabular}


Tabela 30. Médias dos genótipos novos (MGN), médias da testemunha cultivar Carioca (MTE) e estimativas dos ganhos genéticos (GG), para o caráter rendimento de grãos, obtidos pelo método de médias ajustadas (RA) em função dos ensaios finais de feijão do grupo cores conduzidos no estado do Paraná, no período de 1978 a 1995, desdobrados em regiōes (I e II). Dados em kg/ha.

\begin{tabular}{|c|c|c|c|c|c|c|c|}
\hline \multirow[b]{3}{*}{$\begin{array}{l}\text { Ano } \\
\text { (i) }\end{array}$} & \multirow[b]{3}{*}{$\begin{array}{c}\text { Ano } \\
\text { Agrícola }\end{array}$} & \multicolumn{6}{|c|}{ Regiões } \\
\hline & & \multicolumn{3}{|c|}{ I } & \multicolumn{3}{|c|}{ II } \\
\hline & & $\begin{array}{l}\text { MGN } \\
\text { (A) }\end{array}$ & $\begin{array}{l}\text { MTE } \\
\text { (B) } \\
\end{array}$ & $\begin{array}{c}\text { GG } \\
\text { (A-B) } \\
\end{array}$ & $\begin{array}{c}\text { MGN } \\
\text { (C) } \\
\end{array}$ & $\begin{array}{l}\text { MTE } \\
\text { (D) } \\
\end{array}$ & $\begin{array}{c}\text { GG } \\
(C-D) \\
\end{array}$ \\
\hline 1 & $1978 / 79$ & 1184,0 & 1352,2 & $-168,1$ & 1539,6 & 1806,5 & $-266,9$ \\
\hline 3 & $1980 / 81$ & 1307,8 & 1352,2 & $-44,4$ & 1587,1 & 1806,5 & $-219,4$ \\
\hline 4 & $1981 / 82$ & 1261,5 & 1352,2 & $-90,7$ & 1653,0 & 1806,5 & $-153,4$ \\
\hline 5 & $1982 / 83$ & 1327,2 & 1352,2 & $-24,9$ & 1609,5 & 1806,5 & $-197,0$ \\
\hline 6 & $1983 / 84$ & 1354,5 & 1352,2 & 2,3 & 1758,8 & 1806,5 & $-47,7$ \\
\hline 7 & $1984 / 85$ & 1410,7 & 1352,2 & 58,6 & 1764,2 & 1806,5 & $-42,3$ \\
\hline 8 & $1985 / 86$ & 1244,5 & 1352,2 & $-107,7$ & 1534,5 & 1806,5 & $-272,0$ \\
\hline 9 & $1986 / 87$ & 1242,6 & 1352,2 & $-109,6$ & 1595,8 & 1806,5 & $-210,6$ \\
\hline 10 & $1987 / 88$ & 1419,1 & 1352,2 & 67,0 & 1691,1 & 1806,5 & $-115,4$ \\
\hline 11 & $1988 / 89$ & 1164,1 & 1352,2 & $-188,1$ & 1796,8 & 1806,5 & $-9,7$ \\
\hline 12 & $1989 / 90$ & 1269,0 & 1352,2 & $-83,2$ & 1868,7 & 1806,5 & 62,3 \\
\hline 13 & $1990 / 91$ & 1293,7 & 1352,2 & $-58,5$ & 1808,3 & 1806,5 & 1,9 \\
\hline 14 & 1991/92 & 1213,5 & 1352,2 & $-138,7$ & 1722,7 & 1806,5 & $-83,8$ \\
\hline 15 & $1992 / 93$ & 1417,4 & 1352,2 & 65,2 & 1866,3 & 1806,5 & 59,9 \\
\hline 16 & $1993 / 94$ & 1557,4 & 1352,2 & 205,2 & 2047,3 & 1806,5 & 240,9 \\
\hline 17 & $1994 / 95$ & 1585,6 & 1352,2 & 233,4 & 2084,6 & 1806,5 & 278,1 \\
\hline
\end{tabular}


Tabela 31. Médias dos genótipos novos (MGN), médias da testemunha cultivar Carioca (MTE) e estimativas dos ganhos genéticos (GG), para o caráter rendimento de grãos, obtidos pelo método de médias ajustadas (RA) em função dos ensaios intermediários de feijão do grupo preto conduzidos no estado do Paraná, no período de 1977 a 1995, desdobrados em regiões (I e II). Dados em kg/ha.

\begin{tabular}{|c|c|c|c|c|c|c|c|}
\hline \multirow[b]{3}{*}{$\begin{array}{l}\text { Ano } \\
\text { (i) }\end{array}$} & \multirow[b]{3}{*}{$\begin{array}{c}\text { Ano } \\
\text { Agrícola } \\
\end{array}$} & \multicolumn{6}{|c|}{ Regiões } \\
\hline & & \multicolumn{3}{|c|}{$\mathrm{I}$} & \multicolumn{3}{|c|}{ II } \\
\hline & & $\begin{array}{r}\text { MGN } \\
\text { (A) } \\
\end{array}$ & $\begin{array}{l}\text { MTE } \\
\text { (B) } \\
\end{array}$ & $\begin{array}{c}G G \\
(A-B) \\
\end{array}$ & $\begin{array}{c}\text { MGN } \\
\text { (C) } \\
\end{array}$ & $\begin{array}{l}\text { MTE } \\
\text { (D) } \\
\end{array}$ & $\begin{array}{c}\text { GG } \\
\text { (C-D) } \\
\end{array}$ \\
\hline 1 & $1977 / 78$ & 1069,3 & 1075,6 & $-6,2$ & 1322,2 & 1604,6 & $-282,4$ \\
\hline 2 & $1978 / 79$ & 1127,2 & 1075,6 & 51,6 & 1487,1 & 1604,6 & $-117,5$ \\
\hline 3 & $1979 / 80$ & 925,6 & 1075,6 & $-150,0$ & 1503,0 & 1604,6 & $-101,6$ \\
\hline 4 & $1980 / 81$ & 1269,1 & 1075,6 & 193,5 & 1522,7 & 1604,6 & $-81,9$ \\
\hline 5 & $1981 / 82$ & 1247,6 & 1075,6 & 172,0 & 1898,3 & 1604,6 & 293,7 \\
\hline 9 & $1985 / 86$ & 1063,4 & 1075,6 & $-12,1$ & 1666,0 & 1604,6 & 61,4 \\
\hline 11 & $1987 / 88$ & 1399,2 & 1075,6 & 323,6 & 1704,4 & 1604,6 & 99,8 \\
\hline 12 & 1988/89 & 1435,2 & 1075,6 & 359,6 & 1814,8 & 1604,6 & 210,2 \\
\hline 13 & $1989 / 90$ & 1212,3 & 1075,6 & 136,7 & 1758,8 & 1604,6 & 154,1 \\
\hline 14 & 1990/91 & 1441,4 & 1075,6 & 365,8 & 1930,4 & 1604,6 & 325,8 \\
\hline 16 & $1992 / 93$ & 1520,4 & 1075,6 & 444,8 & 1889,7 & 1604,6 & 285,1 \\
\hline 17 & $1993 / 94$ & 1532,7 & 1075,6 & 457,1 & 1948,7 & 1604,6 & 344,0 \\
\hline 18 & $1994 / 95$ & 1856,7 & 1075,6 & 781,1 & 2023,9 & 1604,6 & 419,3 \\
\hline
\end{tabular}


Tabela 32. Médias dos genótipos novos (MGN), médias da testemunha cultivar Carioca (MTE) e estimativas dos ganhos genéticos (GG), para o caráter rendimento de grãos, obtidos pelo método de médias ajustadas (RA) em função dos ensaios finais de feijão do grupo preto conduzidos no estado do Paraná, no período de 1978 a 1995, desdobrados em regióes (I e II). Dados em kg/ha.

\begin{tabular}{|c|c|c|c|c|c|c|c|}
\hline \multirow[b]{3}{*}{$\begin{array}{l}\text { Ano } \\
\text { (i) } \\
\end{array}$} & \multirow{3}{*}{$\begin{array}{c}\text { Ano } \\
\text { Agrícola }\end{array}$} & \multicolumn{6}{|c|}{ Regiões } \\
\hline & & \multicolumn{3}{|c|}{ I } & \multicolumn{3}{|c|}{ II } \\
\hline & & $\begin{array}{c}\text { MGN } \\
\text { (A) } \\
\end{array}$ & $\begin{array}{c}\text { MTE } \\
\text { (B) } \\
\end{array}$ & $\begin{array}{c}\text { GG } \\
(\mathrm{A}-\mathrm{B}) \\
\end{array}$ & $\begin{array}{c}\text { MGN } \\
\text { (C) } \\
\end{array}$ & $\begin{array}{l}\text { MTE } \\
\text { (D) }\end{array}$ & $\begin{array}{c}\text { GG } \\
\text { (C-D) } \\
\end{array}$ \\
\hline 1 & $1978 / 79$ & 1317,5 & 1119,4 & 198,1 & 1674,0 & 1540,4 & 133,5 \\
\hline 2 & $1979 / 80$ & 1304,5 & 1119,4 & 185,1 & 1625,0 & 1540,4 & 84,5 \\
\hline 3 & $1980 / 81$ & 1314,4 & 1119,4 & 195,0 & 1607,7 & 1540,4 & 67,2 \\
\hline 4 & $1981 / 82$ & 1291,1 & 1119,4 & 171,7 & 1716,2 & 1540,4 & 175,7 \\
\hline 5 & $1982 / 83$ & 1152,3 & 1119,4 & 32,9 & 1509,4 & 1540,4 & $-31,1$ \\
\hline 6 & $1983 / 84$ & 1451,7 & 1119,4 & 332,3 & 1368,7 & 1540,4 & $-171,8$ \\
\hline 7 & $1984 / 85$ & 1280,8 & 1119,4 & 161,4 & 1494,7 & 1540,4 & $-45,8$ \\
\hline 8 & $1985 / 86$ & 1245,5 & 1119,4 & 126,1 & 1668,2 & 1540,4 & 127,8 \\
\hline 9 & $1986 / 87$ & 1310,0 & 1119,4 & 190,6 & 1682,7 & 1540,4 & 142,2 \\
\hline 10 & $1987 / 88$ & 1376,1 & 1119,4 & 256,7 & 1680,5 & 1540,4 & 140,1 \\
\hline 11 & $1988 / 89$ & 1466,7 & 1119,4 & 347,2 & 1746,1 & 1540,4 & 205,7 \\
\hline 12 & $1989 / 90$ & 1608,3 & 1119,4 & 488,9 & 1820,2 & 1540,4 & 279,8 \\
\hline 13 & $1990 / 91$ & 1553,3 & 1119,4 & 433,9 & 1937,8 & 1540,4 & 397,3 \\
\hline 14 & $1991 / 92$ & 1504,2 & 1119,4 & 384,8 & 1775,9 & 1540,4 & 235,5 \\
\hline 15 & $1992 / 93$ & 1463,7 & 1119,4 & 344,3 & 1880,2 & 1540,4 & 339,8 \\
\hline 16 & 1993/94 & 1630,6 & 1119,4 & 511,2 & 1961,1 & 1540,4 & 420,7 \\
\hline 17 & $1994 / 95$ & 1421,0 & 1119,4 & 301,6 & 1845,7 & 1540,4 & 305,3 \\
\hline
\end{tabular}


Tabela 33. Médias dos genótipos novos (MGN), médias da testemunha cultivar Carioca (MTE) e estimativas dos ganhos genéticos (GG), para o caráter rendimento de grãos, obtidos pelo método de médias ajustadas (RA) em função dos ensaios intermediários de feijão do grupo cores conduzidos no estado do Paraná, no período de 1977 a 1995, desdobrados em ambientes (desfavoráveis e favoráveis). Dados em $\mathrm{kg} / \mathrm{ha}$.

\begin{tabular}{|c|c|c|c|c|c|c|c|}
\hline \multirow[b]{3}{*}{$\begin{array}{l}\text { Ano } \\
\text { (i) } \\
\end{array}$} & \multirow[b]{3}{*}{$\begin{array}{c}\text { Ano } \\
\text { Agrícola } \\
\end{array}$} & \multicolumn{6}{|c|}{ Ambientes } \\
\hline & & \multicolumn{3}{|c|}{ Desfavoráveis } & \multicolumn{3}{|c|}{ Favoráveis } \\
\hline & & $\begin{array}{c}\text { MGN } \\
\text { (A) } \\
\end{array}$ & $\begin{array}{c}\text { MTE } \\
\text { (B) }\end{array}$ & $\begin{array}{c}\text { GG } \\
\text { (A-B) } \\
\end{array}$ & $\begin{array}{c}\text { MGN } \\
\text { (C) } \\
\end{array}$ & $\begin{array}{c}\text { MTE } \\
\text { (D) } \\
\end{array}$ & $\begin{array}{c}\text { GG } \\
(C-D) \\
\end{array}$ \\
\hline 1 & $1977 / 78$ & 985,8 & 1152,8 & $-167,0$ & 1758,6 & 1984,5 & $-225,9$ \\
\hline 3 & $1979 / 80$ & 912,6 & 1152,8 & $-240,2$ & 1961,6 & 1984,5 & $-22,9$ \\
\hline 4 & $1980 / 81$ & 1110,8 & 1152,8 & $-42,0$ & 2083,3 & 1984,5 & 98,8 \\
\hline 5 & $1981 / 82$ & 1053,2 & 1152,8 & $-99,6$ & 1705,5 & 1984,5 & $-279,0$ \\
\hline 6 & $1982 / 83$ & 803,6 & 1152,8 & $-349,2$ & 1662,5 & 1984,5 & $-322,0$ \\
\hline 7 & $1983 / 84$ & 1237,1 & 1152,8 & 84,2 & 1927,7 & 1984,5 & $-56,8$ \\
\hline 8 & $1984 / 85$ & 1203,7 & 1152,8 & 50,9 & 1852,3 & 1984,5 & $-132,2$ \\
\hline 9 & $1985 / 86$ & 1337,4 & 1152,8 & 184,6 & 1823,8 & 1984,5 & $-160,7$ \\
\hline 10 & $1986 / 87$ & 1054,6 & 1152,8 & $-98,2$ & 1862,2 & 1984,5 & $-122,3$ \\
\hline 11 & $1987 / 88$ & 1043,1 & 1152,8 & $-109,8$ & 1824,6 & 1984,5 & $-159,9$ \\
\hline 12 & $1988 / 89$ & 1152,3 & 1152,8 & $-0,5$ & 1621,8 & 1984,5 & $-362,7$ \\
\hline 13 & $1989 / 90$ & 1032,8 & 1152,8 & $-120,1$ & 1730,7 & 1984,5 & $-253,8$ \\
\hline 14 & $1990 / 91$ & 1388,8 & 1152,8 & 236,0 & 1990,3 & 1984,5 & 5,8 \\
\hline 15 & $1991 / 92$ & 1308,3 & 1152,8 & 155,5 & 2070,7 & 1984,5 & 86,2 \\
\hline 16 & $1992 / 93$ & 1315,1 & 1152,8 & 162,3 & 2190,9 & 1984,5 & 206,4 \\
\hline 17 & $1993 / 94$ & 1322,5 & 1152,8 & 169,7 & 2264,4 & 1984,5 & 280,0 \\
\hline 18 & $1994 / 95$ & 1447,0 & 1152,8 & 294,2 & 2088,1 & 1984,5 & 103,7 \\
\hline
\end{tabular}


Tabela 34. Médias dos genótipos novos (MGN), médias da testemunha cultivar Carioca (MTE) e estimativas dos ganhos genéticos (GG), para o caráter rendimento de grãos, obtidos pelo método de médias ajustadas (RA) em função dos ensaios finais de feijão do grupo cores conduzidos no estado do Paraná, no período de 1978 a 1995, desdobrados em ambientes (desfavoráveis e favoráveis). Dados em $\mathrm{kg} / \mathrm{ha}$.

\begin{tabular}{|c|c|c|c|c|c|c|c|}
\hline \multirow[b]{3}{*}{$\begin{array}{l}\text { Ano } \\
\text { (i) }\end{array}$} & \multirow[b]{3}{*}{$\begin{array}{c}\text { Ano } \\
\text { Agrícola }\end{array}$} & \multicolumn{6}{|c|}{ Ambientes } \\
\hline & & \multicolumn{3}{|c|}{ Desfavoráveis } & \multicolumn{3}{|c|}{ Favoráveis } \\
\hline & & $\begin{array}{c}\text { MGN } \\
\text { (A) } \\
\end{array}$ & $\begin{array}{c}\text { MTE } \\
\text { (B) } \\
\end{array}$ & $\begin{array}{c}\text { GG } \\
(\mathrm{A}-\mathrm{B}) \\
\end{array}$ & $\begin{array}{c}\text { MGN } \\
\text { (C) }\end{array}$ & $\begin{array}{l}\text { MTE } \\
\text { (D) }\end{array}$ & $\begin{array}{c}\text { GG } \\
\text { (C-D) } \\
\end{array}$ \\
\hline 1 & $1978 / 79$ & 902,5 & 1031,1 & $-128,6$ & 1728,7 & 2019,8 & $-291,2$ \\
\hline 3 & $1980 / 81$ & 1021,9 & 1031,1 & $-9,2$ & 1755,3 & 2019,8 & $-264,6$ \\
\hline 4 & $1981 / 82$ & 961,1 & 1031,1 & $-70,0$ & 1832,3 & 2019,8 & $-187,5$ \\
\hline 5 & $1982 / 83$ & 982,2 & 1031,1 & $-48,8$ & 1925,8 & 2019,8 & $-94,0$ \\
\hline 6 & $1983 / 84$ & 1014,4 & 1031,1 & $-16,7$ & 1968,1 & 2019,8 & $-51,7$ \\
\hline 7 & $1984 / 85$ & 988,1 & 1031,1 & $-43,0$ & 2095,3 & 2019,8 & 75,5 \\
\hline 8 & $1985 / 86$ & 919,3 & 1031,1 & $-111,8$ & 1796,0 & 2019,8 & $-223,8$ \\
\hline 9 & $1986 / 87$ & 948,9 & 1031,1 & $-82,2$ & 1767,6 & 2019,8 & $-252,2$ \\
\hline 10 & $1987 / 88$ & 1056,2 & 1031,1 & 25,1 & 1958,7 & 2019,8 & $-61,1$ \\
\hline 11 & $1988 / 89$ & 988,7 & 1031,1 & $-42,4$ & 1927,5 & 2019,8 & $-92,3$ \\
\hline 12 & $1989 / 90$ & 1047,1 & 1031,1 & 16,0 & 2016,2 & 2019,8 & $-3,6$ \\
\hline 13 & $1990 / 91$ & 1070,5 & 1031,1 & 39,4 & 1959,5 & 2019,8 & $-60,4$ \\
\hline 14 & 1991/92 & 1034,5 & 1031,1 & 3,5 & 1839,9 & 2019,8 & $-179,9$ \\
\hline 15 & $1992 / 93$ & 1126,1 & 1031,1 & 95,1 & 2096,8 & 2019,8 & 77,0 \\
\hline 16 & $1993 / 94$ & 1209,9 & 1031,1 & 178,8 & 2303,3 & 2019,8 & 283,5 \\
\hline 17 & $1994 / 95$ & 1368,6 & 1031,1 & 337,6 & 2235,2 & 2019,8 & 215,4 \\
\hline
\end{tabular}


Tabela 35. Médias dos genótipos novos (MGN), médias da testemunha cultivar Carioca (MTE) e estimativas dos ganhos genéticos (GG), para o caráter rendimento de grãos, obtidos pelo método de médias ajustadas (RA) em função dos ensaios intermediários de feijão do grupo preto conduzidos no estado do Paraná, no período de 1977 a 1995, desdobrados em ambientes (desfavoráveis e favoráveis). Dados em $\mathrm{kg} / \mathrm{ha}$.

\begin{tabular}{|c|c|c|c|c|c|c|c|}
\hline \multirow[b]{3}{*}{$\begin{array}{l}\text { Ano } \\
\text { (i) } \\
\end{array}$} & \multirow[b]{3}{*}{$\begin{array}{c}\text { Ano } \\
\text { Agrícola } \\
\end{array}$} & \multicolumn{6}{|c|}{ Ambientes } \\
\hline & & \multicolumn{3}{|c|}{ Desfavoráveis } & \multicolumn{3}{|c|}{ Favoráveis } \\
\hline & & $\begin{array}{r}\text { MGN } \\
\text { (A) } \\
\end{array}$ & $\begin{array}{l}\text { MTE } \\
\text { (B) } \\
\end{array}$ & $\begin{array}{c}\text { GG } \\
(\mathrm{A}-\mathrm{B}) \\
\end{array}$ & $\begin{array}{c}\text { MGN } \\
\text { (C) } \\
\end{array}$ & $\begin{array}{l}\text { MTE } \\
\text { (D) } \\
\end{array}$ & $\begin{array}{c}\text { GG } \\
\text { (C-D) } \\
\end{array}$ \\
\hline 1 & $1977 / 78$ & 1047,6 & 1021,8 & 25,8 & 1450,9 & 1671,2 & $-220,2$ \\
\hline 3 & $1979 / 80$ & 913,1 & 1021,8 & $-108,7$ & 1548,1 & 1671,2 & $-123,1$ \\
\hline 4 & $1980 / 81$ & 1175,3 & 1021,8 & 153,5 & 1562,5 & 1671,2 & $-108,7$ \\
\hline 5 & $1981 / 82$ & 1212,1 & 1021,8 & 190,3 & 1705,6 & 1671,2 & 34,5 \\
\hline 6 & $1982 / 83$ & 1292,1 & 1021,8 & 270,3 & 1607,0 & 1671,2 & $-64,2$ \\
\hline 7 & $1983 / 84$ & 1158,6 & 1021,8 & 136,8 & 1625,2 & 1671,2 & $-45,9$ \\
\hline 8 & $1984 / 85$ & 707,1 & 1021,8 & $-314,7$ & 1541,0 & 1671,2 & $-130,1$ \\
\hline 9 & $1985 / 86$ & 1013,4 & 1021,8 & $-8,4$ & 1597,9 & 1671,2 & $-73,3$ \\
\hline 10 & $1986 / 87$ & 1087,3 & 1021,8 & 65,5 & 1731,9 & 1671,2 & 60,7 \\
\hline 11 & $1987 / 88$ & 1057,9 & 1021,8 & 36,2 & 1902,0 & 1671,2 & 230,8 \\
\hline 12 & $1988 / 89$ & 1159,3 & 1021,8 & 137,5 & 1946,1 & 1671,2 & 274,9 \\
\hline 13 & $1989 / 90$ & 1110,6 & 1021,8 & 88,8 & 1889,5 & 1671,2 & 218,4 \\
\hline 14 & $1990 / 91$ & 1418,6 & 1021,8 & 396,8 & 1986,3 & 1671,2 & 315,1 \\
\hline 15 & 1991/92 & 1302,0 & 1021,8 & 280,2 & 2067,6 & 1671,2 & 396,4 \\
\hline 16 & 1992/93 & 1180,5 & 1021,8 & 158,7 & 2123,9 & 1671,2 & 452,7 \\
\hline 17 & 1993/94 & 1325,7 & 1021,8 & 303,9 & 2093,1 & 1671,2 & 421,9 \\
\hline 18 & $1994 / 95$ & 1466,5 & 1021,8 & 444,7 & 2242,6 & 1671,2 & 571,4 \\
\hline
\end{tabular}


Tabela 36. Médias dos genótipos novos (MGN), médias da testemunha cultivar Carioca (MTE) e estimativas dos ganhos genéticos (GG), para o caráter rendimento de grãos, obtidos pelo método de médias ajustadas (RA) em função dos ensaios finais de feijão do grupo preto conduzidos no estado do Paraná, no período de 1978 a 1995, desdobrados em ambientes (desfavoráveis e favoráveis). Dados em $\mathrm{kg} / \mathrm{ha}$.

\begin{tabular}{|c|c|c|c|c|c|c|c|}
\hline \multirow[b]{3}{*}{$\begin{array}{l}\text { Ano } \\
\text { (i) } \\
\end{array}$} & \multirow[b]{3}{*}{$\begin{array}{c}\text { Ano } \\
\text { Agrícola } \\
\end{array}$} & \multicolumn{6}{|c|}{ Ambientes } \\
\hline & & \multicolumn{3}{|c|}{ Desfavoráveis } & \multicolumn{3}{|c|}{ Favoráveis } \\
\hline & & $\begin{array}{c}\text { MGN } \\
\text { (A) } \\
\end{array}$ & $\begin{array}{l}\text { MTE } \\
\text { (B) } \\
\end{array}$ & $\begin{array}{r}\text { GG } \\
(\mathrm{A}-\mathrm{B}) \\
\end{array}$ & $\begin{array}{c}\text { MGN } \\
\text { (C) } \\
\end{array}$ & $\begin{array}{c}\text { MTE } \\
\text { (D) } \\
\end{array}$ & $\begin{array}{c}\text { GG } \\
(C-D) \\
\end{array}$ \\
\hline 1 & $1978 / 79$ & 1074,2 & 930,5 & 143,7 & 1917,1 & 1756,6 & 160,5 \\
\hline 2 & $1979 / 80$ & 1067,7 & 930,5 & 137,2 & 1868,3 & 1756,6 & 111,7 \\
\hline 3 & $1980 / 81$ & 1096,7 & 930,5 & 166,2 & 1837,4 & 1756,6 & 80,8 \\
\hline 4 & $1981 / 82$ & 1020,6 & 930,5 & 90,0 & 1919,9 & 1756,6 & 163,3 \\
\hline 5 & $1982 / 83$ & 882,6 & 930,5 & $-47,9$ & 1754,3 & 1756,6 & $-2,2$ \\
\hline 6 & $1983 / 84$ & 1120,7 & 930,5 & 190,2 & 1490,6 & 1756,6 & $-266,0$ \\
\hline 7 & $1984 / 85$ & 942,3 & 930,5 & 11,8 & 1752,0 & 1756,6 & $-4,6$ \\
\hline 8 & $1985 / 86$ & 1031,2 & 930,5 & 100,7 & 1894,5 & 1756,6 & 138,0 \\
\hline 9 & $1986 / 87$ & 1084,3 & 930,5 & 153,8 & 1929,3 & 1756,6 & 172,7 \\
\hline 10 & $1987 / 88$ & 1101,6 & 930,5 & 171,1 & 1978,5 & 1756,6 & 222,0 \\
\hline 11 & $1988 / 89$ & 1179,8 & 930,5 & 249,3 & 2034,9 & 1756,6 & 278,3 \\
\hline 12 & $1989 / 90$ & 1327,8 & 930,5 & 397,3 & 2053,3 & 1756,6 & 296,7 \\
\hline 13 & $1990 / 91$ & 1279,8 & 930,5 & 349,3 & 2224,2 & 1756,6 & 467,6 \\
\hline 14 & 1991/92 & 1265,9 & 930,5 & 335,3 & 2036,9 & 1756,6 & 280,3 \\
\hline 15 & 1992/93 & 1251,7 & 930,5 & 321,2 & 2149,2 & 1756,6 & 392,6 \\
\hline 16 & 1993/94 & 1265,4 & 930,5 & 334,8 & 2326,2 & 1756,6 & 569,6 \\
\hline 17 & $1994 / 95$ & 1191,3 & 930,5 & 260,8 & 2139,5 & 1756,6 & 382,9 \\
\hline
\end{tabular}


Tabela 37. Estimativas e erros padrões dos ganhos genéticos anuais médios, em kg/ha e porcentagem, e respectivos detalhamentos obtidos pelo método da regressão com médias ajustadas (RA), em função dos desdobramentos em nivel de safras, regiōes e ambientes, referentes aos ensaios intermediários de feijão do grupo cores, no período de 1977 a 1995, no estado do Paraná.

\begin{tabular}{|c|c|c|c|c|c|c|c|c|c|c|c|c|c|c|}
\hline \multirow[b]{2}{*}{ Itens } & \multirow{2}{*}{\multicolumn{2}{|c|}{ Estado }} & \multicolumn{4}{|c|}{ Safras } & \multicolumn{4}{|c|}{ Regiões } & \multicolumn{4}{|c|}{ Ambientes } \\
\hline & & & Águas & & Secas & & I & & II & & D & & $\mathbf{F}$ & \\
\hline Ganho (kg/ha) & 23,6290 & $* *$ & 21,9652 & * & 20,9785 & $* *$ & 8,0536 & b & 29,9730 & $* * a^{1 /}$ & 24,8607 & $* *$ & 17,9708 & $*$ \\
\hline Ganho (\%) & 1,8264 & & 1,5235 & & 1,8674 & & 0,6317 & & 1,9679 & & 2,7254 & & 1,0398 & \\
\hline Erro Padrão (kg/ha) & 5,3127 & & 8,6927 & & 6,2268 & & 3,7523 & & 8,4744 & & 6,3530 & & 8,1728 & \\
\hline Erro Padrão (\%) & 0,4107 & & 0,6029 & & 0,5543 & & 0,2943 & & 0,5564 & & 0,6965 & & 0,4729 & \\
\hline Refírência (kg/ha) & 1293,7 & & 1441,7 & & 1123,4 & & 1274,8 & & 1523,1 & & 912,2 & & 1728,4 & \\
\hline No. de genótipos & 274 & & 255 & & 254 & & 187 & & 187 & & 268 & & 268 & \\
\hline No. de expenimentros & 109 & & 67 & & 39 & & 44 & & 48 & & 53 & & 54 & \\
\hline Número de Anos & 18 & & 17 & & 17 & & 13 & & 13 & & 17 & & 17 & \\
\hline $\mathrm{R}^{2}$ & 0,5529 & & 0,2986 & & 0,4308 & & 0,2952 & & 0,5321 & & 0,5052 & & 0,2438 & \\
\hline QM Erro Conjunto & 48688,9 & & 56809,4 & & 32767,4 & & 40552,1 & & 63071,8 & & 35597,7 & & 62103,3 & \\
\hline M Hammônica reps. (R) & 3,5466 & & 3,5753 & & 3,5979 & & 3,4045 & & 3,7488 & & 3,5757 & & 3,6073 & \\
\hline M Hammônica exps. (E) & 4,7722 & & 3,0949 & & 1,6944 & & 2,7957 & & 2,284 & & 2,1206 & & 2,6563 & \\
\hline QMErro Conjunto/R.E & 2876,73 & & 5134,07 & & 5374,98 & & 4260,59 & & 7366,25 & & 4694,64 & & 6481,20 & \\
\hline GL Erro Cojunto & 5060 & & 3078 & & 1772 & & 1934 & & 2133 & & 2510 & & 2520 & \\
\hline QM Regressão & 270511,4 & ++ & 230563,8 & + & 210315,1 & ++ & 29766,0 & & 412287,0 & ++ & 262637,5 & ++ & 137235,3 & + \\
\hline SQ $X(X=$ Anos $)$ & 484,5000 & & 477,8824 & & 477,8824 & & 458,9231 & & 458,9231 & & 424,9412 & & 424,9412 & \\
\hline QM Desvio Reg. & 13674,7 & ++ & 36109,9 & t+ & 18529,2 & + & 6461,7 & & 32957,7 & ++ & 17151,0 & + & 28383,5 & ++ \\
\hline GL Desvio da Reg. & 16 & & 15 & & 15 & & 11 & & 11 & & 15 & & 15 & \\
\hline F do Desvio da Reg. & 4,754 & ++ & 7,033 & ++ & 3,447 & $H$ & 1,517 & & 4,474 & H & 3,653 & ++ & 4,379 & ++ \\
\hline
\end{tabular}

*;** Significativo a $5 \%$ e a $1 \%$ de probabilidade respectivamente, pelo teste $t$.

,+++ Signifactivo a $5 \%$ e $1 \%$ de probabilidade respectivamente, pelo teste $\mathrm{F}$.

" Ganhos seguidos por letras distintas, na mesma condição e na mesma linha, diferem estatisticamente pelo teste t a $5 \%$ de probabilidade. 
Tabela 38. Estimativas e erros padrōes dos ganhos genéticos anuais médios, em $\mathrm{kg} / \mathrm{ha}$ e porcentagem, e respectivos detalhamentos obtidos pelo método da regressão com médias ajustadas (RA), em fimção dos desdobramentos em nivel de safras, regiōes e ambientes, referentes aos ensaios finais de feijão do grupo cores, no periodo de 1978 a 1995, no estado do Paraná

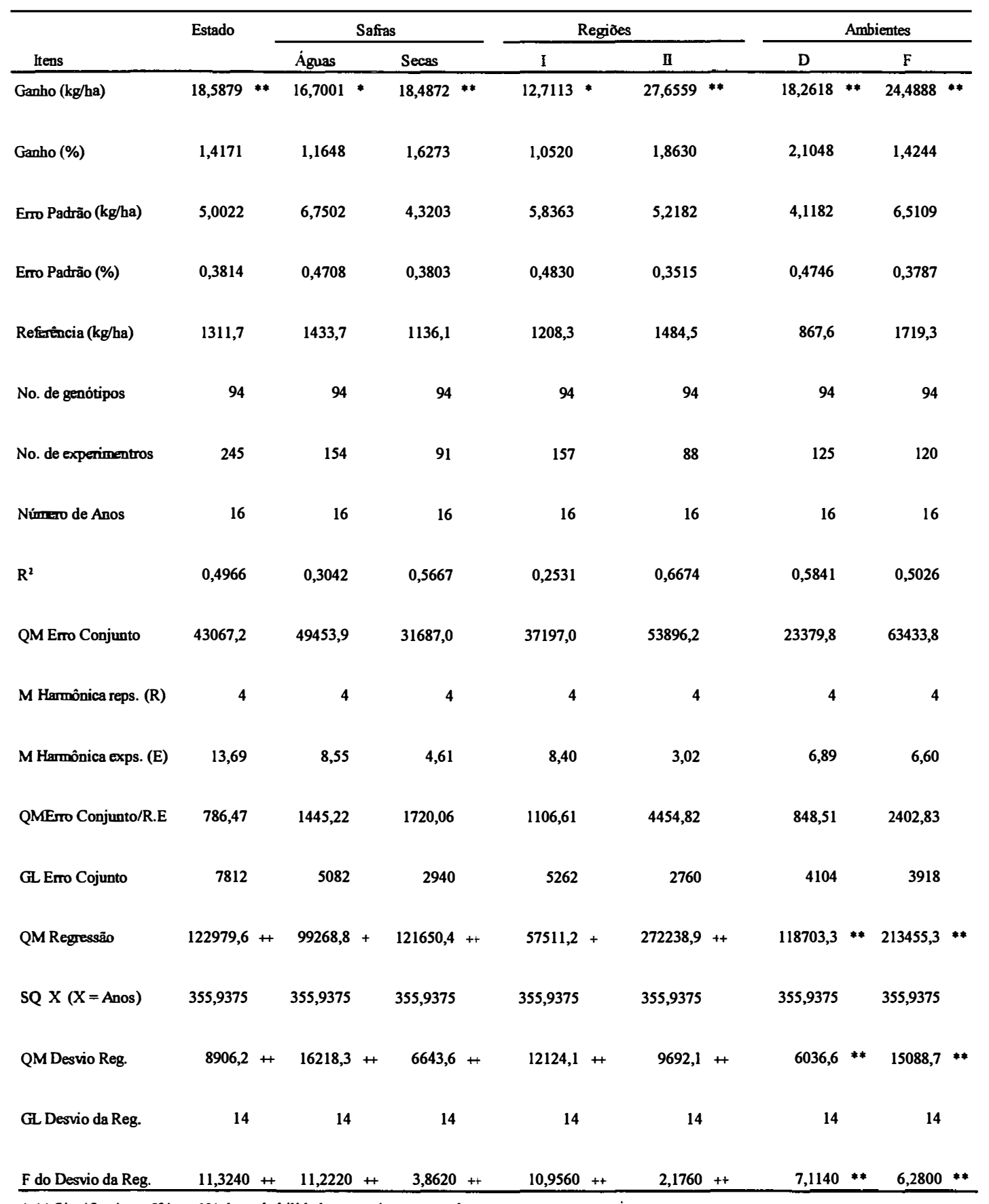

*; ** Significativo a $5 \%$ e a $1 \%$ de probabilidade respectivamente, pelo testot.

,+++ Signifactivo a $5 \%$ e $1 \%$ de probabilidade respectivamente, pelo teste $F$. 
Tabela 39. Estimativas e erros padrües dos ganhos genéticos anuais métios, em kg/ha e porcenøgem, e respectivos detalhamentos obtidos pelo método da regressāo com médias ajustadas (RA), en fimção dos desdobramentos em nivel de safras, regiōes e ambientes, referentes aos ensaios intermediários de feijão do grupo preto, no periodo de 1977 a 1995, no estado do Paraną

\begin{tabular}{|c|c|c|c|c|c|c|c|c|c|c|c|c|c|}
\hline \multirow[b]{2}{*}{ Itens } & \multirow{2}{*}{\multicolumn{2}{|c|}{ Estado }} & \multicolumn{4}{|c|}{ Safras } & \multicolumn{4}{|c|}{ Regiōes } & \multicolumn{3}{|c|}{ Ambientes } \\
\hline & & & Águas & & Secas & & I & & II & & D & & $\mathbf{F}$ \\
\hline Ganho (kg/ha) & 29,7239 & $* *$ & 34,2000 & $* *$ & $16,3126 *$ & * & 34,4445 & $* *$ & $31,2475 * *$ & $* *$ & 19,1519 & $* b^{1}$ & $44,9500 * * a$ \\
\hline Ganho (\%) & 2,4048 & & 2,5855 & & 1,3969 & & 3,4998 & & 2,1882 & & 1,9863 & & 3,3189 \\
\hline Erro Padrăo (kg/ha) & 3,5783 & & 6,4614 & & 6,9565 & & 7,0153 & & 5,3787 & & 7,8343 & & 4,0609 \\
\hline Erro Padrāo (\%) & 0,2895 & & 0,4885 & & 0,5957 & & 0,7128 & & 0,3767 & & 0,8125 & & 0,2998 \\
\hline Referência (kg/ha) & 1236,0 & & 1322,7 & & 1167,8 & & 984,2 & & 1428,0 & & 964,2 & & 1354,4 \\
\hline No. de genótipos & 187 & & 179 & & 178 & & 140 & & 140 & & 179 & & 179 \\
\hline No. de experimentros & 99 & & 60 & & 36 & & 31 & & 45 & & 43 & & 54 \\
\hline Número de Anos & 18 & & 17 & & 17 & & 13 & & 13 & & 17 & & 17 \\
\hline $\mathbf{R}^{2}$ & 0,8118 & & 0,6513 & & 0,2682 & & 0,6867 & & 0,7542 & & 0,2849 & & 0,8909 \\
\hline QM Erro Conjunto & 46513,6 & & 54299,8 & & 34268,8 & & 42199,2 & & 48379,6 & & 32246,2 & & 57615,4 \\
\hline M Hammônica reps. ( $R$ ) & 3,65 & & 3,64 & & 3,71 & & 3,34 & & 3,81 & & 3,71 & & 3,69 \\
\hline M Harmônica exps. (E) & 4,73 & & 3,01 & & 1,69 & & 1,81 & & 2,25 & & 1,97 & & 2,79 \\
\hline QMErro Conjumto/RE & 2697,46 & & 4957,97 & & 5451,12 & & 6971,66 & & 5632,96 & & 4406,38 & & 5605,51 \\
\hline GL Erro Cojinto & 3429 & & 2074 & & 1295 & & 884 & & 1744 & & 1473 & & 1936 \\
\hline QM Regressāo & 428059,6 & ++ & 558951,7 & ++ & 127164,9 & + & 513812,9 & +t & $422859,6+t$ & $+t$ & 155866,1 & + & $858593,4+$ \\
\hline SQ $X(X=$ Anos $)$ & 484,50 & & 477,88 & & 477,88 & & 433,08 & & 433,08 & & 424,94 & & 424,94 \\
\hline QM Desvio Reg. & 6203,6 & ++ & 19951,5 & ++ & 23126,0 & + & 21313,4 & ++ & $12529,2+$ & + & 26081,1 & ++ & 7007,5 \\
\hline GL Desvio da Reg. & 16 & & 15 & & 15 & & 11 & & 11 & & 15 & & 15 \\
\hline F do Desvio da Reg. & 2,300 & ++ & 4,024 & + & 4,242 & t+ & 3,057 & t+ & $2,224+$ & + & 5,919 & ++ & 1,250 \\
\hline
\end{tabular}

*;** Significativo a $5 \%$ e a $1 \%$ de probabilidade respectivamente, pelo teste $t$ +,++ Signifactivo a $5 \%$ e $1 \%$ de probabilidade respectivamente, pelo teste F.

1 Ganhos seguidos por letras distintas, na mesrna condição e na mesma linhz, diferem estatisticamente pelo teste t a $5 \%$ de probabilidade. 
Tabela 40. Estimativas e enros padrües dos ganhos genéticos anuais médios, em $\mathrm{kg} / \mathrm{ha} \mathrm{e}$ porcentrgem, e respectivos detalhamentos obtidos pelo métodb da regressāo com métias ajustadas (RA), em funçāo dos desdobranentos em nivel de safras, regiōes e ambientes, referentes aos ensaios finais de feijão do grupo preto, no período de 1977 a 1995, no estado do Paranń

\begin{tabular}{|c|c|c|c|c|c|c|c|c|c|c|c|c|c|c|}
\hline \multirow[b]{2}{*}{ Itens } & \multirow{2}{*}{\multicolumn{2}{|c|}{ Estado }} & \multicolumn{4}{|c|}{ Safras } & \multicolumn{4}{|c|}{ Regið̄es } & \multicolumn{4}{|c|}{ Ambientes } \\
\hline & & & Aguas & & Secas & & I & & II & & D & & F & \\
\hline Ganho (kg/ha) & 22,1348 & $* *$ & 23,8641 & $* *$ & 17,9420 & * & 18,7451 & ** & 22,6587 & $* *$ & 17,7249 & ** & 28,5732 & ** \\
\hline Ganho (\%) & 1,6379 & & 1,5994 & & 1,5687 & & 1,5303 & & 1,5090 & & 1,8293 & & 1,6788 & \\
\hline Eпro Padrảo (kg/ha) & 4,4276 & & 3,1721 & & 6,0559 & & 4,8113 & & 5,6571 & & 4,4363 & & 6,9712 & \\
\hline Emro Padrão (\%) & 0,3276 & & 0,2126 & & 0,5295 & & 0,3928 & & 0,3767 & & 0,4579 & & 0,4096 & \\
\hline Referência (kg/ha) & 1351,4 & & 1492,1 & & 1143,8 & & 1224,9 & & 1501,6 & & 968,9 & & 1702,0 & \\
\hline No. de genótipos & 98 & & 98 & & 98 & & 98 & & 98 & & 98 & & 98 & \\
\hline No. de experimentros & 189 & & 114 & & 72 & & 89 & & 100 & & 94 & & 95 & \\
\hline Nimero de Anos & 17 & & 16 & & 16 & & 17 & & 17 & & 17 & & 17 & \\
\hline $\mathrm{R}^{2}$ & 0,6249 & & 0,8017 & & 0,3854 & & 0,5030 & & 0,5168 & & 0,5156 & & 0,5283 & \\
\hline QM Erro Conjumto & 43530,5 & & 49641,4 & & 32933,0 & & 41082,9 & & 45241,7 & & 28479,0 & & 58181,9 & \\
\hline M Hannônica reps. (R) & 4 & & 4 & & 4 & & 4 & & 4 & & 4 & & 4 & \\
\hline M Harmônica exps. (E) & 8,86 & & 6,28 & & 3,57 & & 2,69 & & 5,12 & & 3,82 & & 4,80 & \\
\hline QMEnro Conjumto/RE & 1228,07 & & 1974,85 & & 2308,88 & & 3814,57 & & 2208,20 & & 1863,71 & & 3032,71 & \\
\hline GL Erro Cojurnto & 6015 & & 3741 & & 2238 & & 2475 & & 3540 & & 2967 & & 3048 & \\
\hline QM Regressão & 199900,0 & ++ & 229934,1 & ++ & 129973,5 & + & 143362,3 & ++ & 209473,6 & + & 128182,1 & ++ & 333102,7 & + \\
\hline SQ $X(X=$ Anos $)$ & 408 & & 403,75 & & 403,75 & & 408 & & 408 & & 408 & & 408 & \\
\hline QM Desvio Reg & 7998,2 & ++ & 4062,6 & + & 14807,3 & ++ & 9444,7 & $+r$ & 13057,2 & + & 8029,7 & + & 19827,9 & ++ \\
\hline GL Desvio da Reg. & 15 & & 14 & & 14 & & 15 & & 15 & & 15 & & 15 & \\
\hline F do Desvio da Reg & 6,513 & t+ & 2,057 & + & 6,413 & + & 2,476 & ++ & 5,913 & + & 4,308 & + & 6,538 & tt \\
\hline
\end{tabular}


FIGURAS 

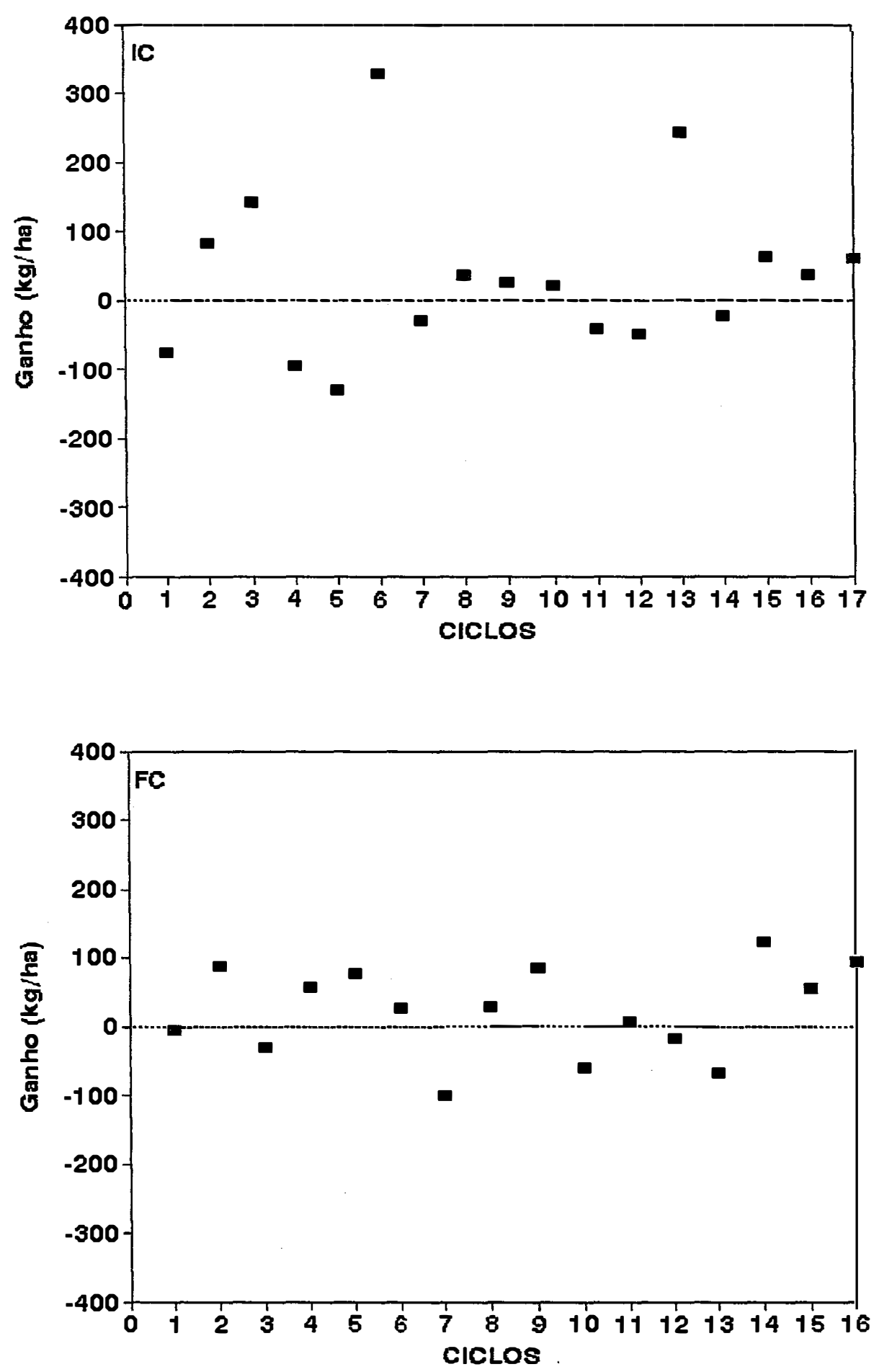

FIGURA 1. Ganhos genéticos anuais observados, expressos em $\mathrm{kg} / \mathrm{ha}$, relativos aos métodos Original (VO), Ponderado 1 (VP1) e Ponderado 2 (VP2), referentes aos ensaios de feijão do grupo cores: intermediários (IC) e finais (FC) respectivamente. 

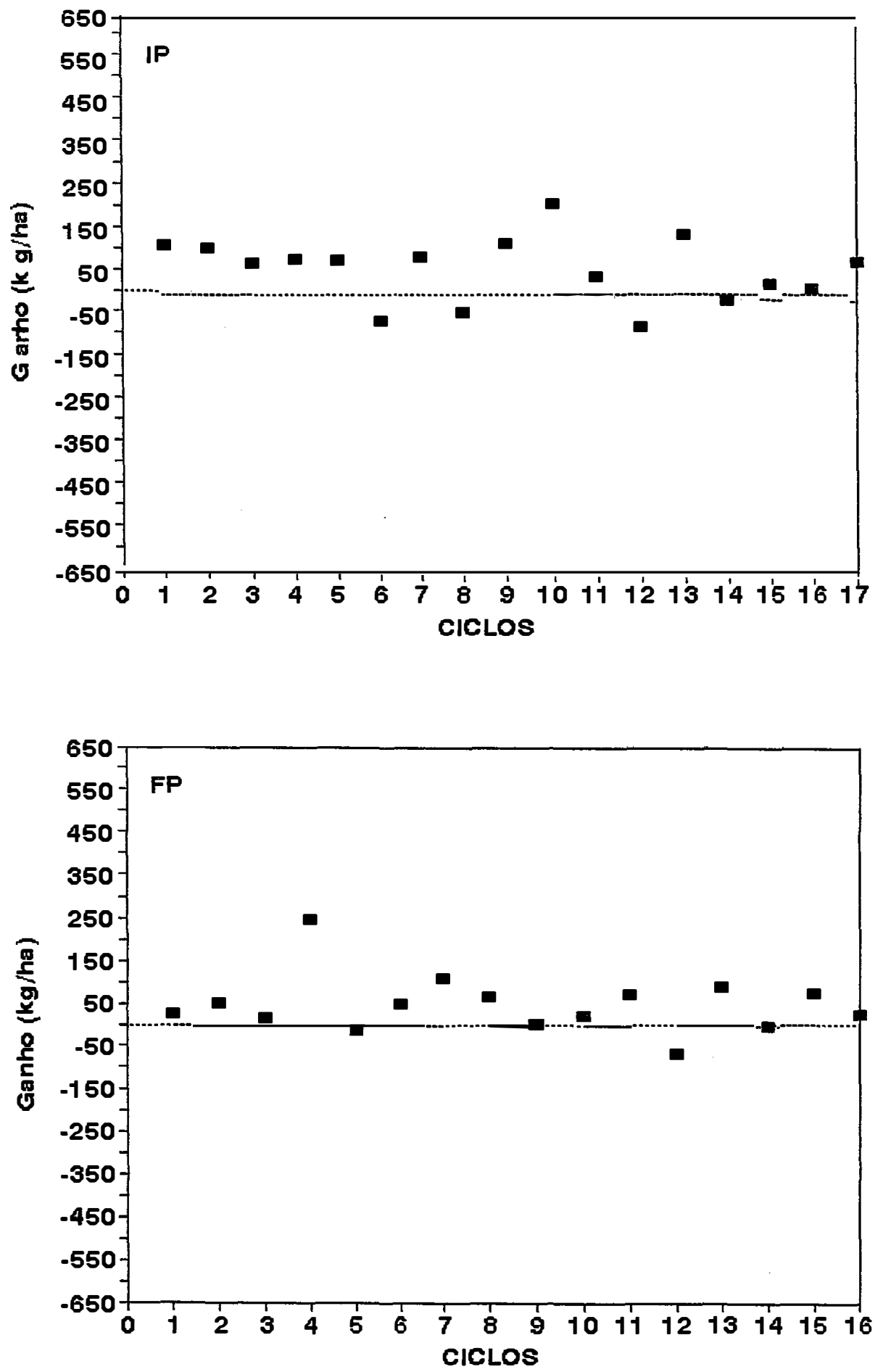

FIGURA 2. Ganhos genéticos anuais observados, expressos em $\mathrm{kg} / \mathrm{ha}$, relativos aos métodos Original (VO), Ponderado 1 (VP1) e Ponderado 2 (VP2), referentes aos ensaios de feijão do grupo preto: intermediários (IP) e finais (FP) respectivamente. 

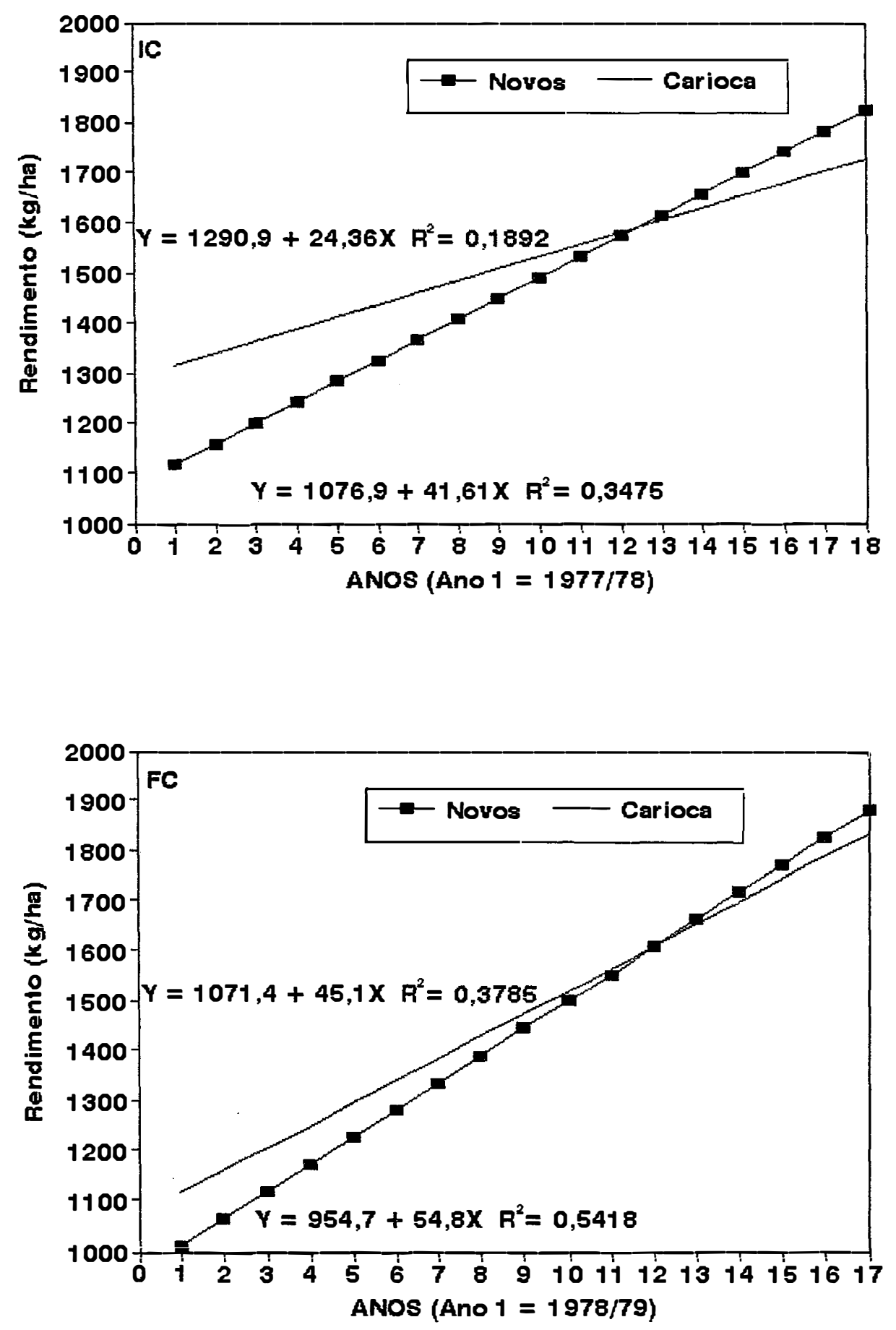

FIGURA 3. Regressões lineares originais (RO) do rendimento de grãos ( $\mathrm{kg} / \mathrm{ha}$ ) dos genótipos novos e da testemunha Carioca em função dos anos, relativos aos ensaios de feijão do grupo cores: Intermediários (IC) e finais (FC) respectivamente. 

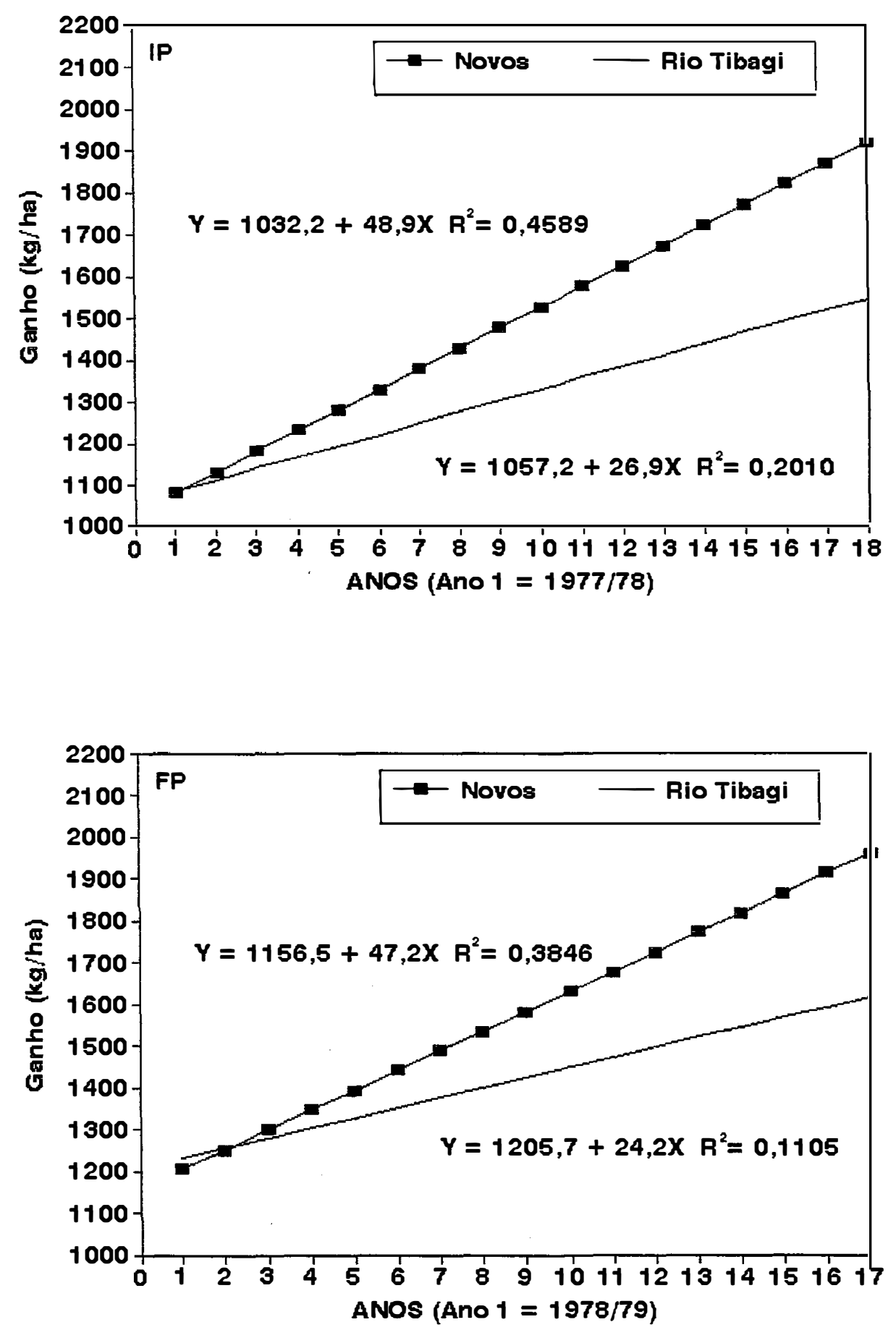

FIGURA 4. Regressões lineares originais (RO) do rendimento de grãos ( $\mathrm{kg} / \mathrm{ha}$ ) dos genótipos novos e da testemunha Rio Tibagi em função dos anos, relativos aos ensaios de feijão do grupo preto: intermediários (IP) e finais (FP) respectivamente. 

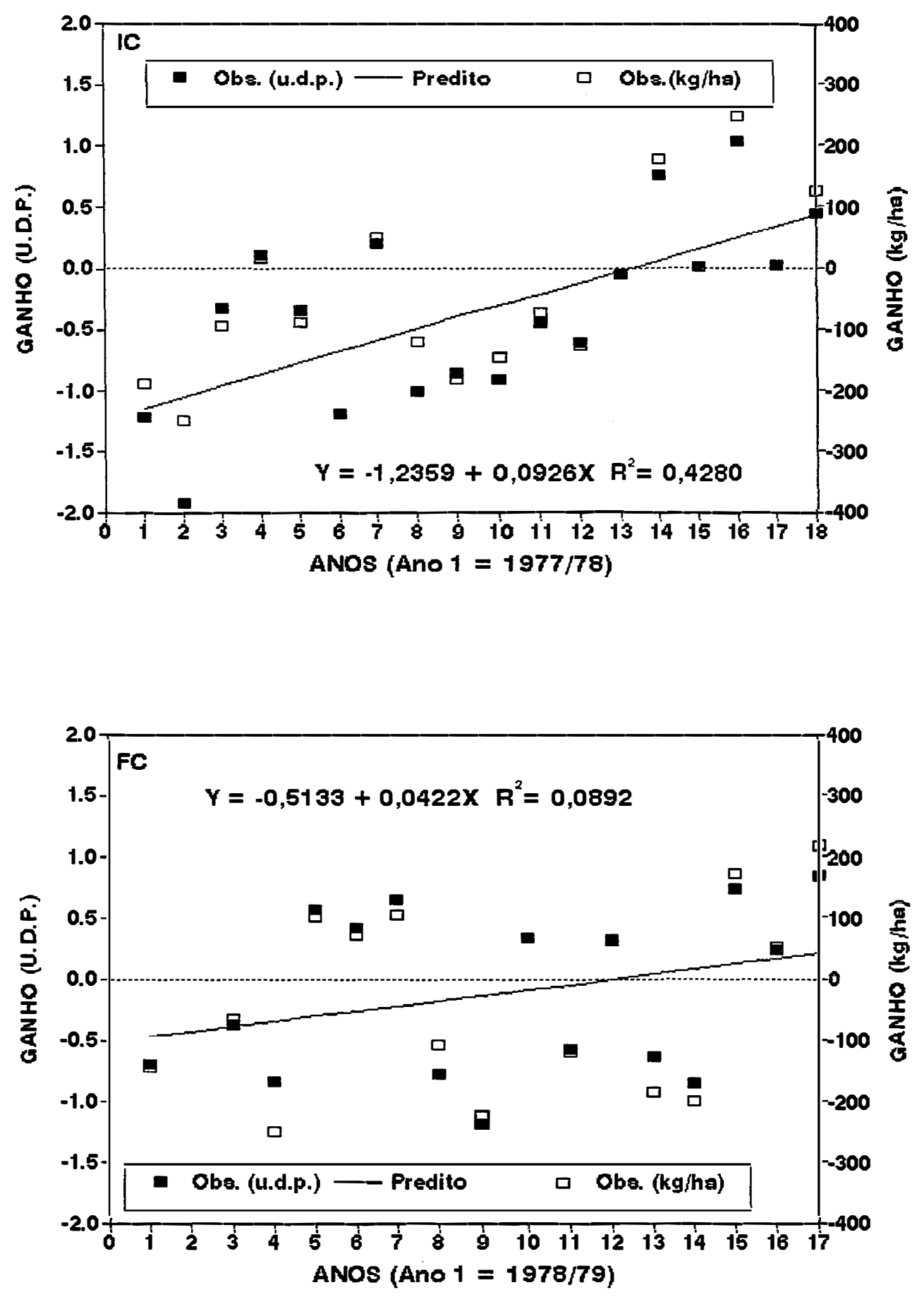

FIGURA 5. Ganhos genéticos observados em unidades de desvio padrão (U.D.P.), em $\mathrm{kg} / \mathrm{ha}$ e preditos pela regressão dos ganhos genéticos estandardizados (RE) em função dos anos, relativos aos ensaios de feijão do grupo cores: intermediários (IC) e finais (FC) respectivamente. 

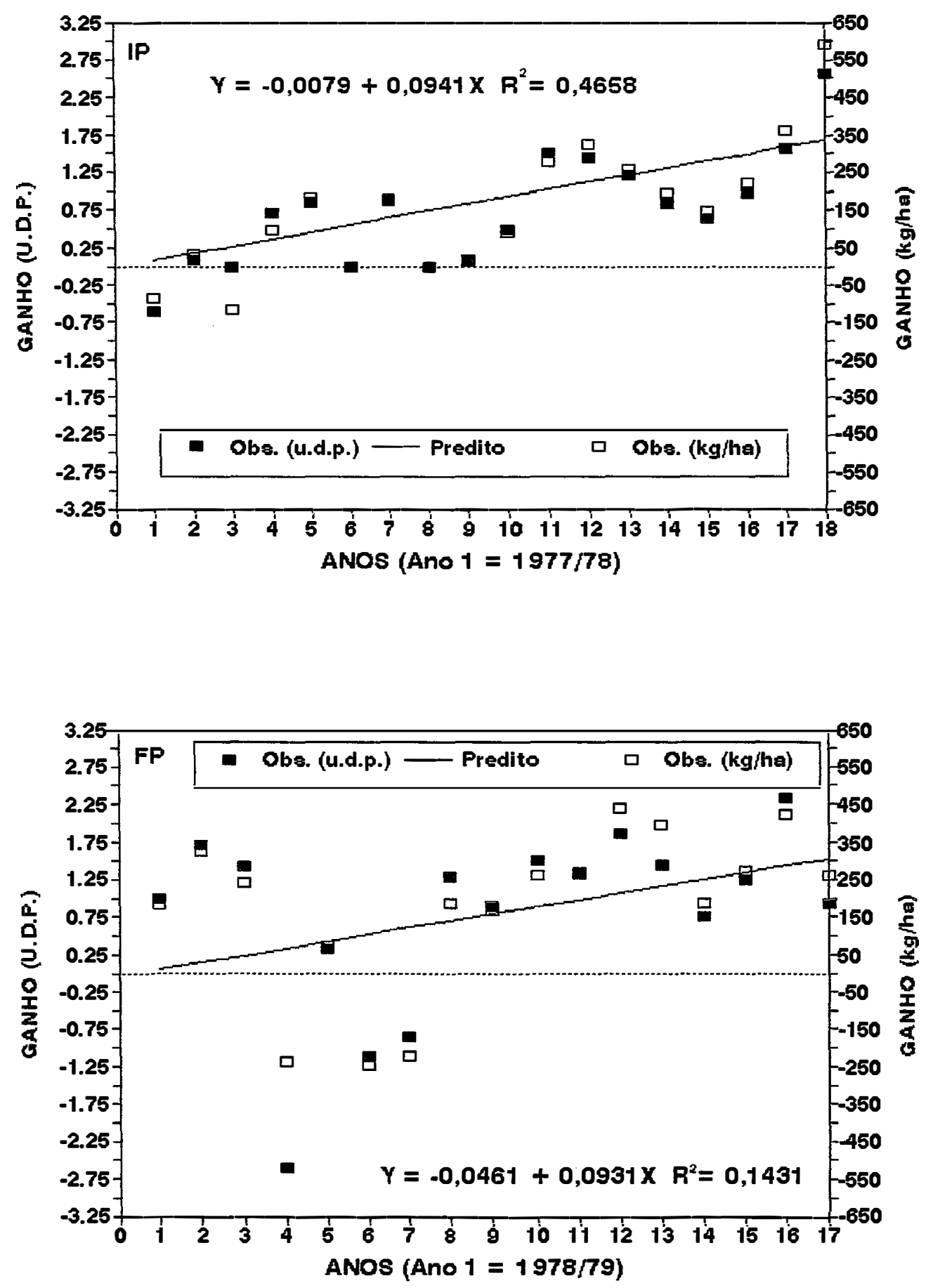

FIGURA 6. Ganhos genéticos observados em unidades de desvio padrão (U.D.P.), em kg/ha e preditos pela regressão dos ganhos genéticos estandardizados (RE) em função dos anos, relativos aos ensaios de feijão do grupo preto: intermediários (IP) e finais (FP) respectivamente. 

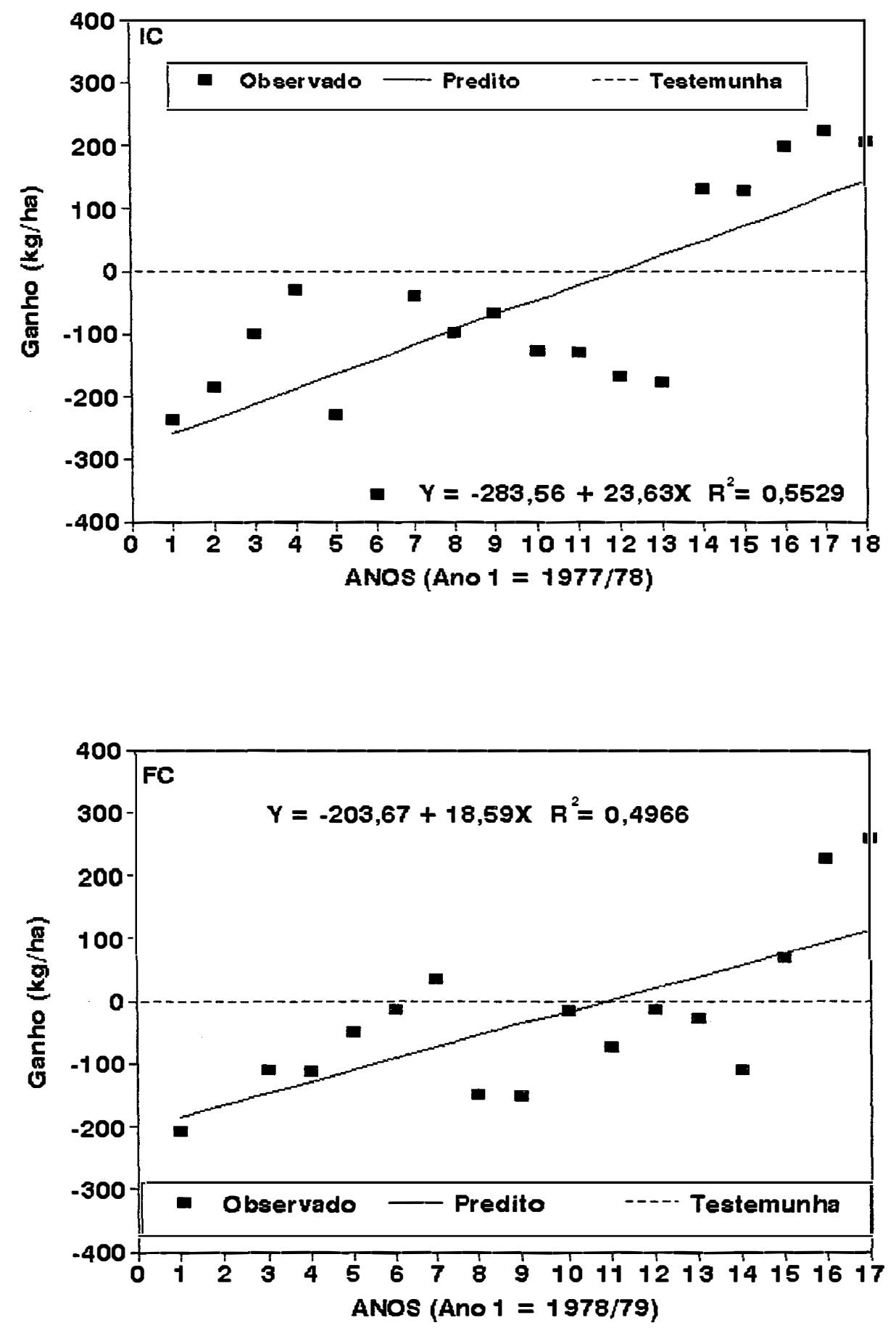

FIGURA 7. Ganhos genéticos observados $(\mathrm{kg} / \mathrm{ha})$ em relação à testemunha Carioca e preditos pela regressão dos ganhos genéticos com médias ajustadas (RA) em função dos anos, relativos aos ensaios de feijão do grupo cores: intermediários (IC) e finais (FC) respectivamente. 

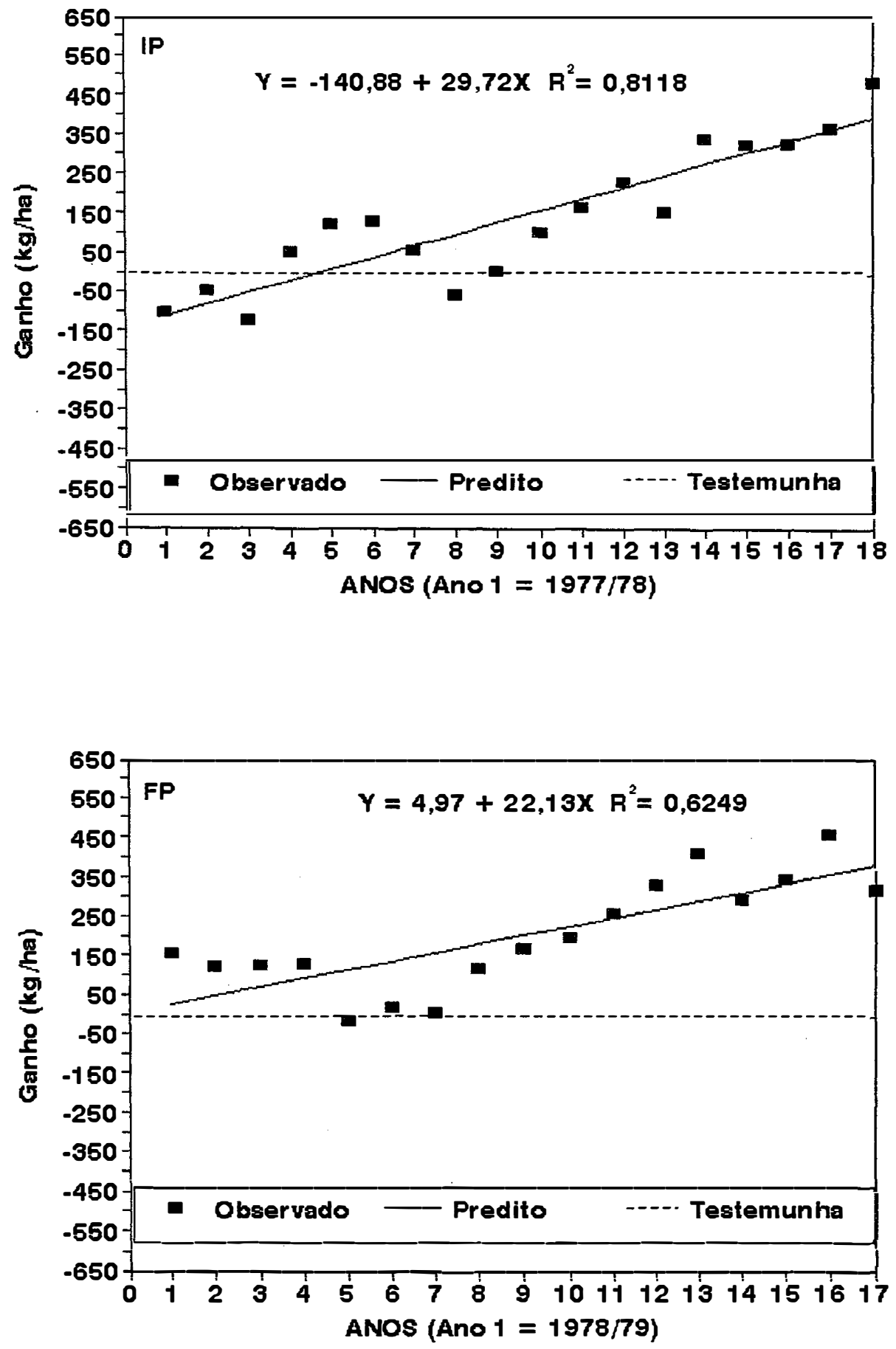

FIGURA 8. Ganhos genéticos observados $(\mathrm{kg} / \mathrm{ha})$ em relação à testemunha Rio Tibagi e preditos pela regressão dos ganhos genéticos com médias ajustadas (RA) em função dos anos, relativos aos ensaios de feijão do grupo preto: intermediários (IP) e finais (FP) respectivamente. 

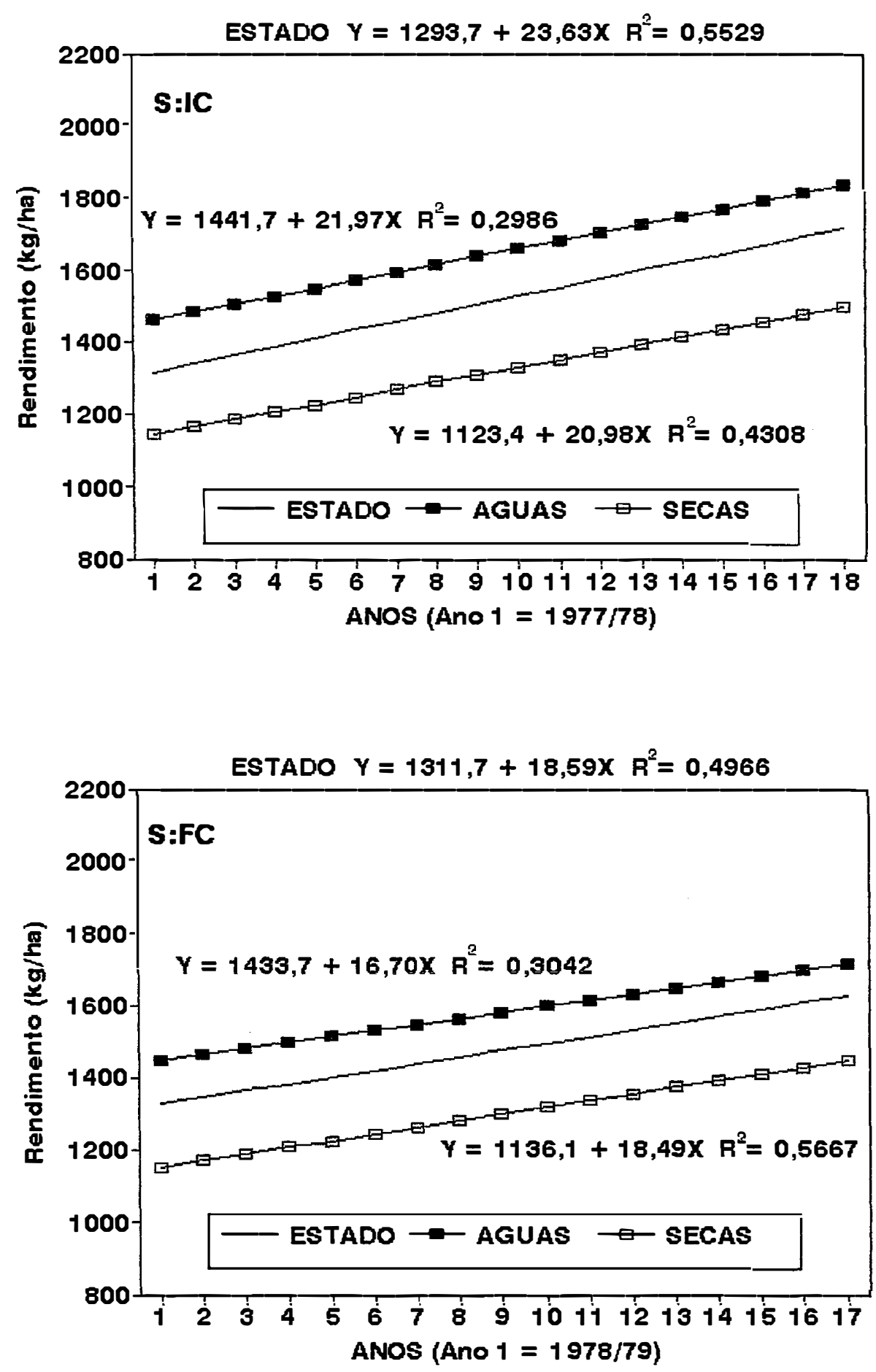

FIGURA 9. Regressões das médias ajustadas (RA) dos genótipos novos em nível estadual e em função da época de semeadura (safra: águas e secas), nos ensaios de feijão do grupo cores: intermediários (IC) e finais (FC) respectivamente. 

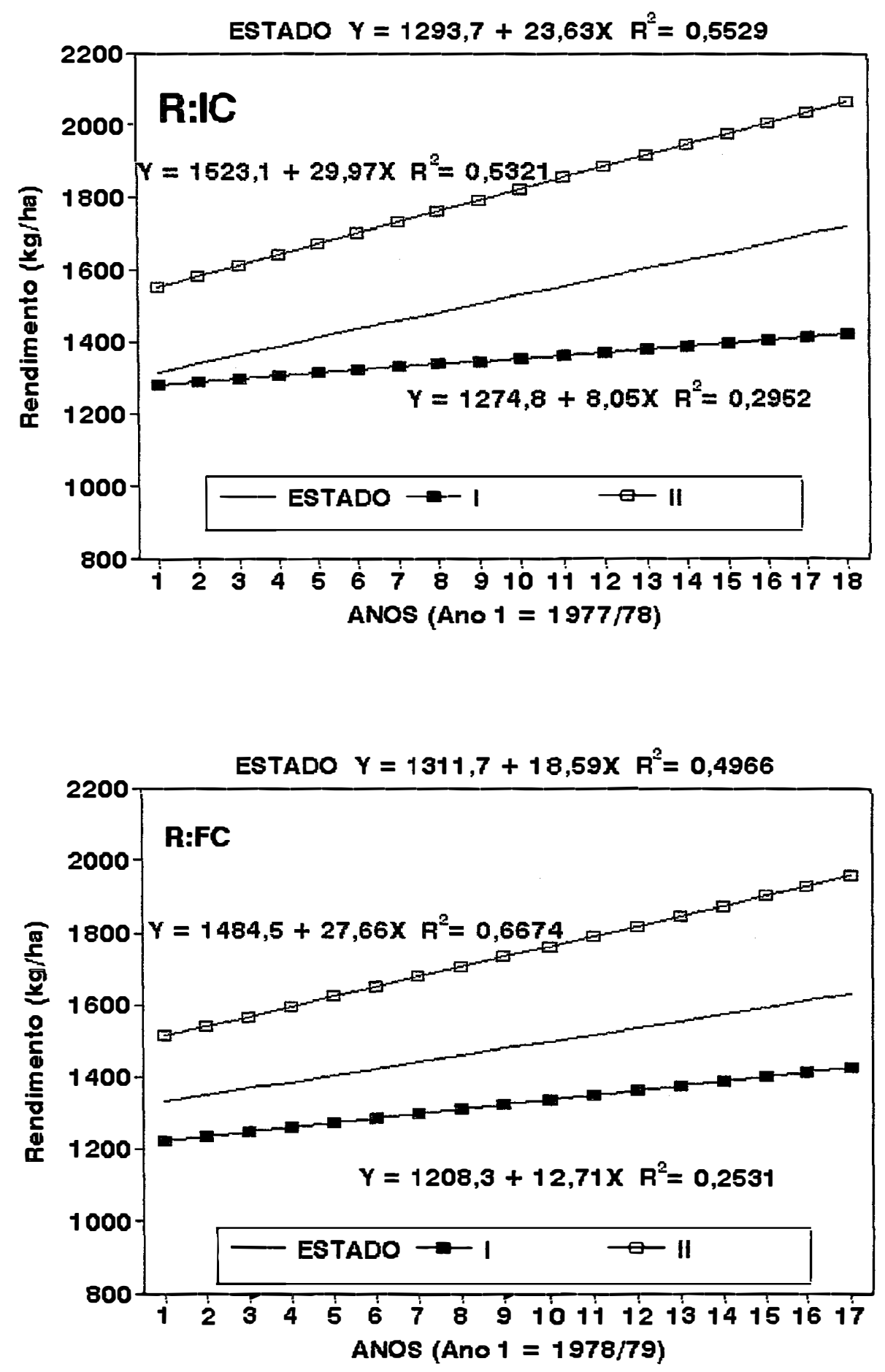

FIGURA 10. Regressões das médias ajustadas (RA) dos genótipos novos em nível estadual e em função das regiões do estado (I e II), nos ensaios de feijão do grupo cores: intermediários (IC) e finais $(\mathbf{F C})$ respectivamente. 

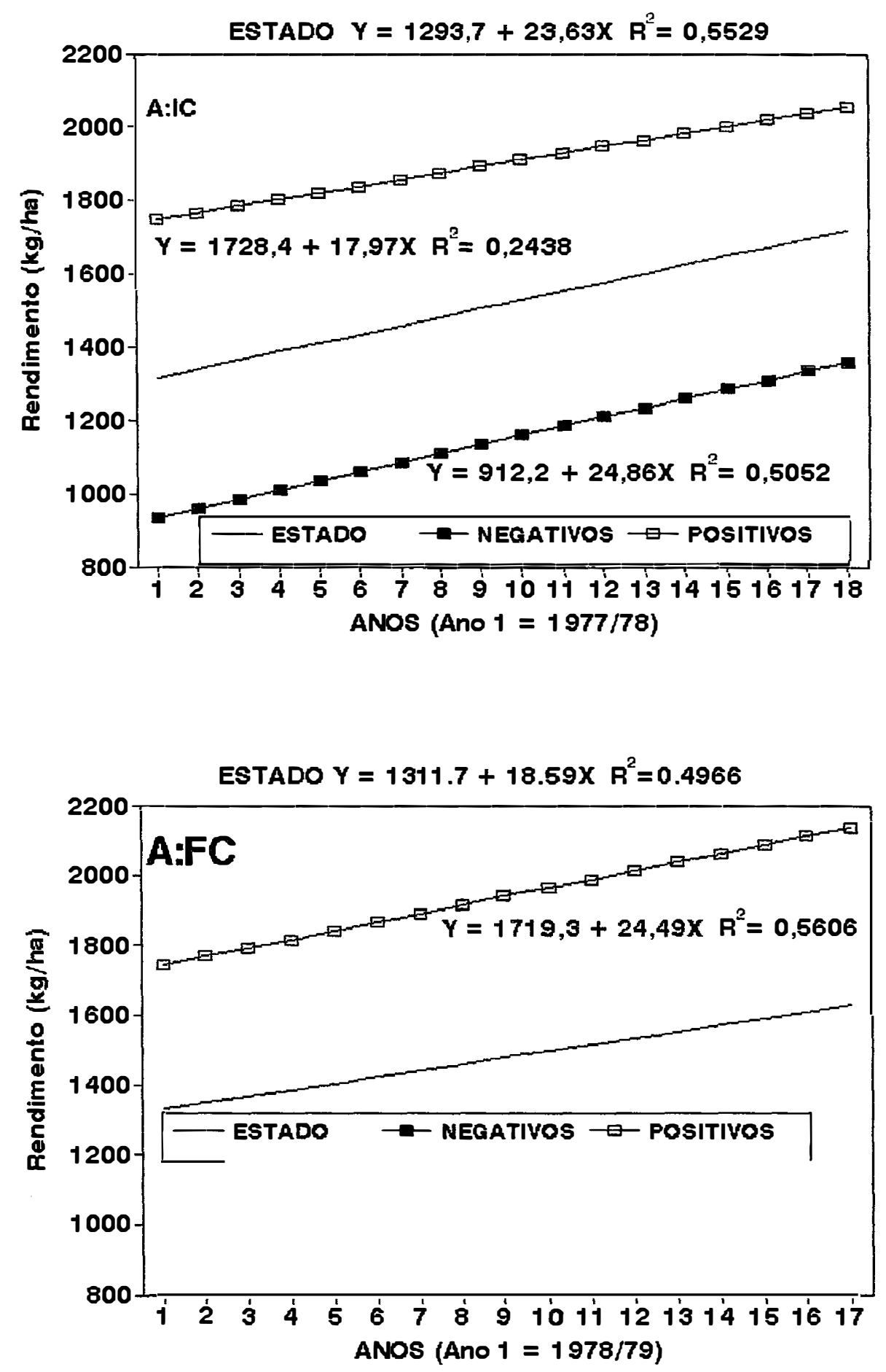

FIGURA 11. Regressões das médias ajustadas (RA) dos genótipos novos em nível estadual e em função dos ambientes (desfavoráveis e favoráveis), nos ensaios defeijão do grupo cores: intermediários (IC) e finais (FC) respectivamente. 

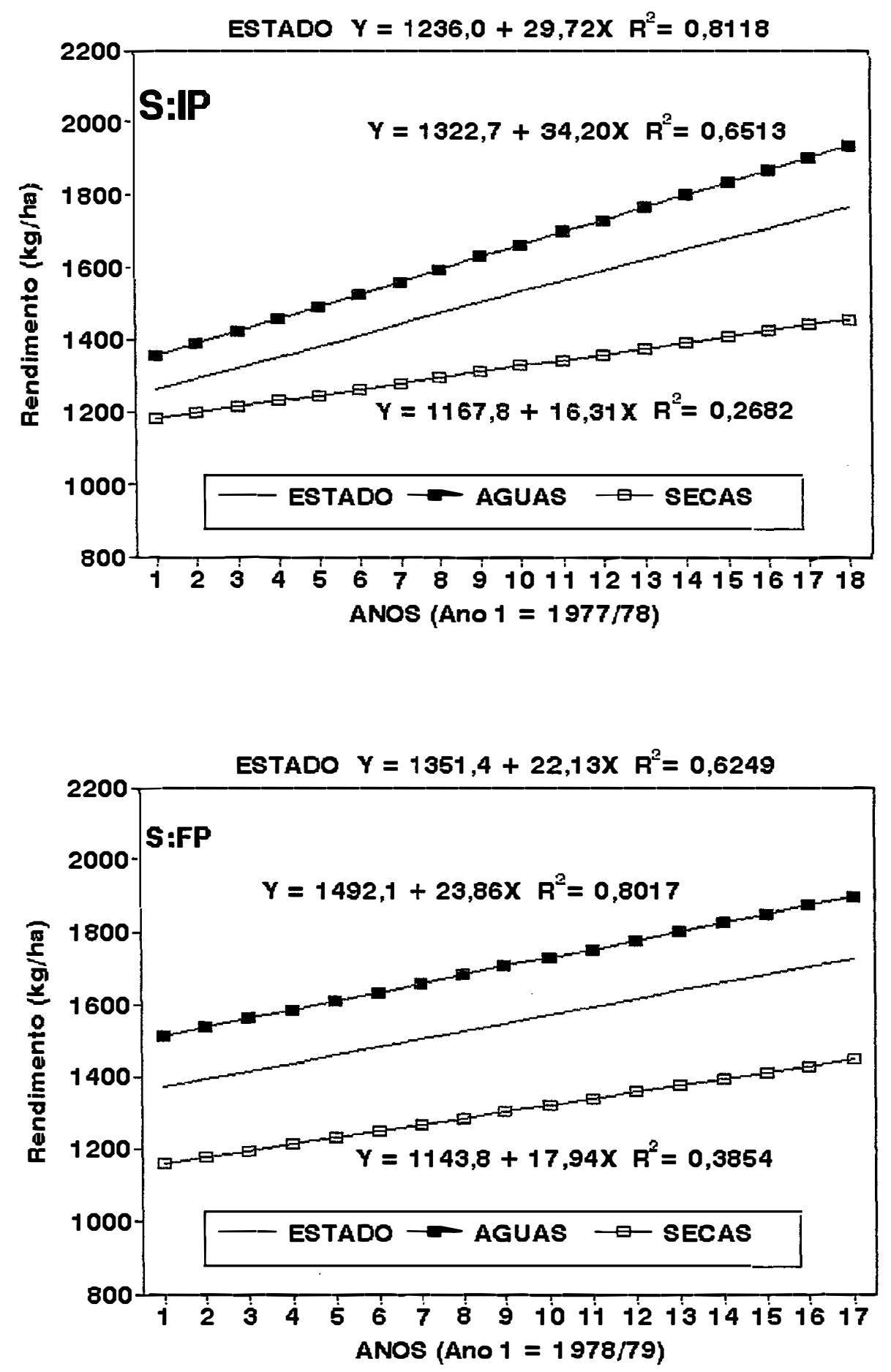

FIGURA 12. Regressões das médias ajustadas (RA) dos genótipos novos em nível estadual e em função da época de semeadura (safra: águas e secas), nos ensaios de feijão do grupo preto: intermediários (IP) e finais (FP) respectivamente. 

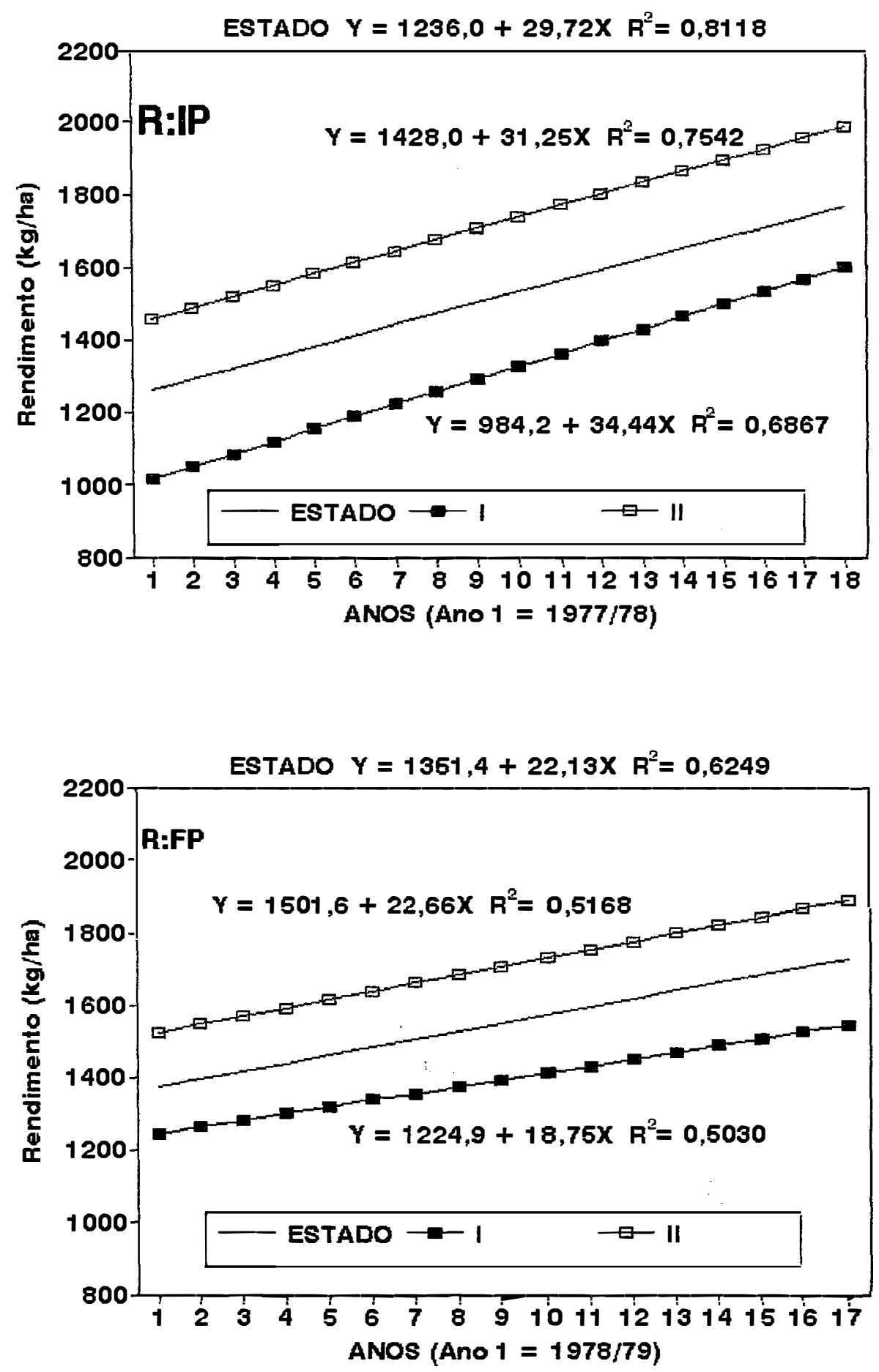

FIGURA 13. Regressões das médias ajustadas (RA) dos genótipos novos em nivel estadual e em função das regiões do estado (I e II), nos ensaios de feijão do grupo preto: intermediários (IP) e finais (FP) respectivamente. 

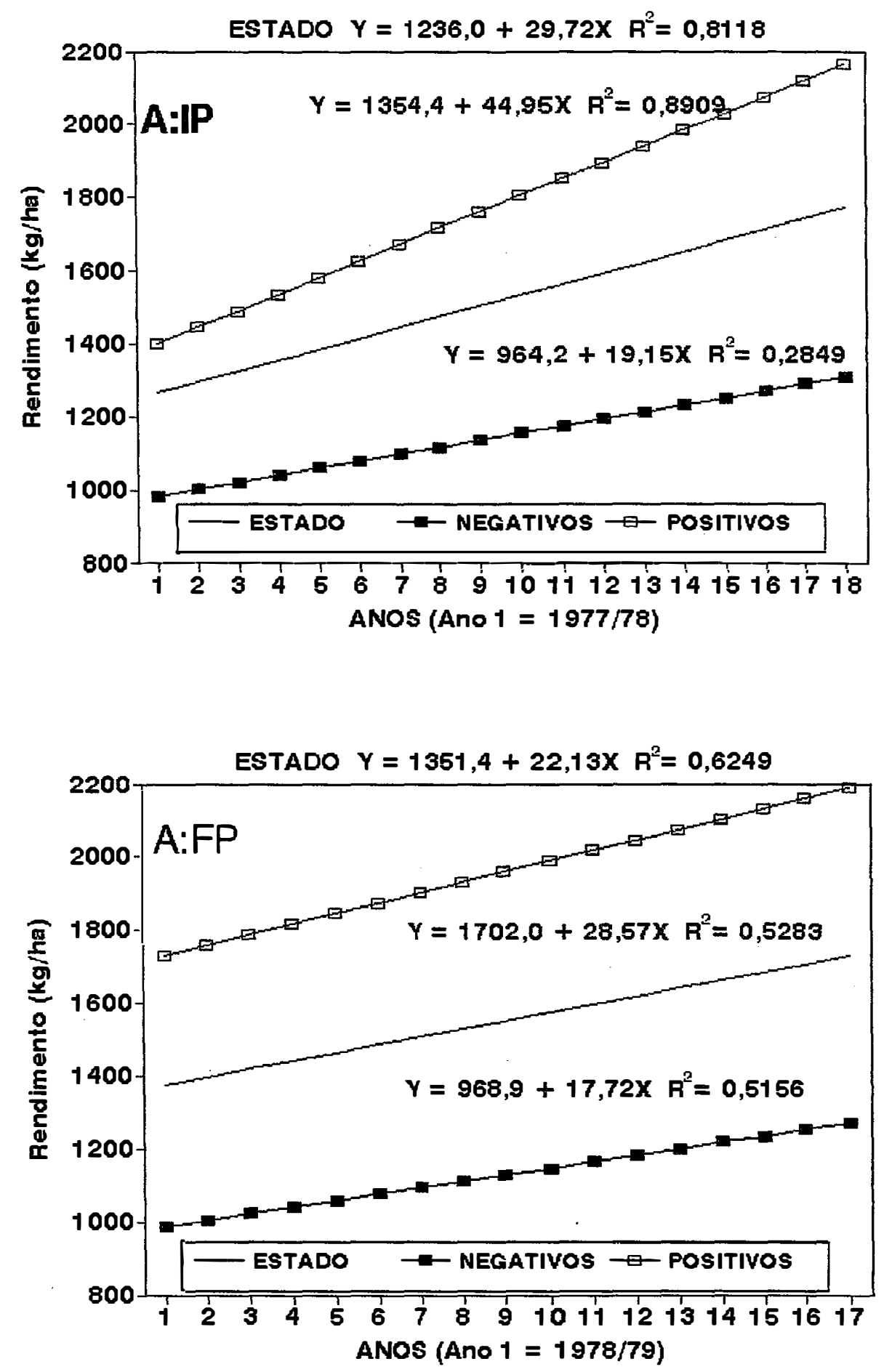

FIGURA 14. Regressões das médias ajustadas (RA) dos genótipos novos em nivel estadual e em função dos ambientes (desfavoráveis e favoráveis), nos ensaios de feijão do grupo preto: intermediários (IP) e finais (FP) respectivamente. 


\section{APÊNDICES}


Apêndice 1. Programa en SAs Versão 6.09, que executa análise de variância individual para blocos ao acaso e análise de residuos.

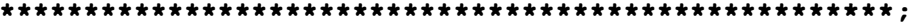

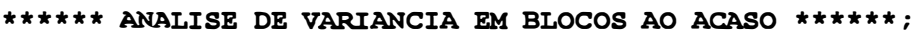

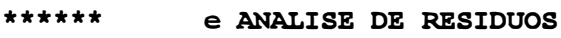
$\star \star \star \star \star \star \star ;$

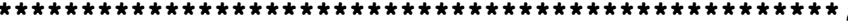

DATA D;

IENGTH REGIAO \$ 2 LOCAL \$ 16 GENOTIPO \$ 16 EXPER \$ 11 :

INPUT LOCAL \$ 1-16 TRAT 17-19 REP 20-21 POP \$ 22-23 GENOTIPO \$ 24-40

REND 41-45 ENSAIO \$ 46-47 GRUPO \$ 48-49 SAFRA \$ 50-51 REGIAO \$ 54-55

ANON 56-58 ANO \$ 59-66 EXPER \$ 67-77 ESTADO \$ 78-79;

CARDS ;

IONDRTNA

11 T CARIOCA

IONDRINA 12 T CARIOCA

LONDRINA 13 T CARIOCA

LONDRINA 14 T CARIOCA

LONDRINA $21 \mathrm{~N}$ AETE $1 / 38$

IONDRINA 22 N AETE $1 / 38$

IONDRINA 23 N AETE $1 / 38$

500 I C A I 1 1977/78 ICA77IDO1

750 I C A I 1 A $1977 / 78$ ICA77IDOI

600 I C A I 1 1977/78 ICA77ID0I

400 I $C$ A I 1 1977/78 ICA77IDO1

650 I C $\quad$ A $\quad$ I 1 1977/78 ICA77ID01

700 I C A I 1 1977/78 ICA77IDO1

620 I C A $\quad$ I 1 1977/78 ICA77IDO1

24 N AETE $1 / 38$

550 I C A $\quad$ I 1 1977/78 ICA77IDOI

- $\cdot$.

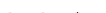

IAAPA 114 T CARIOCA

IAPA $121 \mathrm{~N}$ LP 93-56

122 N IP 93-56

123 N IP 93-56

,

910 I $\dot{c}$ i I $\dot{I} 1 \dot{8}$ i994/95 ICS95IP10

1788 I C S II 18 1994/95 ICS95LP10

2122 I C S II 18 1994/95 ICS95IP10

2357 I C S II 18 1994/95 ICS95IP10

$124 \mathrm{~N}$ LP $93-56$

IAPA

1954 I C S II 18 1994/95 ICS95IP10

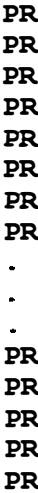

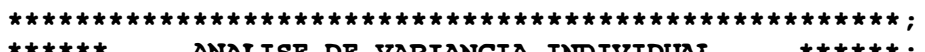

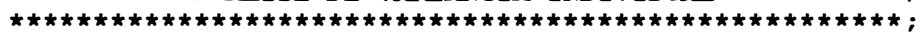

PROC SORT DATA $=D$;

BY ENSAIO GRUPO ANON ANO SAFRA REGIAO LOCAL EXPER GENOTIPO REP;

RUN ;

OPTIONS PS=55 LS=78;

PROC GLM DATA=D;

BY ENSAIO GRUPO ANON ANO SAFRA REGIAO LOCAL EXPER;

CLASSES GENOTIPO REP;

MODEL REND = GENOTIPO REP / SS3;

MRANS TRAT /TUKBY;

OUTPUT OUT = RES R = RESIDUO $\mathrm{P}=$ PREDITO $^{\prime}$;

TITIE 'ANALISE DE VARIANCIA INDIVIDUAL'; RUN ;

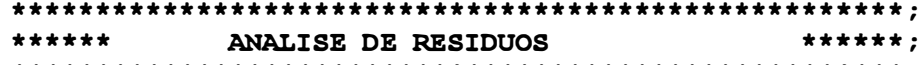

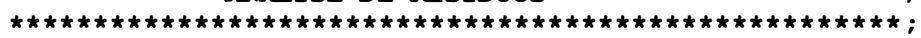

DATA RES1

SET RES ;

RUN ;

RESPERC $=$ (RESIDUO/PREDITO) *100 ;

PROC SORT DATA=RES1;

RUN :

BY ENSAIO GRUPO ANON ANO SAFRA REGIAO LOCAL EXPER DESCENDING RESPERC;

PROC PRINT NOOBS DATA=SIMPLES SPLIT='+' ;

BY ENSATO GRUPO ANON ANO SAFRA REGIAO LOCAL EXPER;

VAR GENOTIPO TRAT REP REND PREDITO RESIDUO RESPERC;

IAABEL RESPERC = 'RESIDUO+SOBRE+PREDITO+ (

TITIE 'ANAIISE DE RESIDUOS - ORDEM POR RESIDUO PBRCENTUUA' :

RUN ;

OPTIONS PS $=45$ LS $=78$;

PROC SORT DATA=RES1;

RUN ;

BY ENSAIO GRUPO ANON ANO SAFRA REGIAO LOCAL EXPER:

PROC PLOT DATA=RES1;

BY ENSAIO GRUPO ANON ANO SAFRA REGIAO LOCAL EXPER:

PLOT RESPERC*REND = $*$, VREF $=0-40.0-20.020 .040 .0$;

RUN ;

TITLE ' RESIDUO SOBRE PREDITO ( $)$ (= RESIDUO PERCENTUAI VS VALOR OBSERVADO DO REND'; 
Apêndice 2. Programa em SAS versão 6.09 para análise conjunta.

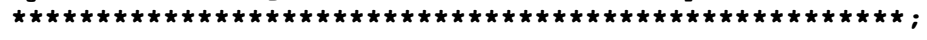

$\hbar \hbar \star \star \star \star$ ANAIISE DE VARIANCIA CONJUNTA

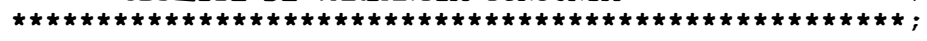

DATA D;

LENGTH REGIAO \$ 2 LOCAL \$ 16 GENOTIPO \$ 16 EXPER \$ 11;

INPUT LOCAL \$ 1-16 TRAT 17-19 REP 20-21 POP \$ 22-23 GENOTIPO \$ 24-40

RRND 41-45 ENSAIO \$ 46-47 GRUPO \$ 48-49 SAFRA \$ 50-51 REGIAO \$ 54-55

ANON 56-58 ANO \$ 59-66 EXPER \$ 67-77 ESTADO \$ 78-79;

CARDS ;

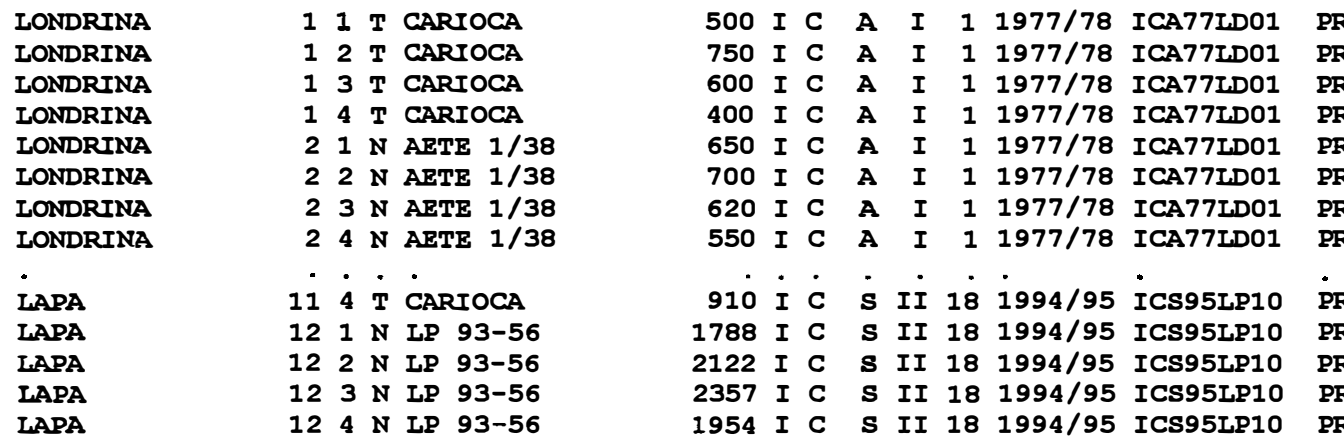

LAPA $124 \mathrm{~N}$ LP $93-56$

RUN ;

PROC SORT DATA=D;

RUN ;

BY ENSAIO GRUPO GENOTIPO EXPER REP;

OPTIONS PS $=55$ LS $=78$;

PROC GLM DATA $=D$;

BY ENSAIO GRUPO;

CLASSES GENOTIPO EXPER REP;

MODEL REND = GENOTIPO EXPER GENOTIPO*EXPER REP (EXPER) / SS3 ;

RUN ;

TITLE 'ANALISE DE VARIANCIA CONJUNTA - MODELO COMPLETO - DADOS POR REPS.' ;

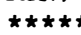

* Caso não haja memória suficiente para rodar os dados por repetição, rodar por médias*;

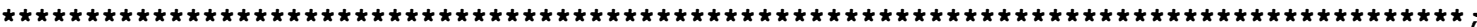

PROC MRANS NWAY MISSING NOPRINT DATA=D;

BY ENSAIO GRUPO GENOTIPO EXPER;

VAR REND;

OUTPUT OUT=MED MRAN=MEDIA N=NREP;

RUN ;

TITLE 'FAZENDO MEDIAS POR GENOTIPO E POR EXPERIMENTO';

PROC SORT DATA=MED;

BY ENSAIO GRUPO GENOTIPO EXPER;

RUN ;

PROC GLM DATA=MRD;

BY ENSAIO GRUPO;

CLASSES GENOTIPO EXPER;

MODEL MEDIA = GENOTIPO EXPER / SS3;

RUN ;

TITLE1 'ANALISE DE VARIANCIA CONJUNTA - DADOS POR MEDIAS'; TITLE2 'QMERRO = QMGXE';

PROC SORT DATA $=D$;

BY ENSAIO GRUPO EXPER GENOTIPO REP;

RUN ;

PROC GLM DATA=D NOPRINT OUTSTAT=ANAVAIND ;

BY ENSAIO GRUPO EXPER:

CLASSES GENOTIPO REP;

MODEL REND = GENOTIPO REP / SS3;

TITLE 'ANALISE DE VARIANCIA INDIVIDUAL';

RUN ;

PROC SORT DATA=ANAVAIND;

BY ENSATO GRUPO SOURCE_; RUN;

PROC MRANS NWAY MISSIN $\bar{G}$ SUM DATA $=D$;

BY ENSAIO GRUPO _SOURCE_;

VAR SS DF;

TITLE1 ' $\mathrm{SS}=\mathrm{SQ}$ '; TITLE2 'DF = GL';

RUN ; 
Apêndice 3. Programa em SAS Versão 6.09 de análise de variância para modelos mistos e estimativas de BLUEs e BLUPs, e estimativas de ganho genético pelo método da regressão das médias ajustadas (LSMRANS) em funçăo dos anos.

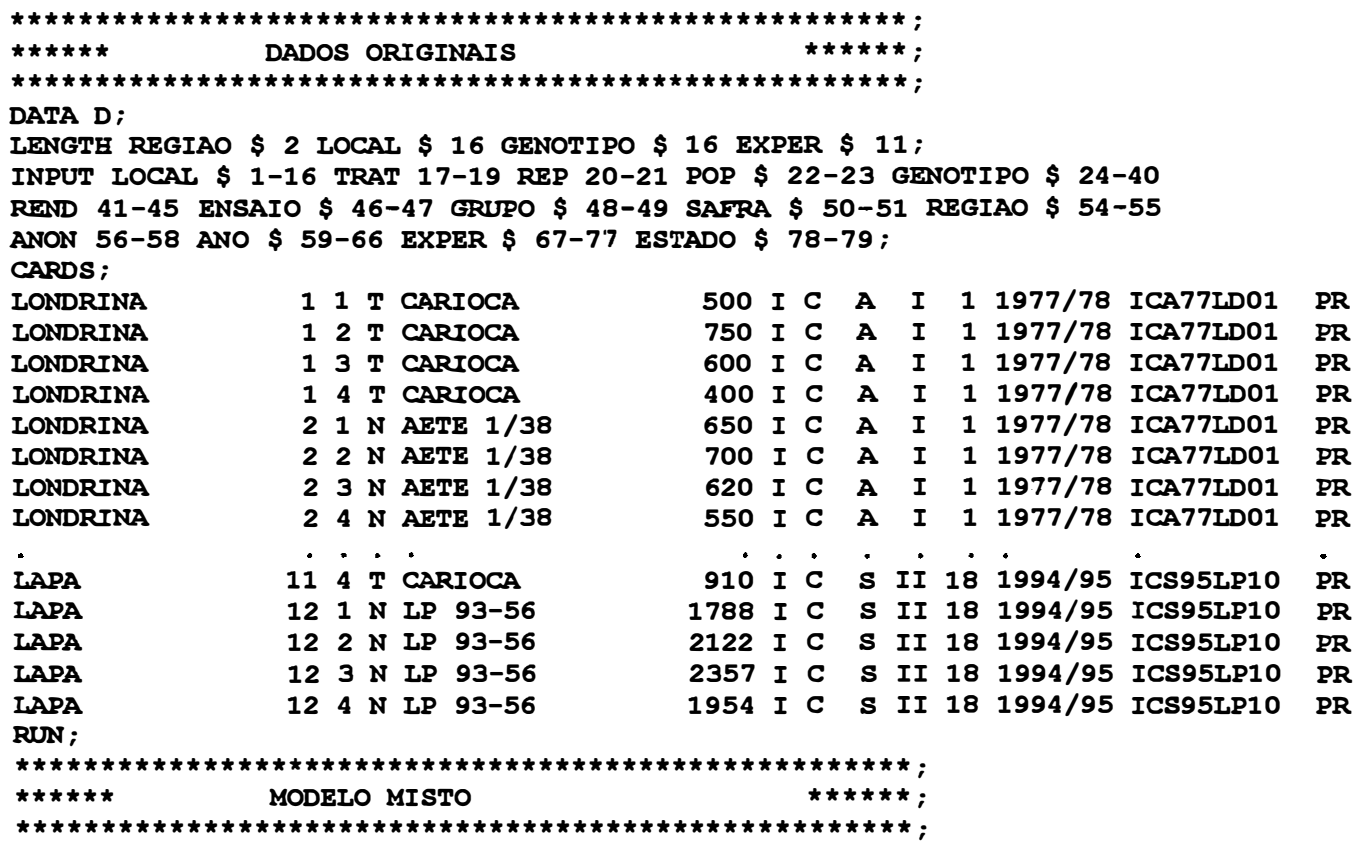

PROC SORT DATA=D;

RUN ;

BY ESTADO ENSAIO GRUPO ANON ANO SAFRA REGIAO LOCAI GENOTIPO EXPER REP;

OPTIONS PS $=55$ LS $=78$;

PROC MIXED DATA=D INFO UPDATE;

BY ESTADO ENSAIO GRUPO;

CLASS GENOTIPO EXPER REP;

MODEL REND = GENOTIPO / $S$; * /S FOrnece OS BLUES de GENOTIPOS ** ;

RANDOM EXPER EXPER*GENOTIPO REP(EXPER) / $\mathrm{S}$; */S FOrnece Os BLUPs $\star \star \star *$; LSMBANS GENOTIPO; * LSMRANS FOInece as MEDIAS AJUSTADAS ***;

MAKE 'LSMRANS' OUT=LSGENG:

RUN ;

TITLE 'APENAS GENOTIPO FIXO - MODELO COMPLETO - DADOS POR REPS. ';

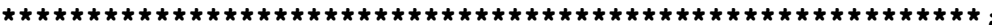

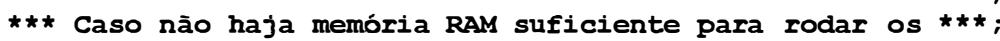

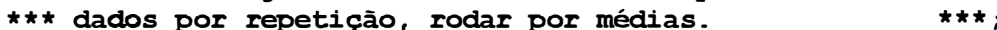

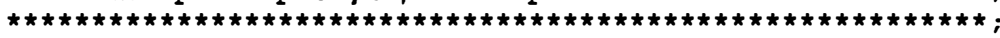

PROC MRANS NWAY MISSING NOPRINT DATA=D;

BY ESTADO ENSAIO GRUPO GENOTIPO EXPER;

VAR REND;

OUTPUT OUT=MRD MRAN=MRDIA N=NREP;

TITLE 'FAZENDO MEDIAS POR GENOTIPO E POR EXPERIMENTO';

PROC SORT DATA $=$ MRD;

RUN;

BY ESTADO ENSAIO GRUPO GENOTIPO EXPER;

PROC MIXED DATA=D INFO UPDATE;

BY ESTADO ENSAIO GRUPO

CLASS GENOTIPO EXPER;

MODEL REND = GENOTIPO $/ S$; * /S FOrnece OS BLUES de GENOTIPOS *** ;

RANDOM EXPER / $;$; * /S FOrnece OS BLUPS ***;

ISMRANS GENOTIPO; * ISMRANS FOrnece as MRDIAS AUUSTADAS * * ;

MAKE 'LSMRANS' OUT=LSGENG;

RUN ;

TITLE 'APENAS GENOTIPO FIXO - MODELO COMPLETO - DADOS POR MEDIAS.'; 


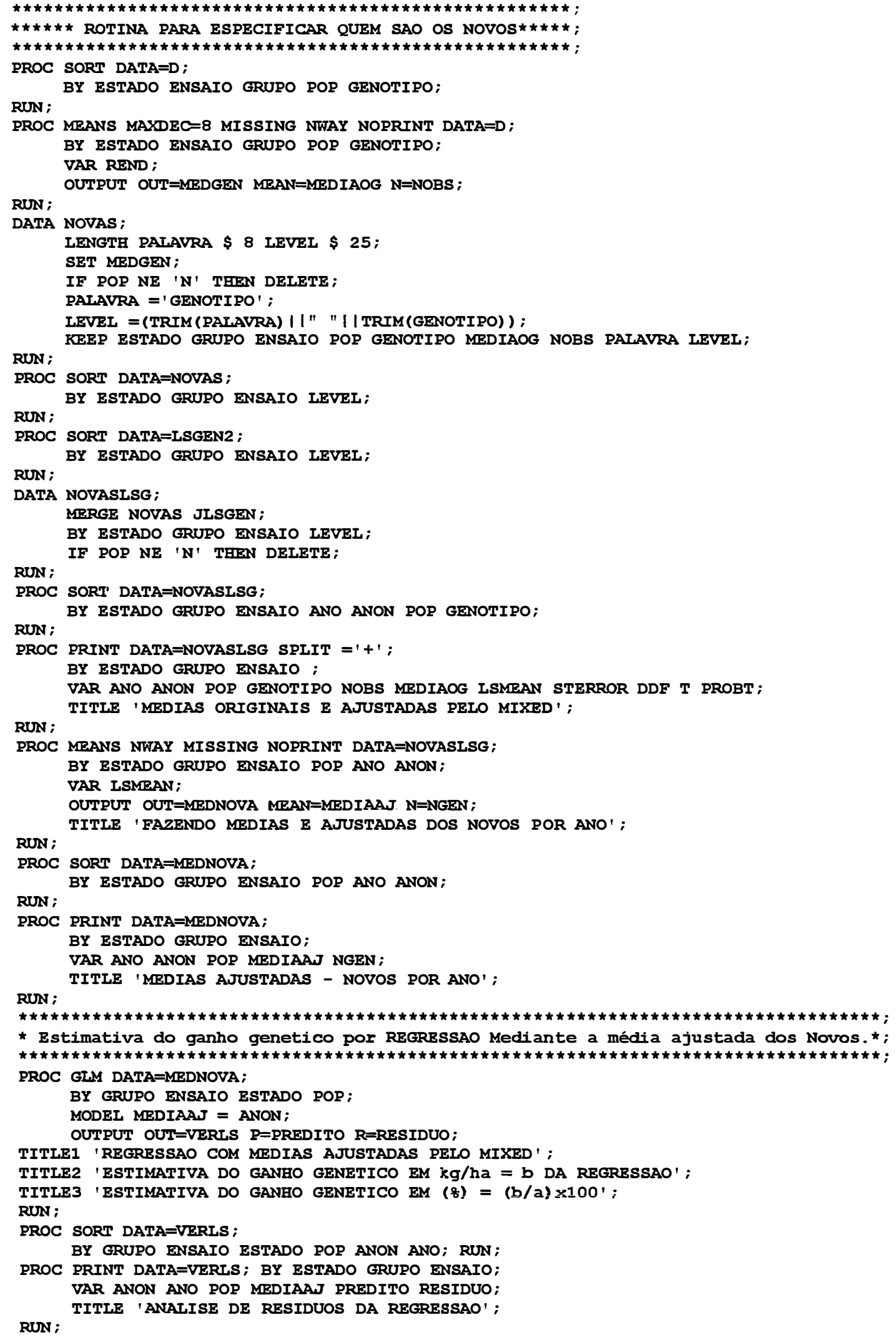

PROC MRANS NWAY MISSING NOPRINT DATA=NOVASLSG; BY ESTADO GRUPO ENSAIO POP ANO ANON;

VAR LSMEAN; OUTPUT OUT=MEDNOVA MEAN=MEDIAAN. N=NGEN ; RUN ; TITLE 'FAZENDO MEDIAS E AJUSTADAS DOS NOVOS POR ANO';

PROC SORT DATA=MEDNOVA;

BY ESTADO GRUPO ENSAIO POP ANO ANON;

RUN ;

PROC PRINT DATA=MEDNOVA;

BY ESTADO GRUPO ENSAIO:

VAR ANO ANON POP MEDIAAN NGEN; RUN ; TITLE 'MRDIAS AJUSTADAS - NOVOS POR ANO';

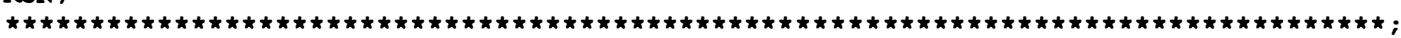

* Estimativa do ganho genetico por REGRBSSAO Mediante a média ajustada dos Novos. ;

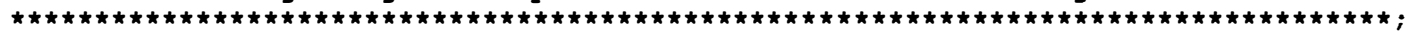
PROC GIM DATA=MEDNOVA;

BY GRUPO ENSAIO ESTADO POP;

MODEL MEDIAAJ = ANON

OUTPUT OUT=VERIS P=PREDITO R=RESIDUO;

TITLE1 'REGRESSAO COM MEDIAS AJUSTADAS PELO MIXED' ;

TITLE2 'ESTIMATIVA DO GANHO GENETICO EM kg/ha = b DA REGRBSAO' :

TITLE3 'ESTIMATIVA DO GANHO GENETICO EM $(q)=(b / a) \times 100$ ';

RUN ;

PROC SORT DATA=VRRL ;

BY GRUPO ENSAIO ESTADO POP ANON ANO; RUN;

PROC PRINT DATA=VERIS; BY ESTADO GRUPO ENSAIO; VAR ANON ANO POP MEDIAAJ PREDITO RESIDUO; TITLE 'ANALISE DE RESIDUOS DA REGRESSAO';

RUN ; 
Apêndice 4. Exemplo da obtenção das médias ajustadas para o método de estimação de ganho genético médio pela regressão com médias ajustadas (RA).

Para melhor visualização das estruturas das matrizes trabalhadas nos modelos mistos, é proposto um exemplo adaptado de DELACY et alii, (1996), no item 4.32 de seu artigo, contendo dois genótipos, em dois ambientes com duas repetições em cada ambiente, totalizando oito dados. Incialmente supõe-se um modelo fixo :

$Y_{i j k}=\mu+g_{i}+a_{j}+g a_{i j}+r_{k(j)}+e_{i j k}$, onde

$Y_{i j k}$ é o valor observado do genótipo i no ambiente $\mathrm{j}$ na repetição k;

$\mu \quad$ é a média geral;

$\mathrm{g}_{\mathrm{i}} \quad$ é o efeito do genótipo $\mathrm{i}(\mathrm{i}=1,2 \ldots, \mathrm{G})$;

$a_{j} \quad$ é o efeito do ambiente $\mathrm{j}(\mathrm{j}=1,2 \ldots, \mathrm{A})$;

$\mathrm{ga}_{\mathrm{ij}}$ é o efeito da interação do genótipo i com o ambiente $\mathrm{j}$;

$\mathrm{r}_{\mathrm{k}(\mathrm{j})}$ é o efeito da repetição $\mathrm{k}$ dentro do ambiente $\mathrm{j}(\mathrm{k}=1,2 \ldots, \mathrm{R})$;

$\mathrm{e}_{\mathrm{ijk}} \quad$ é o erro experimental associado à parcela $\mathrm{ijk}$.

Este mesmo modelo fixo, pode ser expresso em termos matriciais:

$$
\mathrm{Y}=\mathrm{X} \beta+\mathrm{E} \text {, onde }
$$


$\mathrm{Y}=\left[\begin{array}{l}\mathrm{y}_{111} \\ \mathrm{y}_{112} \\ \mathrm{y}_{121} \\ \mathrm{y}_{122} \\ \mathrm{y}_{211} \\ \mathrm{y}_{212} \\ \mathrm{y}_{221} \\ \mathrm{y}_{222}\end{array}\right], \mathrm{X}=\left[\begin{array}{lllllllllllll}1 & 1 & 0 & 1 & 0 & 1 & 0 & 0 & 0 & 1 & 0 & 0 & 0 \\ 1 & 1 & 0 & 1 & 0 & 1 & 0 & 0 & 0 & 0 & 1 & 0 & 0 \\ 1 & 1 & 0 & 0 & 1 & 0 & 1 & 0 & 0 & 0 & 0 & 1 & 0 \\ 1 & 1 & 0 & 0 & 1 & 0 & 1 & 0 & 0 & 0 & 0 & 0 & 1 \\ 1 & 0 & 1 & 1 & 0 & 0 & 0 & 1 & 0 & 1 & 0 & 0 & 0 \\ 1 & 0 & 1 & 1 & 0 & 0 & 0 & 1 & 0 & 0 & 1 & 0 & 0 \\ 1 & 0 & 1 & 0 & 1 & 0 & 0 & 0 & 1 & 0 & 0 & 1 & 0 \\ 1 & 0 & 1 & 0 & 1 & 0 & 0 & 0 & 1 & 0 & 0 & 0 & 1\end{array}\right], \beta=\left[\begin{array}{c}\mu \\ g_{1} \\ g_{2} \\ a_{1} \\ a_{2} \\ (\mathrm{ga})_{11} \\ (\mathrm{ga})_{12} \\ (\mathrm{ga})_{21} \\ (\mathrm{ga})_{22} \\ \mathrm{r}_{1}\left(\mathrm{a}_{1}\right) \\ \mathrm{r}_{2}\left(\mathrm{a}_{1}\right) \\ \mathrm{r}_{1}\left(\mathrm{a}_{2}\right) \\ \mathrm{r}_{2}\left(\mathrm{a}_{2}\right) \\ \left.\varepsilon_{2}\right)\end{array}\right], \mathrm{E}=\left[\begin{array}{l}\varepsilon_{111} \\ \varepsilon_{112} \\ \varepsilon_{121} \\ \varepsilon_{122} \\ \varepsilon_{211} \\ \varepsilon_{212} \\ \varepsilon_{221} \\ \varepsilon_{222}\end{array}\right]$

Considerando-se os efeitos dos genótipos como fixos e os demais termos do modelo como aleatórios, tem-se o modelo misto :

$$
\mathrm{Y}=\mathrm{X} \beta+\mathrm{ZU}+\mathrm{E} \text {, onde }
$$

$\mathrm{Y}=\left[\begin{array}{l}\mathrm{y}_{111} \\ \mathrm{y}_{112} \\ \mathrm{y}_{121} \\ \mathrm{y}_{122} \\ \mathrm{y}_{211} \\ \mathrm{y}_{212} \\ \mathrm{y}_{221} \\ \mathrm{y}_{222}\end{array}\right], \mathrm{X}=\left[\begin{array}{lll}1 & 1 & 0 \\ 1 & 1 & 0 \\ 1 & 1 & 0 \\ 1 & 1 & 0 \\ 1 & 0 & 1 \\ 1 & 0 & 1 \\ 1 & 0 & 1 \\ 1 & 0 & 1\end{array}\right], \beta=\left[\begin{array}{l}\mu \\ g_{1} \\ g_{2}\end{array}\right], Z=\left[\begin{array}{llllllllll}1 & 0 & 1 & 0 & 0 & 0 & 1 & 0 & 0 & 0 \\ 1 & 0 & 1 & 0 & 0 & 0 & 0 & 1 & 0 & 0 \\ 0 & 1 & 0 & 1 & 0 & 0 & 0 & 0 & 1 & 0 \\ 0 & 1 & 0 & 1 & 0 & 0 & 0 & 0 & 0 & 1 \\ 1 & 0 & 0 & 0 & 1 & 0 & 1 & 0 & 0 & 0 \\ 1 & 0 & 0 & 0 & 1 & 0 & 0 & 1 & 0 & 0 \\ 0 & 1 & 0 & 0 & 0 & 1 & 0 & 0 & 1 & 0 \\ 0 & 1 & 0 & 0 & 0 & 1 & 0 & 0 & 0 & 1\end{array}\right], U=\left[\begin{array}{c}a_{1} \\ a_{2} \\ (g a)_{11} \\ (g a)_{12} \\ (g a)_{21} \\ (g a)_{22} \\ r_{1}\left(a_{1}\right) \\ r_{2}\left(a_{1}\right) \\ r_{1}\left(a_{2}\right) \\ r_{2}\left(a_{2}\right)\end{array}\right] E=\left[\begin{array}{l}\varepsilon_{111} \\ \varepsilon_{112} \\ \varepsilon_{121} \\ \varepsilon_{122} \\ \varepsilon_{211} \\ \varepsilon_{212} \\ \varepsilon_{221} \\ \varepsilon_{222}\end{array}\right]$

A próxima etapa é estimar os componentes de variância dos fatores aleatórios e do erro experimental, que podem ser obtidas por processo iterativo com o procedimento REML, para em seguida, compor as matrizes $\mathrm{G}$ e $\mathrm{R}$, segundo as mesmas pressuposições adotadas no trabalho real. 


$$
\mathbf{G}=\left[\begin{array}{cccccccccc}
\sigma_{\mathrm{a}}^{2} & 0 & 0 & 0 & 0 & 0 & 0 & 0 & 0 & 0 \\
0 & \sigma_{\mathrm{a}}^{2} & 0 & 0 & 0 & 0 & 0 & 0 & 0 & 0 \\
0 & 0 & \sigma_{\mathrm{ga}}^{2} & 0 & 0 & 0 & 0 & 0 & 0 & 0 \\
0 & 0 & 0 & \sigma_{\mathrm{ga}}^{2} & 0 & 0 & 0 & 0 & 0 & 0 \\
0 & 0 & 0 & 0 & \sigma_{\mathrm{ga}}^{2} & 0 & 0 & 0 & 0 & 0 \\
0 & 0 & 0 & 0 & 0 & \sigma_{\mathrm{ga}}^{2} & 0 & 0 & 0 & 0 \\
0 & 0 & 0 & 0 & 0 & 0 & \sigma_{\mathrm{r} / \mathrm{a}}^{2} & 0 & 0 & 0 \\
0 & 0 & 0 & 0 & 0 & 0 & 0 & \sigma_{\mathrm{r} / \mathrm{a}}^{2} & 0 & 0 \\
0 & 0 & 0 & 0 & 0 & 0 & 0 & 0 & \sigma_{\mathrm{r} / \mathrm{a}}^{2} & 0 \\
0 & 0 & 0 & 0 & 0 & 0 & 0 & 0 & 0 & \sigma_{\mathrm{r} / \mathrm{a}}^{2}
\end{array}\right] \quad \mathbf{R}=\left[\begin{array}{cccccccccc}
\sigma^{2} & 0 & 0 & 0 & 0 & 0 & 0 & 0 \\
0 & \sigma^{2} & 0 & 0 & 0 & 0 & 0 & 0 \\
0 & 0 & \sigma^{2} & 0 & 0 & 0 & 0 & 0 \\
0 & 0 & 0 & \sigma^{2} & 0 & 0 & 0 & 0 \\
0 & 0 & 0 & 0 & \sigma^{2} & 0 & 0 & 0 \\
0 & 0 & 0 & 0 & 0 & \sigma^{2} & 0 & 0 \\
0 & 0 & 0 & 0 & 0 & 0 & \sigma^{2} & 0 \\
0 & 0 & 0 & 0 & 0 & 0 & 0 & \sigma^{2}
\end{array}\right]
$$

Com todas as matrizes conhecidas, estima-se os efeitos de genótipos fixos (BLUEs), através da expressão, já descrita anteriormente em material e métodos:

$$
\hat{\beta}=\left(X^{\prime} V^{-1} X\right)^{-1} X^{\prime} V^{-1} Y
$$

Resultando nos seguintes valores:

$$
\begin{aligned}
& g_{1}=-150.00 \\
& g_{2}=0.00
\end{aligned}
$$

Estimados os efeitos de genótipos, adiciona-se a estes a média geral, para serem otidas as médias ajustadas dos respectivos genótipos:

Média ajustada de $\mathrm{g}_{1}=1725.00$

Média ajustada de $g_{2}=1875.00$

Este mesmo exemplo, ao ser processado pelo procedimento PROC MIXED do SAS, versão 6.09, gera os seguintes resultados: 


$\begin{array}{ccccr}\begin{array}{l}\text { Dados } \\ \text { OBS }\end{array} & \text { Griginais } & \text { A } & \text { R } & \text { Y } \\ & & & & \\ 1 & \text { G1 } & \text { A1 } & 1 & 1000 \\ 2 & \text { G1 } & \text { A1 } & 2 & 900 \\ 3 & \text { G1 } & \text { A2 } & 1 & 2000 \\ 4 & \text { G1 } & \text { A2 } & 2 & 3000 \\ 5 & \text { G2 } & \text { A1 } & 1 & 1200 \\ 6 & \text { G2 } & \text { A1 } & 2 & 2500 \\ 7 & \text { G2 } & \text { A2 } & 1 & 1700 \\ 8 & \text { G2 } & \text { A2 } & 2 & 2100\end{array}$

Modelo apenas com genótipos fixos

The MIXFD Procedure

Model Information

$\begin{array}{ll}\text { Description } & \text { Value } \\ \text { Data Set } & \text { WORK.D } \\ \text { Dependent Variable } & \text { Y } \\ \text { Covariance Structure } & \text { Variance Components } \\ \text { Residual Variance Method } & \text { Profile } \\ \text { Estimation Method } & \text { REMr }\end{array}$

The MIXED Procedure

Class Level Information

Class Levels Values

G 2 G1 G2

R $\quad 2$ I 12

The MIXED Procedure

Dimensions

Description

Covariance Parameters

Columins in $\mathrm{X}$

Columns in 2

subjects

Max Obs Per subject

Observations Used

Observations Not Used

Total Observations
Value

4

3

10

1

8

8 
The MIXED Procedure

REMI Estimation Iteration History

$\begin{array}{rrrr}\text { Iteration } & \text { Evaluations } & \text { objective } & \text { Criterion } \\ 0 & 1 & 88.98011186 & \\ 1 & 1 & 87.84321425 & 0.00000000\end{array}$

Convergence criteria met.

The MIXED Procedure

Covariance Parameter Estimates (REML)

\begin{tabular}{lrrrrr} 
Cov Parm & Ratio & Estimate* & Std Error & $Z$ & Pr $>|z|$ \\
A & & & & & \\
$G * A$ & 0.01724138 & 5000.0000000 & 616075.02587 & 0.01 & 0.9935 \\
R(A) & 1.43965517 & 417500.00000 & 808602.18897 & 0.52 & 0.6056 \\
Residual & 0.23275862 & 67500.000000 & 257257.16705 & 0.26 & 0.7930 \\
\hline & 1.00000000 & 290000.00000 & 290000.00000 & 1.00 & 0.3173
\end{tabular}

* Estimativas dos componentes de variância

The MIXED Procedure

Model Fitting Information for $Y$

Description

Observations

Variance Estimate

standard Deviation Estimate REMI Log Likelihood

Akaike's Information Criterion Schwarz's Bayesian Criterion -2 RBMI Log Likelihood

\section{Value}

8.0000 290000.0 538.5165 $-49.4352$

$-53.4352$

$-53.0188$

98.8705

The MIXED Procedure

Solution for Fixed Effects (BLUEs)

$\begin{array}{lrrrrr}\text { Parameter } & \text { Estimate } & \text { Std Error } & \text { DDF } & T & \text { Pr > I T | } \\ & & & & & \\ \text { INTERCEPT } & 1875.0000000 & 548.29280499 & 2 & 3.42 & 0.0759 \\ \text { G G1 } & -150.0000000 & 750.00000000 & 2 & -0.20 & 0.8600 \\ \text { G G2 } & 0.00000000 & . & . & . & .\end{array}$


The MIXED Procedure Solution for Random Effects (BLUPs)

Parameter

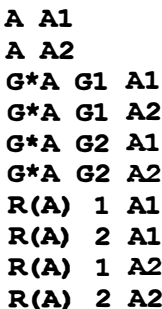

Estimate

$-6.25000000$

6.25000000

$-539.2708333$

539.27083333

17.39583333

$-17.39583333$

$-137.4816176$

53.10661765

$-68.98897059$

153.36397059

Std Error

70.43392293

70.43392293

521.48075386

521.48075386

521.48075386

521.48075386

234.51999192

234.51999192

234.51999192

234.51999192
DDF

T $\operatorname{Pr}>|\mathrm{T}|$

The MIXED Procedure

Tests of Fixed Effects

Source

NDF DDF TYPe III $F \quad$ Pr $>F$

G

11

$0.04 \quad 0.8743$

The MIXID Procedure

Least Squares Means (Médias Ajustadas)

Level

LSMEAAN

std Error

DDF

T $\operatorname{Pr}>|T|$

G G1

G G2

1725.0000000

1875.0000000
548.29280499

548.29280499
3.15

3.42
0.9374

0.9374

0.4097

0.4097

0.9764

0.9764

0.6171

0.8419

0.7963

0.5803

The MIXID Procedure

Predicted Values

$\begin{array}{llllrrrr}\text { Observed } & \text { Predicted } & \text { Var Pred } & \text { SE Pred } & \text { L95M } & \text { U95M } & \text { Residual } \\ & & & & & & \\ 1000.000 & 1041.9975 & 150472.1 & 387.9073 & -627.033 & 2711.028 & -\mathbf{- 4 1 . 9 9 7 5} \\ 900.0000 & 1232.5858 & 150472.1 & 387.9073 & -436.445 & 2901.616 & -332.586 \\ 2000.000 & 2201.5319 & 150472.1 & 387.9073 & 532.5014 & 3870.562 & -201.532 \\ 3000.000 & 2423.8848 & 150472.1 & 387.9073 & 754.8544 & 4092.915 & 576.1152 \\ 1200.000 & 1748.6642 & 150472.1 & 387.9073 & 79.6338 & 3417.695 & -548.664 \\ 2500.000 & 1939.2525 & 150472.1 & 387.9073 & 270.2220 & 3608.283 & 560.7475 \\ 1700.000 & 1794.8652 & 150472.1 & 387.9073 & 125.8348 & 3463.896 & -94.8652 \\ 2100.000 & 2017.2181 & 150472.1 & 387.9073 & 348.1877 & 3686.249 & 82.7819\end{array}$

ORDEM pOr LSMRAN (Média Ajustada)

$\begin{array}{crrrrrr}\text { OBS } & \text { LEVEL } & \text { LSMEAN } & \text { SE } & \text { DDF } & \text { T } & \text { P_T } \\ 1 & \text { G G2 } & 1875.0000000 & 548.29280499 & 2 & 3.42 & 0.0759 \\ 2 & \text { G G1 } & 1725.0000000 & 548.29280499 & 2 & 3.15 & 0.0879\end{array}$




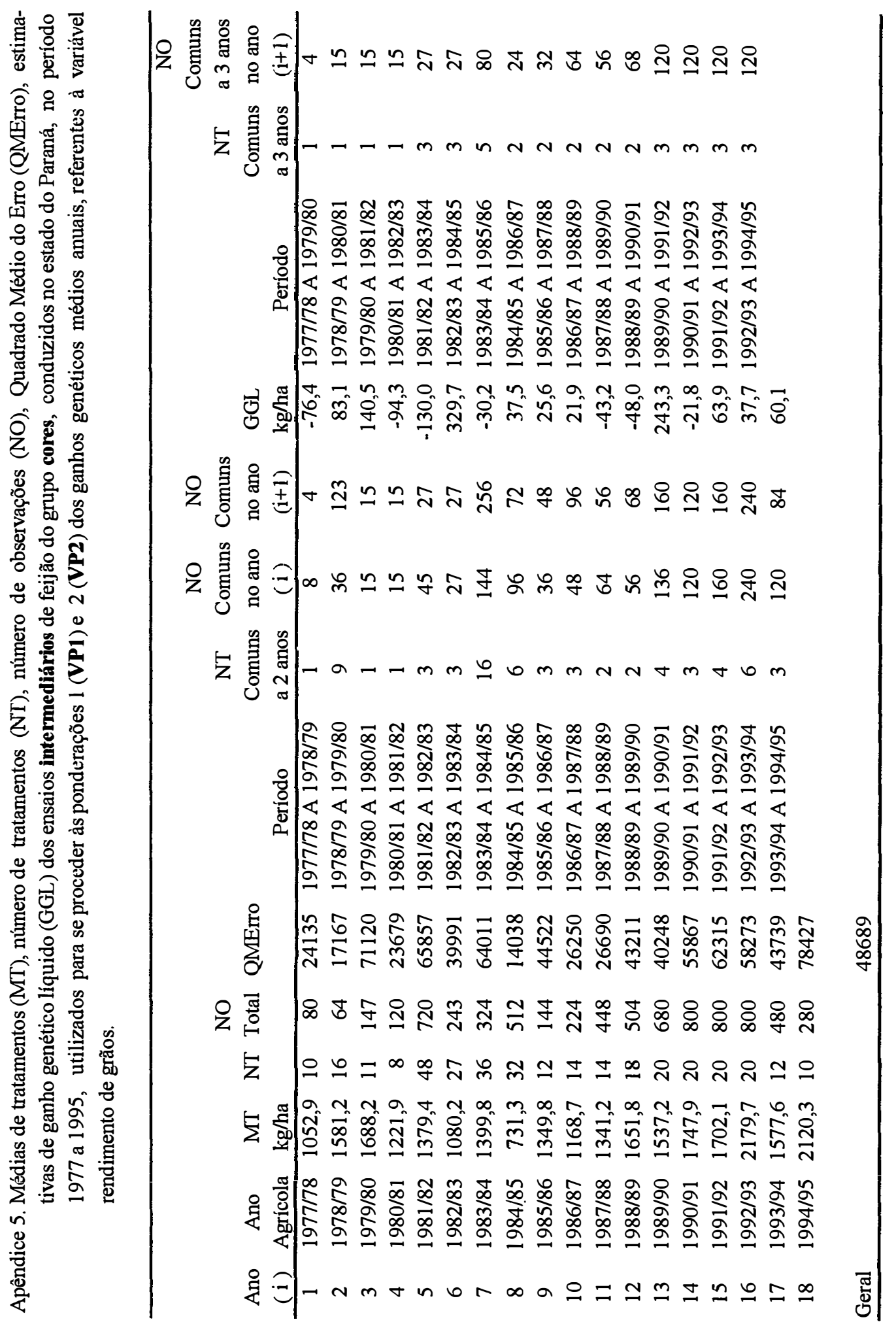




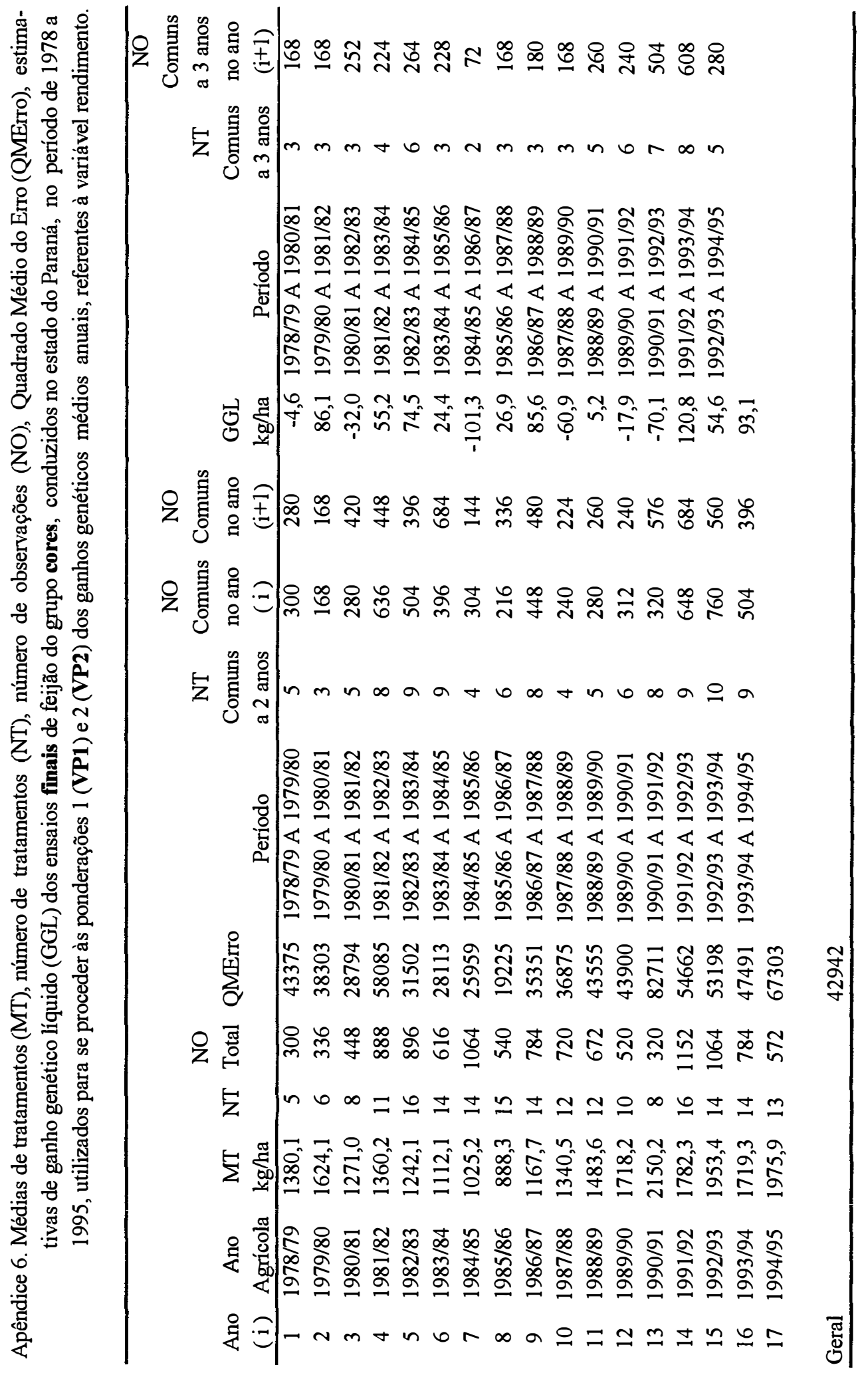




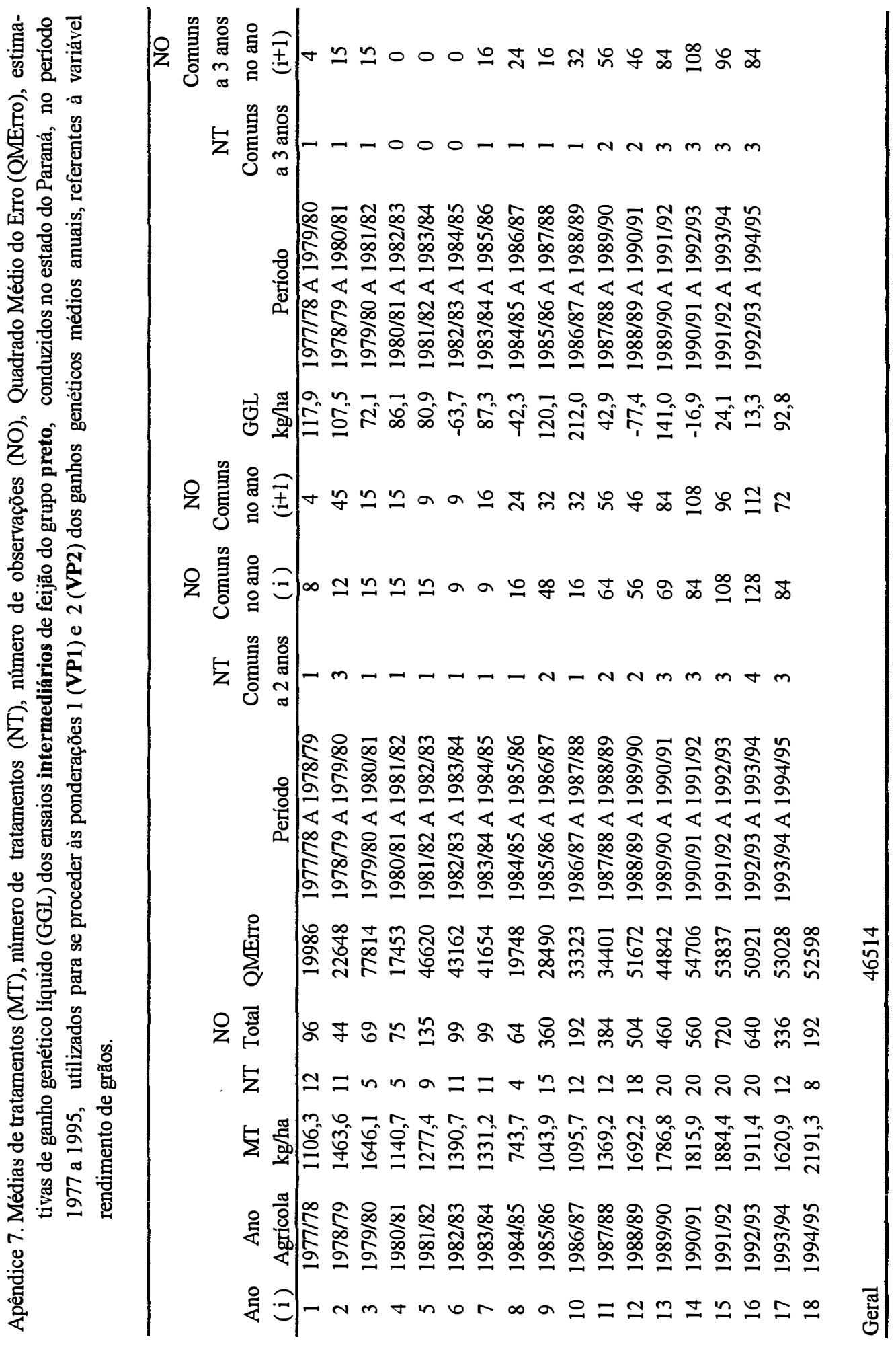




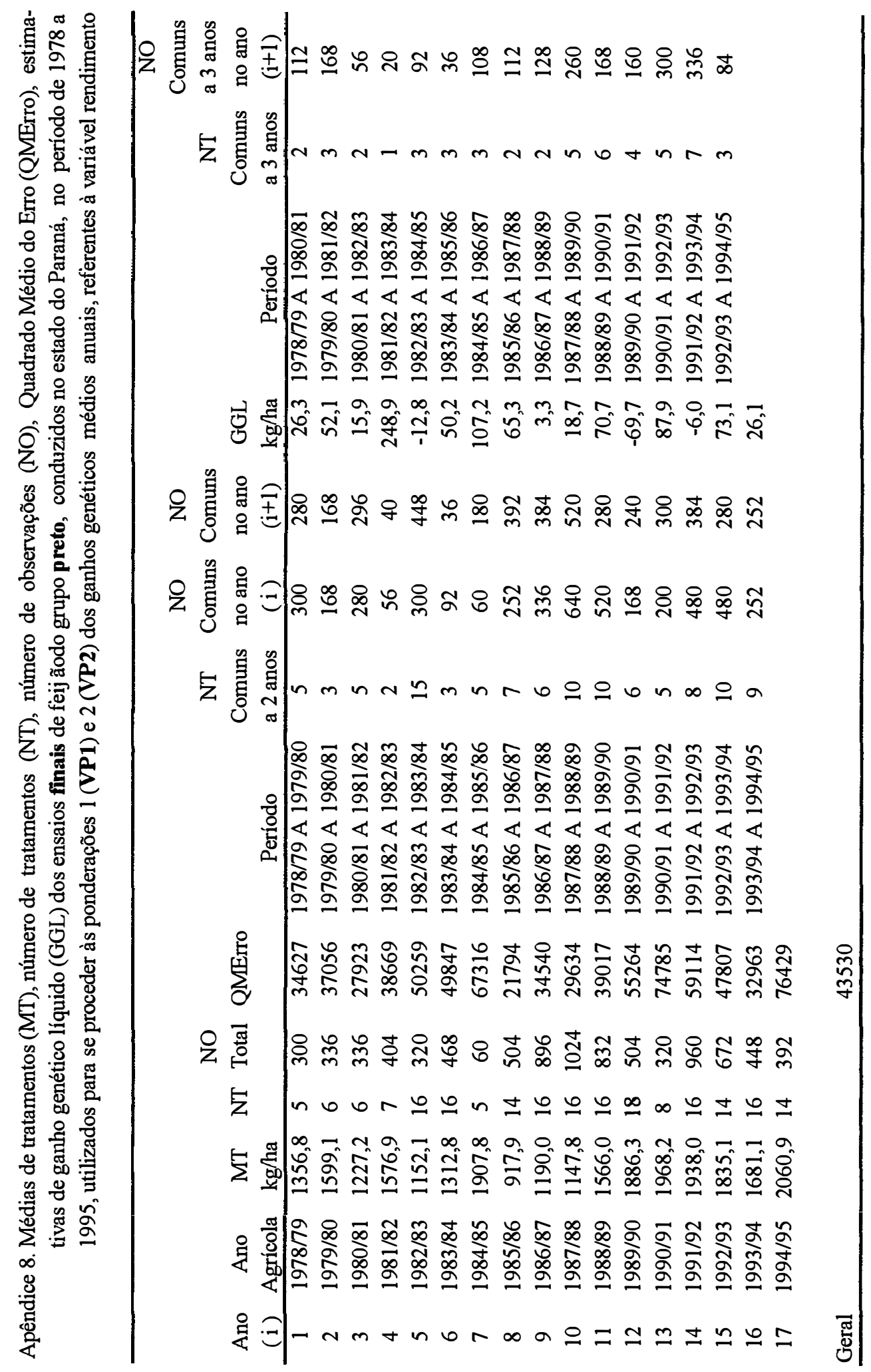


Apêndice 9. Médias originais e ajustadas dos genótipos novos e do cultivar testemunha Carioca, obtidas nos ensaios finais de feijão do grupo cores no período: 1978/79 a 1983/84. Paraná. Dados em kg/ha.

\begin{tabular}{|c|c|c|c|c|c|c|c|c|}
\hline \multirow[b]{3}{*}{ Obs. } & \multirow{3}{*}{$\begin{array}{c}\text { Ano } \\
\text { Agrícola }\end{array}$} & \multirow{3}{*}{$\begin{array}{l}\text { Ano } \\
\text { (i) }\end{array}$} & \multirow{3}{*}{ Genótipos } & \multirow{3}{*}{$\begin{array}{l}\mathrm{N}^{\circ} . \mathrm{de} \\
\text { Ensaios } \\
\text { no Ano }\end{array}$} & \multicolumn{2}{|c|}{ Médias Originais } & \multirow{3}{*}{$\begin{array}{c}\mathrm{N}^{\circ} . \mathrm{de} \\
\text { Ensaios } \\
\text { Total }\end{array}$} & \multirow{3}{*}{$\begin{array}{c}\text { Médias } \\
\text { Ajustadas } \\
\text { kg/ha }\end{array}$} \\
\hline & & & & & No Ano & Geral & & \\
\hline & & & & & $\mathrm{kg} / \mathrm{ha}$ & $\mathrm{kg} / \mathrm{ha}$ & & \\
\hline 1 & $1978 / 79$ & 1 & CARIOCA & 15 & 1504,7 & 1515,4 & 245 & 1515,4 \\
\hline 2 & $1978 / 79$ & 1 & AETÉ 1_38 & 15 & 1453,0 & 1627,1 & 29 & 1516,9 \\
\hline \multirow[t]{2}{*}{3} & $1978 / 79$ & 1 & ROXINHO 44 & 15 & 1265,8 & 1208,3 & 29 & 1098,1 \\
\hline & $1978 / 79$ & 1 & MÉDIA DOS NOVOS & & 1359,4 & 1417,7 & & 1307,5 \\
\hline \multirow[t]{2}{*}{4} & $1979 / 80$ & 2 & CARIOCA & 14 & 1743,8 & 1515,4 & 245 & 1515,4 \\
\hline & 1979/80 & 2 & MÉDIA DOS NOVOS & & - & - & & - \\
\hline 5 & $1980 / 81$ & 3 & CARIOCA & 14 & 1328,8 & 1515,4 & 245 & 1515,4 \\
\hline 6 & $1980 / 81$ & 3 & RAI 12 & 14 & 1160,2 & 1192,5 & 35 & 1267,8 \\
\hline 7 & $1980 / 81$ & 3 & RAI 15 & 14 & 1137,8 & 1137,8 & 14 & 1288,7 \\
\hline 8 & 1980/81 & 3 & RAI 46 & 14 & 1333,3 & 1333,3 & 14 & 1484,2 \\
\hline \multirow[t]{2}{*}{9} & $1980 / 81$ & 3 & RAI 53 & 14 & 1426,3 & 1426,3 & 14 & 1577,2 \\
\hline & 1980/81 & 3 & MÉDIA DOS NOVOS & & 1264,4 & 1272,5 & & 1404,5 \\
\hline 10 & $1981 / 82$ & 4 & CARIOCA & 21 & 1590,1 & 1515,4 & 245 & 1515,4 \\
\hline 11 & $1981 / 82$ & 4 & H 753-7-CM(7B) & 21 & 1464,5 & 1417,1 & 35 & 1509,1 \\
\hline 12 & $1981 / 82$ & 4 & H 753-B-5-CM(9B) & 21 & 1365,9 & 1365,9 & 21 & 1391,0 \\
\hline 13 & $1981 / 82$ & 4 & H 757-B-23-22-CM & 20 & 1287,3 & 1201,9 & 34 & 1285,7 \\
\hline 14 & $1981 / 82$ & 4 & H 7619-2-CM(7B) & 21 & 1417,6 & 1344,8 & 35 & 1436,9 \\
\hline \multirow[t]{2}{*}{15} & $1981 / 82$ & 4 & H 767-1-CM(7C) & 13 & 1156,8 & 1155,6 & 27 & 1390,3 \\
\hline & 1981/82 & 4 & MÉDIA DOS NOVOS & & 1338,4 & 1297,1 & & 1402,6 \\
\hline 16 & $1982 / 83$ & 5 & CARIOCA & 14 & 1188,7 & 1515,4 & 245 & 1515,4 \\
\hline 17 & $1982 / 83$ & 5 & MD 122-A & 14 & 1004,4 & 1004,4 & 14 & 1196,9 \\
\hline 18 & $1982 / 83$ & 5 & MD 447 & 14 & 1396,9 & 1356,5 & 25 & 1631,0 \\
\hline 19 & $1982 / 83$ & 5 & MD 466 & 14 & 1216,1 & 1216,1 & 14 & 1408,7 \\
\hline 20 & $1982 / 83$ & 5 & MD 470 & 14 & 1144,9 & 1144,9 & 14 & 1337,5 \\
\hline 21 & $1982 / 83$ & 5 & MD 480-A & 14 & 1329,9 & 1238,7 & 25 & 1513,1 \\
\hline 22 & $1982 / 83$ & 5 & MULATINHO VG BCA & 14 & 1487,2 & 1178,6 & 44 & 1544,7 \\
\hline \multirow[t]{2}{*}{23} & $1982 / 83$ & 5 & PAU DE FERRO & 14 & 1442,5 & 1345,9 & 25 & 1620,3 \\
\hline & $1982 / 83$ & 5 & MÉDIA DOS NOVOS & & 1288,8 & 1212,2 & & 1464,6 \\
\hline 24 & $1983 / 84$ & 6 & CARIOCA & 11 & 1073,4 & 1515,4 & 245 & 1515,4 \\
\hline 25 & $1983 / 84$ & 6 & AYSÓ & 11 & 1262,8 & 1143,0 & 30 & 1590,1 \\
\hline 26 & $1983 / 84$ & 6 & BAC 14 & 11 & 1317,6 & 1237,6 & 30 & 1684,8 \\
\hline 27 & $1983 / 84$ & 6 & BAC 5 & 11 & 1167,7 & 1167,7 & 11 & 1546,3 \\
\hline 28 & 1983/84 & 6 & CARIOCA 80 & 11 & 1217,1 & 1105,8 & 30 & 1553,0 \\
\hline \multirow[t]{2}{*}{29} & 1983/84 & 6 & CARIOCA PREC1070 & 11 & 752,8 & 752,8 & 11 & 1131,4 \\
\hline & 1983/84 & 6 & MÉDIA DOS NOVOS & & 1143,6 & 1081,4 & & 1501,1 \\
\hline
\end{tabular}


Apêndice 10. Médias originais e ajustadas dos genótipos novos e do cultivar testemunha Carioca, obtidas nos ensaios finais de feijão do grupo cores no período: 1984/85 a 1987/88. Paraná. Dados em kg/ha.

\begin{tabular}{|c|c|c|c|c|c|c|c|c|}
\hline \multirow[b]{3}{*}{ Obs. } & \multirow{3}{*}{$\begin{array}{c}\text { Ano } \\
\text { Agrícola }\end{array}$} & \multirow{3}{*}{$\begin{array}{l}\text { Ano } \\
\text { (i) }\end{array}$} & \multirow[b]{3}{*}{ Genótipos } & \multirow{3}{*}{$\begin{array}{c}\mathrm{N}^{\circ} \cdot \mathrm{de} \\
\text { Ensaios } \\
\text { no Ano }\end{array}$} & \multicolumn{2}{|c|}{ Médias Originais } & \multirow{3}{*}{$\begin{array}{c}\mathrm{N}^{\circ} \cdot \mathrm{de} \\
\text { Ensaios } \\
\text { Total }\end{array}$} & \multirow{3}{*}{$\begin{array}{c}\text { Médias } \\
\text { Aj ustadas } \\
\text { kg/ha }\end{array}$} \\
\hline & & & & & No Ano & Geral & & \\
\hline & & & & & $\mathrm{kg} / \mathrm{ha}$ & $\mathrm{kg} / \mathrm{ha}$ & & \\
\hline 30 & $1984 / 85$ & 7 & CARIOCA & 19 & 964,7 & 1515,4 & 245 & 1515,4 \\
\hline 31 & $1984 / 85$ & 7 & BAC 31 & 19 & 1114,0 & 1114,0 & 19 & 1600,8 \\
\hline 32 & $1984 / 85$ & 7 & BAC 38 & 19 & 1197,3 & 1197,3 & 19 & 1684,1 \\
\hline 33 & $1984 / 85$ & 7 & MD 477 & 19 & 1061,9 & 1061,9 & 19 & 1548,7 \\
\hline 34 & $1984 / 85$ & 7 & $\mathrm{MD} 621$ & 19 & 1024,8 & 1024,8 & 19 & 1511,6 \\
\hline \multirow[t]{2}{*}{35} & $1984 / 85$ & 7 & RAI 267 & 19 & 958,1 & 916,9 & 28 & 1409,7 \\
\hline & $1984 / 85$ & 7 & MÉDIA DOS NOVOS & & 1071,2 & 1063,0 & & 1551,0 \\
\hline 36 & $1985 / 86$ & 8 & CARIOCA & 9 & 975,5 & 1515,4 & 245 & 1515,4 \\
\hline 37 & $1985 / 86$ & 8 & IAPARBAC 14 & 9 & 1081,4 & 1081,4 & 9 & 1587,1 \\
\hline 38 & $1985 / 86$ & 8 & IAPARBAC 30 & 9 & 825,6 & 825,6 & 9 & 1331,3 \\
\hline 39 & $1985 / 86$ & 8 & IAPARBAC 31 & 9 & 779,2 & 779,2 & 9 & 1284,9 \\
\hline 40 & $1985 / 86$ & 8 & IAPARBAC 32 & 9 & 826,7 & 901,9 & 23 & 1247,8 \\
\hline 41 & $1985 / 86$ & 8 & IAPARBAC 44 & 9 & 894,8 & 894,8 & 9 & 1400,5 \\
\hline 42 & $1985 / 86$ & 8 & IAPARBAC 53 & 9 & 856,8 & 1111,2 & 23 & 1457,1 \\
\hline 43 & $1985 / 86$ & 8 & IAPARBAC 56 & 9 & 885,2 & 885,2 & 9 & 1390,9 \\
\hline 44 & $1985 / 86$ & 8 & IAPARBAC 63 & 9 & 780,9 & 780,9 & 9 & 1286,6 \\
\hline 45 & $1985 / 86$ & 8 & IAPARBAC 68 & 9 & 736,1 & 736,1 & 9 & 1241,8 \\
\hline \multirow[t]{2}{*}{46} & $1985 / 86$ & 8 & MD 632 & 9 & 1010,2 & 1078,1 & 23 & 1424,0 \\
\hline & 1985/86 & 8 & MÉDIA DOS NOVOS & & $\mathbf{8 6 7 , 7}$ & 907,4 & & 1365,2 \\
\hline 47 & $1986 / 87$ & 9 & CARIOCA & 14 & 1347,8 & 1515,4 & 245 & 1515,4 \\
\hline 48 & $1986 / 87$ & 9 & A 295 & 14 & 1193,3 & 1193,3 & 14 & 1436,6 \\
\hline 49 & $1986 / 87$ & 9 & FT 84-276 & 14 & 1150,5 & 1169,1 & 29 & 1361,8 \\
\hline 50 & $1986 / 87$ & 9 & FT 84-277 & 14 & 895,2 & 895,2 & 14 & 1138,5 \\
\hline 51 & $1986 / 87$ & 9 & FT 84-292 & 14 & 1076,6 & 1139,2 & 29 & 1331,9 \\
\hline 52 & $1986 / 87$ & 9 & IAPARBAC 204 & 14 & 1371,5 & 1417,4 & 29 & 1610,0 \\
\hline 53 & $1986 / 87$ & 9 & IAPARBAC 209 & 14 & 1197,9 & 1240,6 & 29 & 1433,2 \\
\hline \multirow[t]{2}{*}{54} & $1986 / 87$ & 9 & MD 640 & 14 & 985,4 & 985,4 & 14 & 1228,6 \\
\hline & 1986/87 & 9 & MÉDIA DOS NOVOS & & 1124,3 & 1148,6 & & 1362,9 \\
\hline 55 & $1987 / 88$ & 10 & CARIOCA & 15 & 1300,0 & 1515,4 & 245 & 1515,4 \\
\hline 56 & $1987 / 88$ & 10 & EMP 117 & 15 & 1385,6 & 1385,6 & 15 & 1531,0 \\
\hline 57 & $1987 / 88$ & 10 & FT 84-879 & 15 & 1358,7 & 1384,9 & 29 & 1459,0 \\
\hline 58 & $1987 / 88$ & 10 & IAPARBAC 206 & 15 & 1420,3 & 1420,3 & 15 & 1565,7 \\
\hline \multirow[t]{2}{*}{59} & $1987 / 88$ & 10 & IAPARBAC 290 & 15 & 1296,5 & 1296,5 & 15 & 1442,0 \\
\hline & $1987 / 88$ & 10 & MÉDIA DOS NOVOS & & 1365,3 & 1371,8 & & 1499,4 \\
\hline
\end{tabular}


Apêndice 11. Médias originais e ajustadas dos genótipos novos e do cultivar testemunha Carioca, obtidas nos ensaios finais de feijão do grupo cores no período: 1988/89 a 1991/92. Paraná. Dados em kg/ha.

\begin{tabular}{|c|c|c|c|c|c|c|c|c|}
\hline \multirow[b]{3}{*}{ Obs. } & \multirow{3}{*}{$\begin{array}{c}\text { Ano } \\
\text { Agrícola }\end{array}$} & \multirow{3}{*}{$\begin{array}{l}\text { Ano } \\
\text { (i) }\end{array}$} & \multirow[b]{3}{*}{ Genótipos } & \multirow{3}{*}{$\begin{array}{c}\mathrm{N}^{\circ} \text {. de } \\
\text { Ensaios } \\
\text { no Ano }\end{array}$} & \multicolumn{2}{|c|}{ Médias Originais } & \multirow{3}{*}{$\begin{array}{c}\mathbf{N}^{0} . \mathrm{de} \\
\text { Ensaios } \\
\text { Total }\end{array}$} & \multirow{3}{*}{$\begin{array}{l}\text { Médias } \\
\text { Ajustadas } \\
\text { kg/ha }\end{array}$} \\
\hline & & & & & No Ano & Geral & & \\
\hline & & & & & $\mathrm{kg} / \mathrm{ha}$ & $\mathrm{kg} / \mathrm{ha}$ & & \\
\hline 60 & $1988 / 89$ & 11 & CARIOCA & 14 & 1562.7 & $\overline{1515,4}$ & 245 & 1515,4 \\
\hline 61 & $1988 / 89$ & 11 & FT 84-1654 & 14 & 1408,0 & 1408,0 & 14 & 1405,5 \\
\hline 62 & $1988 / 89$ & 11 & FT 84-293A & 14 & 1417,6 & 1417,6 & 14 & 1415,1 \\
\hline 63 & 1988/89 & 11 & FT 84-835 & 14 & 1423,5 & 1423,5 & 14 & 1421,1 \\
\hline 64 & 1988/89 & 11 & IAPARBAC 300 & 14 & 1392,7 & 1392,7 & 14 & 1390,2 \\
\hline 65 & 1988/89 & 11 & IAPARBAC 8612 & 14 & 1498,3 & 1498,3 & 14 & 1495,8 \\
\hline \multirow[t]{2}{*}{66} & $1988 / 89$ & 11 & IAPARBAC 8622 & 14 & 1511,8 & 1511,8 & 14 & 1509,4 \\
\hline & 1988/89 & 11 & MÉDIA DOS NOVOS & & 1442,0 & 1442,0 & & 1439,5 \\
\hline 67 & $1989 / 90$ & 12 & CARIOCA & 13 & 1595,5 & 1515,4 & 245 & 1515,4 \\
\hline 68 & $1989 / 90$ & 12 & CNF 86-9 & 13 & 1536,1 & 1847,5 & 74 & 1539,0 \\
\hline 69 & $1989 / 90$ & 12 & FT $85-215$ & 13 & 1648,2 & 1648,2 & 13 & 1451,8 \\
\hline 70 & $1989 / 90$ & 12 & FT 85-77 & 13 & 1645,9 & 1645,9 & 13 & 1449,5 \\
\hline 71 & $1989 / 90$ & 12 & FT 86-109 & 13 & 1694,9 & 1694,9 & 13 & 1498,5 \\
\hline \multirow[t]{2}{*}{72} & 1989/90 & 12 & IAPARBAC 879 & 13 & 1771,5 & 1771,5 & 13 & 1575,1 \\
\hline & $1989 / 90$ & 12 & MÉDIA DOS NOVOS & & 1659,3 & 1721,6 & & 1502,8 \\
\hline 73 & 1990/91 & 13 & CARIOCA & 10 & 2225,2 & 1515,4 & 245 & 1515,4 \\
\hline 74 & 1990/91 & 13 & CNF 86-8 & 10 & 2074,2 & 2019,4 & 47 & 1613,7 \\
\hline \multirow[t]{2}{*}{75} & 1990/91 & 13 & MD 806 & 10 & 2006,8 & 1782,9 & 28 & 1360,3 \\
\hline & 1990/91 & 13 & MÉDIA DOS NOVOS & & 2040,5 & 1901,1 & & 1487,0 \\
\hline 76 & 1991/92 & 14 & CARIOCA & 18 & 1911,8 & 1515,4 & 245 & 1515,4 \\
\hline 77 & 1991/92 & 14 & FT $87-183$ & 18 & 1986,6 & 1952,2 & 51 & 1675,5 \\
\hline 78 & $1991 / 92$ & 14 & LMP-1 & 18 & 1776,4 & 1776,4 & 18 & 1461,2 \\
\hline 79 & 1991/92 & 14 & LMP-2 & 18 & 1782,1 & 1782,1 & 18 & 1466,9 \\
\hline 80 & 1991/92 & 14 & LP 88-175 & 18 & 1794,7 & 1816,1 & 51 & 1539,3 \\
\hline 81 & 1991/92 & 14 & LP 88-195 & 18 & 1813,9 & 1813,9 & 18 & 1498,7 \\
\hline 82 & 1991/92 & 14 & LP 88-197 & 18 & 1889,7 & 1889,7 & 18 & 1574,4 \\
\hline 83 & 1991/92 & 14 & LP 88-201 & 18 & 1880,2 & 1880,2 & 18 & 1564,9 \\
\hline \multirow[t]{2}{*}{84} & 1991/92 & 14 & UEL-1 & 18 & 773,3 & 773,3 & 18 & 458,1 \\
\hline & 1991/92 & 14 & MÉDIA DOS NOVOS & & 1712,1 & 1710,5 & & 1404,9 \\
\hline
\end{tabular}


Apêndice 12. Médias originais e ajustadas dos genótipos novos e do cultivar testemunha Carioca, obtidas nos ensaios finais de feijão do grupo cores no período: 1992/93 a 1994/95. Paraná. Dados em kg/ha.

\begin{tabular}{|c|c|c|c|c|c|c|c|c|}
\hline \multirow{2}{*}{ Obs. } & \multirow[b]{2}{*}{$\begin{array}{c}\text { Ano } \\
\text { Agrícola }\end{array}$} & \multirow[b]{2}{*}{$\begin{array}{l}\text { Ano } \\
\text { (i) }\end{array}$} & \multirow[b]{2}{*}{ Genótipos } & \multirow{2}{*}{$\begin{array}{l}\mathrm{N}^{\circ} \text {. de } \\
\text { Ensaios } \\
\text { no Ano }\end{array}$} & \multicolumn{2}{|c|}{ Médias Originais } & \multirow{2}{*}{$\begin{array}{c}\mathrm{N}^{\circ} . \mathrm{de} \\
\text { Ensaios } \\
\text { Total }\end{array}$} & \multirow{2}{*}{$\begin{array}{l}\text { Médias } \\
\text { Ajustadas } \\
\text { kg/ha }\end{array}$} \\
\hline & & & & & $\begin{array}{c}\text { No Ano } \\
\mathrm{kg} / \mathrm{ha}\end{array}$ & $\begin{array}{l}\text { Geral } \\
\mathrm{kg} / \mathrm{ha}\end{array}$ & & \\
\hline 85 & $1992 / 93$ & 15 & CARIOCA & 19 & 1817,2 & 1515,4 & 245 & 1515,4 \\
\hline 86 & $1992 / 93$ & 15 & FT $86-14$ & 19 & 1996,0 & 1996,0 & 19 & 1615,4 \\
\hline 87 & $1992 / 93$ & 15 & FT $86-51$ & 19 & 1929,3 & 1929,3 & 19 & 1548,7 \\
\hline 88 & $1992 / 93$ & 15 & IAPARMD 820 & 19 & 1686,8 & 1686,8 & 19 & 1306,2 \\
\hline 89 & $1992 / 93$ & 15 & LP 90-15 & 19 & 2157,7 & 1989,6 & 44 & 1733,5 \\
\hline \multirow[t]{2}{*}{90} & 1992/93 & 15 & LP 90-19 & 19 & 2182,6 & 1974,4 & 44 & 1718,3 \\
\hline & $1992 / 93$ & 15 & MÉDIA DOS NOVOS & & 1990,5 & 1915,2 & & 1584,4 \\
\hline 91 & 1993/94 & 16 & CARIOCA & 14 & 1757,3 & 1515,4 & 245 & 1515,4 \\
\hline 92 & $1993 / 94$ & 16 & A-285 & 14 & 1899,3 & 1952,8 & 25 & 1791,3 \\
\hline 93 & $1993 / 94$ & 16 & LP 91-1 & 14 & 1864,2 & 1964,9 & 25 & 1803,4 \\
\hline 94 & $1993 / 94$ & 16 & LP 91-2 & 14 & 1784,7 & 1875,5 & 25 & 1714,0 \\
\hline \multirow[t]{2}{*}{95} & 1993/94 & 16 & LP 91-27 & 14 & 1687,9 & 1821,2 & 25 & 1659,8 \\
\hline & 1993/94 & 16 & MÉDLA DOS NOVOS & & 1809,0 & 1903,6 & & 1742,1 \\
\hline 96 & 1994/95 & 17 & CARIOCA & 11 & 1813,3 & 1515,4 & 245 & 1515,4 \\
\hline 97 & $1994 / 95$ & 17 & APORE் & 11 & 2180,1 & 2180,1 & 11 & 1922,8 \\
\hline 98 & $1994 / 95$ & 17 & LP 91-22 & 11 & 2073,7 & 2073,7 & 11 & 1816,4 \\
\hline 99 & $1994 / 95$ & 17 & LP 91-23 & 11 & 2139,5 & 2139,5 & 11 & 1882,2 \\
\hline \multirow[t]{2}{*}{100} & $1994 / 95$ & 17 & LP 91-3 & 11 & 1732,9 & 1732,9 & 11 & 1475,6 \\
\hline & $1994 / 95$ & 17 & MÉDIA DOS NOVOS & & 2031,5 & 2031,5 & & 1774,2 \\
\hline
\end{tabular}

